Pacific Northwest

\title{
K West Basin Sand Filter Backwash Sample Analysis
}

\section{March 2016}

SK Fiskum MR Smoot
DS Coffey

KN Pool 


\title{
DISCLAIMER
}

This report was prepared as an account of work sponsored by an agency of the United States Government. Neither the United States Government nor any agency thereof, nor Battelle Memorial Institute, nor any of their employees, makes any warranty, express or implied, or assumes any legal liability or responsibility for the accuracy, completeness, or usefulness of any information, apparatus, product, or process disclosed, or represents that its use would not infringe privately owned rights. Reference herein to any specific commercial product, process, or service by trade name, trademark, manufacturer, or otherwise does not necessarily constitute or imply its endorsement, recommendation, or favoring by the United States Government or any agency thereof, or Battelle Memorial Institute. The views and opinions of authors expressed herein do not necessarily state or reflect those of the United States Government or any agency thereof.

\author{
PACIFIC NORTHWEST NATIONAL LABORATORY \\ operated by \\ BATTELLE \\ for the \\ UNITED STATES DEPARTMENT OF ENERGY \\ under Contract DE-AC05-76RL01830
}

Printed in the United States of America

Available to DOE and DOE contractors from the

Office of Scientific and Technical Information,

P.O. Box 62, Oak Ridge, TN 37831-0062;

ph: (865) 576-8401

fax: $(865) 576-5728$

email: reports@adonis.osti.gov

Available to the public from the National Technical Information Service

5301 Shawnee Rd., Alexandria, VA 22312

ph: (800) 553-NTIS (6847)

email: orders@intis.gov $<$ http://www.ntis.gov/about/form.aspx $>$

Online ordering: http://www.ntis.gov

This document was printed on recycled paper. 


\section{K West Basin Sand Filter Backwash Sample Analysis}

March 2016

SK Fiskum

DS Coffey

MR Smoot

KN Pool

Prepared for

the U.S. Department of Energy

under Contract DE-AC05-76RL01830

Pacific Northwest National Laboratory

Richland, Washington 99352 



\section{Executive Summary}

A sand filter is used to help maintain water clarity at the $\mathrm{K}$ West Basin where highly radioactive sludge is stored. Eventually that sand filter will require disposal. The radionuclide content of the solids trapped in the sand filter will affect the selection of the sand filter disposal pathway. The Pacific Northwest National Laboratory (PNNL) was contracted by the K Basin Operations \& Plateau Remediation Project (operations contractor $\mathrm{CH} 2 \mathrm{M}$ Hill) to analyze the radionuclide content of the solids collected from the backwash of the K West Basin sand filter. The radionuclide composition in the sand filter backwash solids will be used by $\mathrm{CH} 2 \mathrm{M}$ Hill to determine if the sand filter media and retained sludge solids will be designated as transuranic waste for disposal purposes or can be processed through less expensive means.

On October 19, 2015, K Basin Operations \& Plateau Remediation Project staff backwashed the sand filter into the North Load-Out Pit (NLOP) and immediately collected sample slurry from a sampling tube positioned 24 in. above the NLOP floor. The $764 \mathrm{~g}$ sand filter backwash slurry sample, KW-105 SFBW001, was submitted to PNNL for analysis on October 20, 2015. Solids from the slurry sample were consolidated into two samples (i.e., a primary and a duplicate sample) by centrifuging and measured for mass $(0.82 \mathrm{~g}$ combined - wet centrifuged solids basis $)$ and volume $(0.80 \mathrm{~mL}$ combined $)$. The solids were a dark brown/orange color, consistent with iron oxide/hydroxide. The solids were dried; the combined dry solids mass was $0.1113 \mathrm{~g}$, corresponding to 0.0146 weight percent (wt\%) solids in the original submitted sample slurry. The solids were acid-digested using nitric and hydrochloric acids. Insoluble solids developed upon dilution with $0.5 \mathrm{M} \mathrm{HNO}_{3}$, corresponding to an average $6.5 \mathrm{wt} \%$ of the initial dry solids content.

The acid digestate and insoluble solids were analyzed separately by gamma spectrometry. Nominally, $7.7 \%$ of the ${ }^{60} \mathrm{Co}$ was present in the insoluble solids; less than $1 \%$ of other gamma-emitters (i.e., ${ }^{137} \mathrm{Cs}$, ${ }^{154 / 155} \mathrm{Eu}$, and ${ }^{241} \mathrm{Am}$ ) were present in the insoluble solids.

Aliquots of the acid digestate were analyzed directly using gamma energy analysis (GEA) and after separations for ${ }^{238} \mathrm{Pu},{ }^{239+240} \mathrm{Pu},{ }^{237} \mathrm{~Np}$, and ${ }^{241} \mathrm{Am}$ radioisotopes using alpha energy analysis (AEA). The ${ }^{90} \mathrm{Sr}$ was measured by liquid scintillation counting (LSC) on the Sr-separated fraction. The plutonium isotopic distribution of the acid digestate was analyzed following $\mathrm{Pu}$ separations by thermal ionization mass spectrometry (TIMS). Table ES.1 summarizes the results for the primary and duplicate samples.

The ${ }^{239+240} \mathrm{Pu}$ concentration ( $\mu \mathrm{Ci} / \mathrm{g}$ dry) relative to ${ }^{90} \mathrm{Sr}$ and to ${ }^{137} \mathrm{Cs}$ concentrations $(\mu \mathrm{Ci} / \mathrm{g}$ dry) was examined. The K West Basin sludge has a ${ }^{239+240} \mathrm{Pu} /{ }^{90} \mathrm{Sr}$ ranging from 0.1 to 1.2 and the ${ }^{239+240} \mathrm{Pu} /{ }^{137} \mathrm{Cs}$ ratio ranging from 0.10 to 0.47 . In contrast, the sand filter backwash solids ${ }^{239+240}{ }^{2} \mathrm{Pu} /{ }^{90} \mathrm{Sr}$ ratio was 10.6 and the ${ }^{239+240} \mathrm{Pu} /{ }^{137} \mathrm{Cs}$ ratio was 2.0. The ratio differences indicate a relative enhancement of the $\mathrm{Pu}$ concentration in the sand filter solids relative to the ${ }^{137} \mathrm{Cs}$ and ${ }^{90} \mathrm{Sr}$ sludge concentrations currently in the $\mathrm{K}$ West Basin. A dose-to-curie radioisotope evaluation of the sand filter waste form may need to consider this dissimilarity. 
PNNL-25241

Table ES.1. Radionuclide Characterization in KW-105 SFBW-001 Acid Digestate (Dry Solids Mass Basis)

\begin{tabular}{|c|c|c|c|c|}
\hline \multirow[b]{2}{*}{ Analyte } & $\begin{array}{c}\text { 68122-TI-001-F } \\
\text { (Primary Sample) }\end{array}$ & $\begin{array}{c}\text { 68122-TI-001-G } \\
\text { (Duplicate Sample) }\end{array}$ & Average & \multirow{2}{*}{$\begin{array}{c}\text { Relative Percent } \\
\text { Difference }\end{array}$} \\
\hline & \multicolumn{3}{|c|}{$\mu \mathrm{Ci} / \mathrm{g}$ Dry Mass } & \\
\hline${ }^{60} \mathrm{Co}$ (GEA) & $1.08 \mathrm{E}-1^{(\mathrm{a})}$ & $9.91 \mathrm{E}-2^{(\mathrm{a})}$ & $1.04 \mathrm{E}-1^{(\mathrm{a})}$ & 8.6 \\
\hline${ }^{137} \mathrm{Cs}$ (GEA) & $1.02 \mathrm{E}+2$ & $9.49 \mathrm{E}+1$ & $9.85 \mathrm{E}+1$ & 7.2 \\
\hline${ }^{152} \mathrm{Eu}(\mathrm{GEA})$ & $3.88 \mathrm{E}-2$ & $3.13 \mathrm{E}-2$ & $3.51 \mathrm{E}-2$ & $21^{(\mathbf{b})}$ \\
\hline${ }^{154} \mathrm{Eu}(\mathrm{GEA})$ & $1.54 \mathrm{E}+0$ & $1.46 \mathrm{E}+0$ & $1.50 \mathrm{E}+0$ & 5.3 \\
\hline${ }^{155} \mathrm{Eu}(\mathrm{GEA})$ & $2.28 \mathrm{E}-1$ & $2.55 \mathrm{E}-1$ & $2.42 \mathrm{E}-1$ & 11 \\
\hline${ }^{238} \mathrm{Pu}(\mathrm{AEA})$ & $2.63 \mathrm{E}+01$ & $2.61 \mathrm{E}+1$ & $2.62 \mathrm{E}+1$ & 0.8 \\
\hline${ }^{239+240} \mathrm{Pu}(\mathrm{AEA})$ & $1.99 \mathrm{E}+2$ & $2.00 \mathrm{E}+2$ & $2.00 \mathrm{E}+2$ & 0.4 \\
\hline${ }^{241} \mathrm{Am}(\mathrm{GEA})$ & $9.64 \mathrm{E}+1$ & $1.06 \mathrm{E}+2$ & $1.01 \mathrm{E}+2$ & 9.5 \\
\hline${ }^{241} \mathrm{Am}(\mathrm{AEA})$ & $9.39 \mathrm{E}+1$ & $8.69 \mathrm{E}+1$ & $9.04 \mathrm{E}+1$ & 7.7 \\
\hline${ }^{237} \mathrm{~Np}(\mathrm{AEA})$ & $1.80 \mathrm{E}-3$ & $2.09 \mathrm{E}-3$ & $1.94 \mathrm{E}-3$ & 15 \\
\hline${ }^{90} \mathrm{Sr}(\mathrm{LSC})$ & $1.88 \mathrm{E}+1$ & $1.88 \mathrm{E}+1$ & $1.88 \mathrm{E}+1$ & 0.5 \\
\hline \multicolumn{5}{|c|}{ Plutonium Isotopic Fractionation, Weight \% Basis } \\
\hline${ }^{238} \mathrm{Pu}(\mathrm{AEA})$ & 0.0639 & 0.0632 & 0.0635 & 1.1 \\
\hline${ }^{239} \mathrm{Pu}(\mathrm{TIMS})$ & 86.33 & 86.33 & 86.33 & 0.002 \\
\hline${ }^{239} \mathrm{Pu}$ (TIMS) & 12.98 & 12.98 & 12.98 & 0.04 \\
\hline${ }^{241} \mathrm{Pu}$ (TIMS) & 0.3935 & 0.3915 & 0.3925 & 0.50 \\
\hline${ }^{242} \mathrm{Pu}$ (TIMS) & 0.2363 & 0.2354 & 0.2359 & 0.38 \\
\hline
\end{tabular}

The GEA analyte reference date is November 24, 2015; the AEA and ${ }^{90} \mathrm{Sr}$ measured by LSC reference date is December $15-30,2015$.

(a) An additional 7.0 and $8.5 \%$ of the ${ }^{60} \mathrm{Co}$ activity remained with the undissolved solids for the sample and duplicate, respectively.

(b) The RPD passed the mean difference test; see Appendix B. 


\section{Acknowledgments}

The authors wish to acknowledge the work of Lori Darnell, Katharine Carson, Michael Cantaloub, Larry Greenwood, Chuck Soderquist, James Peterson, and Truc Trang-Le for their radioanalytical work inclusive of acid digestions, separations, counting, and reporting. The authors also thank Andy Schmidt, Cal Delegard, and Rick Shimskey for technical reviews of data calculations and final report.

Contributions from Mike Parker, technical editor, are also greatly appreciated. 



\section{Acronyms and Abbreviations}

$\begin{array}{ll}\text { AEA } & \text { alpha energy analysis } \\ \text { ASO } & \text { Analytical Support Operations } \\ \text { ASR } & \text { Analytical Service Request } \\ \text { BTR } & \text { Buyer's Technical Representative } \\ \text { CHPRC } & \text { CH2M Hill Plateau Remediation Company } \\ \text { GEA } & \text { gamma energy analysis } \\ \text { HASQARD } & \text { Hanford Analytical Services Quality Assurance Requirements Document } \\ \text { ID } & \text { identification } \\ \text { KBO \& PR } & \text { K Basin Operations \& Plateau Remediation Project } \\ \text { LSC } & \text { liquid scintillation counting } \\ \text { NBS } & \text { National Bureau of Standards } \\ \text { NLOP } & \text { North Load-Out Pit } \\ \text { PNNL } & \text { Pacific Northwest National Laboratory } \\ \text { QC } & \text { quality control } \\ \text { RPD } & \text { relative percent difference } \\ \text { RPL } & \text { Radiochemical Processing Laboratory } \\ \text { RPM } & \text { revolutions per minute } \\ \text { TI } & \text { test instruction } \\ \text { TIMS } & \text { thermal ionization mass spectrometry } \\ \text { TRU } & \text { transuranic } \\ \text { UDS } & \text { undissolved solids }\end{array}$





\section{Contents}

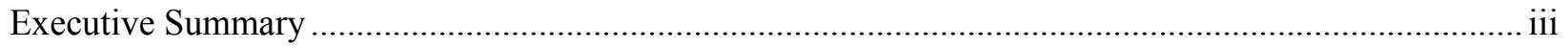

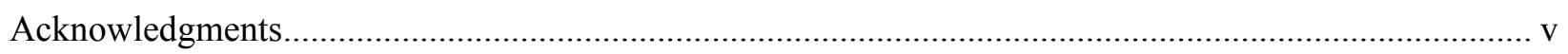

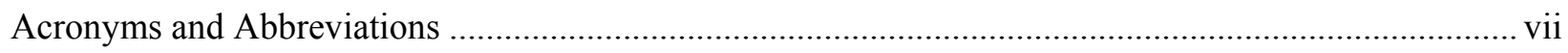

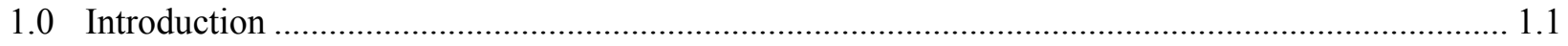

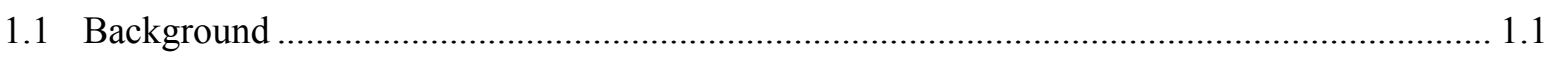

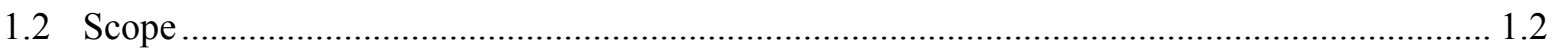

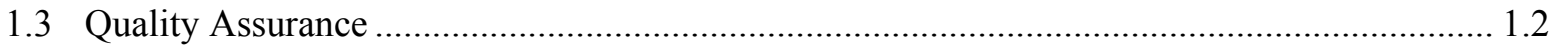

2.0 Sand Filter Backwash Sample Handling and Analysis............................................................ 2.1

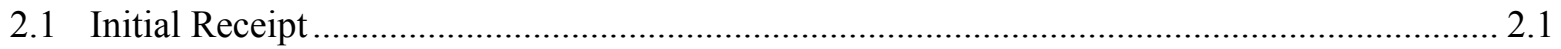

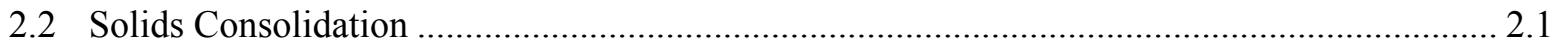

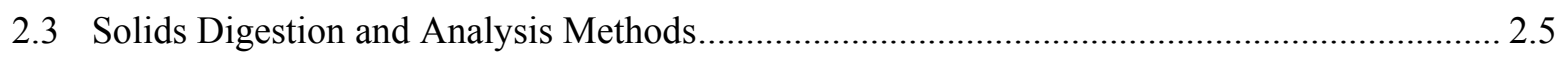

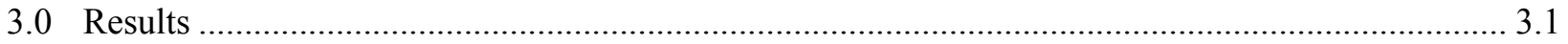

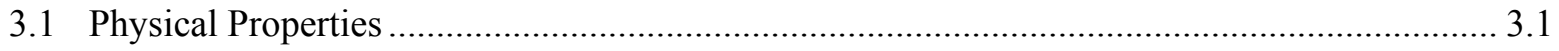

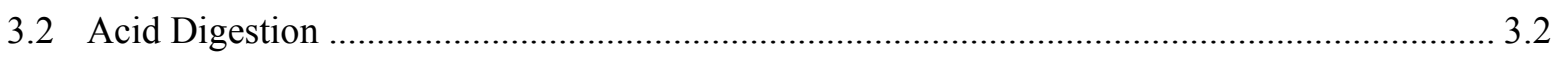

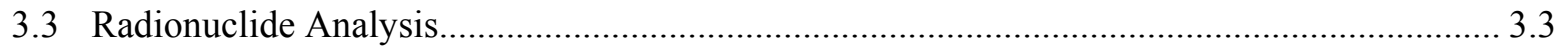

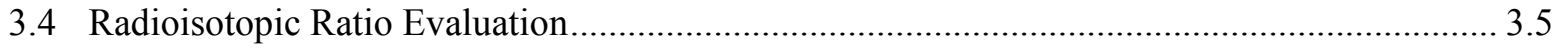

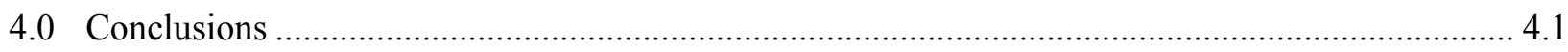

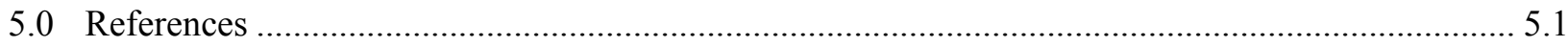

Appendix A - Completed Test Instruction 68122-TI-001, Sandfilter Backwash Solids Consolidation.. A.1

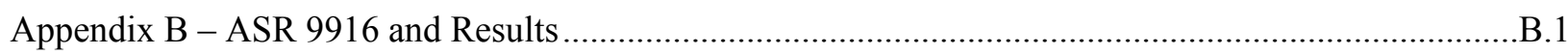




\section{Figures}

2.1 As-Received Sample KW-105 SFBW-001 in a 1 L Polyethylene Bottle ....................................... 2.1

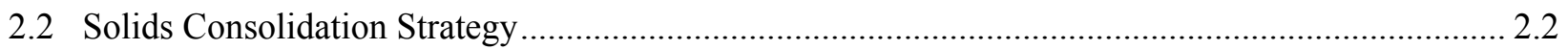

2.3 Centrifuge Tubes with Consolidated Sludge and Clarified Decanted Water.................................. 2.3

2.4 Transfer Pipet Used to Transfer the Solids Slurry …..................................................................... 2.3

2.5 Centrifuged Solids KW-105 SFBW-001 Sample and Duplicate ................................................... 2.5

3.1 Post-Precipitated Solids from Sample 68122-TI-001-F.............................................................. 3.2

\section{Tables}

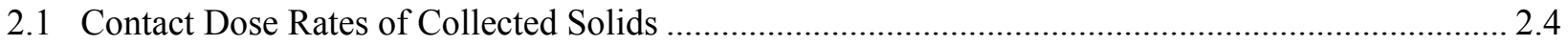

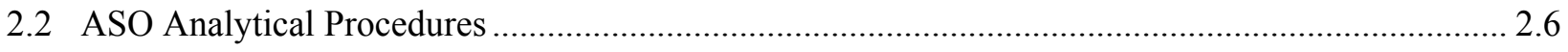

3.1 Physical Properties of KW-105 SFBW-001 Centrifuged Solids .................................................... 3.1

3.2 Weight Percent Solids in Sample KW-105 SFBW-001 Slurry ..................................................... 3.1

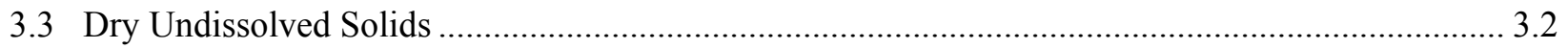

3.4 Radionuclide Summary Results for the Acid Digestate, Dry Centrifuged Solids Mass Basis .......... 3.3

3.5 Radionuclide Summary Results for the Acid Digestate, Wet Centrifuged Solids Mass Basis .......... 3.3

3.6 Radionuclide Summary Results for the UDS, Dry Solids Mass Basis .......................................... 3.4

3.7 Relative Radionuclide Content in the Acid Digestate and UDS ..................................................... 3.4

3.8 Plutonium Isotopic Analysis by TIMS and AEA for the Acid Digestate ...................................... 3.5

3.9 Isotopic Ratios in Backwash Sand Filter and Containerized Sludge .............................................. 3.6 
PNNL-25241

\subsection{Introduction}

A sand filter is used to help maintain water clarity at the $\mathrm{K}$ West Basin where highly radioactive sludge is stored. Eventually that sand filter will require disposal. The radionuclide content of the solids trapped in the sand filter will affect the selection of the sand filter disposal pathway. The Pacific Northwest National Laboratory (PNNL) was contracted by the K Basin Operations \& Plateau Remediation Project (KBO \& $\mathrm{PR}$ ), operations contractor $\mathrm{CH} 2 \mathrm{M}$ Hill, to analyze selected radionuclides in the centrifuged solids collected from the backwash of the K West Basin sand filter. The radionuclide composition in the sand filter backwash solids will be used by $\mathrm{CH} 2 \mathrm{M}$ Hill to determine if the sand filter media and retained sludge solids will be designated as transuranic (TRU) waste for disposal purposes or can be processed through less expensive means.

\subsection{Background}

Containerized radioactive sludge material is currently present in the $\mathrm{K}$ West Basin located at the Hanford Site in southeast Washington. The sludge genesis and composition has been previously reported (Fiskum et al. 2011; Shimskey et al. 2013; Fountain et al. 2013; Makenas et al. 1997; Johnson 2014). The sludge is stored under $\sim 15$ to $20 \mathrm{ft}$ of water in the K West Basin, which contains $\sim 1.2$ million gallons of water. The water in the $\mathrm{K}$ West Basin provides shielding from radiological dose of the highly radioactive sludge as well as general environmental protection by minimizing sludge dispersibility. The water in the K West Basin is continuously conditioned by passing through a recirculation cooling system to remove decay heat, passing through filters to remove particulate material, and passing through ion exchange media to remove dissolved radioactive species. The filtration systems in the K West Basin have been previously described by Kurta (1998). One of the filters in the filtration system is called the sand filter and it specifically traps entrained particulates from the K West Basin water and thus lower turbidity and improve clarity. It consists of a $7.5 \mathrm{in}$. depth of $1.4 \mathrm{~mm}$ support sand and a $32 \mathrm{in}$. depth of $0.3 \mathrm{~mm}$ filter sand in a 78 in. diameter vessel.

The K East Basin (now demolished) sand filter backwash was previously characterized for particle size and morphology. ${ }^{1}$ The K East Basin sand filter backwash solids particle size distribution was found to range from 0.46 to 10.2 microns with a median value of 1.8 to 2.5 microns. The chemical composition was assumed to consist of iron hydroxides, aluminum hydroxides, uranium oxides and silica (Schmidt 2006). Radionuclide and chemical composition of the KE North Loadout Pit (also referred to as the Sand Filter Backwash Pit) has been described in Shelor et al. (2004) and Mellinger et al. (2004). ${ }^{2}$

Minimal characterization has been conducted on the K West Basin sand filter since the transfer of the $\mathrm{K}$ East Basin and K West Basin sludge into large engineered containers. However, the general chemical compositions and physical properties found in the K East Basin backwash are expected to be similar to those in the K West Basin sand filter.

\footnotetext{
1 “Measurement of Particle Size Distributions in 105-KE Basin Water Samples," CH2M-0403713, transmitted from WS Calloway (CH2M Hill) to RM Jochen (FH) December 2, 2004, CH2M HILL Hanford Group, Inc., Richland, WA — as reported by Schmidt (2006).

${ }^{2}$ Schmidt AJ and RB Baker. 2004. "Revised Design and Safety Basis Value for Physical Properties, Radionuclide, and Chemical Composition of Sludge in the KE Basin North Load Pit, PNNL Letter Report 46497-RPT03, Rev 1. Transmitted to WW Rutherford (Flour Hanford) and JP Sloughter (Numatec Hanford Company) by KL Silvers on February 24, 2004, via PNNL transmittal letter 46497-L05.
} 
PNNL-25241

\subsection{Scope}

KBO \& PR requested the radiochemical characterization of ${ }^{238} \mathrm{Pu},{ }^{239+240} \mathrm{Pu},{ }^{241} \mathrm{Am},{ }^{237} \mathrm{~Np},{ }^{90} \mathrm{Sr}$, and gamma emitter concentrations in the sand filter backwash centrifuged solids to better understand the sand filter radionuclide loading and better characterize the sand filter for waste-disposal purposes. By understanding the gamma-emitting isotope concentration relationship to the alpha-emitting isotope concentration, a dose-to-Curie estimate of total actinide loading may be determined. These data can also be used to help determine if the spent sand filter media with entrained solids will be categorized as TRU waste.

The backwash of the skimmer system sand filter into the North Load-Out Pit (NLOP) was conducted in accordance with procedure, OP-07-065W, Backwash Sand Filter at 105-KW by KBO \& PR staff on October 19, 2015. Immediately (i.e., within 1 minute) after the backwash, a sample tube was lowered to 24 in. above the floor of the NLOP, the sample pump started, and the sample bottle filled per work package 1K-15-03261/0, 105-KW Sample Backwash Pit After Sand Filter Backwash. KBO \& PR shipped the sand filter backwash sample, KW-105 SFBW-001, to PNNL on October 20, 2015.

This report summarizes the sample-handling processes used to consolidate the backwash solids and the concentrations of gamma-emitting and alpha-emitting radionuclides in the backwash solids conducted at PNNL under Project 68122. In addition, limited physical property testing of the wet centrifuged solids (wt $\%$ wet and dry solids and density of centrifuged solids) was conducted and is reported herein.

\subsection{Quality Assurance}

Elements of KBC-33786, Rev. 2, Quality Assurance Project Plan/Sampling and Analysis Plan for Sludge in the $K W$ Engineered Containers (Baker et al. 2009) were applied to the sample preparation and analysis process and included PNNL commitment to the following:

1. continuation of PNNL on the CH2M Hill Plateau Remediation Company (CHPRC) evaluated supplier list for laboratory services

2. sample receipt and preparation for analysis

3. sample analysis and analysis of applicable quality assurance samples

4. disposal of residues and sample waste

5. data verification prior to delivery to the CHPRC

6. preparation of a data package for delivery to the project/buyer's technical representative (BTR).

The quality assurance program requirements defined Baker et al. (2009) invoke the Hanford Analytical Services Quality Assurance Requirements Document (HASQARD), Rev. 3, Volumes 1 and 4. All work was conducted to meet these requirements.

A test instruction (TI), 68122-TI-001, Rev. 0, Sandfilter Backwash Solids Consolidation, was prepared to delineate how initial sample handling and solids consolidation were to be conducted. The draft TI underwent technical, Quality Engineer, and project management reviews at PNNL. The CHPRC BTR also reviewed and approved the TI before implementation. The analytical procedures used in sample analysis were also reviewed and approved for use by the BTR before implementation. All reviewer issues and comments were resolved before issuing the TI. Following testing, the completed TI underwent technical review and Quality Engineer surveillance (SR 68122-2015-001, Surveillance of Completed Test Instruction 68122-TI-001, Sandfilter Backwash Solids Consolidation). Similarly, the analytical data 
PNNL-25241

reports underwent technical reviews and Quality Engineer surveillance (ASO-2016-010, QE Review of ASO ASR 9916 for Project 68122: K Basin Sandfilter Backwash Samples). All issues were resolved before finalizing the TI and analytical reports. 



\subsection{Sand Filter Backwash Sample Handling and Analysis}

This section describes sample receipt, sample handling, solids consolidation, and analysis test procedures applied to the backwash filter sample, KW-105 SFBW-001.

\subsection{Initial Receipt}

One $\sim 750 \mathrm{~mL}$ slurry sample, KW-105 SFBW-001, was received at PNNL's Radiochemical Processing Laboratory (RPL) on October 20, 2015 under chain of custody (see Appendix A, Attachment E). The sample was received in a $1 \mathrm{~L}$ polyethylene bottle. Flocculant solids were visible on the bottom of the container; however the fluid was lightly colored tan, indicative of a small particle size solid suspension. The sample contact dose rates were $1 \mathrm{mR} / \mathrm{h}$ gamma and $18 \mathrm{mR} / \mathrm{h}$ beta-gamma (closed and open window respectively) taken with an RO-20 portable ion chamber survey meter from the bottom of the container. Figure 2.1 provides images of the as-received container and the settled solids. The settled solids were a rust-brown color (consistent with iron oxides).

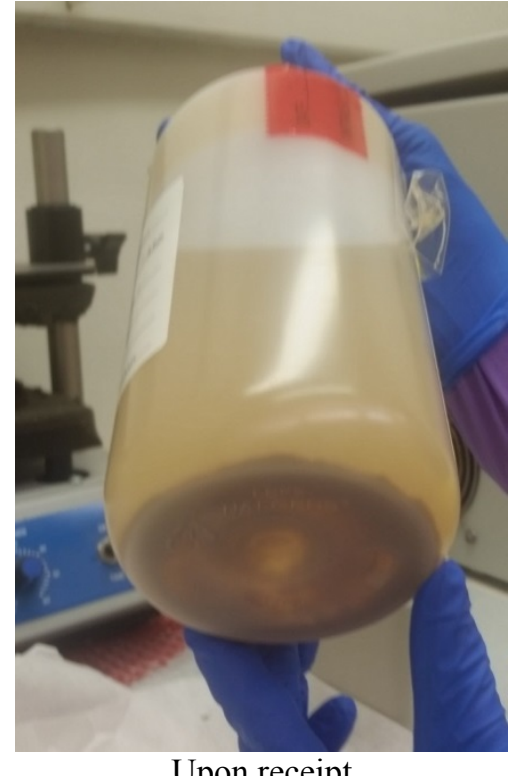

Upon receipt

(Note the light-tan aqueous phase)

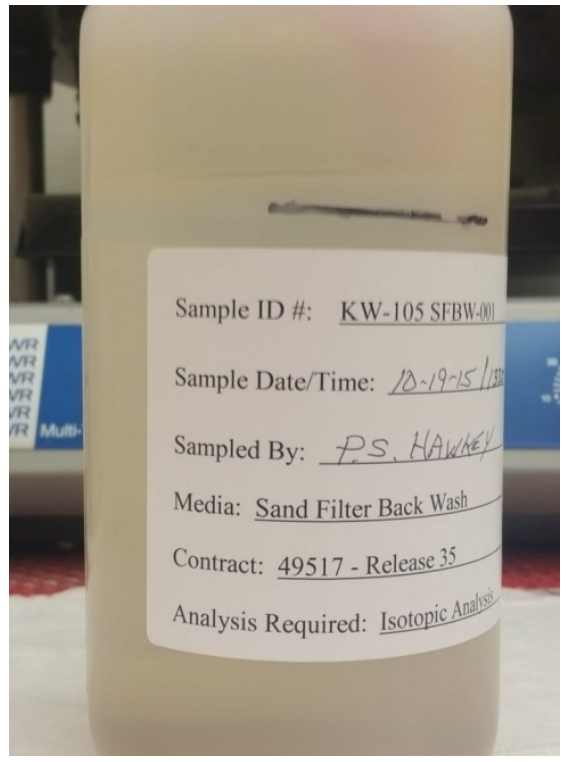

After 24-h settling time (Note the colorless aqueous phase)

Figure 2.1. As-Received Sample KW-105 SFBW-001 in a 1 L Polyethylene Bottle

\subsection{Solids Consolidation}

The entire sample was processed to consolidate all of the solids according to TI 68122-TI-001, Sandfilter Backwash Solids Consolidation. The completed TI is provided in Appendix A. One goal of this work was to determine the volume of centrifuged solids; therefore, the solids were to be consolidated into one or two (depending on total volume) volume-calibrated centrifuge tubes. Figure 2.2 illustrates the solids consolidation/processing strategy. 
PNNL-25241

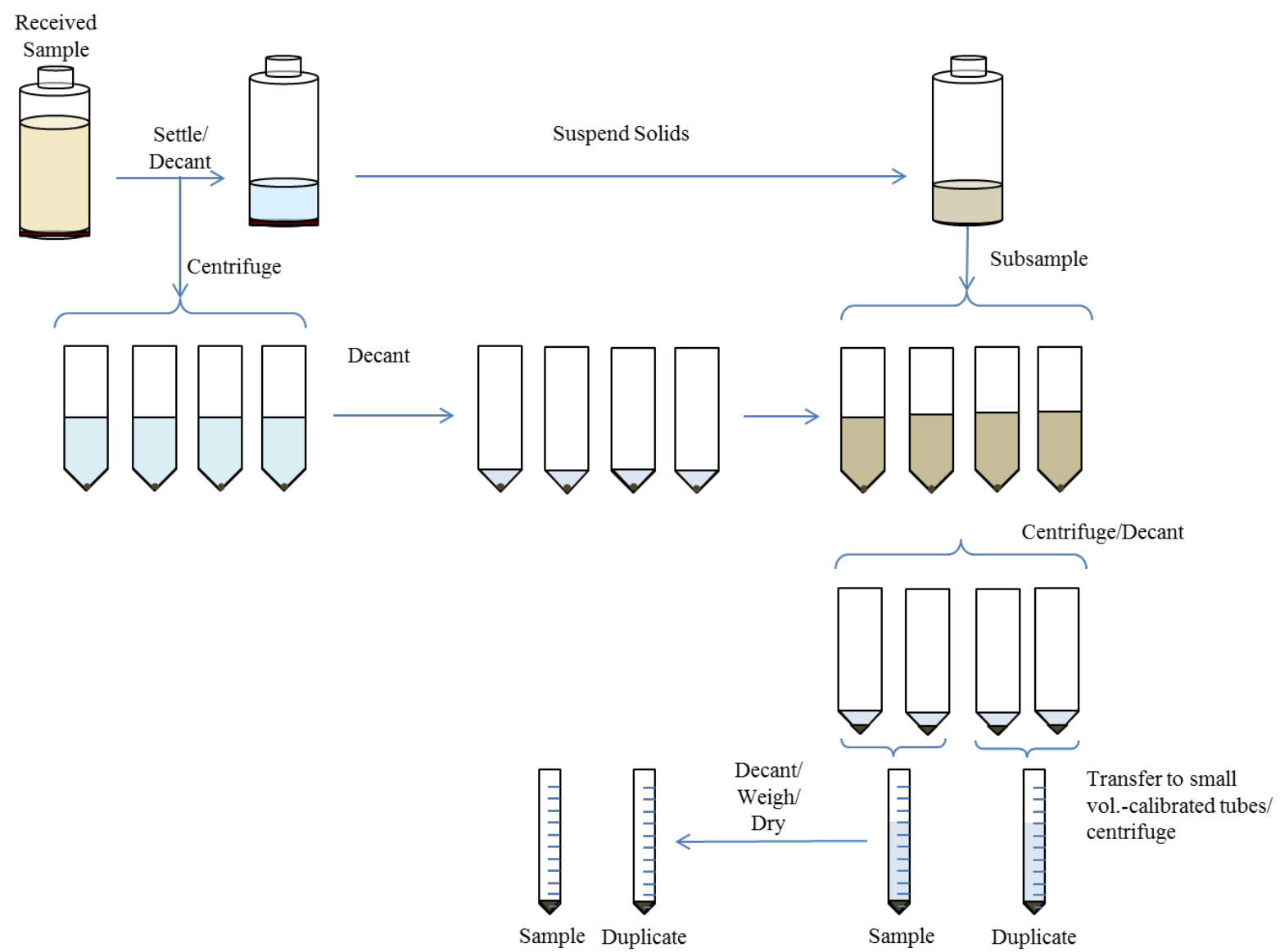

Figure 2.2. Solids Consolidation Strategy

The received sample container was weighed. The solids were allowed to settle overnight in the asreceived container. After the 24-h settling period, the supernate was visually less turbid-i.e., the aqueous phase appeared colorless (see Figure 2.1). The aqueous phase was removed by siphoning, in $45 \mathrm{~mL}$ increments, using a polystyrene serological pipet, into each of four $50 \mathrm{~mL}$ polypropylene centrifuge tubes with plug-seal caps (Fisherbrand). Water was removed well above the settled solids level so as not to disturb the settled solids layer. The centrifuge tubes with water were then centrifuged at 1500 RPM for 20 minutes. Any solids collected at the bottom of a centrifuge tube remained undisturbed while decanting the aqueous phase from the centrifuge tube into a separate bottle (decantate). This process was repeated six times until the bulk of the water phase of sample KW-105 SFBW-001 had been processed. In all cases, the decantate was colorless and clear.

Next, the remaining sample in the as-received container (settled solids and water cover layer) was agitated by swirling to suspend the solids, which were then transferred into the four centrifuge tubes used to clarify the water. Additional aqueous phase sample water (from the decantate) was used to achieve a quantitative transfer from the sample bottle into the four centrifuge tubes. Efforts were made to distribute the solids equally between the four centrifuge tubes. Figure 2.3 shows the four centrifuge tubes with centrifuged sludge sample material (container identification (ID) numbers left to right 68122-TI-001-A through 68122-TI-001-D) and the clarified decanted water collected in a $1 \mathrm{~L}$ polycarbonate bottle (container ID 68122-TI-001-E). The transfer pipet used to transfer the water and then the slurried solids was lightly coated with yellow material, indicating that a small amount of solids adhered to the plastic (see Figure 2.4). This material was not recoverable. The emptied original sample container was weighed and the net sample mass received was calculated. 


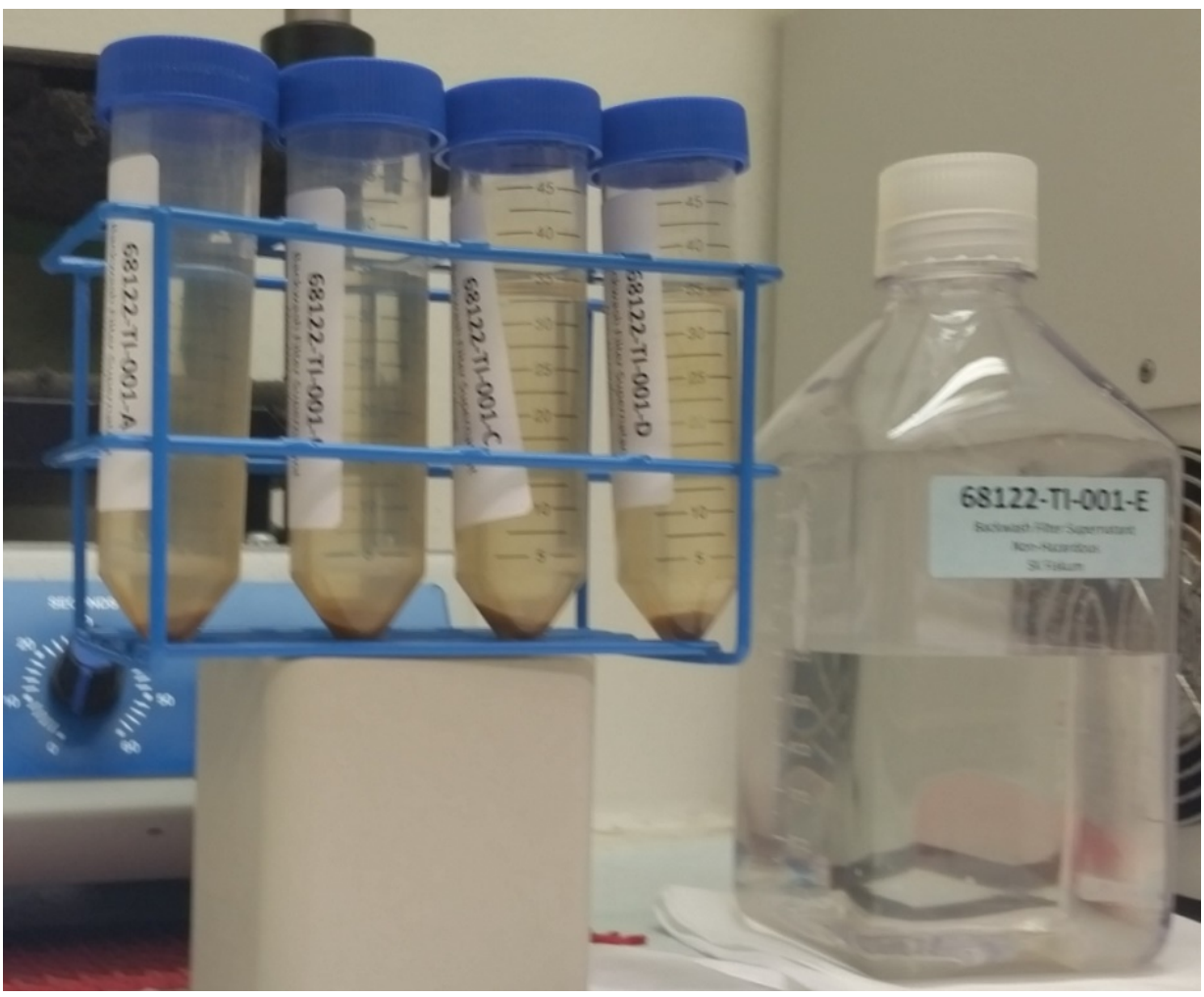

Figure 2.3. Centrifuge Tubes with Consolidated Sludge and Clarified Decanted Water

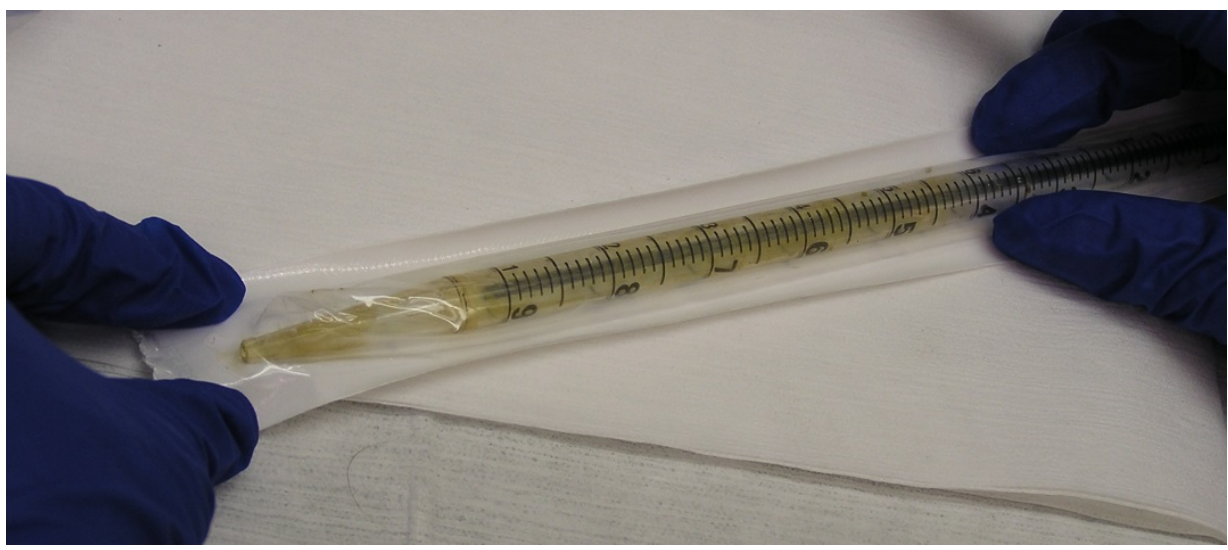

Figure 2.4. Transfer Pipet Used to Transfer the Solids Slurry

The contact dose rates for each of the four samples were measured with an RO-20 portable ion chamber survey meter and are provided in Table 2.1 under the "Initial" subheading. These dose rates are qualitative and were collected to obtain a sense of how well the radioactivity was distributed across the four containers. In general, the dose rates were similar, except for the last container (i.e., 68122-TI-001D) which was appreciably lower. 
PNNL-25241

Table 2.1. Contact Dose Rates of Collected Solids, mR/hour

\begin{tabular}{|c|c|c|c|c|}
\hline Centrifuge Cone ID $>>$ & 68122-TI-001-A & 68122-TI-001-B & 68122-TI-001-C & 68122-TI-001-D \\
\hline \multicolumn{5}{|c|}{ Initial } \\
\hline Open window & 5 & 5 & 5 & 2 \\
\hline Closed window & 3 & 3.5 & 3.5 & 1 \\
\hline \multicolumn{5}{|c|}{ Final, after Re-Split } \\
\hline Open window & 5.5 & NA & NA & 5 \\
\hline Closed window & $<0.5$ & NA & NA & $<0.5$ \\
\hline
\end{tabular}

Sufficient sample volume existed to create two samples (i.e., a primary and a duplicate sample) to support the solids analysis. Therefore, it was necessary to evenly split the sample activity (determined by dose rate) between the primary and duplicate samples. To this end, subsamples 68122-TI-001-A and 68122-TI001-D, which had different dose rates, were combined and re-split; subsamples 68122-TI-001-B and 68122-TI-001-C appeared equivalent and were not further re-processed. The dose rates for 68122-TI-001A and 68122-TI-001-D achieved after the re-splitting are shown in Table 2.1 under the subheading "Final, after Re-Split." The final dose rates indicate the subsamples had a higher combined dose rate than obtained with the initial measurement, which clearly cannot be the case. However, these measurements are not quantitative and significant changes can result by small changes in sample position in front of the detector, room background dose rate, and operator differences. Based on the near-equivalence of the final dose rate measurements, the re-combined and re-split subsamples 68122-TI-001-A and 68122-TI-001-D were considered equivalent to each other.

The solids from 68122-TI-001-A and 68122-TI-001-B were slurried, transferred, and combined into a tared, 10-mL glass, graduated, centrifuge cone (i.e., heavy-duty with screw cap closure, Kimble-Chase part number 45200-10) labeled 68122-TI-001-G. The solids from 68122-TI-001-C and 68122-TI-001-D were slurried, transferred, and combined into another tared, $10 \mathrm{~mL}$ glass, graduated, centrifuge cone labeled 68122-TI-001-F. These centrifuge tubes allowed for higher fidelity in volume measurement readings (to the nearest $0.1 \mathrm{~mL}$ ) and could be placed in an oven to dry the solids for determination of dry solids mass. The consolidated solids were centrifuged at 1500 RPM for 30 minutes. Final centrifuged solids volumes were estimated to be $0.4 \mathrm{~mL}$ in each tube. Because the solids level was slanted and not even, it was difficult to discern exact solids volume. Images of the collected solids are shown in Figure 2.5; for a reference point, an arrow is positioned at the $0.5 \mathrm{~mL}$ volume graduation mark. The solids were dark brown/orange in color, consistent with iron oxides/hydroxides.

The overburden of water was removed until it was at the $0.5 \mathrm{~mL}$ volume point in each centrifuge tube. Each centrifuge tube and its contents were weighed and the total slurry and centrifuged solids mass was calculated according to Equation 2.1, where the water density was assumed to be $1 \mathrm{~g} / \mathrm{mL}$.

$$
\mathrm{M}_{\mathrm{CS}}=\mathrm{G}-\mathrm{T}-\mathrm{W}
$$

where $\quad \mathrm{M}_{\mathrm{CS}}=$ Mass of wet centrifuged solids

$\mathrm{G}=$ Gross centrifuge cone mass

$\mathrm{T}=$ Centrifuge cone mass

$\mathrm{W}=$ Water mass (and volume above centrifuged solids)

The centrifuged solids density was calculated by dividing the solids mass by the solids volume. 


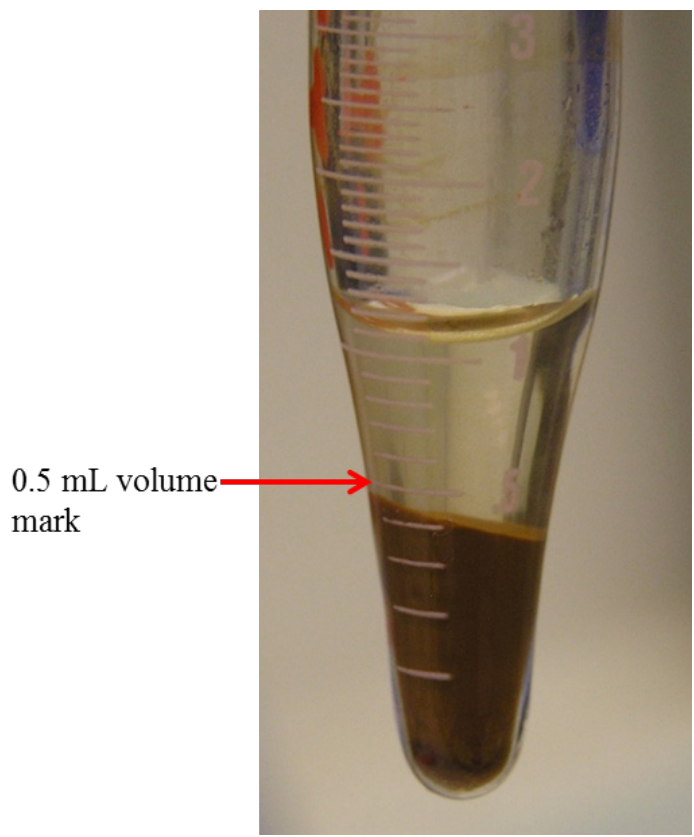

68122-TI-001-F

(combined 68122-TI-001-C and 68122-TI-001-D)

ASR Sample ID 16-0032

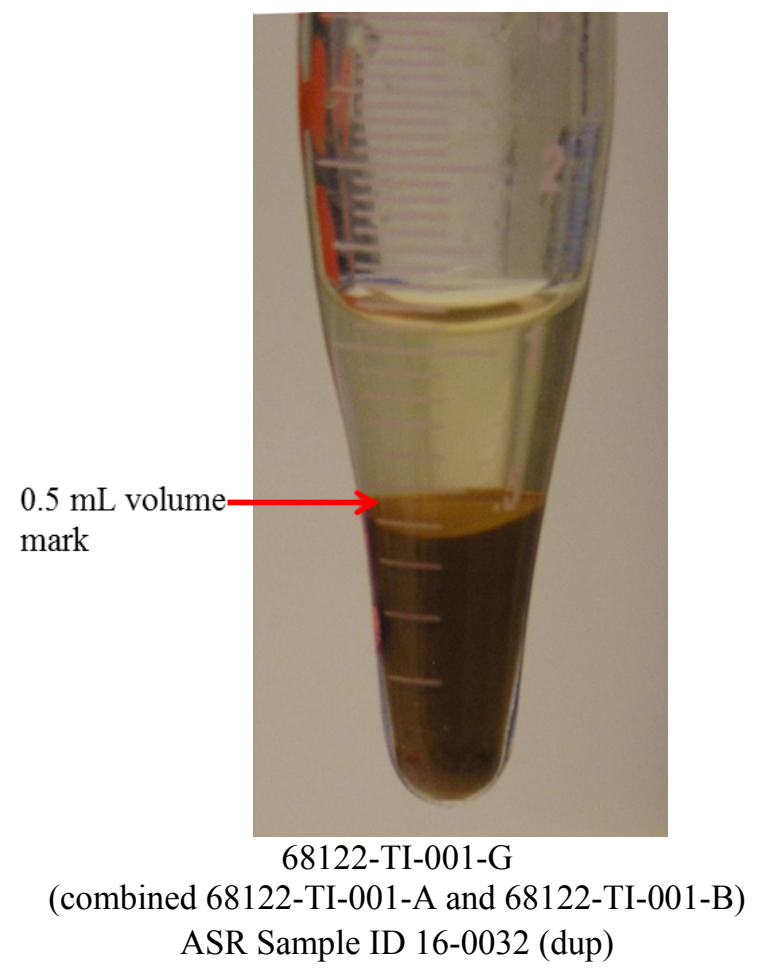

ASR Sample ID 16-0032 (dup)

Figure 2.5. Centrifuged Solids KW-105 SFBW-001 Sample and Duplicate

\subsection{Solids Digestion and Analysis Methods}

The solids samples were submitted to the Analytical Support Operations (ASO) laboratory for drying and mass measurement, acid digestion, and radiochemical analysis under Analytical Service Request (ASR) 9916. Figure 2.5 and Appendix B cross reference sample IDs and ASR sample IDs. The ASR was submitted with special instructions (see Appendix B) that delineated sample handling and analysis processes and processes for handling and analysis of any observed undissolved solids (UDS).

The centrifuged solids were dried in the centrifuge cone at $105^{\circ} \mathrm{C}$ to constant mass. The net sample mass was calculated by subtracting the gross mass from the centrifuge cone tare mass. The solids were aciddigested using a combination of $\mathrm{HNO}_{3}$ and $\mathrm{HCl}$. The UDS were removed from the acid digestate using centrifugation and washed with dilute $\mathrm{HNO}_{3}$ before drying to constant mass. The sample acid digestate and UDS wash were combined and brought to a known volume from which aliquots were collected for various radiochemical processing and isotopic analyses. The procedures applied to the sample and sample duplicate are provided in Table 2.2. 
PNNL-25241

Table 2.2. ASO Analytical Procedures

\begin{tabular}{|c|c|c|c|}
\hline Analyte & Separation & Mounting & Analysis / Counting \\
\hline $\begin{array}{l}\text { Sample and } \\
\text { UDS dry } \\
\text { mass }\end{array}$ & NA & NA & $\begin{array}{l}\text { RPG-CMC-503, Rev. 0, } \\
\text { Determination of Physical } \\
\text { Properties of Solutions, } \\
\text { Sludges, Slurries, and Solids }\end{array}$ \\
\hline $\begin{array}{l}\text { Acid } \\
\text { digestion }\end{array}$ & $\begin{array}{l}\text { RPG-CMC-129, Rev. 0, } \\
\text { HNO }-H C l \text { Acid Extraction of } \\
\text { Solids Using a Dry-Block } \\
\text { Heater }\end{array}$ & NA & NA \\
\hline GEA & NA & NA & $\begin{array}{l}\text { RPG-CMC-450, Rev. } 2 \\
\text { Gamma Energy Analysis } \\
\text { (GEA) and Low-Energy } \\
\text { Photon Spectrometry (LEPS) }\end{array}$ \\
\hline $\begin{array}{l}{ }^{238} \mathrm{Pu} \text { and } \\
{ }^{239+240} \mathrm{Pu} / \mathrm{AEA}\end{array}$ & $\begin{array}{l}\text { RPG-CMC-4017, Rev. 0, } \\
\text { Analysis of Environmental } \\
\text { Water Samples for Actinides } \\
\text { and Strontium-90 }\end{array}$ & $\begin{array}{l}\text { RPG-CMC-496, Rev.1, } \\
\text { Coprecipitation Mounting of } \\
\text { Actinides for Alpha } \\
\text { Spectroscopy }\end{array}$ & $\begin{array}{l}\text { RPG-CMC-422, Rev. } 2 \\
\text { Solutions Analysis: Alpha } \\
\text { Spectrometry }\end{array}$ \\
\hline${ }^{241} \mathrm{Am} / \mathrm{AEA}$ & $\begin{array}{l}\text { RPG-CMC-4017, Rev. 0, } \\
\text { Analysis of Environmental } \\
\text { Water Samples for Actinides } \\
\text { and Strontium-90 }\end{array}$ & $\begin{array}{l}\text { RPG-CMC-496, Rev. } 1 \text {, } \\
\text { Coprecipitation Mounting of } \\
\text { Actinides for Alpha } \\
\text { Spectroscopy }\end{array}$ & $\begin{array}{l}\text { RPG-CMC-422, Rev. } 2 \\
\text { Solutions Analysis: Alpha } \\
\text { Spectrometry }\end{array}$ \\
\hline${ }^{237} \mathrm{~Np} / \mathrm{AEA}$ & $\begin{array}{l}\text { RPG-CMC-4017, Rev. 0, } \\
\text { Analysis of Environmental } \\
\text { Water Samples for Actinides } \\
\text { and Strontium-90 }\end{array}$ & $\begin{array}{l}\text { RPG-CMC-496, Rev. } 1 \text {, } \\
\text { Coprecipitation Mounting of } \\
\text { Actinides for Alpha } \\
\text { Spectroscopy }\end{array}$ & $\begin{array}{l}\text { RPG-CMC-422, Rev. } 2 \\
\text { Solutions Analysis: Alpha } \\
\text { Spectrometry }\end{array}$ \\
\hline${ }^{90} \mathrm{Sr}$ & $\begin{array}{l}\text { RPG-CMC-476, Rev. 0, } \\
\text { Strontium Separation using } \\
\text { Eichrom Strontium Resin }\end{array}$ & NA & $\begin{array}{l}\text { RPG-CMC-474, Rev. } 1 \text {, } \\
\text { Measurement of Alpha and } \\
\text { Beta Activity by Liquid } \\
\text { Scintillation Spectrometry }\end{array}$ \\
\hline $\mathrm{Pu}$ isotopic & $\begin{array}{l}\text { RPG-CMC- } 455 \text {, Rev. } 0 \text {, } \\
\text { Separation of Uranium and } \\
\text { Plutonium for Isotopic } \\
\text { Analysis by Mass } \\
\text { Spectroscopy }\end{array}$ & NA & $\begin{array}{l}\text { RPL-TIMS-001, Rev. 0, } \\
\text { Thermal Ionization Mass } \\
\text { Spectrometry (TIMS) }\end{array}$ \\
\hline
\end{tabular}

Renormalization of the thermal ionization mass spectrometry (TIMS) analysis results was required. Despite care in the separation, a very small carry-over and/or contamination of $U$ into the Pu fraction interfered with the analysis of ${ }^{238} \mathrm{Pu}$ (from the ${ }^{238} \mathrm{U}$ isobar; also see Appendix B). Therefore, the ${ }^{238} \mathrm{Pu}$ analysis by AEA provides more accurate results for this radioisotope. The correct contribution of ${ }^{238} \mathrm{Pu}$ with respect to ${ }^{239} \mathrm{Pu}$ was determined by the following steps:

- AEA provided relative amounts of ${ }^{238} \mathrm{Pu}$ and combined ${ }^{239+240} \mathrm{Pu}$ in terms of activities $(\mu \mathrm{Ci})$ per gram of sludge. In AEA, ${ }^{238} \mathrm{U}$ interference does not contribute to the ${ }^{238} \mathrm{Pu}$ or to the ${ }^{239+240} \mathrm{Pu}$ AEA peaks.

- The relative contributions of ${ }^{239} \mathrm{Pu}$ and ${ }^{240} \mathrm{Pu}$ to the ${ }^{239+240} \mathrm{Pu}$ AEA peak were apportioned based on the ${ }^{239} \mathrm{Pu}$ and ${ }^{240} \mathrm{Pu}$ TIMS values and the specific activities of the individual ${ }^{239} \mathrm{Pu}$ and ${ }^{240} \mathrm{Pu}$ isotopes. This provided activities of the individual ${ }^{239} \mathrm{Pu}$ and ${ }^{240} \mathrm{Pu}$ isotopes per gram of sample.

- At that point, the activities of the ${ }^{238} \mathrm{Pu}$ and the ${ }^{239} \mathrm{Pu}$ per gram of sample were known.

- The atom percent $(\mathrm{At} \%)$ of ${ }^{238} \mathrm{Pu}$, with respect to the $\mathrm{At} \%$ of ${ }^{239} \mathrm{Pu}$ reported by TIMS was calculated using Equation 2.2: 
At $\%{ }^{238} \mathrm{Pu}=\frac{\mu \mathrm{Ci}{ }^{238} \mathrm{Pu} / \mathrm{g} \text { sludge }}{\mu \mathrm{Ci}{ }^{239} \mathrm{Pu} / \mathrm{g} \text { sludge }} \times \frac{\mathrm{Ci}^{239} \mathrm{Pu} / \mathrm{g}{ }^{239} \mathrm{Pu}}{\mathrm{Ci}{ }^{238} \mathrm{Pu} / \mathrm{g}{ }^{238} \mathrm{Pu}} \times \frac{\mathrm{g}{ }^{239} \mathrm{Pu} / \mathrm{mole}^{239} \mathrm{Pu}}{\mathrm{g}{ }^{238} \mathrm{Pu} / \mathrm{mole}^{238} \mathrm{Pu}} \times \mathrm{At} \%{ }^{239} \mathrm{Pu}$

in which the first term includes the specific activities of ${ }^{238} \mathrm{Pu}$ and ${ }^{239} \mathrm{Pu}$ in the sample, the second term includes the specific activities of ${ }^{238} \mathrm{Pu}$ and ${ }^{239} \mathrm{Pu}$ with respect to their isotopically pure element (from National Bureau of Standards [NBS] values), the third term includes the atomic weights of the ${ }^{238} \mathrm{Pu}$ and ${ }^{239} \mathrm{Pu}$ isotopes (from NBS values), and the fourth term is the At $\%$ of ${ }^{239} \mathrm{Pu}$ found by TIMS.

- The $\mathrm{At} \%{ }^{238} \mathrm{Pu}$, with respect to the $\mathrm{At} \%{ }^{239} \mathrm{Pu}$ (TIMS) as determined by this method, was less than the ${ }^{238} \mathrm{Pu}$ value reported by TIMS. Therefore, the individual $\mathrm{Pu}$ isotope percentages by the above calculation for ${ }^{238} \mathrm{Pu}$ and the other $\mathrm{Pu}$ isotope percentages by TIMS, are summed and renormalized. This calculation approach provided the correct $\mathrm{At} \%$ for all $\mathrm{Pu}$ isotopes. 



\subsection{Results}

This section presents the results of the physical property and radionuclide analyses of the consolidated solids collected from backwash filter sample KW-105 SFBW-001.

\subsection{Physical Properties}

The calculated total slurry mass received was $764 \mathrm{~g}$. The centrifuged solids mass, volume, and density and the dry centrifuged solids mass for the primary and duplicate sample are shown in Table 3.1. The centrifuged water and sludge volumes were read against a scale with $0.1 \mathrm{~mL}$ volume increments. The water left above the solids was brought to the $0.5 \mathrm{~mL}$ mark, minimizing the need to interpolate between $0.1 \mathrm{~mL}$ volume graduations. However, volume measures can only be reported to two significant figures at best. In both the sample and duplicate sample cases, the centrifuged solids densities are not much different than the density of water.

Table 3.1. Physical Properties of KW-105 SFBW-001 Centrifuged Solids

\begin{tabular}{lcc}
\hline Sample ID & $\begin{array}{c}68122-\mathrm{TI}-001-\mathrm{F} \\
16-0032\end{array}$ & $\begin{array}{c}68122-\mathrm{TI}-001-\mathrm{G} \\
16-0032 \text { (dup) }\end{array}$ \\
\hline Centrifuge cone tare $(\mathrm{g})$ & 20.6859 & 20.6253 \\
Centrifuge cone gross mass with wet solids $(\mathrm{g})$ & 21.2217 & 21.1095 \\
Centrifuged solids volume (mL) & 0.40 & 0.40 \\
Total slurry volume (mL) & 0.50 & 0.50 \\
Centrifuged solids mass (g) & 0.44 & 0.38 \\
Centrifuged solids density (g/mL) & 1.1 & 0.96 \\
Centrifuge cone gross mass with dry solids $(\mathrm{g})$ & 20.7404 & 20.6821 \\
Dry centrifuged solids mass $(\mathrm{g})$ & 0.0545 & 0.0568 \\
Mass loss on drying $(\%)$ & 87 & 85 \\
\hline
\end{tabular}

The wt $\%$ wet centrifuged solids in the as-received slurry sample was calculated from combining the wet centrifuged solids masses of the primary and duplicate samples and dividing by the total received sample mass. The wt $\%$ dry centrifuged solids was calculated by combining the total dry solids masses of the primary and duplicate samples and dividing by the total received sample mass. Results are summarized in Table 3.2.

Table 3.2. Weight Percent Solids in Sample KW-105 SFBW-001 Slurry

\begin{tabular}{lc}
\hline Total slurry mass $(\mathrm{g})$ & 764.2 \\
Combined wet centrifuged solids mass $(\mathrm{g})$ & 0.82 \\
Wet centrifuged solids (wt $\%)$ & 0.11 \\
Combined dry centrifuged solids mass (g) & 0.1113 \\
Dry centrifuged solids ${ }^{(\mathrm{a})}(\mathrm{wt} \%)$ & 0.0146 \\
\hline
\end{tabular}

(a) The dry solids mass does not consider mass contribution from dissolved solids. 


\subsection{Acid Digestion}

The acid digestion procedure appeared to dissolve all solids. Upon adding water to dilute the acid, solids precipitated. As shown in Figure 3.1 the consolidated solids were flocculant, similar to colloidal silica, and colored dark gray. The aqueous phase is intensely yellow, characteristic of dissolved iron in $\mathrm{HCl}$.

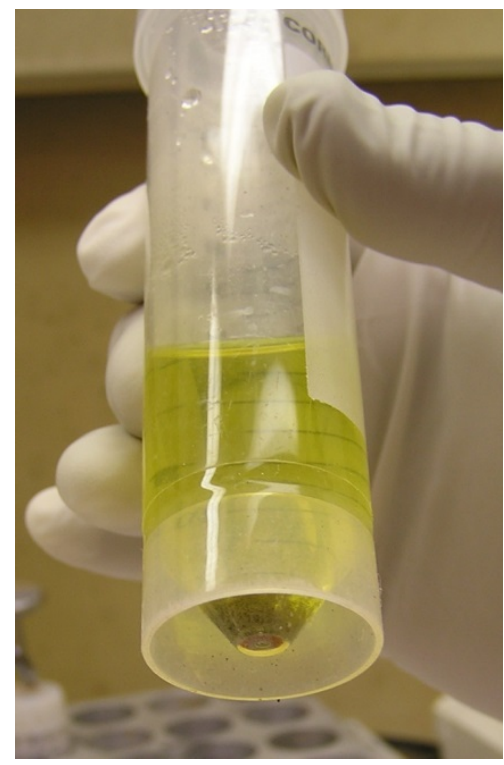

Figure 3.1. Post-Precipitated Solids from Sample 68122-TI-001-F

The solids were separated from the aqueous phase using centrifugation and decanting. The solids were washed several times with $0.5 \mathrm{M} \mathrm{HNO}_{3}$ and dried. The dried solids masses and images are provided in Table 3.3. The average UDS represents $\sim 6.5 \%$ of the total dry solids.

Table 3.3. Dry Undissolved Solids

\begin{tabular}{|c|c|c|}
\hline Parameter & $\begin{array}{c}\text { 68122-TI-001-F } \\
16-0032 \\
\end{array}$ & $\begin{array}{c}\text { 68122-TI-001-G } \\
16-0032 \text { (dup) }\end{array}$ \\
\hline Dry UDS mass (g) & 0.0039 & 0.0039 \\
\hline UDS remaining (dry solids mass basis) (\%) & 6.7 & 6.4 \\
\hline Image & & \\
\hline
\end{tabular}




\subsection{Radionuclide Analysis}

All radionuclide analyses were conducted on the acid digestate. Gamma energy analysis (GEA) was also performed on the UDS samples. Table 3.4 and Table 3.5 provide the results summaries for the measured radionuclides in the acid digestate reported on a dry mass basis (see the ASO reports in Appendix B for full discussion) and wet centrifuged solids mass basis, respectively.

Table 3.4. Radionuclide Summary Results for the Acid Digestate, Dry Centrifuged Solids Mass Basis

\begin{tabular}{|c|c|c|c|c|}
\hline & $\begin{array}{c}\text { 68122-TI-001-F } \\
16-0032 \\
\end{array}$ & $\begin{array}{c}\text { 68122-TI-001-G } \\
16-0032 \text { (dup) }\end{array}$ & Average & \multirow[b]{2}{*}{ RPD } \\
\hline Analyte & \multicolumn{3}{|c|}{$\mu \mathrm{Ci} / \mathrm{g}$ Dry Mass } & \\
\hline${ }^{60} \mathrm{Co}$ (GEA) & $1.08 \mathrm{E}-1^{\text {(a) }}$ & $9.91 \mathrm{E}-2^{(\mathrm{a})}$ & $1.04 \mathrm{E}-1^{(\mathrm{a})}$ & $8.6^{(\mathrm{a})}$ \\
\hline${ }^{137} \mathrm{Cs}$ (GEA) & $1.02 \mathrm{E}+2$ & $9.49 \mathrm{E}+1$ & $9.85 \mathrm{E}+1$ & 7.2 \\
\hline${ }^{152} \mathrm{Eu}$ (GEA) & $3.88 \mathrm{E}-2$ & $3.13 \mathrm{E}-2$ & $3.51 \mathrm{E}-2$ & $21^{(b)}$ \\
\hline${ }^{154} \mathrm{Eu}$ (GEA) & $1.54 \mathrm{E}+0$ & $1.46 \mathrm{E}+0$ & $1.50 \mathrm{E}+0$ & 5.3 \\
\hline${ }^{155} \mathrm{Eu}(\mathrm{GEA})$ & $2.28 \mathrm{E}-1$ & $2.55 \mathrm{E}-1$ & $2.42 \mathrm{E}-1$ & 11 \\
\hline${ }^{238} \mathrm{Pu}(\mathrm{AEA})$ & $2.63 \mathrm{E}+01$ & $2.61 \mathrm{E}+1$ & $2.62 \mathrm{E}+1$ & 0.8 \\
\hline${ }^{239+240} \mathrm{Pu}(\mathrm{AEA})$ & $1.99 \mathrm{E}+2$ & $2.00 \mathrm{E}+2$ & $2.00 \mathrm{E}+2$ & 0.4 \\
\hline${ }^{241} \mathrm{Am}$ (GEA) & $9.64 \mathrm{E}+1$ & $1.06 \mathrm{E}+2$ & $1.01 \mathrm{E}+2$ & 9.5 \\
\hline${ }^{241} \mathrm{Am}$ (AEA) & $9.39 \mathrm{E}+1$ & $8.69 \mathrm{E}+1$ & $9.04 \mathrm{E}+1$ & 7.7 \\
\hline${ }^{237} \mathrm{~Np}(\mathrm{AEA})$ & $1.80 \mathrm{E}-3$ & $2.09 \mathrm{E}-3$ & $1.94 \mathrm{E}-3$ & 15 \\
\hline${ }^{90} \mathrm{Sr}(\mathrm{LSC})$ & $1.88 \mathrm{E}+1$ & $1.88 \mathrm{E}+1$ & $1.88 \mathrm{E}+1$ & 0.5 \\
\hline
\end{tabular}

The GEA analyte reference date is November 24, 2015; the alpha energy analysis (AEA) and ${ }^{90} \mathrm{Sr}$ liquid scintillation counting (LSC) reference date is December 15-30, 2015.

ASR 9916, ASO sample 16-0032 and 16-0032 duplicate; see Appendix B.

Bolded values indicate the relative percent difference (RPD) exceeded acceptance criteria of $20 \%$.

(a) An additional 7.0 and $8.5 \%$ of the ${ }^{60} \mathrm{Co}$ remained with the UDS for the sample and duplicate, respectively, see Table 3.7.

(b) The RPD passed the mean difference test; see Appendix B.

Table 3.5. Radionuclide Summary Results for the Acid Digestate, Wet Centrifuged Solids Mass Basis

\begin{tabular}{|c|c|c|c|c|}
\hline \multirow[b]{2}{*}{ Analyte } & $\begin{array}{c}\text { 68122-TI-001-F } \\
16-0032 \\
\end{array}$ & $\begin{array}{l}\text { 68122-TI-001-G } \\
16-0032 \text { (dup) }\end{array}$ & Average & \multirow[b]{2}{*}{ RPD } \\
\hline & \multicolumn{3}{|c|}{$\mu \mathrm{Ci} / \mathrm{g}$ Wet Centrifuged Solids } & \\
\hline${ }^{60} \mathrm{Co}$ (GEA) & $1.35 \mathrm{E}-2^{(\mathrm{a})}$ & $1.47 \mathrm{E}-2^{(\mathrm{a})}$ & $1.41 \mathrm{E}-2^{(\mathrm{a})}$ & $8.1^{\text {(a) }}$ \\
\hline${ }^{137} \mathrm{Cs}(\mathrm{GEA})$ & $1.28 \mathrm{E}+1$ & $1.40 \mathrm{E}+1$ & $1.34 \mathrm{E}+1$ & 9.5 \\
\hline${ }^{152} \mathrm{Eu}(\mathrm{GEA})$ & $4.85 \mathrm{E}-3$ & $4.63 \mathrm{E}-3$ & 4.74E-3 & 4.7 \\
\hline${ }^{154} \mathrm{Eu}(\mathrm{GEA})$ & $1.93 \mathrm{E}-1$ & 2.16E-1 & 2.04E-1 & 11 \\
\hline${ }^{155} \mathrm{Eu}(\mathrm{GEA})$ & $2.85 \mathrm{E}-2$ & $3.77 \mathrm{E}-2$ & $3.31 \mathrm{E}-2$ & $28^{(b)}$ \\
\hline${ }^{238} \mathrm{Pu}(\mathrm{AEA})$ & $3.29 \mathrm{E}+0$ & $3.86 \mathrm{E}+0$ & $3.57 \mathrm{E}+0$ & 16 \\
\hline${ }^{239+240} \mathrm{Pu}(\mathrm{AEA})$ & $2.49 \mathrm{E}+1$ & $2.96 \mathrm{E}+1$ & $2.73 \mathrm{E}+1$ & 17 \\
\hline${ }^{241} \mathrm{Am}(\mathrm{GEA})$ & $1.21 \mathrm{E}+1$ & $1.57 \mathrm{E}+1$ & $1.39 \mathrm{E}+1$ & 26 \\
\hline${ }^{241} \mathrm{Am}(\mathrm{AEA})$ & $1.17 \mathrm{E}+1$ & $1.28 \mathrm{E}+1$ & $1.23 \mathrm{E}+1$ & 9.0 \\
\hline${ }^{237} \mathrm{~Np}(\mathrm{AEA})$ & $2.25 \mathrm{E}-4$ & $3.08 \mathrm{E}-4$ & $2.67 \mathrm{E}-4$ & 31 \\
\hline${ }^{90} \mathrm{Sr}(\mathrm{LSC})$ & $2.35 \mathrm{E}+0$ & $2.79 \mathrm{E}+0$ & $2.57 \mathrm{E}+0$ & 17 \\
\hline
\end{tabular}

The GEA analyte reference date is November 24, 2015; the AEA and ${ }^{90} \mathrm{Sr}$ reference date is December 15-30, 2015.

Bolded values indicate the RPD exceeded acceptance criteria of $20 \%$.

(a) An additional 7.0 and $8.5 \%$ of the ${ }^{60} \mathrm{Co}$ activity remained with the UDS for the sample and duplicate, respectively, see Table 3.7 .

(b) The RPD passed the mean difference test; see Appendix B. 
The sample averages and relative percent deviations (RPDs) are also provided in Table 3.4 and Table 3.5. RPDs that exceed $20 \%$ are in bold font to indicate where the data quality objective (RPD $\leq 20 \%$ ) was exceeded. The dry solids net mass uncertainty was about $5 \%$; the wet centrifuged solids mass uncertainty was 16 to $18 \%$. The higher RPDs associated with the results on a wet centrifuged solids mass basis reflect the higher uncertainties associated with the centrifuged solids mass measurements.

The concentrations of gamma-emitting radionuclides in the UDS are provided in Table 3.6 along with the averages and RPDs. Only the ${ }^{241} \mathrm{Am}$ result in the UDS exceeded $20 \%$ RPD, indicating good overall precision.

Table 3.6. Radionuclide Summary Results for the UDS, Dry Solids Mass Basis

\begin{tabular}{|c|c|c|c|c|}
\hline & $\begin{array}{c}\text { 68122-TI-001-F UDS } \\
16-0032 \\
\end{array}$ & $\begin{array}{c}\text { 68122-TI-001-G UDS } \\
\text { 16-0032 (dup) }\end{array}$ & Average UDS & \multirow[b]{2}{*}{ RPD } \\
\hline Analyte & & $\mu \mathrm{Ci} / \mathrm{g}$ dry mass & & \\
\hline${ }^{60} \mathrm{Co}$ (GEA) & $1.13 \mathrm{E}-1$ & $1.34 \mathrm{E}-1$ & $1.24 \mathrm{E}-1$ & 17 \\
\hline${ }^{137} \mathrm{Cs}$ (GEA) & $1.01 \mathrm{E}+1$ & $1.07 \mathrm{E}+1$ & $1.04 \mathrm{E}+1$ & 5.8 \\
\hline${ }^{152} \mathrm{Eu}(\mathrm{GEA})$ & $2.31 \mathrm{E}-3$ & $2.06 \mathrm{E}-3$ & $2.19 \mathrm{E}-3$ & 11 \\
\hline${ }^{154} \mathrm{Eu}$ (GEA) & $3.26 \mathrm{E}-2$ & $3.41 \mathrm{E}-2$ & $3.34 \mathrm{E}-2$ & 4.5 \\
\hline${ }^{155} \mathrm{Eu}$ (GEA) & $4.18 \mathrm{E}-3$ & $5.03 \mathrm{E}-3$ & $4.61 \mathrm{E}-3$ & 18 \\
\hline${ }^{241} \mathrm{Am}$ (GEA) & $1.25 \mathrm{E}+0$ & $1.78 \mathrm{E}+0$ & $1.52 \mathrm{E}+0$ & 35 \\
\hline
\end{tabular}

The analyte activity fractionation to the UDS residue was evaluated for the measured gamma-emitters. The activity was corrected to total activity, as opposed to being evaluated on a per gram basis. Table 3.7 shows the total microCuries analyte in the acid digestate and UDS as well as the fraction remaining in the UDS. The total activity is heavily weighted to the acid digestate. Except for ${ }^{60} \mathrm{Co}$ present at $\sim 8 \%$ in the UDS, analytes were present at much less than $1 \%$ in the UDS. It is assumed that the $\mathrm{Sr}, \mathrm{Pu}$, and $\mathrm{Np}$ are similarly fractionated to the acid digestate (chemistry following that of $\mathrm{Am}$ and $\mathrm{Eu}$ ), and that the results shown in Table 3.4 accurately reflect the ${ }^{90} \mathrm{Sr}, \mathrm{Pu}$, and $\mathrm{Np}$ radionuclide concentrations in the initial centrifuged solids.

Table 3.7. Relative Radionuclide Content in the Acid Digestate and UDS

\begin{tabular}{|c|c|c|c|c|c|c|}
\hline \multirow[b]{2}{*}{ Analyte } & \multicolumn{3}{|c|}{$\begin{array}{c}\text { 68122-TI-001-F } \\
16-0032\end{array}$} & \multicolumn{3}{|c|}{$\begin{array}{c}\text { 68122-TI-001-G } \\
\text { 16-0032 (dup) }\end{array}$} \\
\hline & $\begin{array}{c}\mu \mathrm{Ci} \text { in } \\
\text { acid digest }^{(\mathrm{a})}\end{array}$ & $\begin{array}{l}\mu \mathrm{Ci} \text { in } \\
\mathrm{UDS}^{(\mathrm{b})}\end{array}$ & $\begin{array}{l}\text { Fraction } \\
\text { in UDS }\end{array}$ & $\begin{array}{c}\mu \mathrm{Ci} \text { in } \\
\text { acid digest }^{(\mathrm{a})}\end{array}$ & $\begin{array}{l}\mu \mathrm{Ci} \text { in } \\
\mathrm{UDS}^{(\mathrm{b})}\end{array}$ & $\begin{array}{l}\text { Fraction } \\
\text { in UDS }\end{array}$ \\
\hline${ }^{60} \mathrm{Co}$ & $5.89 \mathrm{E}-3$ & $4.41 \mathrm{E}-4$ & $7.0 \%$ & $5.63 \mathrm{E}-3$ & $5.23 \mathrm{E}-4$ & $8.5 \%$ \\
\hline${ }^{137} \mathrm{Cs}$ & $5.56 \mathrm{E}+0$ & $3.94 \mathrm{E}-2$ & $0.70 \%$ & $5.39 \mathrm{E}+0$ & 4.17E-2 & $0.77 \%$ \\
\hline${ }^{152} \mathrm{Eu}$ & $2.11 \mathrm{E}-3$ & $9.01 \mathrm{E}-6$ & $0.42 \%$ & $1.78 \mathrm{E}-3$ & $8.03 \mathrm{E}-6$ & $0.45 \%$ \\
\hline${ }^{154} \mathrm{Eu}$ & $8.39 \mathrm{E}-2$ & $1.27 \mathrm{E}-4$ & $0.15 \%$ & $8.29 \mathrm{E}-2$ & $1.33 \mathrm{E}-4$ & $0.16 \%$ \\
\hline${ }^{155} \mathrm{Eu}$ & $1.24 \mathrm{E}-2$ & $1.63 \mathrm{E}-5$ & $0.13 \%$ & $1.45 \mathrm{E}-2$ & $1.96 \mathrm{E}-5$ & $0.14 \%$ \\
\hline${ }^{241} \mathrm{Am}$ (GEA) & $5.25 \mathrm{E}+0$ & $4.88 \mathrm{E}-3$ & $0.09 \%$ & $6.02 \mathrm{E}+0$ & $6.94 \mathrm{E}-3$ & $0.12 \%$ \\
\hline
\end{tabular}

(a) The radionuclide concentration (Table 3.4) was multiplied by the dry centrifuged solids sample mass (Table 3.1). (b) The radionuclide concentration (Table 3.6) was multiplied by the UDS mass (Table 3.3). 
Table 3.8 provides the normalized $\mathrm{Pu}$ isotopic mass ratio (see Section 2.3 for normalization discussion). $\mathrm{The} \mathrm{Pu}$ isotopic fractions are similar to the fractions measured in the sludge samples collected from SCSCON-220 (Fiskum et al. 2011) after decay-correction for ${ }^{241} \mathrm{Pu}$.

Table 3.8. Plutonium Isotopic Analysis by TIMS and AEA for the Acid Digestate

\begin{tabular}{ccccc}
\hline Analyte & $\begin{array}{c}68122-\text { TI-001-F } \\
16-0032\end{array}$ & $\begin{array}{c}68122-\text { TI-001-G } \\
\text { 16-0032 (dup) }\end{array}$ & Average & RPD \\
\hline \multicolumn{5}{c}{ Atom Percent (Normalized) } \\
\hline${ }^{238} \mathrm{Pu}(\mathrm{AEA})$ & 0.0642 & 0.0635 & 0.0638 & 1.1 \\
${ }^{239} \mathrm{Pu}$ & 86.38 & 86.38 & 86.38 & 0.002 \\
${ }^{240} \mathrm{Pu}$ & 12.93 & 12.93 & 12.93 & 0.04 \\
${ }^{241} \mathrm{Pu}$ & 0.3904 & 0.3885 & 0.3895 & 0.50 \\
${ }^{242} \mathrm{Pu}$ & 0.2335 & 0.2326 & 0.2331 & 0.38 \\
\hline \multicolumn{5}{c}{ Weight Percent (Normalized) } \\
\hline${ }^{238} \mathrm{Pu}(\mathrm{AEA})$ & 0.0639 & 0.0632 & 0.0635 & 0.002 \\
${ }^{239} \mathrm{Pu}$ & 86.33 & 86.33 & 86.33 & 0.04 \\
${ }^{240} \mathrm{Pu}$ & 12.98 & 12.98 & 12.98 & 0.50 \\
${ }^{241} \mathrm{Pu}$ & 0.3935 & 0.3915 & 0.3925 & 0.38 \\
${ }^{242} \mathrm{Pu}$ & 0.2363 & 0.2354 & 0.2359 & \\
\hline
\end{tabular}

Reference date is January 27, 2016.

\subsection{Radioisotopic Ratio Evaluation}

The $\mathrm{Pu}$ is expected to be trapped as a fine particulate in the sand filter while the much more soluble Cs and $\mathrm{Sr}$ are expected to pass through the sand filter. Additionally, as basin water continues to be passed through the sand filter, $\mathrm{Cs}$ and $\mathrm{Sr}$ will be washed from the trapped particulates, further depleting their inventory in the particulates. The isotopic ratios of ${ }^{239+240} \mathrm{Pu}$ to ${ }^{90} \mathrm{Sr}$ and ${ }^{239+240} \mathrm{Pu}$ to ${ }^{137} \mathrm{Cs}$ were evaluated for the sand filter backwash sample in terms of $\mu \mathrm{Ci} / \mathrm{g}$ dry solids. The sample isotopic ratios were compared to the ratios from sludge in the large engineered containers $(-500 \mu \mathrm{m}$ sieve fraction where possible) as well as the suspended solids collected after a 30-minute settling time (i.e., SCS-CON-220, SCS-CON-240, SCS-CON-250, and SCS-CON-260) that had been decay-corrected to November 24, 2015 (sample KW-105 SFBW-001 reference date). The backwash sand filter ${ }^{239+240} \mathrm{Pu} /{ }^{90} \mathrm{Sr}$ and ${ }^{239+240} \mathrm{Pu} /{ }^{137} \mathrm{Cs}$ isotopic ratios were uniquely higher than all other $\mathrm{K}$ West Basin sludge samples as shown in Table 3.9. This indicates that the radiological content of the sand filter backwash solids is not well represented by the isotopic mix ratio of the sludge itself. Relative to the ${ }^{137} \mathrm{Cs}$ content, the $\mathrm{Pu}$ is 4 to $20 \times$ higher in the sand filter solids than in the K West Basin sludge source material. Relative to the ${ }^{90} \mathrm{Sr}$ content, the $\mathrm{Pu}$ is 10 to $100 \times$ higher in the sand filter solids than in the K West Basin sludge source material. The ratio differences indicate a relative enhancement of the $\mathrm{Pu}$ concentration in the sand filter solids relative to the ${ }^{137} \mathrm{Cs}$ and ${ }^{90} \mathrm{Sr}$ sludge concentrations currently in the K West Basin. A dose-to-curie radioisotope evaluation of the sand filter waste form may need to consider this dissimilarity. 
PNNL-25241

Table 3.9. Isotopic Ratios in Backwash Sand Filter and Containerized Sludge

\begin{tabular}{|c|c|c|c|c|}
\hline Description & Sample ID & ${ }^{239+240} \mathrm{Pu} /{ }^{90} \mathrm{Sr}^{(\mathrm{a}, \mathrm{d})}$ & ${ }^{239+240} \mathrm{Pu} /{ }^{137} \mathrm{Cs}^{(\mathrm{b}, \mathrm{d})}$ & $\begin{array}{c}\text { Analytical Data Source } \\
\text { Reference }\end{array}$ \\
\hline $\begin{array}{l}\text { Backwash sand filter } \\
\text { sample }\end{array}$ & $\begin{array}{c}\text { KW- } \\
105 \text { SFBW-001 }\end{array}$ & 10.6 & 2.0 & Data in this report \\
\hline $\begin{array}{l}\text { KW } 210 \text { container } \\
\text { composite, }-500 \mu \mathrm{m} \\
\text { sieve fraction }\end{array}$ & $\begin{array}{c}\text { Average of } \\
\text { TI008-SA } \\
\text { and TI008-SB }\end{array}$ & 1.21 & 0.27 & (Fountain et al. 2013) \\
\hline $\begin{array}{l}\text { KW220 container } \\
\text { composite, }-500 \mu \mathrm{m} \\
\text { sieve fraction }\end{array}$ & TI009-SB-s & ${ }^{90} \mathrm{Sr}$ not analyzed & 0.23 & (Fiskum et al. 2011) \\
\hline KW230 Core A2 & TI023-1C & 0.14 & 0.41 & (Shimskey et al. 2013) \\
\hline KW230 Core A3 & TI024-2C & 0.10 & 0.13 & (Shimskey et al. 2013) \\
\hline KW230 Core B2 & TI024-3C & 0.14 & 0.38 & (Shimskey et al. 2013) \\
\hline KW230 Core B4 & TI024-4C & 0.12 & 0.22 & (Shimskey et al. 2013) \\
\hline $\begin{array}{l}\text { KW } 240 \text { container } \\
\text { composite, }-500 \mu \mathrm{m} \\
\text { sieve fraction }\end{array}$ & TI010-SD & $0.11^{(\mathrm{c})}$ & 0.12 & (Fiskum et al. 2011) \\
\hline $\begin{array}{l}\text { KW } 250 \text { container } \\
\text { composite, }-500 \mu \mathrm{m} \\
\text { sieve fraction }\end{array}$ & TI011-SB & $0.12^{(\mathrm{c})}$ & 0.10 & (Fiskum et al. 2011) \\
\hline $\begin{array}{l}\text { KW260 container } \\
\text { composite, }-500 \mu \mathrm{m} \\
\text { sieve fraction }\end{array}$ & TI012-SB & $0.14^{(\mathrm{c})}$ & 0.16 & (Fiskum et al. 2011) \\
\hline $\begin{array}{l}\text { KW240 suspended } \\
\text { solids in settling test }\end{array}$ & SSK240-S & ${ }^{90} \mathrm{Sr}$ not analyzed & 0.37 & (Fiskum et al. 2010) \\
\hline $\begin{array}{l}\text { KW250 suspended } \\
\text { solids in settling test }\end{array}$ & SSK250-S & ${ }^{90} \mathrm{Sr}$ not analyzed & 0.25 & (Fiskum et al. 2010) \\
\hline $\begin{array}{l}\text { KW260 suspended } \\
\text { solids in settling test }\end{array}$ & SSK260-S & ${ }^{90} \mathrm{Sr}$ not analyzed & 0.46 & (Fiskum et al. 2010) \\
\hline $\begin{array}{l}\text { KW220 suspended } \\
\text { solids in settling test }\end{array}$ & SSK220A3-S & ${ }^{90} \mathrm{Sr}$ not analyzed & 0.47 & (Fiskum et al. 2010) \\
\hline $\begin{array}{l}\text { KE NLOP suspended } \\
\text { solids from top sample }\end{array}$ & KENLOP-DS2 & 1.26 & 0.61 & Shelor et al. 2004 \\
\hline $\begin{array}{l}\text { KE NLOP top } 1 / 3 \text { of } \\
\text { core sample }\end{array}$ & KENLOP-AB2 & 2.77 & 0.48 & Shelor et al. 2004 \\
\hline \multicolumn{5}{|c|}{$\begin{array}{l}\text { (a) } \mu \mathrm{Ci}{ }^{239+240} \mathrm{Pu} / \mathrm{g} \text { dry solids divided by } \mu \mathrm{Ci}{ }^{90} \mathrm{Sr} / \mathrm{g} \text { dry solids. } \\
\text { (b) } \mu \mathrm{Ci}{ }^{239+240} \mathrm{Pu} / \mathrm{g} \text { dry solids divided by } \mu \mathrm{Ci}^{137} \mathrm{Cs} / \mathrm{g} \text { dry solids. } \\
\text { (c) }{ }^{90} \mathrm{Sr} \text { was not analyzed in the }-500 \mu \mathrm{m} \text { sieve fraction; the given ratio was calculated from the average A and B } \\
\text { reconstituted core samples. } \\
\text { (d) Reference date is November } 24,2015 \text {. }\end{array}$} \\
\hline
\end{tabular}

Per Fiskum et al. (2011), the ${ }^{90} \mathrm{Sr}$ and ${ }^{137} \mathrm{Cs}$ concentrations were nearly equivalent in the $\mathrm{K}$ Basin water (3.36E-4 and 5.83E-4 $\mu \mathrm{Ci} / \mathrm{g}$, respectively). The Cs is expected to be soluble in water and $\mathrm{Sr}$ will have some solubility in water. The higher $\mathrm{Pu}$ fractionation in the sand filter solids relative to $\mathrm{Cs}$ and $\mathrm{Sr}$ is expected based on solubility and functionality of the filter. However the extent of the divergence of the $\mathrm{Pu} / \mathrm{Cs}$ and $\mathrm{Pu} / \mathrm{Sr}$ ratios relative to other sludge types was higher than expected. 


\subsection{Conclusions}

The sand filter backwash slurry sample, KW-105 SFBW-001, was successfully processed and analyzed for physical properties and radioisotopic concentrations. These properties will enable KBO \& PR staff at $\mathrm{CH} 2 \mathrm{MHill}$ to better evaluate the radionuclide composition of the sand filter located at the $\mathrm{K}$ West Basin.

- Sample receipt, handling, and analyses were executed consistent with the planning and no issues were encountered.

- The backwash solids physical characteristics were consistent with the majority composition of iron oxides/hydroxides: the color was orange/brown, the wet centrifuged solids density was close to 1 $\mathrm{g} / \mathrm{mL}$, and the mass loss on drying was about $86 \mathrm{wt} \%$. However, mineral phase characterization was not conducted.

- Most of the radionuclide activity dissolved in the acid digestion, indicating that the acid digestate values were well-representative of the sand filter samples. The radionuclide activity fractions remaining in the UDS portion of the sample were $7.7 \%{ }^{60} \mathrm{Co}$ and $<1 \%{ }^{241} \mathrm{Am},{ }^{154 / 155} \mathrm{Eu}$, and ${ }^{137} \mathrm{Cs}$.

- The duplicate subsamples analytes ${ }^{60} \mathrm{Co},{ }^{137} \mathrm{Cs},{ }^{152} \mathrm{Eu},{ }^{154} \mathrm{Eu},{ }^{155} \mathrm{Eu},{ }^{238} \mathrm{Pu},{ }^{239+240} \mathrm{Pu},{ }^{237} \mathrm{~Np},{ }^{241} \mathrm{Am}$, and ${ }^{90} \mathrm{Sr}$ were quantified on a dry mass basis and the primary and duplicate samples met quality control precision acceptance criteria of $\leq 20 \%$.

- The Pu isotopic ratios, measured with TIMS and AEA, were consistent with sludge Pu isotopic ratios in SCS-CON-210 and SCS-CON-220 core samples.

- The relative fraction of $\mathrm{Pu}$, when compared to ${ }^{90} \mathrm{Sr}$ and ${ }^{137} \mathrm{Cs}$, was higher in the backwash sand filter sample than in the K West Basin sludge, indicating a physical enrichment of Pu in the sand filter solids. 

PNNL-25241

\subsection{References}

Baker RB, JL Westcott, TL Welsh, JA Pottmeyer, AJ Schmidt. 2009. Quality Assurance Project Plan/Sampling and Analysis Plan for Sludge in the KW Engineered Containers; KBC-33786, Rev. 2. CH2M Hill, Richland, Washington.

Fiskum SK, JM Billing, SJ Bos, CA Burns, CD Carlson, DS Coffey, JV Crum, RC Daniel, CH Delegard, MK Edwards, OT Farmer, LR Greenwood, SA Jones, D Neiner, BM Oliver, KN Pool, AJ Schmidt, RW Shimskey, SI Sinkov, SZ Soderquist, CJ Thompson, ML Thomas, T Trang-Le, and MW Urie. 2011. Characterization Data Package for Containerized Sludge Samples Collected from Engineered Containers SCS-CON-240, 250, 260, and 220. PNNL-19035 Rev. 1, Battelle, Pacific Northwest National Laboratory, Richland, Washington.

Fiskum SK, OP Bredt, CA Burns, CD Carlson, DS Coffey, RC Daniel, PJ MacFarlan, KN Pool, AJ Schmidt, GJ Sevigny, RW Shimskey, and LA Snow. 2010. Stage 1 and Stage 2 Settling Studies of KBasin Containerized Sludge. PNNL-19213, Pacific Northwest National Laboratory, Richland, Washington.

Fountain MS, SK Fiskum, DL Baldwin, SJ Bos, CA Burns, CD Carlson, DS Coffey, RC Daniel, CH Delegard, MK Edwards, LR Greenwood, D Neiner, BM Oliver, KN Pool, AJ Schmidt, RW Shimskey, SI Sinkov, LA Snow, CZ Soderquist, CJ Thompson, T Trang-Le, and MW Urie. 2013. Characterization Data Package for Containerized Sludge Samples Collected from Engineered Container SCS-CON-210. PNNL-20650 Rev. 2, Pacific Northwest National Laboratory, Richland, Washington.

Johnson M. 2014. Spent Nuclear Fuel Project Technical Databook, Volume 2, Sludge. HNF-SD-SNF-TI025, Revision 25, Volume 2, CH2MHill, Richland, Washington.

Kurta J. 1998. System Description - The Basin Water Systems. HNF-SD-SNF-SDD-016, DE\&S Hanford, Inc., Richland, Washington.

Makenas BJ, TL Welsh, RB Baker, EW Hoppe, AJ Schmidt, J Abrefah, JM Tingey, PR Bredt, and GR Golcar. 1997. Analysis of sludge from Hanford K East Basin canisters. HNF-SP-1201.

Mellinger GB, CH Delegard, AJ Schmidt, GJ Sevigny. 2004. Evaluation and Recommendation of Waste Form and Packaging for Disposition of the K East Basin North Loadout Pit Sludge. PNNL-14741, Pacific Northwest National Laboratory, Richland, Washington.

Schmidt AJ. 2006. Water Clarity Simulant for K East Basin Filtration Testing. PNNL-15615, Pacific Northwest National Laboratory, Richland, Washington.

Shelor JL, MG Plys, M Epstein, JP Sloughter, J Abrafah, CH Delegard, AJ Schmidt. 2004. Gas Behavior in Large Diameter Containers (LDCs) During and Following Loading with 105K East North Loadout Pit Sludge. SNF-22059, Revision 0, Flour Hanford, Richland, Washington.

Shimskey RW, JM Billing, SJ Bos, CA Burns, DS Coffey, RC Daniel, CH Delegard, MK Edwards, SK Fiskum, LR Greenwood, SA Jones, M Luna, D Neiner, BM Oliver, KN Pool, AJ Schmidt, SI Sinkov, LA Snow, CZ Soderquist, CJ Thompson, T Trang-Le, and MW Urie. 2013. Characterization Data Package for Containerized Sludge Samples Collected from Engineered Container SCS-CON-230. PNNL-20470 Rev. 1, Pacific Northwest National Laboratory, Richland, Washington. 



\section{Appendix A}

Completed Test Instruction 68122-TI-001, Sandfilter Backwash Solids Consolidation 



\section{Appendix A}

\section{Completed Test Instruction 68122-TI-001, Sandfilter Backwash Solids Consolidation}

Appendix A provides the completed test instruction (TI) used to describe solids the consolidation approach, give step by step instructions, and record data and annotations. Attached to the TI are underpinning records of balance calibration and daily performance checks, pictorial summary, sample chain of custody provided by $\mathrm{CH} 2 \mathrm{M}$ Hill, technical review, and data calculations.

The technical review is conducted by staff other than the analyst performing the work and who is knowledgeable of the area being reviewed. The technical review elements include data evaluation, method and quality control (QC) sample performance against requirements, compliance with technical and QC requirements, transcription accuracy into data analysis tables, calculation accuracy, consistency and reasonableness of the data.

Also included in Appendix A is the Quality Engineer's surveillance report, SR-68122-2015-005 that evaluates completeness, method implementation and QC sample performance against data quality requirements, compliance with technical and QC requirements, transcription accuracy, calculation accuracy, consistency and reasonableness of data, verification of technical review issue resolution, and as appropriate tracking of corrective actions and completion.

No Occurrence or Deficiency Reports were issued during the processing activity.

\section{Appendix A Table of Contents}

Test Instruction 68122-TI-001, Sandfilter Backwash Solids Consolidation........................................... A.3

68122-TI-001, Attachment A, Balance Performance Check Logs ..................................................... A.24

68122-TI-001, Attachment B, Balance Calibrations........................................................................ A.27

68122-TI-001, Attachment C, Picture Contact Sheet ........................................................................ A.30

68122-TI-001, Attachment D, Email from CHPRC BTR 10/22/15 .................................................... A.32

68122-TI-001, Attachment E, CH2MHill CHPRC Chain of Custody and Shipping Documentation.... A.34

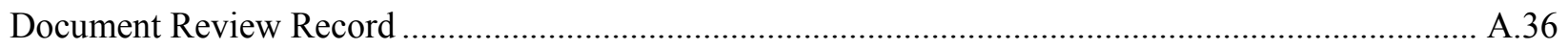

68122-TI-001 Data Reduction final.xlsx .................................................................................... A.37

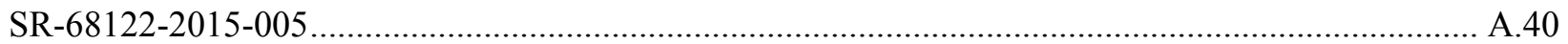





\section{TEST INSTRUCTION}

\section{TITLE: Sandfilter Backwash Solids Consolidation}

Unique Numerical Designation: 68122-TI-001

Revision Number: 0

Effective Date: Upon final signature

Controlling Procedure No: RPL-OP-001, current revision, Routine Research Operations

\section{Test Instruction Approvals}

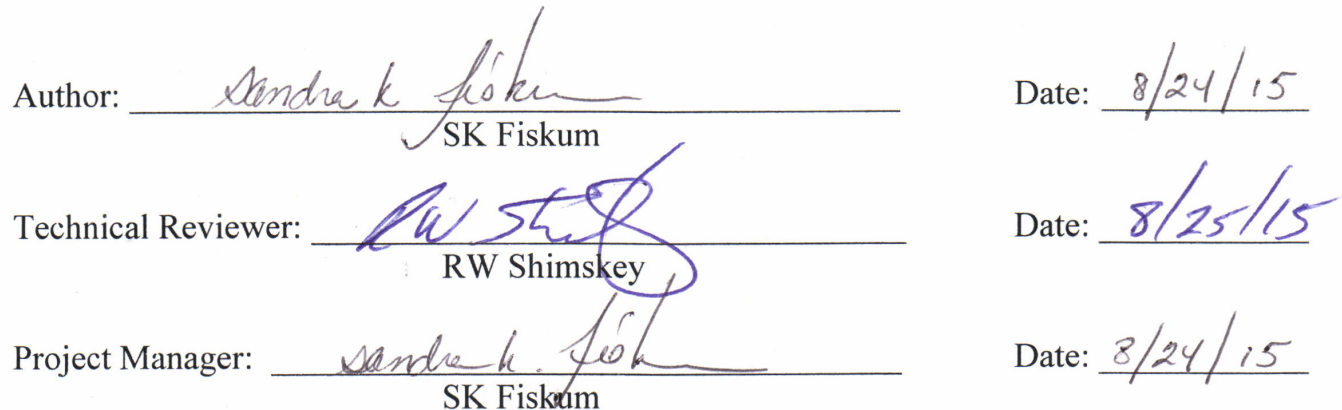

CSM Approval: $\frac{\text { Chrcle Soderguildt }}{\text { CZ Soderquist }} \quad$ Date: 8.2415

Project Quality Engineer: $\frac{\text { Befborah Cefleys }}{\text { DS Coffey }}$ Date: 8/24/15

Buyer's Technical
Representative (BTR): $\frac{4272}{\text { GM Davis }}$

\section{Test Instruction Completion Review}

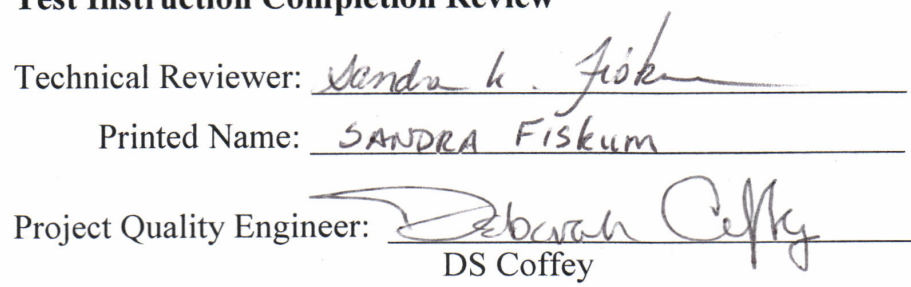

Date: $10 / 28 / 15$

Date: $20 / 28 / 15$

Date: $10 \cdot 29 / 2015$ 


\section{Project Specific Documents}

- $\quad$ Baker RB, JL Westcott, TL Welsh, JA Pottmeyer, and AJ Schmidt. 2009. Quality Assurance Project Plan/Sampling and Analysis Plan for Sludge in the KW Engineered Containers. KBC-33786, Rev. 2, CH2M Hill Plateau Remediation, Company, Richland, Washington.

- Westcott JL, BJ Makenas, TL Welsh, JA Pottmeyer, and AJ Schmidt. 2009. Data Quality Objectives for Sampling and Analysis of K Basin Sludge (DQO), HNF-36985, Rev. 3, CH2M Hill Plateau Remediation, Company, Richland, Washington.

- Letter 52578-2015-L03 from SK Fiskum to JO Honeyman, Cost Estimate for Analysis of the Sandfilter Backwash Solids, May 27, 2015.

- CH2M Hill Plateau Remediation, Contract 49517, Release 35, Statement of Work, Isotopic Analysis from PNNL (July 7, 2015), Amendment 1.

\section{Purpose}

Provide characterization data to allow the client to characterize the sand filter media for disposal. The sand filter is located in the K West Basin.

\section{Applicability}

This test instruction (TI) applies to Radiochemical Processing Laboratory (RPL) staff performing work with the K-Basin sandfilter backwash sample obtained from the K West basin sandfilter system (Project Number 68122). It provides direction to staff on required material manipulations and data recording in order to meet the project technical and quality requirements.

Work with the bulk samples is anticipated to be performed in radiological fume hoods. However, if the sample dose rate is too high for hand manipulations (including use of extension tools), parts of this sample preparation activity will be moved to, and conducted in, the Shielded Facility Operations (SFO) Shielded Analytical Laboratory (SAL, hot cells). All work will be conducted under the direction of a Cognizant Scientist.

This TI does not address safety procedures; the safe-handling constraints are implemented through the governing procedure RPL-OP-001, Routine Research Operations for in-cell (if needed) and fume hood manipulations. Applicable SFO procedures for transfers in and out of the hot cells may be applied as needed.

\section{Scope}

The scope of this TI is to receive/unpackage the sample, consolidate the suspended and settled solids in the as-received $750-\mathrm{mL}$ aqueous sample into two equivalent aliquots, and determine the centrifuged solids volume and mass.

The centrifuged solids will then be submitted to the Analytical Support Organization (ASO) for determination of dry sample mass, acid digestion, and radiochemical analysis of Cs-137 and other gamma emitters by gamma energy analysis, $\mathrm{Pu}-238, \mathrm{Pu}-239+240$, Np-237, and Am-241 by alpha energy analysis, and Sr-90 by beta analysis. An additional acid-digested aliquot will be purified for Pu isotopic analysis and analyzed thermal ionization mass spectrometry.

Page 2 of 21 
PNNL-25241

68122-TI-001

Revision 0

\section{Quality Assurance (QA)}

Elements of the Quality Assurance Project Plan /Sampling and Analysis Plan for Sludge in the KW Engineered Containers, KBC-33786, Rev. 2 December 2009 that apply to this sample preparation process include the following. Item (2) specifically applies to this TI; others apply to analysis, data reviews, and reporting. Pacific Northwest National Laboratory (PNNL) will perform the following:

1) Continue to be maintained on the CHPRC evaluated supplier list for laboratory services.

2) Receive samples at the laboratory and prepare the samples for analysis.

3) Analyze samples of sludge and associated applicable quality assurance samples.

4) Dispose of residues and sample waste.

5) Verify data prior to delivery to the customer.

6) Prepare data packages for delivery to the project/ Buyer's Technical Representative (BTR).

This document outlines PNNL's approach for handling and analyzing the backwash filter sample. The quality assurance program requirements defined in the Quality Assurance Project Plan (QAPjP)/Sampling and Analysis Plan (SAP) invoke Hanford Analytical Services Quality Assurance Requirements Document (HASQARD), Rev. 3, Volumes 1 and 4, and balance controls. The applicable quality control (QC) requirements that will be implemented for this work as defined in this test instruction are summarized in Table 1.

Table 1. QC Requirement and Implementation

\begin{tabular}{|c|c|}
\hline QC Requirement & Implementation \\
\hline $\begin{array}{l}\text { Controlling sample } \\
\text { identification }\end{array}$ & $\begin{array}{l}\text { K Basin Operations and Central Plateau Remediation Project (KBO\&PR) } \\
\text { will apply a unique code to the sample. Sample splits from the backwash } \\
\text { sample will be uniquely identified through this TI. }\end{array}$ \\
\hline Container selection & $\begin{array}{l}\text { Containers will be made of glass or plastic, consistent with the intended } \\
\text { storage and follow-on processing. }\end{array}$ \\
\hline Sample Preservation & Not applicable for current scope. \\
\hline $\begin{array}{l}\text { Sample chain of custody } \\
\text { (COC) }\end{array}$ & $\begin{array}{l}\text { COC is implemented by KBO\&PR and provided with sample receipt at the } \\
\text { RPL facility; internal COC is not required. Sample custody is maintained } \\
\text { during the sample preparation phase. Sample security is maintained by } \\
\text { limited access to the building and to laboratory areas. When the ASO } \\
\text { laboratory receives samples, an Analytical Service Request (ASR) is } \\
\text { generated. }\end{array}$ \\
\hline Sample storage & $\begin{array}{l}\text { It is anticipated that the entire sample will be split and acid digested. It is } \\
\text { not anticipated that sample storage will be required. }\end{array}$ \\
\hline $\begin{array}{l}\text { Sample handling and } \\
\text { transfer }\end{array}$ & $\begin{array}{l}\text { Handling and transfers will be conducted in a manner to minimize potential } \\
\text { for contamination (clean glassware and sampling devices), minimize loss } \\
\text { (use secondary containment during process operations), and minimize } \\
\text { tendency for sample to dry out (except where drying is required) where the } \\
\text { wetting agent is deionized (DI) water. }\end{array}$ \\
\hline $\begin{array}{l}\text { Compositing and } \\
\text { composite sub-sampling, }\end{array}$ & $\begin{array}{l}\text { Mixing will be conducted on a best-effort basis. The sample will be } \\
\text { thoroughly shaken to suspend finely divided solids as appropriate when } \\
\text { sub-samples are pulled for centrifugation. Sub-samples will be pipetted out } \\
\text { of the received sample container. }\end{array}$ \\
\hline
\end{tabular}


Table 1. QC Requirement and Implementation, continued

\begin{tabular}{|l|l|}
\hline QC Requirement & Implementation \\
\hline Holding time limits & $\begin{array}{l}\text { A 6-month holding time has been designated for metals analysis by } \\
\text { inductively coupled plasma optical emission spectrometry [ICP-OES]. } \\
\text { Because radionuclide measurement is needed, in this case a hold time does } \\
\text { not apply. }\end{array}$ \\
\hline Waste disposition & $\begin{array}{l}\text { Waste will be processed through the normal waste operations protocols and } \\
\text { procedures. }\end{array}$ \\
\hline $\begin{array}{l}\text { Preparing required QC } \\
\text { samples }\end{array}$ & $\begin{array}{l}\text { Within the scope of work for this TI, QC sample requirements entail the } \\
\text { creation of a sample duplicate for analysis. }\end{array}$ \\
\hline Balance checks & $\begin{array}{l}\text { Calibration of balances will be verified using one mass loading daily when } \\
\text { used to assess accuracy. The balance performance results will be logged } \\
\text { into this TI. }\end{array}$ \\
\hline
\end{tabular}

This TI will be approved by the BTR (QAPjP/SAP 3.4.3); the BTR's signature on the front page attests to the BTR approval.

\section{Processing Summary}

Part of the aqueous phase will be transferred to large-volume centrifuge containers and centrifuged to consolidate the fines; supernate will be decanted. The remaining sample will be mixed and the slurry transferred equally to the centrifuge containers with a transfer pipet. The slurry will be centrifuged to consolidate the solids and the supernate will be decanted. The client has requested to be present to observe the solids at this point.

After decanting supernate, the solids will be consolidated into one or two tared 15- or 40-mL glass, graduated, centrifuge cones (depending on solids quantity) and re-centrifuged. The centrifuged solids volume will be measured. The aqueous phase will be decanted and gross sample mass measured and net wet solids mass will be calculated. The sludge may be transferred into one centrifuge cone if the volume is not sufficient to measure-this option will be discussed with the BTR before proceeding and will likely hinge on which aspects are of greater importance: sludge density determination or duplicate analytical samples. A sample processing flow diagram is provided in Figure 1. 


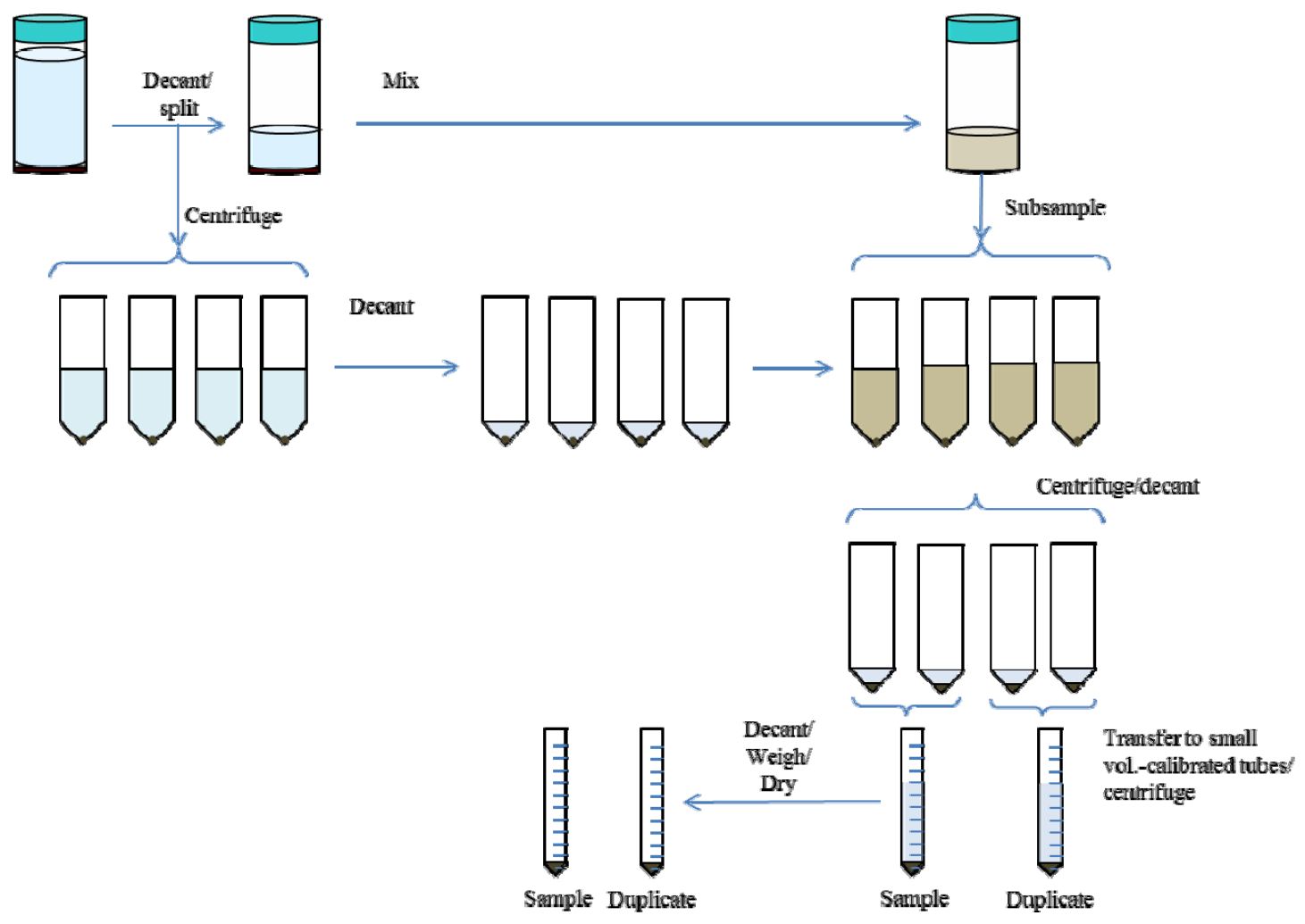

Figure 1. Sample Processing

The wet centrifuged solids will be transferred to the ASO laboratory for additional processing according to an ASR. ASO staff will dry the solids at $105^{\circ} \mathrm{C}$ to constant mass and the gross mass will be reported. The solids will be acid digested and the digestate will be analyzed for the radionuclides (except for gamma energy analysis, all analyses require radiochemical separation). Undigested residue will be weighed and measured for gamma emitters assuming the residue can be successfully transferred into a container suitable for gamma counting. Radionuclide measurement results will be provided on a dry mass basis.

\section{Issues of Concern}

Issues are of concern as defined below. The BTR will be kept informed as status progresses.

1) The relative uncertainty in the net sample mass increases as the sample mass decreases. Centrifuge tube mass measures will be collected on a four-place balance $(0.0001 \mathrm{~g}$ readability with uncertainty of $\sim 0.0006 \mathrm{~g}$ ). The uncertainty in the net sample mass will include the uncertainty in the tare weight and the gross sample masses according to Equation 1 where $u$ is the total uncertainty and $u_{T}$ is the uncertainty in the centrifuge container tare mass and $u_{G}$ is the uncertainty in the centrifuge plus dry solids mass.

$$
u=\sqrt{u_{F}^{2}+u_{G}^{2}}
$$

Eq. 1 
PNNL-25241

68122-TI-001

Revision 0

In this case the uncertainty in mass is expected to be $\sim 0.0009 \mathrm{~g}$. If the net sample mass is $0.01 \mathrm{~g}$, the mass uncertainty will represent $0.0009 \mathrm{~g} / 0.01 \mathrm{~g}=9 \%$. This uncertainty will be added to the analytical uncertainty.

2) Once solids are consolidated, the solids dose rate may be too high to prepare in a fume hood. It is possible that part of the sample manipulations and the drying and acid digestion may have to occur in the hot cells.

\section{Acronyms}

ALARA As low as reasonably achievable

ASO Analytical Support Operations

ASR Analytical Service Request

BPCL Balance performance Check log (form)

BTR Buyer's Technical Representative

COC chain of custody

DI deionized

DRR Document review record (form)

HASQARD Hanford Analytical Services Quality Assurance Requirements Document

ICP-OES inductively coupled plasma optical emission spectrometry

ID identification

KBO\&PR K Basin Operations \& Plateau Remediation Project

LRB laboratory record book (project-specific)

M\&TE measuring and test equipment

PNNL Pacific Northwest National Laboratory

QA quality assurance (program)

QAPjP Quality Assurance Project Plan

QC quality control (samples/activities)

RPL Radiochemical Processing Laboratory

RPT Radiological Protection Technologist

SAL Shielded Analytical Laboratory

SAP Sampling and Analysis Plan

SFO Shield Facility Operations

TI test instruction 


\section{M\&TE List}

Note:
A minimum of one balance performance check is to be performed daily when the balance is used.
This entails the measure of one mid-range mass check, recording it on the balance performance
check log (BPCL) form and comparing it to the acceptance criterion. The result will be used to
verify that the balance is in working order with respect to accuracy.
If the balance is out of statistical process control, the Cognizant Scientist will provide guidance
on how to proceed. The balance level may be verified, the balance re-zeroed, and then the control
masses re-measured, or the balance may be re-calibrated by the user and the control masses re-
measured. If the control masses are still out of the control limits, the statistical process control
limits may be re-evaluated/re-established or other corrective action may be pursued (e.g.,
recalibrate balance; segregate, tag as out-of-service, and replace balance) with the concurrence of
the Quality Engineer (QE).

List the balance information.

Balance 1: Make, model: Sartorius MSG234

Location: SAL

Capacity range: 0 to $240 \mathrm{~g}$

Calibration ID: 40023610 Cal. Expiration Date: February 2016

Balance 2: Make, model: _Sartorius R200D

Location:__ RPL Lab 525

Capacity range: $\quad 0$ to $200 \mathrm{~g}$

Calibration ID:__39080058___ Cal. Expiration Date: __ August 2016

Balance 3: Make, model: Mettler AT400

Location: _RPL Lab 305

Capacity range: 0 to $400 \mathrm{~g}$

Calibration ID: _ N04143_Cal. Expiration Date: __August 2016

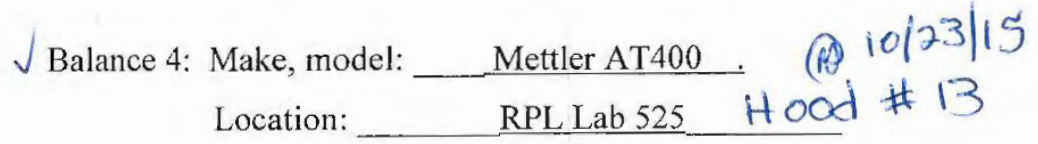

Capacity range: $\quad 0$ to $400 \mathrm{~g}$

Calibration ID:_1113061397_Cal. Expiration Date: ___ August 2016

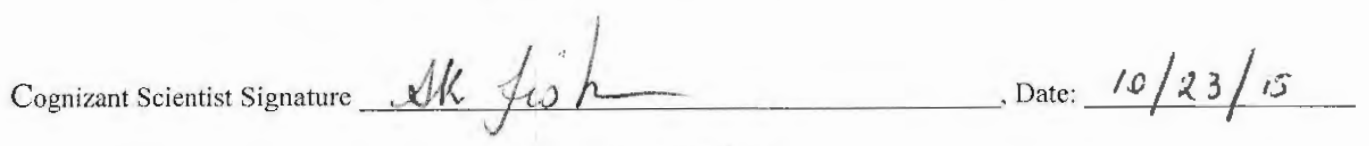

Page 7 of 21 
PNNL-25241

68122-TI-001

Revision 0

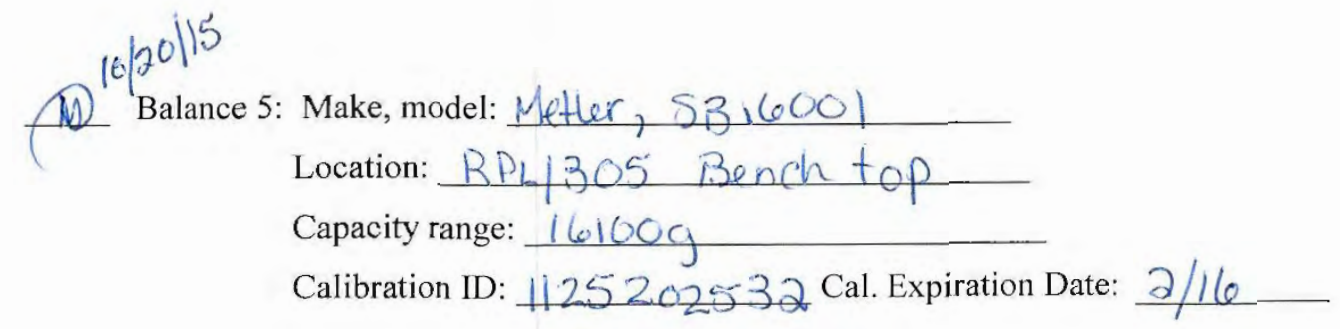

Cognizant Scientist Signature tok. fioke_Date: $10 / 23 / 15$

Page 8 of 21 
68122-TI-001

Revision 0

\section{Work Instructions}

\subsection{General Guidelines}

The following general guidelines apply to all operations discussed in this TI.

1. TIs are controlled documents; TI steps are expected to be completed as written and TIs initialed and dated as work is performed. Skipping steps is not acceptable.

2. When a TI needs to be modified during the performance of work, modification needs to be discussed, before implementing, with the Project Manager (PM) and QE to determine what needs to be done to manage the work control process (this may include documenting modifications in notes, revising and re-issuing the TI, or issuing an addendum to the TI). Documentation for changes defined by the PM or QE needs to be added to the TI when received.

3. Concurrence for proposed changes or modifications also needs to be obtained from the $\mathrm{K}$ Basin client before the change or modification is implemented. Documentation for concurrence for changes needs to be added to the $\mathrm{TI}$ when received.

4. The PM or delegate is the point of contact for the request to modify TIs and to define and document how changes will be made. When TIs are revised during work, major revisions require the same level of review and approval as the initial TI to adequately evaluate the impact of changes on data and to evaluate those objectives and technical and quality requirements are adequately addressed and will be attained as expected. Minor or editorial changes require concurrence from the PM; the PM decides if the change is major or minor.

5. All TI and laboratory record book (LRB) entries need to be complete and legible. Initials need to be associated with a printed name, see Table 2 for printed name-initials cross-reference. Error corrections are to be made using a single line-out that is initialed and dated. If the reason for the correction is not obvious, an explanation may need to be added describing why the correction was made.

6. Initial and sign Table 2.

7. When finished with a Step, initial and date the item or step. This indicates that the step has been completed, by whom, and when.

8. Keep the sample in a sealed container as much as possible to prevent it from drying unless directed to do otherwise in this TI.

9. Minimize cross-contamination between samples and contamination of samples from outside sources. Use new or cleaned tools as directed in this TI or by the Cognizant Scientist.

10. Record any observations, problems, or information that might be needed later concerning samples and collection of representative sub-samples for analysis in space provided in this TI. Report any highly unusual/unexpected observation to the PM and QE, who will discuss the observation with the client. The Cognizant Scientist is authorized to stop work and re-plan to address anomalies based on evolving conditions during sample handling. 
68122-TI-001

Revision 0

Table 2. Test Instruction User Identification

\begin{tabular}{|c|c|c|c|}
\hline Initials & Printed Name & Signature & Position \\
\hline$\infty$ & Margaret Smoot & me conout & Technician \\
\hline$\Delta k+$ & Sandra Fiskum & Nondra $h$ & Cognizant Scientist \\
\hline & Rick Shimskey & & Cognizant Scientist \\
\hline & & w/e $10 / 23 / 15$ & \\
\hline & & & \\
\hline
\end{tabular}

Cognizant Scientist Signature whe gesken_ Date: $10 / 23 / 15$

Page 10 of 21 
68122-TI-001

Revision 0

\subsection{Sample Container Preparation}

Date 10/3/3 SInit 2.1

Date 10/14/15 Init_n 2.2

Date G|in/15Init 2.3
Select four 50-mL centrifuge containers with "leakproof" caps.

Verify they hold water when tightened. Dry the centrifuge containers. (poly centrifuge tubes) $100 / 10 / 15$

Label the centrifuge containers 68122-TI-001-A, -B, -C, and -D.

Prepare a 1-L poly bottle by labeling it as follows:

\section{2-TI-001-E}

Backwash Filter Supernate

Non-hazardous

SK Fiskum

Date $10 / 15 / 5$ Init no 2.4 Tare the containers (use of the laboratory 305 balance is fine).

M 2.4.1 Record the balance ID: $\mathrm{NO} 04143$ (confirm balance is listed on the M\&TE list or add the balance information to the M\&TE list)

no 2.4.2 Balance check weight ID: Fisna

no 2.4.3 Balance check weight mass: 299.9996

WO 2.4.4 Verify that daily check was performed and acceptable $(\square)$ yeA.

(nQ 2.4.5 Tare containers and record tare weights on Table 3.

Table 3. Centrifuge Container Tare

\begin{tabular}{|c|c|}
\hline Container ID & Tare weight (g) \\
\hline 68122-TI-001-A & \\
\hline 68122-TI-001-B & \\
\hline 68122-TI-001-C & \\
\hline 68122-TI-001-D & \\
\hline 68122-TI-001-E & \\
\hline
\end{tabular}

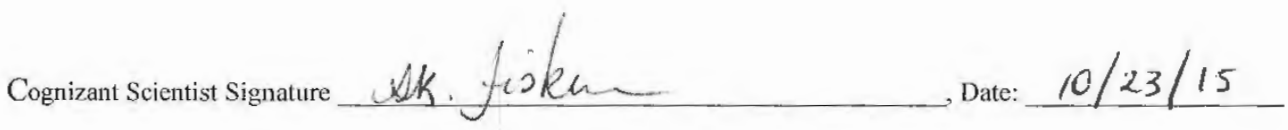


PNNL-25241

68122-TI-001

Revision 0

\subsection{Sample Receipt and Unpackaging}

The sample Viking shipping container needs to be opened in the presence of a Radiological Protection Technologist (RPT).

Datelydoc/sInit fro 3.1 Look over the chain of custody (COC) documentation for general correctness. Sign the COC and provide the original to SK Fiskum (10/0/26/15 Sample ID: Kw-105 SFBw-001 (taken from photo

Date 19 ifsisnit OS 3.2 Unpack the sample from the Viking container; reserve the Viking Records) container for return-shipment to the client. container sent back to client per

Tim 3.2.1 Record the contact dose rate Sk fiskum in 10/20/15

Open Window: $1 \gamma \& 18 \beta$.

Returned on shipping

Closed Window: $\leq 5 x$,

and the $30-\mathrm{cm}$ dose rate: $\leq .5 \mathrm{mr}$

truck after samph ID

Dosimeter type RO20

was verifued with COC ID

Check the RWP limits; is dose rate within limits? yes

Date ${ }^{i 0} / 2 / 15$ Init 3.3 Record observations of the sample. Check visually for presence of settled solids.

$$
\begin{aligned}
& \text { trok photos iojzolis-(No mac Both color chart) } \\
& \text { - Supernate was slightly turbid upon } \\
& \text { (im) } 10 / 2 u / 15 \text { Fecipet. receipt } \\
& \text { - Supernate was visualy less turbid } \\
& \text { thanen 10/20/15 (Axer photos Captured } \\
& \text { on } 10 / 21 / 15)
\end{aligned}
$$

Date 10/ai) / ISnit 3.4 Take photos of the sample showing the sample identification (ID) and the water level, turbidity, and any potential solids. Include Mac

Beth Color Checker chart (or equivalent) for comparison/reference.

Date $10 / 21 / 19$ nit 3.5 Weigh the sample.

10) 3.5.1 Record the balance ID: $\$ 25202532$ (confirm balance is listed on the M\&TE list or add the balance information to the M\&TE list)

BO 3.5.2 Balance check weight ID: Good, Bad \& the ugly

3.5.3 Balance check weight mass: 13000.4
3.5.4 Verify that daily check was performed and acceptable $(\checkmark)$, yed

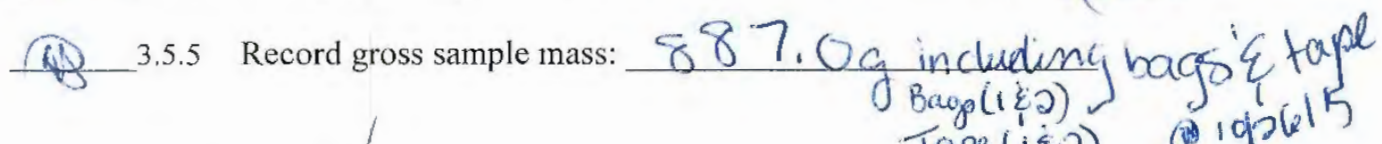

Cognizant Scientist Signature OK. fioken Date: $10 / 27 / 15$

Page 12 of 21 
Notes:

$10 / 15 / 15 \rightarrow$ also weighed 68122 - TI-001-F (20.6780 g) \&. $68122-T 1-001-G(20.6185)$, which are both $10 \mathrm{~mL}$ glass centrifuge tubes. (1) $10 / 15 / 1 \mathrm{~s}$ $\rightarrow$ labled with orange paint pen m $10 / 15 / 15$ \& allowed to dry in oven over an hr. also did leak check on

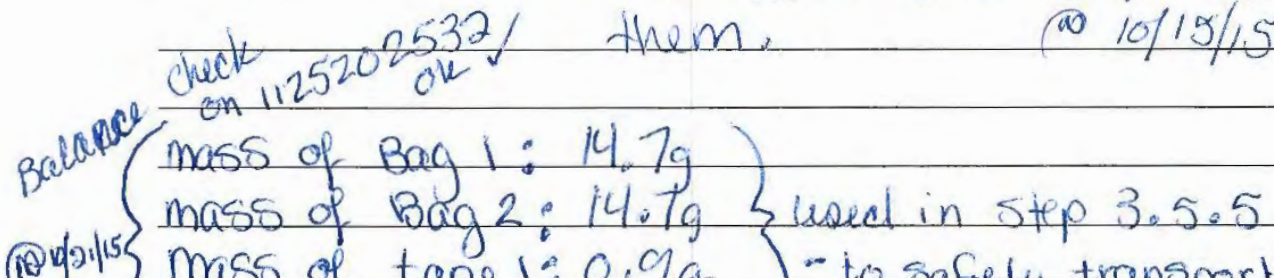

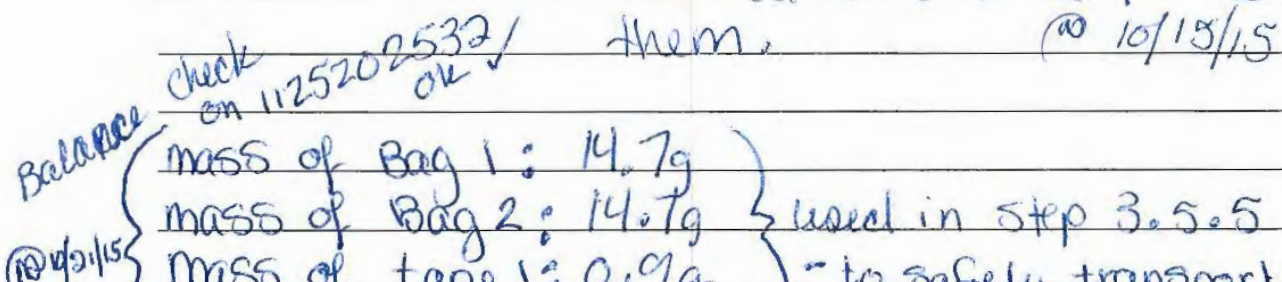

(iv) 1915 mass of tape 1:0.9g - to safely transport sample mass of tape 2:0.9 0 (o abcelance with appropriate capacity.

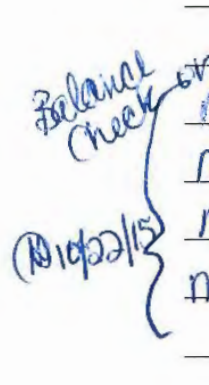

$11252025320 \mathrm{~kJ}$ Mass of Bag3:14,79

$\left.\begin{array}{l}\text { mass of tape 3: } 1.19 \\ \text { mass of tape 4: log }\end{array}\right\}$ reason in step 4.14 for the same 3.5 .5 .

Dose Rates taken after steps done in Step 4.19 19/23115 Desemeter type: Ro20

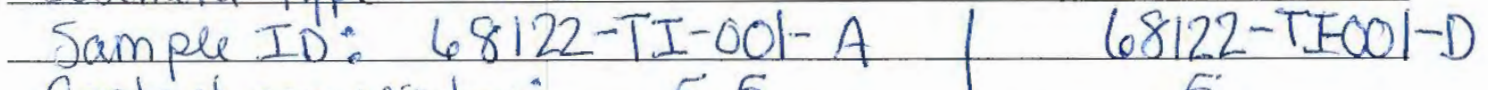

Contact open window: \begin{tabular}{lr} 
Contact Close Windowi $\quad$ & $\quad 0.5$ \\
$30 \mathrm{~cm}:$ & 50.5 \\
\hline
\end{tabular} 5.5 5 $<0.5$ $<0.5$

Cognizant Scientist Signature de droken Date: $10 / 23 / 15$ 
PNNL-25241

68122-TI-001

Revision 0

\subsection{Solids Consolidation}

NOTE: Lead brick sample holders and bricks should be used as needed to keep dose at as low as reasonably achievable (ALARA) levels. Date 10/20/gnit $4.1 \quad \begin{aligned} & \text { Set the sample aside in a clean secondary containment and leave } \\ & \text { undisturbed overnight to allow solids to settle. }\end{aligned}$

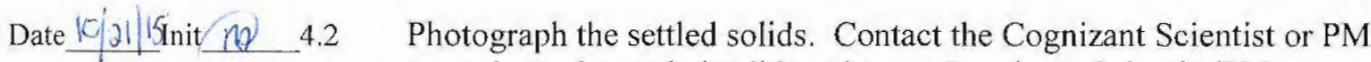
to evaluate the settled solids volume. Cognizant Scientist/PM Discussion: same set $\frac{\text { taken }(n) 10 / 21 / 15}{2.4}$

Date_Iofyl|15- Init 4.3

Date $10121 / 15$ Init ND 4.4

Place the centrifuge containers into a support stand lined up from A to D and uncap.

Open the sample bottle/jar and decant, using a transfer pipet, the water starting from the top surface. Place a transfer pipet load of water into each successive centrifuge container (starting with $\mathrm{A}$ and ending with D). Once each container has one pipet volume of water, start the filling cycle again from $A$ to $D$. Continue until each centrifuge container is filled to about 35 to $40 \mathrm{~mL}$.

Date $10 / 21 / 15$ Init 4.5 Cap the sample container.

Date $\stackrel{10 / 21 / 15}{\text { Init (no } 4.6}$

Cap the-centrifuge containers-and centrifuge for 20 minutes at 1500 RPM. Gentrifuge tontoiners howe to caps (10 $10 / 2115$

Return centrifuge containers to the rack and examine for centrifuged solids. Take photographs of the samples (show sample ID in the image). If the supernate is cloudy, contact the Cognizant Scientist before proceeding.

Dateiopi/ISInit 4.8

Decant the aqueous phase from each centrifuge container, using a transfer pipet and being careful not to disturb the solids. If solids are disturbed, the sample will need to he re-centrifuged. Collect the water in the 1-L polybottle, $68122-\mathrm{TI}-001-\mathrm{E}$. Leave about $5 \mathrm{~mL}$ of water overburden in each centrifuge container. If no solids are present, the entire contents can be transferred. Annotate in Table 4 the volume processed and if suspended solids were observed for each centrifuge container.

10121115

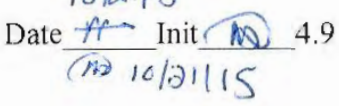

Repeat Steps 4.3 through 4.8 until the parent sample volume has been reduced to about $120 \mathrm{~mL}$. Annotate in Table 4 the volume processed and if suspended solids were observed for each centrifuge

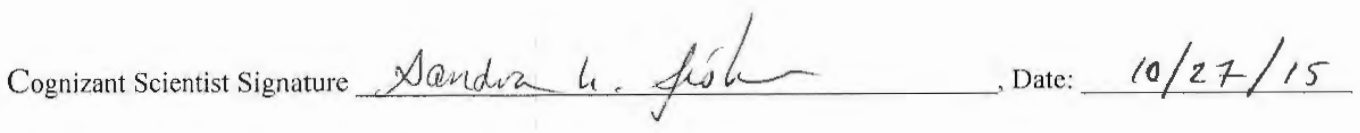

Page 14 of 21 
68122-TI-001

Revision 0

container. (Note, six cycles are anticipated, additional rows provided in case additional centrifuge cycles are required.

Table 4. Centrifuging Step Log

\begin{tabular}{|c|c|c|c|c|c|c|}
\hline \multirow{5}{*}{\multicolumn{2}{|c|}{ 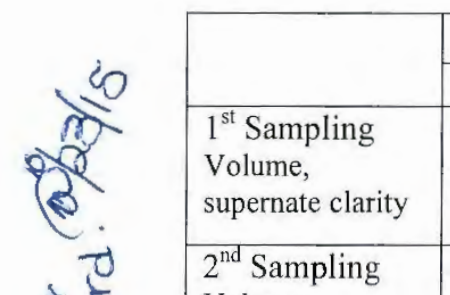 }} & \multicolumn{4}{|c|}{ Centrifuge Container ID } & \multirow{15}{*}{$\begin{array}{l}\text { * Note: } \\
\text { Rinsed } \\
\text { with liquid } \\
\text { From } \\
68122- \\
\text { TIO01-E. } \\
\text { W } 10 / 21115\end{array}$} \\
\hline & & 68122-TI-001-A & 68122-TI-001-B & \begin{tabular}{|l|} 
68122-TI-001-C \\
\end{tabular} & 68122-TI-001-D & \\
\hline & & & $45 \mathrm{~mL}$ & $45 \mathrm{~mL}$ & & \\
\hline & & very clear & very Clear & very Clear & Very clear & \\
\hline & & $45 \mathrm{~mL}$ & $45 \mathrm{~mL}$ & & & \\
\hline \multirow{11}{*}{ 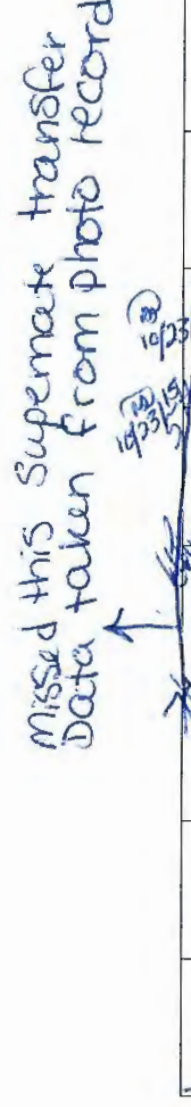 } & supernate clarity & very clear & very clear & Very Clear & 4 veryclear & \\
\hline & $\begin{array}{l}3^{\text {rd }} \text { Sampling } \\
\text { Volume, }\end{array}$ & $\checkmark 45 \mathrm{~mL}$ & $45 \mathrm{~mL}$ & $45 \mathrm{ml}$ & $45 \mathrm{~mL}$ & \\
\hline & supernate clarity & veryclear & verycleat & - very Claar & very clear & \\
\hline & 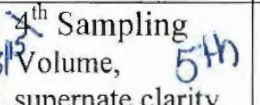 & $\begin{array}{l}\checkmark \text { Solids } 4 \text { sim } \\
\text { transfer }\end{array}$ & $4 \operatorname{sinL}$ & $45 \mathrm{~mL}$ & & \\
\hline & ${ }^{\text {supernate clartity }}$ & very clea & ersupe & & & \\
\hline & $\begin{array}{l}\text { Volume, } 6 \text { th } \\
\text { supernate clarity }\end{array}$ & \& Rinke & & & & \\
\hline & $\begin{array}{l}\text { th }^{\text {th }} \text { Sampling } \\
\text { Volume, } \quad \text { th }^{\text {th }} \\
\text { supernate clarity }\end{array}$ & $\begin{array}{l}45 \mathrm{mi} \\
\text { very clar }\end{array}$ & $\begin{array}{l}45 \mathrm{ml} \\
\text { very dear }\end{array}$ & $\begin{array}{l}415 \mathrm{~mL} \\
\text { verydear }\end{array}$ & $\begin{array}{l}45 \mathrm{mh} \\
\text { veruclea }\end{array}$ & \\
\hline & $\begin{array}{l}\text { Sampling } 1 \mathrm{th} \\
\text { Volume, } \\
\text { supernate clarity }\end{array}$ & & & & & \\
\hline & & & & & & \\
\hline & & & & & & \\
\hline & & & & & & \\
\hline
\end{tabular}

Dateloper//5Init (n) 4.10 Mix the parent sample to suspend solids-this can be accomplished with the transfer pipet (rapid in and out motions) or by swirling.

Date 10/21/ H I nit 4.11 Using the same technique described in Step 4.4, transfer the suspended solids into each of the four centrifuge containers. Resuspend the parent sample solids as needed so that the solids are equally distributed across each centrifuge tube.

Cognizant Scientist Signature D R. fiokn_Date: $10 / 23 / 15$ 
Date $10 \% 21 /{ }^{15}$ Init 4.12 Add water from 68122-TI-001-E to the parent bottle as needed to quantitatively transfer the solids.

Date $20 / 31 / 5$ Init 4.13 Cap the sample bottle and centrifuge containers.

Date 10/32 Knit 4.14 Weigh the emptied sample bottle.

4.14.1 Record the balance ID: 1125202532 (confirm balance is listed on the M\&TE list or add the balance information to the M\&TE list).

(D) 4.14.2 Balance check weight ID: Good, Bad É ugly

A 4.14.3 Balance check weight mass: 13000.3

10. 4.14.4 Verify that daily check was performed and acceptable $(\checkmark)$ (AS) $\sqrt{ }$ S

(10) 4.14.5 Record emptied container mass: $123.1 \mathrm{~g}$ with bags \& tape

Date $1021 / 15$ Init 4.15 Centrifuge the centrifuge containers for 30 minutes at $1500 \mathrm{RPM}$. $10 / 26 / 15$

Date $10 / 21$ / IStnit 4.16 Return centrifuge containers to the rack and examine for centrifuged solids. Take photographs of the samples (show sample ID in the image). If the supernate is cloudy, contact the Cognizant Scientist before proceeding.

Datelo/3/15Init 4.17 Decant the aqueous phase from each centrifuge container, using a transfer pipet and being careful not to disturb the solids. Collect the water in the 1-L polybottle, $68122-\mathrm{TI}-001-\mathrm{E}$. Leave about $5 \mathrm{~mL}$ of water overburden in each centrifuge container.

Date 10/23/4nit 4.18 Obtain a dose rate for each sample from the RPT and record in Table 5.

Dosimeter type RO20

Cognizant Scientist Signature the feble Date: $10 / 27 / 15$

Page 16 of 21 
Table 5. Centrifuge Container Dose Rates

\begin{tabular}{|c|c|}
\hline Container ID & Dose Rates, $\mathrm{mR} / \mathrm{hr}$ \\
\hline 68122-TI-001-A & $\begin{array}{l}\text { Contact open window } \quad 5 \\
\text { Contact closed window } 3 \\
30 \mathrm{~cm}<0.5\end{array}$ \\
\hline 68122-T-I001-B & $\begin{array}{l}\text { Contact open window } \frac{5}{2} \\
\text { Contact closed window } 3.5 \\
30 \mathrm{~cm}<0.5\end{array}$ \\
\hline 68122-TI-001-C & $\begin{array}{l}\text { Contact open window } \frac{5}{5} \\
\text { Contact closed window } 3.5 \\
30 \mathrm{~cm} \quad<0.5\end{array}$ \\
\hline 68122-TI-001-D & $\begin{array}{l}\text { Contact open window } \frac{2}{2} \\
\text { Contact closed window } 1 \\
30 \mathrm{~cm}<0.5\end{array}$ \\
\hline 68122-TI-001-E & $\begin{array}{l}\text { Contact open window } \angle 0,5 \\
\text { Contact closed window } \angle 0,5 \\
30 \mathrm{~cm}<0,5\end{array}$ \\
\hline Parent bottle & $\begin{array}{l}\text { Contact open window }<0.5 \\
\text { Contact closed window }<0.5 \\
30 \mathrm{~cm}<0.5\end{array}$ \\
\hline
\end{tabular}

Date $\$ 23 / 5$ Init 40

HOLDPOINT - Share dose rate results with SK Fiskum, PM, to determine if continued work in fume hood is viable and if processing of all four solids subsamples or two solids subsamples will be conducted (this decision depends on the quantity of solids collected and variation in the dose rates). Client has requested to be present to observe the consolidated solids at this point.

Holdpoint Direction: BKC are ok, but Combine Ab \& Re-split take another dose rate

see page 13 for New Dose rates
taken after
This stephep. Cognizant Scientist Signature - in an a tempt to keep dose rafe *'s as evenly split as possible PM signature/date sk. folken $10 / 23 / 15$
Date: $10 / 27 / 15$ 
Date $10 / 15 / 15$ Init_no 4.20

Date $10 / 15 / 15$ Init 4.21

Datek/23/15Init_n 4.22

(10) 4.22 .1

no 4.22.2 Balance check weight ID: Sleepy

(M) 4.22.3 Balance check weight mass: 300.00179

(10) 4.22.4 Verify that daily check was performed and acceptable $(\checkmark) \wedge \checkmark$ ye

4.22.5 Tare centrifuge tubes and record tare weights on Table 6.

Table 6. Centrifuge Container Tare

\begin{tabular}{|c|c|}
\hline Container ID & Tare weight (g) \\
\hline $\begin{array}{r}\text { 68122-TI-001-80 } \\
\text { क010 }\end{array}$ & 20.6253 \\
\hline 68122-TI-001-DuF F & 20.6859 \\
\hline
\end{tabular}

hood \#13

in lab525

$*$ this is the balace for Acid digests digets. (Nuplatis wanted to use same balace through out analysis i 0123115

Date $0 / 23$ 15Init 100 Stage the centrifuge tubes in a rack to maintain them upright and in secondary containment.

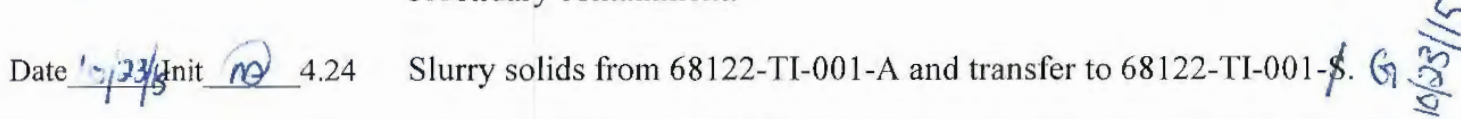

Date1923/15Init m 4.25 Slurry solids from 68122-TI-001-B and transfer to 68122-TI-001-8. G

Date Icy33iginit_a 4.26 Slurry solids from 68122-TI-001-C and transfer to 68122-TI-001G.Dup. F

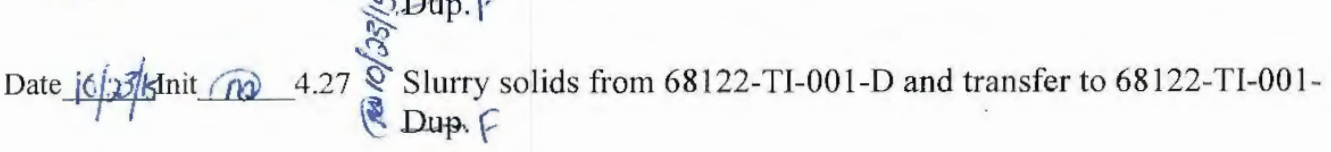

Cognizant Scientist Signature $\not K$. fisken_ Date: $10 / 27 / 15$ 
68122-TI-001

Revision 0

Datelo/23/51nit $10 \quad 4.28$

Date 10/23/15nit mo 4.29

Datelo/23/15Init 40.30

Date $10 \% 33 / 5$ init (n) 4.31

Date $10 / 23 / 15$ Init 402

Date $/ \mathrm{c} / 23 / / 5$ Init 4.33

Date $19.3 / 15$ Init no 4.34
Allow solids in each centrifuge tube to settle. If needed, decant water with a transfer pipet from the glass centrifuge tube back to the larger centrifuge container to slurry and remove residual solids.

The total volume in the centrifuge tubes needs to be equivalent to balance the centrifuge- -adjust with the decant water in 68122-TI$001-\mathrm{E}$, as needed.

Cap the centrifuge tubes.

Centrifuge for 30 minutes at 1500 RPM.

Return centrifuge tubes to the rack and examine for centrifuged solids. Take photographs of the samples (show sample ID in the image). If the supernate is cloudy, contact the Cognizant Scientist before proceeding.

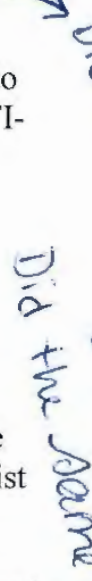

Decant the aqueous phase from each centrifuge tube, using a transfer pipet and being careful not to disturb the solids. If solids are disturbed, the sample will need to be centrifuged again. Collect the decant water in the-250-mE polybottle, 68122-TI-001-E. Leave about $1 \mathrm{~mL}$ of water overburden in each centrifuge tube.

$$
\checkmark \text { IL tupo (m) 10/23/15 }
$$

Record the centrifuged solids volume, total slurry volume, and measure the gross sample mass (same balance that the tare was taken).

Record the balance ID: 1113292667 (confirm balance is listed on the M\&TE list or add the balance information to the M\&TE list)

(M) 4.34.2 Balance check weight ID: Sieypy

(N) 4.34 .3 Balance check weight mass: $300.0017 \mathrm{~g}$

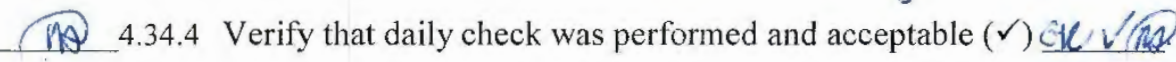

(A) 4.34.5 Record information in Table 7.

Table 7. Sample Volumes and Masses

\begin{tabular}{|l|c|c|}
\hline Parameter & $68122-$ TI-001-s G & 68122-TI-001-Dum \\
\hline Centrifuged solids volume, $\mathrm{mL}$ & $0.4 \mathrm{ml}$ & $0.4 \mathrm{~mL}$ \\
\hline Slurry volume, $\mathrm{mL}$ & $0.5 \mathrm{~m}$ & $0.5 \mathrm{mP}$ \\
\hline Gross mass, g & 21.1095 & 21.2217 \\
\hline
\end{tabular}

Cognizant Scientist Signature Sk. fioken Date: $10 / 23 / 15$

Page 19 of 21

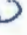
实然

¿

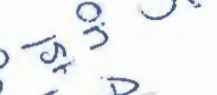

\section{(}
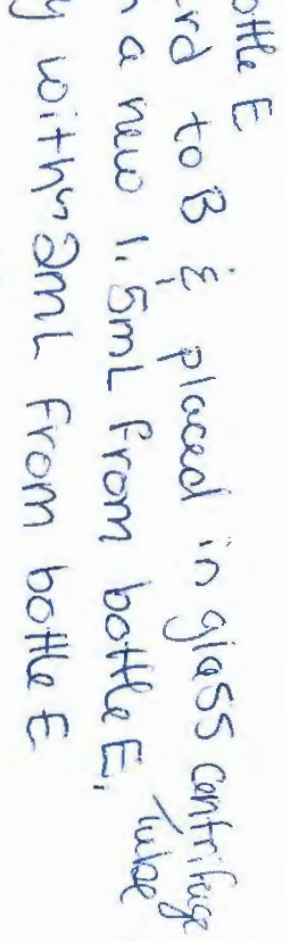
Date $1021 / 15$ Init 4.35 Submit Samples to the ASO for drying, acid digestion, and analysis. Record the ASR number: 9916

Notes:

Took photos of empty centrifuge tubes with ID's: $68122-T I-001-A$

A $10130615622-T T-001-B$ $68122-T I-001-C$ $68122-T I-001-D$

also took a photo of the mac-beth color chart

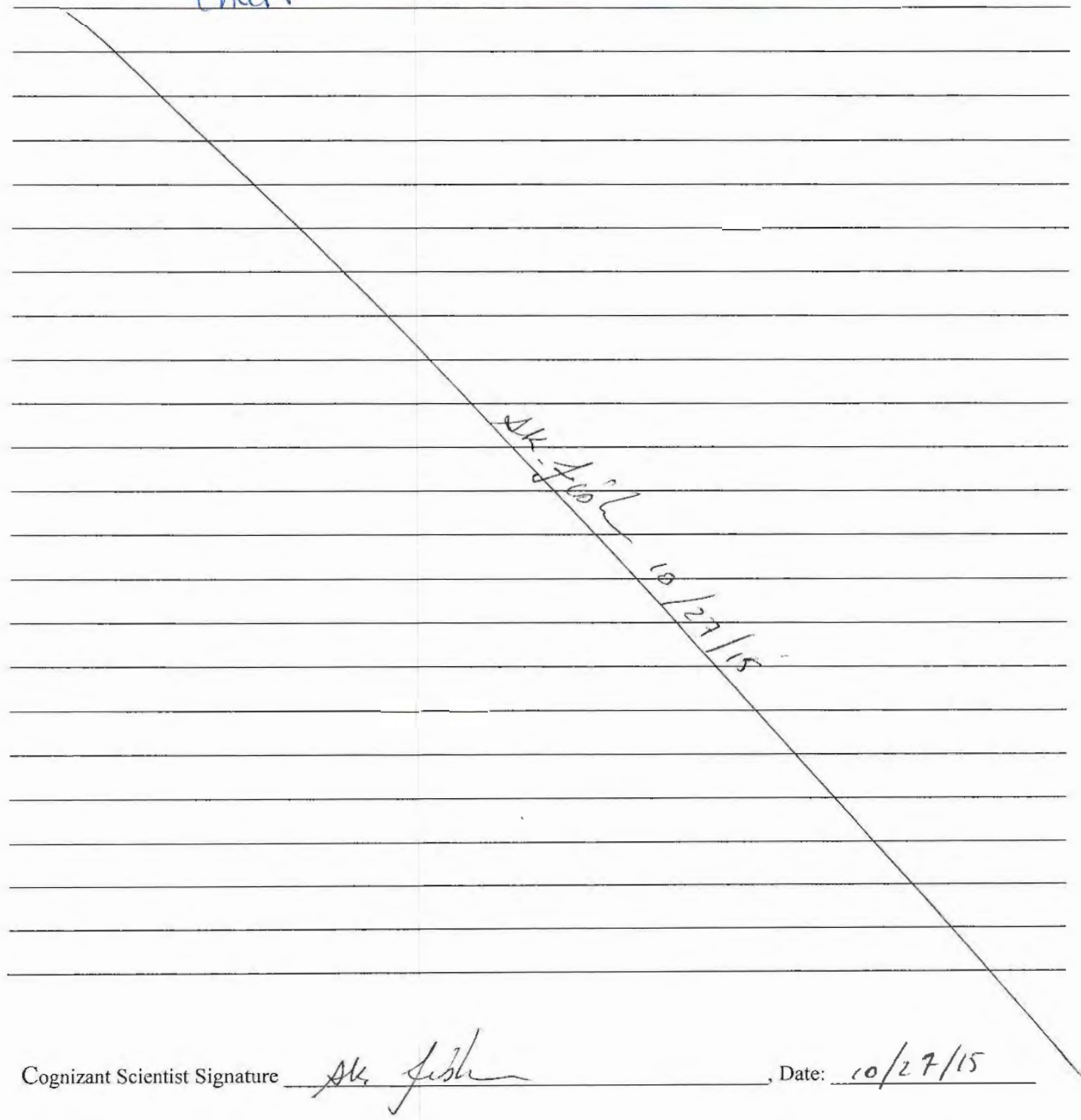

Page 20 of 21 
PNNL-25241

68122-TI-001

Revision 0

\subsection{Closing Activities}

Date $10 / 2315$ nit 5.1 Download images and create a contact sheet and attach to this TI. A HachmentC

Date $10 / 28 / \mathrm{s}$ Init Het_ 5.2 Generate calculation worksheets (sludge mass and density after centrifuging) and attach a printed copy of reviewed calculations to this TI.

Date 10.23 Init 15.3 Collect relevant BPCL form copies and attach to this TI. Attachment A

Date 10031 15 Init_ 5.4 Be sure balance Calibration Reports are attached to the TI. Attachmenf B

Date10/2315Init_ 5.5 Attach any relevant Occurrence, Deficiency, or Nonconformance

Reports generated during the work to this TI.

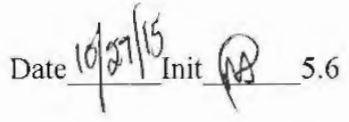

Submit completed TI for technical review. Attach completed

Document Review Record (DRR) form by the technical reviewer to

TI.

Date $10 / 2 \%$ Init $\downarrow K+5.7 \quad$ Submit technically reviewed TI to the QE for review.

$$
\begin{gathered}
\text { * Attachment D } \rightarrow \text { email correspondence regarding this TI } \\
\text { * A Hachment E } \rightarrow \text { original Chain of Eo Custody Docs } \\
\text { inclucled With the shipment of the } \\
\text { Sample (m) } 10 / 26 / 15
\end{gathered}
$$

Cognizant Scientist Signature the feśl_ Date: $10 / 27 / 15$ 
PNNL-25241

$68122-$ TIOOOI

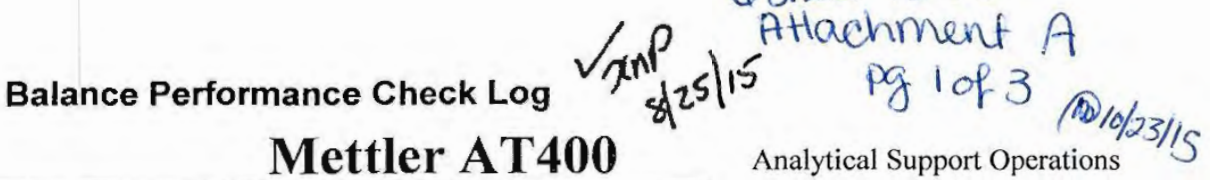

Pacific Northwest National Laboratory Mettler AT400

Analytical Support Operation

\begin{tabular}{|c|}
\hline Balance Information \\
\hline$\frac{\text { Identificaiton (e.g. WD34567) }}{\text { N04143 }}$ \\
\hline$\frac{\text { Location (e.g. Building/Room) }}{\text { RPL / 305 Benchtop }}$ \\
\hline Calibration Due Date \\
Aug-16 \\
\hline
\end{tabular}

\begin{tabular}{|c|c|c|c|c|c|c|c|c|}
\hline Check Weight (CW) Information & $\# \mathbf{1}$ & $\begin{array}{c}\mathrm{CW} \\
\text { Units }\end{array}$ & $\# 2$ & \begin{tabular}{|c|}
$\mathrm{CW}$ \\
Units \\
\end{tabular} & $\# \mathbf{3}$ & $\begin{array}{l}\mathrm{CW} \\
\text { Units }\end{array}$ & \#4 & \begin{tabular}{|c|}
$\mathrm{CW}$ \\
Units \\
\end{tabular} \\
\hline CW Identification & FIONA & 8 & 28 & 3 & 40 & -1 & & - \\
\hline CW Assigned Mass (+Units): & 299.9999 & g & se & $\mathrm{g}$ & 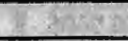 & $\mathrm{g}$ & 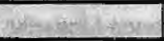 & g \\
\hline Method for Assigning Diff/Range ${ }^{(a)}$ : & Option 1 & & Option 1 & & Option 1 & $\sqrt{x+4}$ & Option 1 & \\
\hline CW Difference \pm Mass (+Units): & 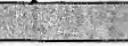 & $\overline{5}$ & & 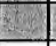 & 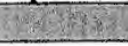 & 8 & & 3 \\
\hline Range Low Mass (+Units) \&: & 299.9978 & g_. & & $\mathrm{g}$ & & g. & & g. \\
\hline Range High Mass (+Units): & 300.0020 & g & & g & & g & & $g$ \\
\hline
\end{tabular}

(a) Enter "Option \#1" or "Option \#2" from Procedure PNL-ASO-052, Table 1. For factors $>3$, append factor in parentheses, e.g., Option \#1 (4)

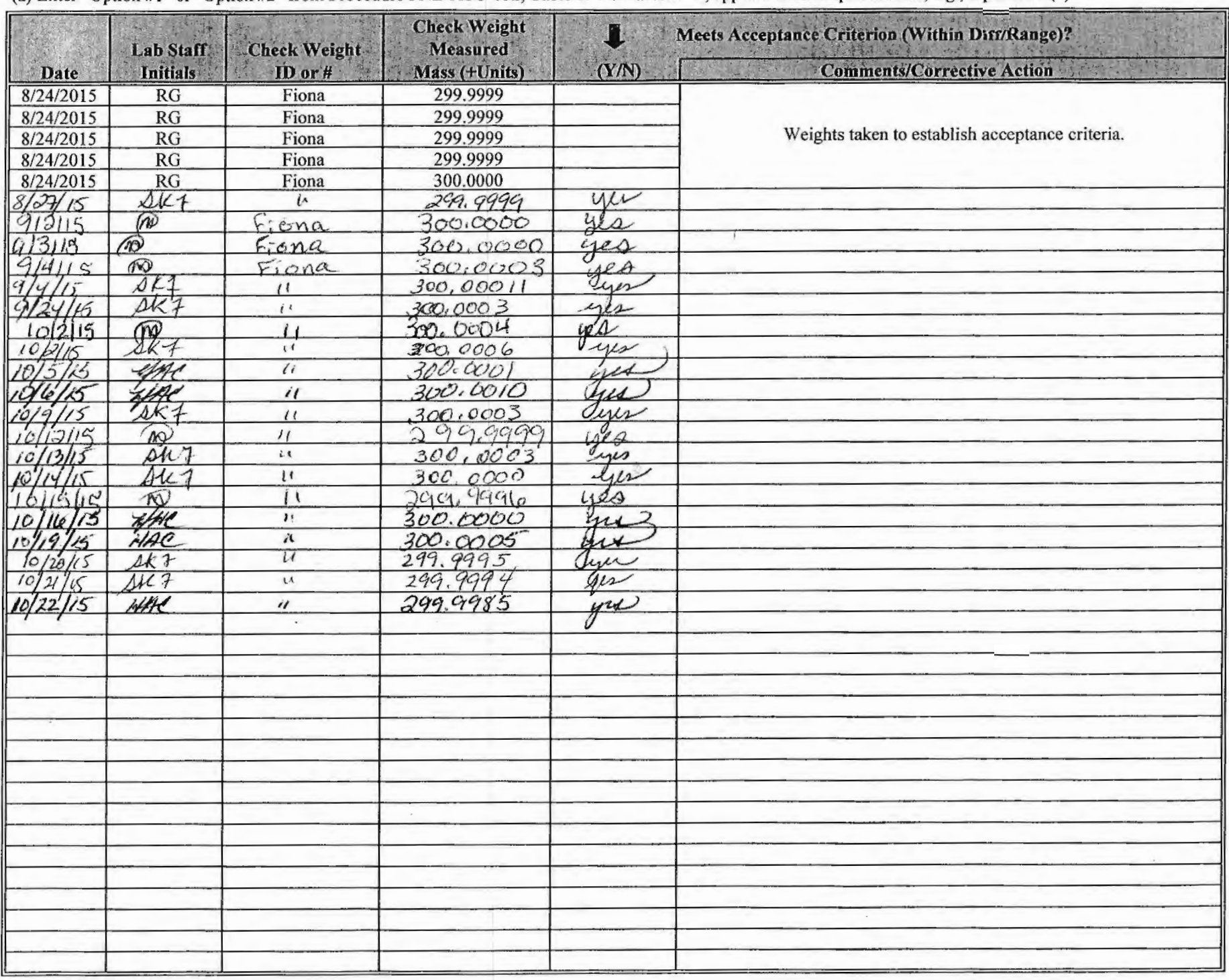

$>$ Complete all column entries.

$>$ For corrections, place single line through incorrect entry, enter correction and initial/date.

$>$ When full, forward to the ASO M\&TE Records Custodian; replace with new Log.

$>$ Following recalibration, lineouV/ initial/date unused rows and forward to ASO M\&TE Records Custodian; replace with new Log.

$>$ To calibrate or recalibrate a balance contact the ASO M\&TE Records Custodian.

$>$ If additional check weights are used on balance, enter appropriate information on another sheet and append to this Log form.

Reviewer Signature Date

Date to ASO Records

BPCL 8_24_15_Mettler AT 400_N04143_RPL_305_Benchtop.xls 
PNNL-25241

(1)

Balance Performance Check Log $\left.\sqrt{x} \frac{1}{212}\right)^{15}$
$68122-T I 001$ AHachment A

pg 2 of 3

Radiochemical Processing Laboratory

\begin{tabular}{|c|}
\hline Balance Information \\
\hline$\frac{\text { Identificaiton (e.g. WD34567) }}{1125202532}$ \\
\hline$\frac{\text { Location (e.g. Building/Room) }}{\text { RPL/305 (benchtop) }}$ \\
\hline$\frac{\text { Calibration Due Date }}{\text { Feb-16 }}$ \\
\hline
\end{tabular}

\begin{tabular}{|c|c|c|c|c|}
\hline Check Weight (CW) Information & $\# 1$ & \begin{tabular}{|c|}
$\mathrm{cW}$ \\
Units
\end{tabular} & $\# 2$ & $\begin{array}{l}\mathrm{ch} \\
\text { Unit }\end{array}$ \\
\hline CW Identification & Good, Bad \& Ugly & & & \\
\hline CW Assigned Mass (+Units): & 13000.0 & $g$ & & g \\
\hline \multirow{2}{*}{$\begin{array}{r}\text { Method for Assigning Diff/Range }{ }^{(\mathrm{a})} \text { : } \\
\text { CW Difference } \pm \text { Mass (+Units): }\end{array}$} & Option 1 & & Option 1 & \\
\hline & & & & \\
\hline Range Low Mass (+Units) \&: & 12998.8 & g. & & $\mathrm{g}$ \\
\hline Range High Mass (+Units): & 13001.2 & $\mathrm{~g}$ & & \\
\hline
\end{tabular}

\section{Mettler SB16001}

(a) Enter "Option \#1" or "Option \#2" from Procedure ADM-RSEG-BALANCES, Table 1. For factors >3, append factor in parentheses, e.g., Option \#1 (4)

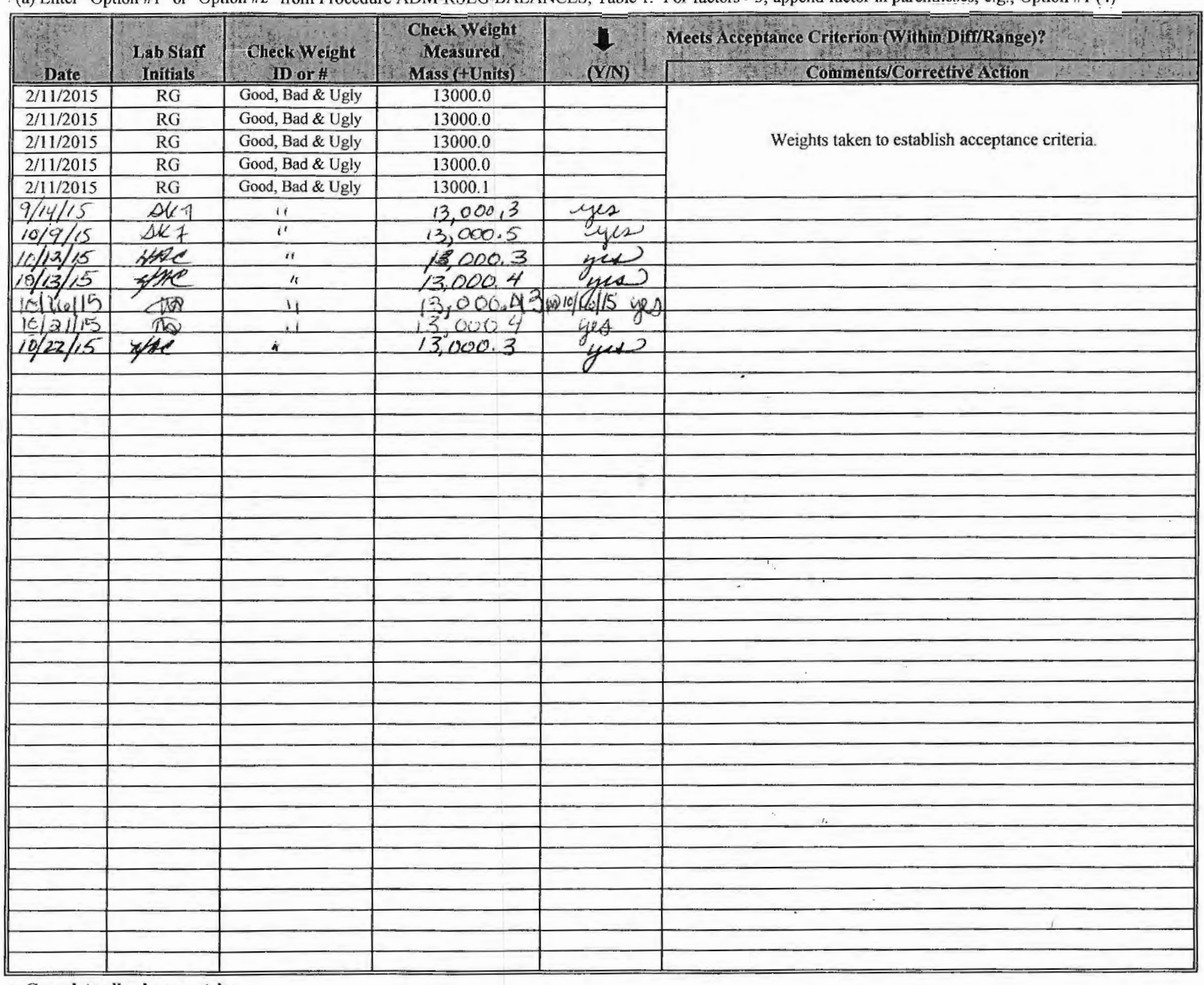

\section{$>$ Complete all column entries.}

$>$ For corrections, place single line through incorrect entry, enter correction and initial/date.

$>$ When full, forward to the Balance Calibration Coordinator and request a new log; replace with new Log.

$>$ Following Vendor recalibration, lineout/initial/date unused rows and forward to Balance Calibration Coordinator who will replace the BPCL with a new log.

$>$ To calibrate or recalibrate a balance contact the Balance Calibration Coordinator.

> If additional check weights are used on balance, enter appropriate information on another sheet and append to this Log form.

Reviewer Signature Date

Date to ASO Records 
PNNL-25241

$68122-T I-001$ Attochment A

pg 3 of 3 \% $10 / 23 / 15$

Balance Performance Check Log Mettler AT 400

Pacific Northwest National Laboratory

\begin{tabular}{|c|}
\hline Balance Information \\
\hline Identificaiton (e.g. WD34567) \\
\hline 1113292667 \\
\hline Location (e.g. Building/Room) \\
RPL / 420 Fumehood \#13 \\
\hline Calibration Due Date \\
Aug-16 \\
\hline
\end{tabular}

\begin{tabular}{|r|}
\hline Check Weight (CW) Information \\
\hline CW Identification \\
\hline CW Assigned Mass (+Units): \\
\hline Method for Assigning Diff/Range ${ }^{(a)}:$ \\
CW Difference \pm Mass (+Units): \\
Or Range Low Mass (+Units) \&: \\
Range High Mass (+Units): \\
\hline
\end{tabular}

\begin{tabular}{c|c|c|}
\hline$\# 1$ & $\begin{array}{c}\text { CW } \\
\text { Units }\end{array}$ & \#2 \\
\hline SLEEPY & & \\
\hline 300.0001 & $\mathrm{~g}$ & \\
\hline Option 1 & & Option 1 \\
\hline 299.9980 & $\mathrm{~g}$ & \\
\hline 300.0022 & $\mathrm{~g}$ & \\
\hline
\end{tabular}

Analytical Support Operations

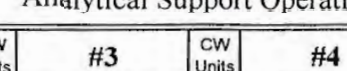

$\mathrm{CW}$
Units
Un

(a) Enter "Option \#1" or "Option \#2" from Procedure PNL-ASO-052, Table 1. For factors >3, append factor in parentheses, e.g., Option \#1 (4)

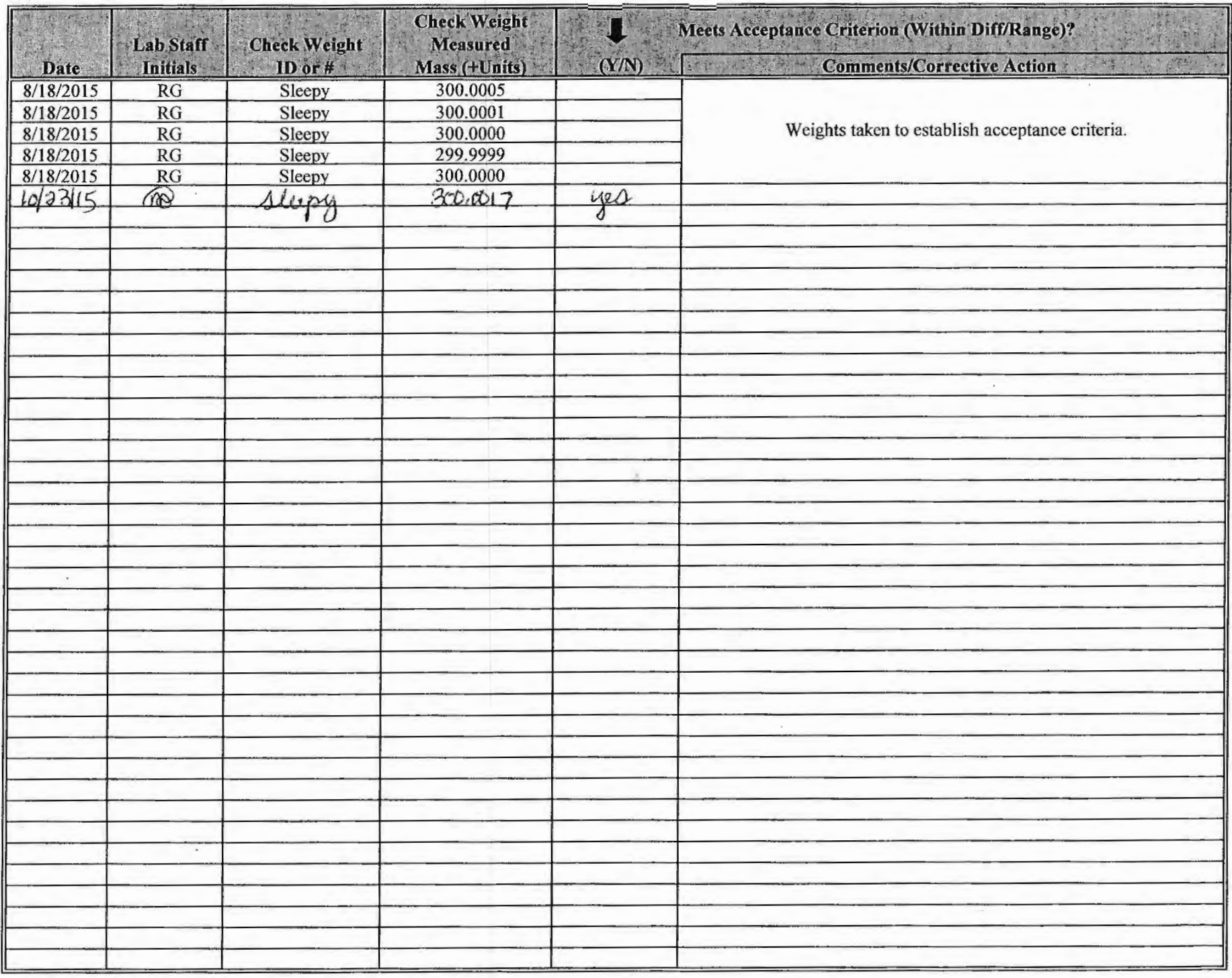

$>$ Complete all column entries.

$>$ For corrections, place single line through incorrect entry, enter correction and initial/date.

$>$ When full, forward to the ASO M\&TE Records Costodian; replace with new Log.

$>$ Following recalibration, lineou/ initialdate unused rows and forward to ASO M\&TE Records Custodian; replace with new Log.

$>$ To calibrate or reealibrate a balance contact the ASO M\&TE Records Custodian.

$>$ If additional check weights are used on balance, enter appropriate information on another sheet and append to this $\log$ form.

Reviewer Signature

Date

Date to ASO Records

BPCL 8_18_15_Mettler AT 400_1113292667_RPL_420_Fumehood.xls 
PNNL-25241

$68122-T I-001$ Attachment B

Pg 1 of 3 \% $1 \% 1 / 5$

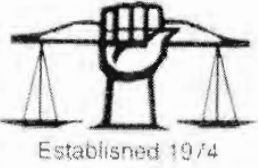

Battelle Pacific N.W. Natil. Lab 902 Battelle Blvd.

Richland. WA 99354

\section{QUALITY CONTROL SERVICES}

1.AEGOAATCY EOUPMENT - GALEB - SEFVICE - CALIERATION - REPAIRS 2340 SE 11 Ave Portand. Otegon 97214 . Box 14931 Porland. Oregon 97293

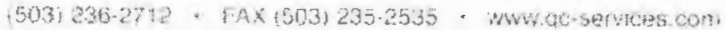

Report Number: BATN03N04143150824

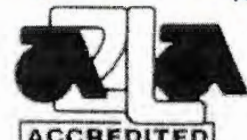

ACCAEDITED

Callbration Sarvices

Canticate tivither: :5900

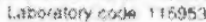

A2LA ACCREDITED CERTIFICATE OF CALIBRATION WITH DATA

\begin{tabular}{|c|c|c|c|c|c|}
\hline Item & Make & Model & Serial Number & Customer ID & Location \\
\hline Balance & Mettler & $\mathrm{AT} 400$ & $\mathrm{~N} 04143$ & $360-06-01-048$ & RPL 305 \\
\hline Units & Readability & SOP & Cal Date & Last Cal Date & Cal Due Date \\
\hline$y$ & 0.0001 & $Q(0) 2$ & $8 / 24 / 15$ & $8 / 22 / 14$ & $8 / 2016$ \\
\hline
\end{tabular}

\section{FUNCTIONAL CHECKS}

\begin{tabular}{|c|c|c|c|c|c|}
\hline \multicolumn{2}{|c|}{ ECCENTRICITY } & \multicolumn{2}{|c|}{ LINEARITY } & \multicolumn{2}{|c|}{ STANDARD DEVIATION } \\
\hline Test Wt: & Tot: & Test Wt: & Tol: & Test Wt: & Tol: \\
\hline 200 & 0.0004 & $100 \times 4$ & 0.0005 & 100 & 0.0002 \\
\hline
\end{tabular}

As-Found:

Pass: घ Fail: 口

As-Left:

Pass: $\mathbb{Z}$. Fail:

\section{As-Found:}

Pass: Ø Fail: As-Left:

Pass: घ Fail:
1. 100.0000

2. 100.0000

3. 100,0001

4. 100.0001
5.100 .0002

6. 100.0001

7.99 .9999

8.100 .0000
9.100.0001

10. 100.0000

Resuit:

0.00008
ENVIRONMENTAL CONDITIONS

口 $\square \square$

Good Fair Poor

Temperature: $23.9^{\circ} \mathrm{C}$

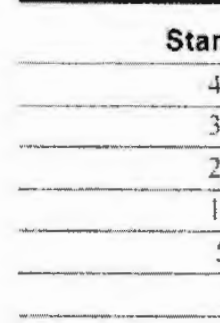

\section{A2LA ACCREDITED SECTION OF REPORT}

As-Found As-Left

399,9989

Expanded Uncertainty

400

400.0000

300.0002

299.9995

0.00025

200

200. 0005

200.0001

$\frac{100}{50}$

100.0002

100.0000

50.0002

50.0001

0.00020

1.0002
0.00020

JAccepted $\square$ Rejected / Per Clause(s): $176, b$

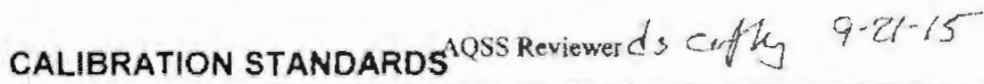

\begin{tabular}{ccccccc}
\hline Item & Make & Model & Serial Number & Cal Date & Cal Due Date & NIST ID \\
\hline Weight Set & Rice Lake & $30 \mathrm{~kg}-1 \mathrm{mg}$ & $\$ 751$ & $12 / 2 / 4$ & $12+2015$ & OR-13-314-C \\
\hline
\end{tabular}

Permanent Information Concerning this Equipment:

\section{Comments/info Concerning this Calibration:}

8/15 PO $\$ 263294$ As found as left within tolerance.
Report prepared/reviewed by: Yh. Whanc/ Date:
Technician: R. Hintz

\section{Signature:}

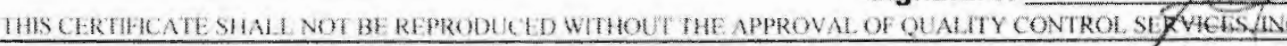

The uncertanty is cafeslated according to the iSO Guide to the Expression of Uncertainty in Measurement and includes the uncertainty of standards used combined with

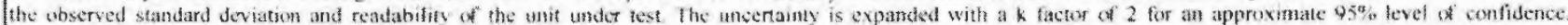
instrunents listed above were calibuted using standarós traceable to the National institue of Standards and Technology (NIST) Calibration data reflect results at the time and location of calibratom Calibration data shoud be reviewed to insure that the instrument is performing to its required atectracy. Calibtations comply with ISO/EC 17025 and ANSL/Z540-1-199: quality standards 
PNNL-25241

$68122-T I-001$ Attachment B

pg 2 of 3 noropalis

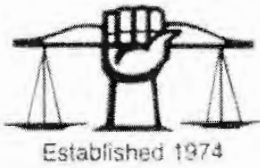

Battelle Pacific N.W. Nat\}. Lab 902 Battelle Bivd.

Richland, WA 99354

\section{QUALITY CONTROL SERVICES}

LABOFATORY EOUPMENT - SALES - GEWVICE CALBRATION - REPAAS 2340 SE $11^{\text {th }}$ Ave. Portland, Oregon $97214 \cdot$ Box 14831 Portiand, Oregon 97293

(503) 236-2712 . FAX (503) 235-2535 * www qe-services com

Report Number: BAIN03112520253215021 i

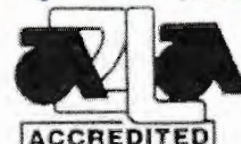

ACCREDITED

\section{A2LA ACCREDITED CERTIFICATE OF CALIBRATION WITH DATA}

INSTRUMENT INFORMATION

\begin{tabular}{|cccccc}
\hline Hem & Make & Model & Serial Number & Customer ID & Location \\
Balance & Mettler & SB 16001 & 1125202532 & 1125202532 & RPL.305 \\
Units & Readability & SOP & Cal Date & Last Cal Date & Cal Due Date \\
\hline $\mathrm{g}$ & 0.1 & $\mathrm{QCO} 1210 / 14$ & $2 / 11 / 15$ & $7 / 14 / 14$ & $2 / 2016$ \\
\hline
\end{tabular}

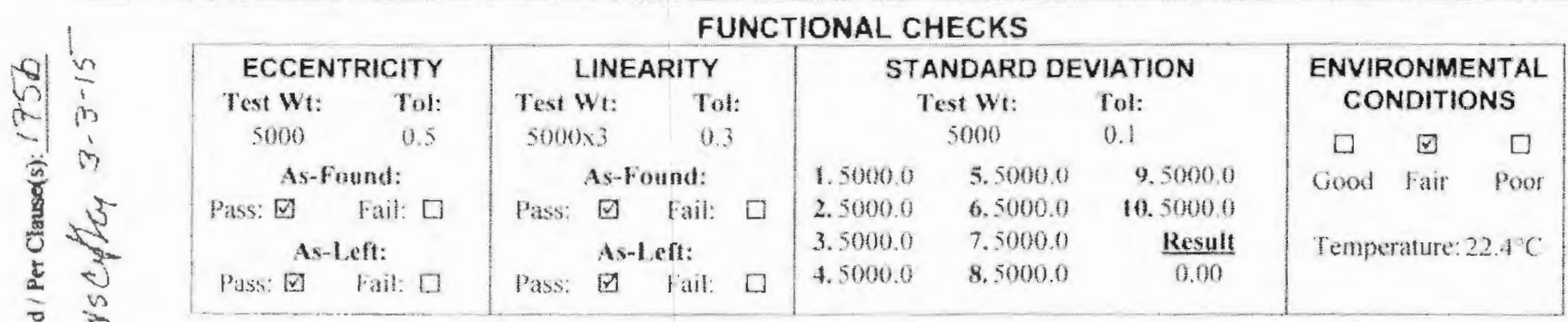

\section{A2LA ACCREDITED SECTION OF REPORT}

Standard

As-Found

As-Left

15000.1

10000.0

50000

2000.0

1000.0

Expanded Uncertainty

10000

5000

9999.8

4999.9

2000.0

500.0

0.11
0.11
0.11
0.11
0.11

CALIBRATION STANDARDS

\begin{tabular}{|c|c|c|c|c|c|c|}
\hline Item & Make & Model & Serial Number & Cal Date & Cal Due Date & NIST ID \\
\hline Weight Set & Rice Lake & $30 \mathrm{~kg}-1 \mathrm{mg}$ & $\$ 751$ & $12 / 2,14$ & $12 / 2015$ & $\mathrm{OR}-13-314-\mathrm{C}$ \\
\hline
\end{tabular}

Permanent Information Concerning this Equipment:

\section{Comments/lnfo Concerning this Calibration:}

$2.15 \mathrm{PO}=251158$ As found as left within tolerance (manufacturer specifications).

Report prepared/reviewed by: hevlancel Date: $2+19 / 15$
Technician: R. Hint

Signature:

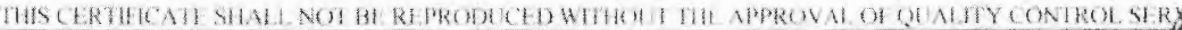

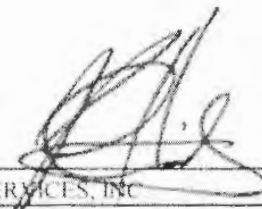

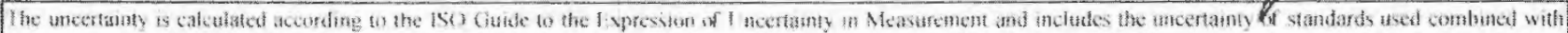

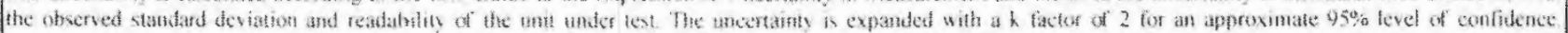

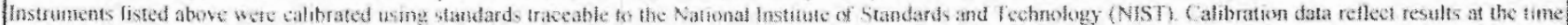

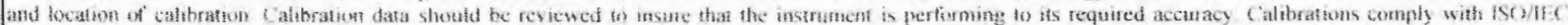

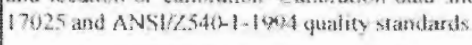

PT ID: BATNO3 
PNNL-25241

$68122-T I-001$

Attochment $B$

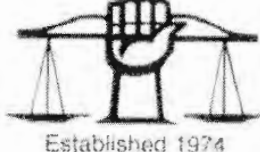

Battelle Pacific N.W. Natl. Lab 902 Battelle Blvd.

Richland, WA 99354

\section{QUALITY CONTROL SERVICES}

LABORATORY EOULMENT - SALES - SERVICE C ALBRAMON FEPAIRS 23.0 SE $1 t^{\text {in }}$ Ave Potland, Oregon 9721 - Box 14831 Portiand. Oregon 97293 (503) $236-2712 \cdot F a x+50342452535 \cdot$ www ac-services con

Report Number: BATN031113292667150818

\section{A2LA ACCREDITED \\ CERTIFICATE OF CALIBRATION WITH DATA}

INSTRUMENT INFORMATION

\begin{tabular}{|ccccccc}
\hline Itern & Make & Model & Serial Number & Customer ID & Location \\
\hline Balance & Mettler & AT 400 & 1113292667 & $360-06-01-037$ & RPL 420 \\
Units & Readability & SOP & Cal Date & Last Cal Date & Cal Due Date \\
\hline $\mathrm{g}$ & 0.0001 & QC012 & $8 / 18 / 15$ & $8 / 20 / 14$ & $8 / 2016$ \\
\hline
\end{tabular}

FUNCTIONAL CHECKS

\begin{tabular}{|c|c|c|c|c|c|c|c|c|c|}
\hline \multicolumn{2}{|c|}{ ECCENTRICITY } & \multicolumn{2}{|c|}{ LINEARITY } & \multicolumn{3}{|c|}{ STANDARD DEVIATION } & \multirow{2}{*}{\multicolumn{3}{|c|}{$\begin{array}{c}\text { ENVIRONMENTAL } \\
\text { CONDITIONS }\end{array}$}} \\
\hline Test Wt: & Tol: & \multirow{2}{*}{$\begin{array}{l}\text { Test Wt: } \\
100 \times 4\end{array}$} & \multirow{2}{*}{$\begin{array}{c}\text { Tol: } \\
0.0005\end{array}$} & \multirow{2}{*}{\multicolumn{2}{|c|}{$\begin{array}{c}\text { Test Wt: } \\
50\end{array}$}} & \multirow{2}{*}{$\begin{array}{l}\text { Tol: } \\
0.0002\end{array}$} & & & \\
\hline 200 & 0.0004 & & & & & & $\square$ & ఐ & $\square$ \\
\hline \multicolumn{2}{|c|}{ As-Found: } & \multicolumn{2}{|c|}{ As-Found: } & 1.49 .9999 & 5.49 .9997 & 9.49 .9998 & Good & Fair & Poor \\
\hline Pass: 曰 & Fail: $\square$ & Pass: Ø & Fatl: $\square$ & $\begin{array}{l}2.49 .9999 \\
3.49 .9999\end{array}$ & $\begin{array}{l}6.49 .9995 \\
7.49 .9994\end{array}$ & $\begin{array}{c}\text { 10. } 49.9995 \\
\text { Result }\end{array}$ & \multirow{2}{*}{\multicolumn{3}{|c|}{ Temperature: $22.8^{\circ} \mathrm{C}$}} \\
\hline Pass: As $^{\text {As- }}$ & $\begin{array}{l}\text { fft: } \\
\text { Fail: } \square\end{array}$ & Pass: & $\begin{array}{l}\text { ft: } \\
\text { Fail: } \square\end{array}$ & $\begin{array}{l}3.49 .9999 \\
4.49 .9999\end{array}$ & $\begin{array}{l}7.49 .9994 \\
8.49 .9993\end{array}$ & $\frac{\text { Result }}{0.00023}$ & & & \\
\hline
\end{tabular}

\begin{tabular}{|c|c|c|c|}
\hline Standard & As-Found & As-Left & Expanded Uncertainty \\
\hline 400 & 399.9996 & 400.0003 & 0.00050 \\
\hline 300 & 299.9995 & 300.0001 & 0.00050 \\
\hline 200 & 199.9997 & 200.0001 & 0.00048 \\
\hline 100 & 99.9998 & 100.0000 & 0.00048 \\
\hline 50 & 49.9998 & 49.9999 & 0.00048 \\
\hline 1 & 0.9998 & 0.9999 & 0.00048 \\
\hline
\end{tabular}

CALIBRATION STANDARD́S Reviewer $1 \mathrm{~s} \mathrm{Cl} / \mathrm{hy} \quad 9.21-15$

Permanent Information Concerning this Equipment:

\section{Comments/lnfo Concerning this Calibration:}

$8 / 15 \mathrm{PO}+263294$. As found $f$ as left within tolerance.

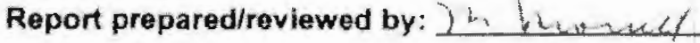
D
Technician: R. Hintz

Signature: Instruments listed above were calibrated using standard traceable to the Nationat institute of Standarts and Technology iNiST, Calibration data rellect results at the time and location of calibration, Calibration data should be reviewed in insure that the instrument is perforning to its fequired accuracy. Calibrations conply with ISOAEC 17025 and ANSUZ5-40-1-1994 Gaality standards 
PNNL-25241

$68122-T I-001$

Atlachment $C$

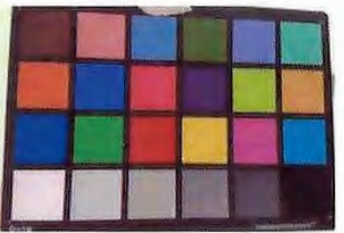

Color Chart 10-23-15.jpg

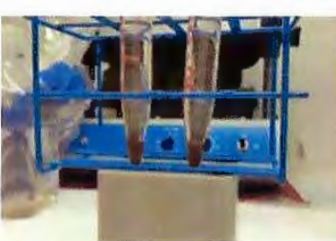

Initial spin down.1.jpg

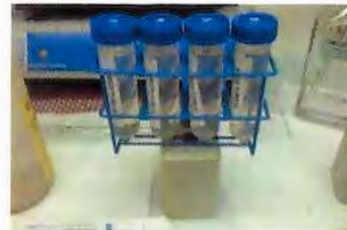

after 2 nd supernate spin.1.jpg

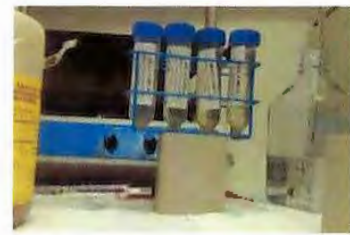

after 4th supernate spin.jpg

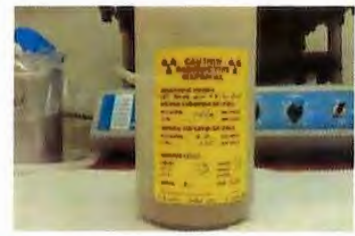

Sample condtion after 24hrs.jpg (no) $10 / 23 / 15$

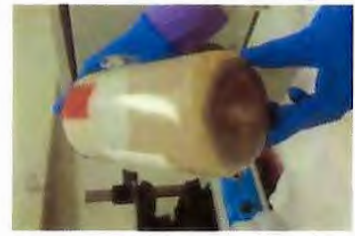

ived sample condition 10-20-1 Shipping conditions 10-20-15.jpg R. As received 10-20-15: io/23/15

(40) $10 / 23 / 15$ (15/20\%
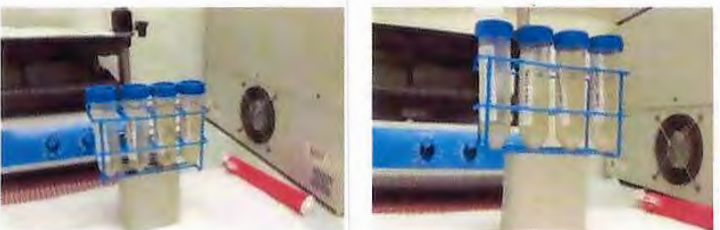

mpty tubes after step 4.28.1.jF Empty tubes after step 4.28.jpg Empty tubes after Step 4. 28.1. Jog

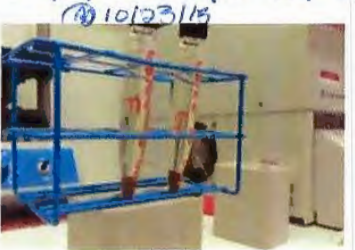

Initial spin down.2.jpg

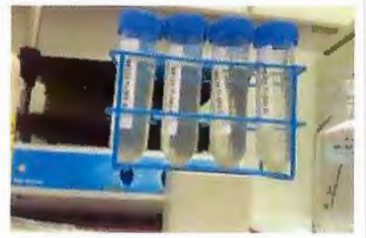

after 2nd supernate spin.jpg

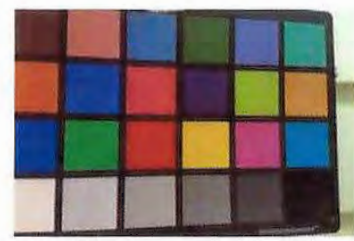

Color chart 10-21-15.jpg

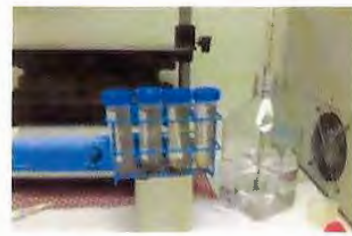

Solids transfer rinse 1.1.jpg

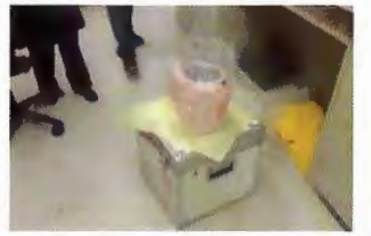

.jpg

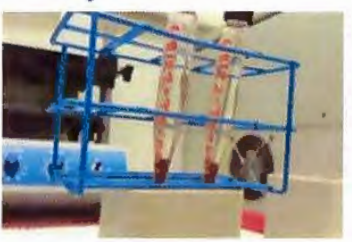

Initial spin down.jpg

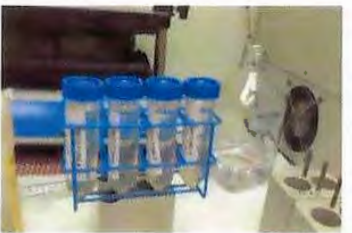

after 3rd supernate spin.1.jpg

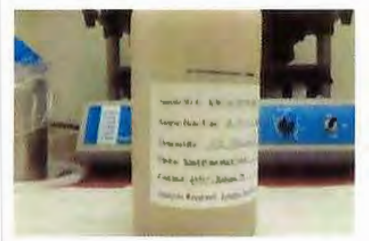

Sample condtion after $24 \mathrm{hrs} .1 . j \mathrm{f}$ ins $10 \% 23 / 15$

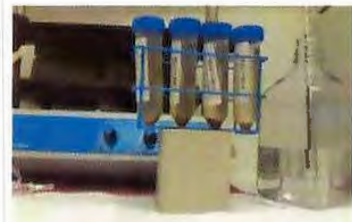

Solids transfer rinse 1.jpg

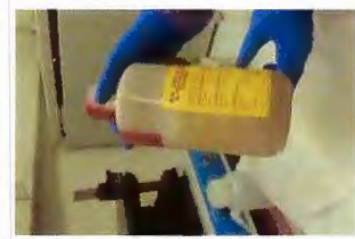

eived sample condition 10-20
As received sample Condition 10-20-15. jpg (A) $10 / 23 / 15$

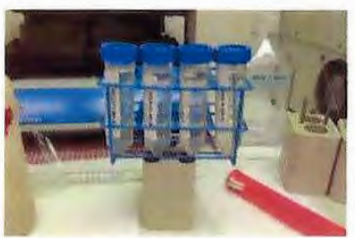

after 1st supernate spin.1.jpg

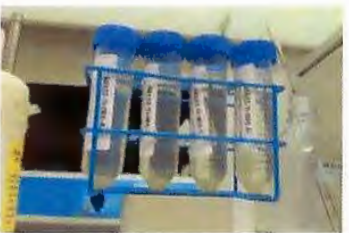

after 3rd supernate spin.jpg

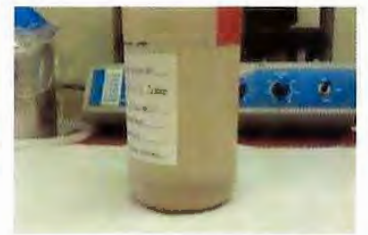

ample condtion after $24 \mathrm{hrs}$.2.jp ample condtion after $24 \mathrm{hrs}$.3.jk Sample fol 10/23/15

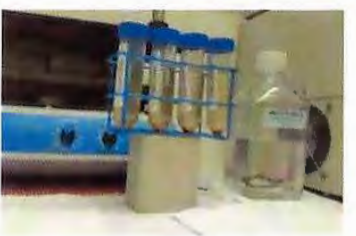

Solids transfer rinse 2.jpg

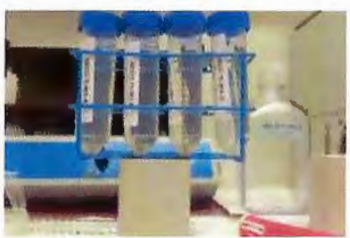

after 1 st supernate spin.jpg

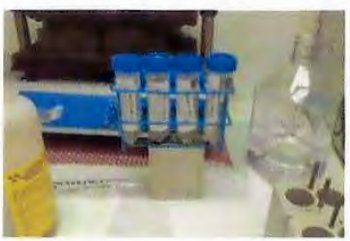

after 4 th supernate spin.1.jpg

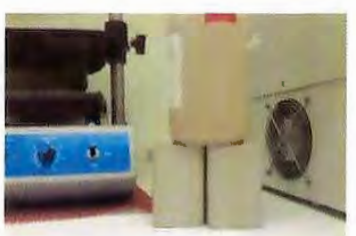

ing sample (10/33/is Jpg

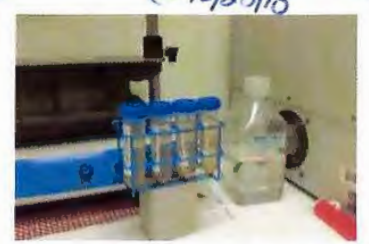

Solids transfer rinse 2.1.jpg 
PNNL-25241

$68122-T I-001$ A Hachment $C$ pg 2 of 2

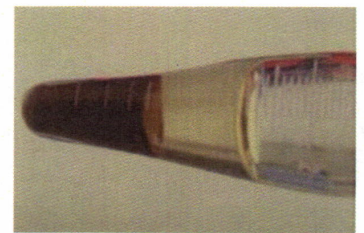

68122-TI-001-G solids.jpg

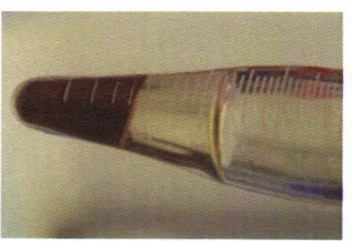

68122-TI-001-F solids.jpg

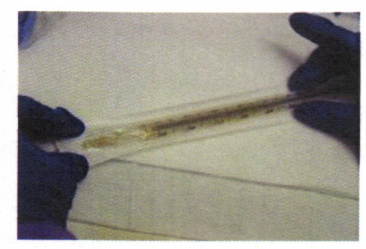

j8122TI0-001 transfer tube.jps 
PNNL-25241

$68122-$ TIOOI

Atachment D

pgl of 2

Fiskum, Sandra K

Subject:

FW: sample observation

From: Johnson, Michael E (CHPRC)

Sent: Thursday, October 22, 2015 8:49 AM

To: Fiskum, Sandra $\mathrm{K}$

Cc: Davis, George M (CHPRC)

Subject: RE: sample observation

Sandy,

I confirm that CHPRC observation is not required of the $105-\mathrm{KW}$ sand filter backwash sample from the north load-out pit.

Michael L. Johnson

Senior Technical Advisor

CII2MHILL Plateau Remediation Company

Office 509-372-3628

Coll 509-430-3291

From: Fiskum, Sandra K [mailto:sandy.fiskum@pnnl.gov]

Sent: Thursday, October 22, 2015 7:55 AM

To: Johnson, Michael E

Cc: Davis, Mike

Subject: RE: sample observation

The quantity of centrifuged solids in each of the $50-\mathrm{mL}$ centrifuge tubes appears to be on the order of 0.3 to 0.5 $\mathrm{mL}$.

I believe that we have enough total solids to conduct duplicate sample analysis as indicated in the test

instruction (Figure 1) - that is $\sim 0.6$ to $1 \mathrm{~mL}$ centrifuged solids/sample.

I believe we can get reasonable volume and mass measures in our 10 - $\mathrm{mL}$ glass centrifuge tubes.

I would like to proceed in completing the TI steps. Step 4.19 indicates client observation request. Your message below indicates that this is not necessary. Please confirm this for our records with an email response indicating that client observation is not required.

Thank you,

Sandy

From: Johnson, Michael E (CHPRC)

Sent: Thursday, October 22, 2015 5:22 AM 
PNNL-25241

To: Fiskum, Sandra K

Subject: RE: sample observation

Sandy,

I appreciate the photographs.

I don't need to see the samples in person.

Mike Davis is away on personal business and won't be back until November 2. He is periodically checking his email.

I think Mike Davis was more interested in getting a general tour of the lab.

Does it look like you`11 have enough sample to perform the requested analyses?

Thank you,

Michael E. Johnson

Senior Technical Advisor

CH2MHILL Plateau Remediation Company

Office 509-372-3628

Cell 509-430-3291

From: Fiskum, Sandra K [mailto:sandy.fiskum@pnnl.gov]

Sent: Wednesday, October 21, 2015 2:01 PM

To: Davis, Mike; Johnson, Michael E

Subject: sample observation

Mike and John,

Some time back you had requested the opportunity to come and see the samples.

Attached is a picture of the initial spin-down processing of the samples (4 conical vial with brown solids at bottom; the jug of water to the right is the decanted water).

The samples are located in a Radiation Area. If you want to see them, I will need to request dosimeters for you. This could be arranged perhaps for Monday or Tuesday. Do you still want to see the samples or is the photograph sufficient?

Thank you,

\section{Sandy Fiskum}

Senior Research Scientist

Pacific Northwest National Laboratory

509-375-5677 
PNNL-25241

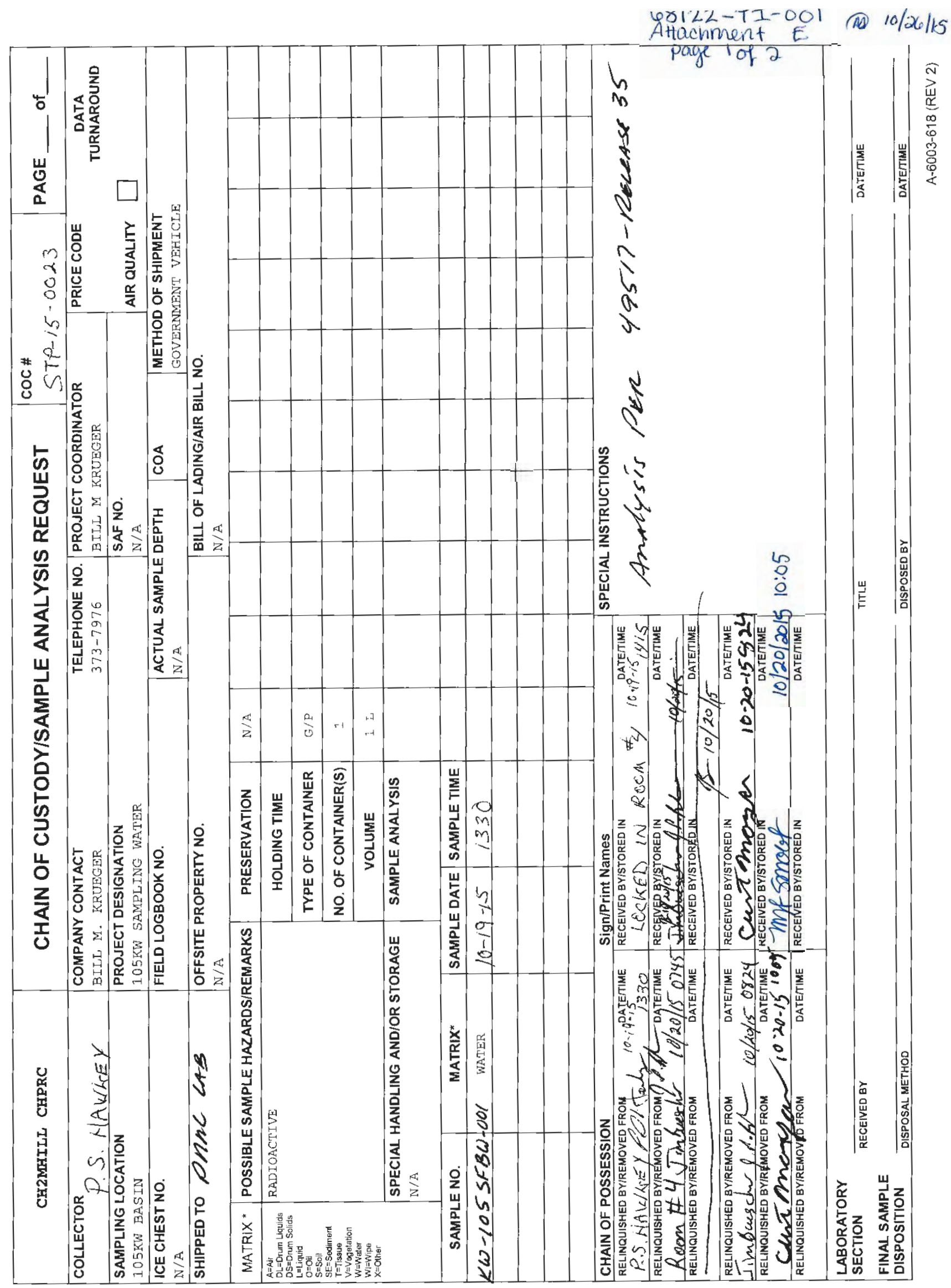


PNNL-25241

$68122-11-001$

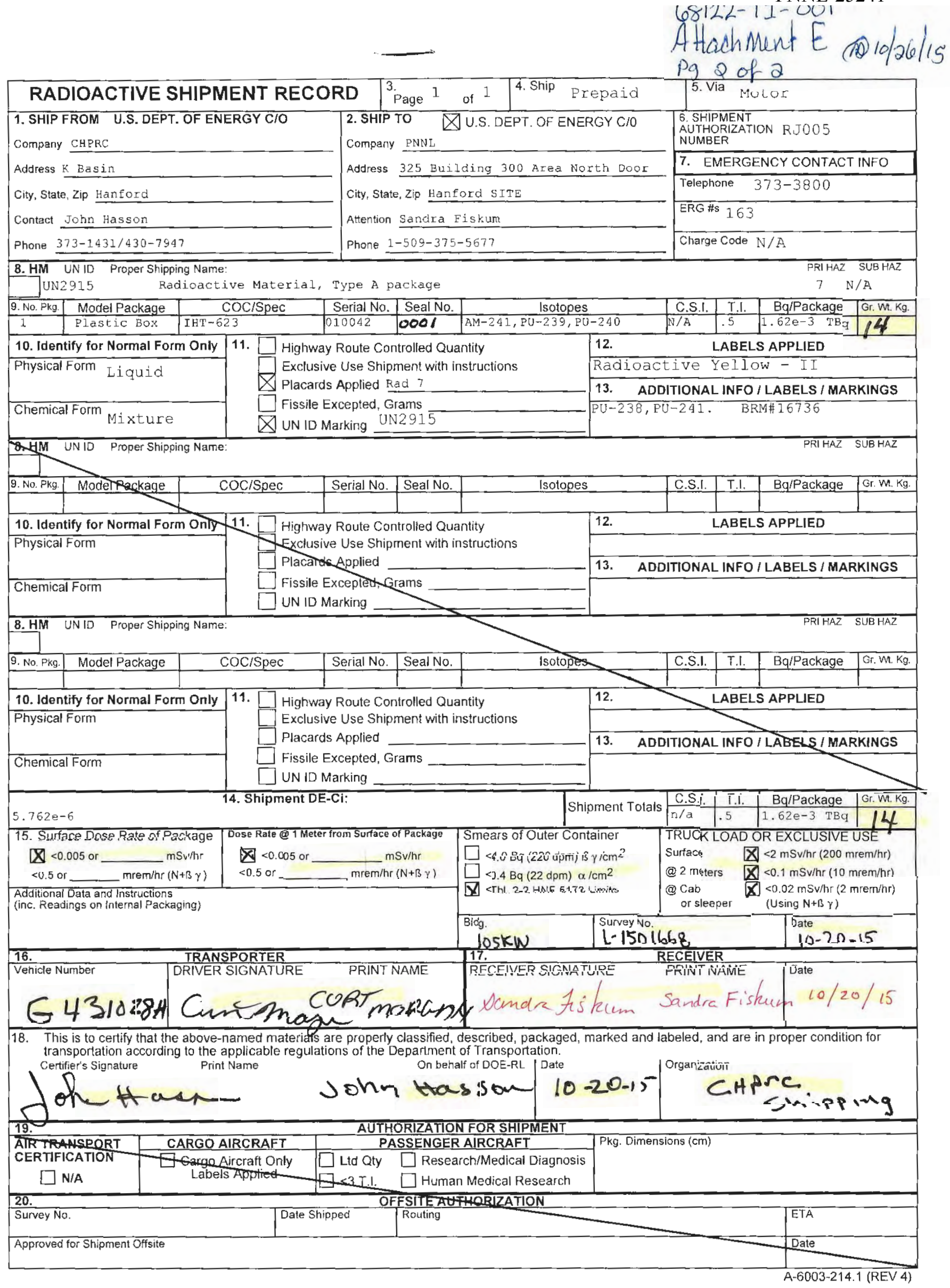




\begin{tabular}{|c|c|c|c|}
\hline & $\begin{array}{c}\text { PL K Basin Proje } \\
\begin{array}{c}52578 \\
68122\end{array}\end{array}$ & \multicolumn{2}{|c|}{ Document Review Record } \\
\hline Title: & \multicolumn{3}{|c|}{ Completed 68122-TI-001 Sandfilter Backwash Solids Consolidation } \\
\hline \multicolumn{3}{|c|}{ Please return the completed form to: } & Comments Due: \\
\hline \multicolumn{2}{|c|}{ Organization/Department: } & Designated Reviewer: & $\begin{array}{l}\text { Reviewer Signature/Date: } \\
\text { (Upon completion of review) }\end{array}$ \\
\hline & D9H63 & SK Fiskum & sandre k tiok \\
\hline
\end{tabular}

It is optional, but helpful when comments are identified as to type or if the reviewer wishes to specify mandatory comments requiring resolution. In this case, the following conventions apply:

*Type: $\mathbf{E}$-Editorial, addresses word processing errors that do not adversely impact the integrity of the calculation.

$\mathbf{O}$ - Optional, comment resolution would provide clarification, but does not impact the integrity of the work or calculations

M - Mandatory, comment shall be resolved; reviewer identifies impact on the integrity of the work or calculations

\begin{tabular}{|c|c|c|c|c|}
\hline $\begin{array}{l}\text { Comment } \\
\text { Number }\end{array}$ & $\begin{array}{l}\text { Section/ } \\
\text { Page }\end{array}$ & Type & Comment & Comment Resolution \\
\hline . & $\begin{array}{l}\text { Step 3.5.5 } \\
\text { and 4.14.5 }\end{array}$ & $\mathrm{E}$ & $\begin{array}{l}\text { Identify if the gross mass includes } \\
\text { the over-package of bags and tape. }\end{array}$ & $\begin{array}{l}\text { Added note that the gross container mass } \\
\text { includes the bags and tape used to safely } \\
\text { removed the bottle from the CA fume hood } \\
\text { and move to laboratory with a balance to } \\
\text { accommodate the weight. }\end{array}$ \\
\hline 2 & Step 4.19 & $\mathrm{E}$ & $\begin{array}{l}\text { Annotate where the new dose } \\
\text { rates are for the re-mixed and split } \\
-\mathrm{A} \text { and }-\mathrm{D} \text { samples are located. }\end{array}$ & $\begin{array}{l}\text { Added note to indicate new dose rates are on } \\
\text { page } 13 \text {. }\end{array}$ \\
\hline 3 & throughout & $\mathrm{E}$ & $\begin{array}{l}\text { Minor editorial changes (spelling) } \\
\text { as identified. }\end{array}$ & Spelling errors fixed as identified. \\
\hline \multicolumn{5}{|l|}{ END } \\
\hline & & & & \\
\hline & & & & \\
\hline & & & & \\
\hline & & & & \\
\hline & & & & \\
\hline
\end{tabular}

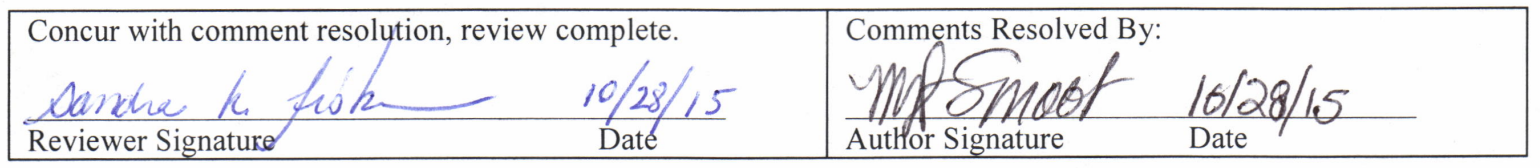


Title: $\quad$ Calculations from 68122-TI-001, Sandfilter Backwash Salids Cansolidatian

Filename: $\quad$ 68122-TI-001 Data Reduction.xlsx

Revision: $\quad 0$

Date Prepared: $\quad 10 / 28 / 2015$

Prepared By: $\quad$ SK Fiskum

Purpose: $\quad$ The purpose of this spreadsheet is to calculate the net mass and density of centrifuged solids sample splits from KW-105SFBW-001, $\mathrm{K}$ West Basin backwash from the sand filter. Data used in this file are taken from raw data recorded in 68122-Ti-001.

Approach:

Solids received in a 750-mL volume as a dilute slurry were consolidated into 2 centrifuge tubes. The tubes were 10-mL glass with high fidelity (nearest $0.1 \mathrm{~mL}$ ) of volume readability.

Simple subtraction, summation, and division is used to calculate the total centrifuged solids mass and wt\% centrifuged solids in the received slurry.

File: 68122-T1-001 Data Reduction Final.xlsx 
PNNL-25241

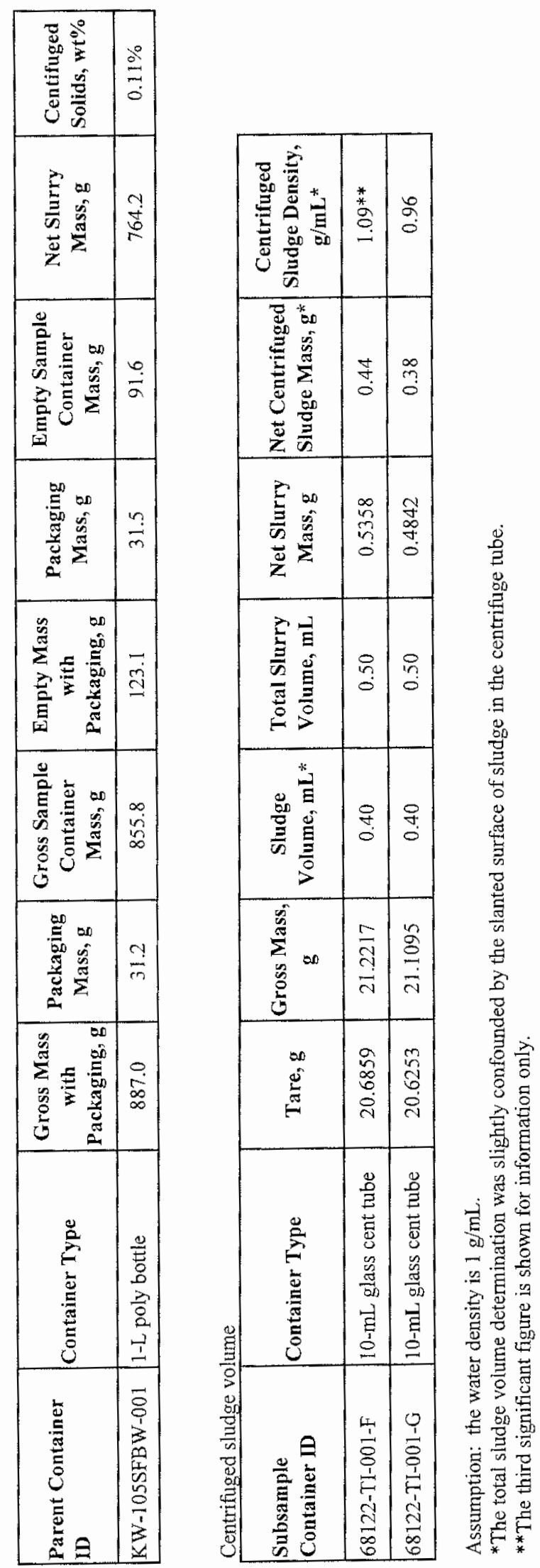

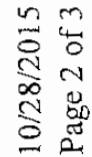

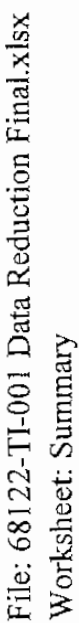




\section{Spreadsheet Review Form}

\begin{tabular}{|c|c|c|c|}
\hline Spreadsheet Author Name: & SK Fiskum & Review Date: & $10 / 27 / 2015$ \\
\hline Date Prepared: & $10 / 23 / 2015$ & Spreadsheet Subject: & $\begin{array}{c}\text { Calculations from } 68122-\mathrm{TT}-001 \\
\text { Sandfilter Backwash Solids } \\
\text { Consolidation }\end{array}$ \\
\hline Reviewer Name: & RW Shimskey & File Name: & 68122-TI-001 Data Reduction.xlsx \\
\hline Reviewer Title: & Sr Research Engineer & Revision No. & 0 \\
\hline
\end{tabular}

\section{Scope of Spreadsheet Review: (Check one or more of the following)}

\begin{tabular}{|c|l|c|l|}
\hline$\square$ & $\begin{array}{l}\text { General Validation Review: (General review and } \\
\text { spot checks) }\end{array}$ & $\square$ & $\begin{array}{l}\text { Independent calculation check (With hand calculations or } \\
\text { independent spreadsheet software) }\end{array}$ \\
\hline$\square$ & $\begin{array}{l}\text { Review of updated spreadsheet/calc (Revised } \\
\text { portion only) }\end{array}$ & $\square$ & Other: \\
\hline$\square$ & $\begin{array}{l}100 \% \text { Verification Review (Verification of all } \\
\text { cells/calculations) }\end{array}$ & & \\
\hline
\end{tabular}

\section{REVIEW CHECK LIST}

\begin{tabular}{|c|c|c|c|c|c|c|c|}
\hline \multicolumn{8}{|l|}{ Spreadsheet/Calculation Identification } \\
\hline Spreadsheet Information & Yes & No & NA & Input Values & Yes & No & $\mathbf{N A}$ \\
\hline Title: & $x$ & & & \multirow{2}{*}{$\begin{array}{l}\text { Are input parameters correct (verified with } \\
\text { source?) }\end{array}$} & \multirow{2}{*}{$\mathbf{x}$} & & \\
\hline Revision Number: & $\mathbf{x}$ & & & & & & \\
\hline Date Prepared: & $\mathbf{x}$ & & & Are parameter units consistent? & $x$ & & \\
\hline Prepared by: & $\mathbf{x}$ & & & Are input values properly referenced? & $\mathrm{x}$ & & \\
\hline General Statement of Purpose: & $\mathrm{x}$ & & & Are input uncertainties correct? & $\mathrm{x}$ & & \\
\hline General Description of Approach: & $x$ & & & \multirow{2}{*}{\multicolumn{4}{|c|}{$\begin{array}{l}\text { Comments: } \\
\text { Corrections with formatting and use of significant figures made. }\end{array}$}} \\
\hline Comments: & & & & & & & \\
\hline Assumptions & Yes & No & NA & Equations/Approach & Yes & No & $\mathbf{N A}$ \\
\hline Are assumptions clearly stated? & & & $\mathrm{x}$ & Are equation algorithms adequately defined? & $x$ & & \\
\hline Are assumptions supported and justified? & & & $\mathbf{x}$ & Are equations properly referenced? & $\mathbf{x}$ & & \\
\hline Are assumptions reasonable? & & & $\mathbf{x}$ & $\begin{array}{l}\text { Are limitations of approach/equations } \\
\text { identified? }\end{array}$ & $\mathbf{x}$ & & \\
\hline \multicolumn{4}{|c|}{ Comments: There are no assumptions with this data set. } & Are equations appropriate? & $\mathbf{x}$ & & \\
\hline Results/Conclusions & Yes & No & $\mathbf{N A}$ & Are units consistent? & $\mathrm{x}$ & & \\
\hline Are formulas consistent in cells? & $x$ & & & \multirow{3}{*}{\multicolumn{4}{|c|}{$\begin{array}{l}\text { Comments: Equations are simple add/subtract, multiply and } \\
\text { divide. }\end{array}$}} \\
\hline Are calculations correct? & $x$ & & & & & & \\
\hline Are conclusions consistent with results? & & & $x$ & & & & \\
\hline $\begin{array}{l}\text { Are conclusions consistent with applicable } \\
\text { limits? }\end{array}$ & & & $\mathbf{x}$ & \multicolumn{4}{|l|}{ Reviewer Sign/Date: } \\
\hline
\end{tabular}

File: 68122-TJ-001 Data Reduction Final.xlsx 
PNNL-25241

\section{PLANNING}

Topic/Issue to be evaluated: Surveillance of Completed Test Instruction 68122-TI-001, Sandfilter Backwash Solids Consolidation

This surveillance was undertaken to evaluate completed test instruction (TI) 68122-TI-001 Sandfilter Backwash Solids Consolidation. TI-001 was used between 13 October 2015 and 27 October 2015. Margaret Smoot performed the work, Sandy Fiskum performed the technical review of the completed TI and Rick Shimskey performed the technical review of the data reduction and reporting spreadsheet, 68122 TI-001 Data Reduction.xlsx, prepared by Sandy Fiskum.

\section{Source of Requirement(s):}

- Baker RB, JL Westcott, TL Welsh, JA Pottmeyer, and AJ Schmidt. 2009. Quality Assurance Project Plan/Sampling and Analysis Plan for Sludge in the KW Engineered Containers. KBC-33786, Rev. 2, CH2M Hill Plateau Remediation, Company, Richland, Washington.

- Westcott JL, BJ Makenas, TL Welsh, JA Pottmeyer, and AJ Schmidt. 2009. Data Quality Objectives for Sampling and Analysis of K Basin Sludge (DQO), HNF-36985, Rev. 3, CH2M Hill Plateau Remediation, Company, Richland, Washington.

- Letter 52578-2015-L03 from SK Fiskum to JO Honeyman, Cost Estimate for Analysis of the Sandfilter Backwash Solids, May 27, 2015.

- CH2M Hill Plateau Remediation, Contract 49517, Release 35, Statement of Work, Isotopic Analysis from PNNL (July 7, 2015), Amendment 1.

Other Applicable Documents:

ADM-RSEG-BALANCES, Rev. 1 (or latest revision), Balance Calibration Verification

Test Instruction 68122-TI-001, Sandfilter Backwash Solids Consolidation

\section{PERFORMANCE}

\begin{tabular}{|l|l|}
\hline Date Initiated: $10 / 28 / 15$ & Location: RPL/525, 410, and 305 \\
\hline Date Completed: $10 / 29 / 15$ & $\begin{array}{l}\text { DRAFT Report Issued: } 10 / 29 / 15 \\
\text { FINAL Report Issued: } 10 / 29 / 15\end{array}$ \\
\hline $\begin{array}{l}\text { Contacts: Sandy Fiskum, Rick Shimskey, and } \\
\text { Peg Smoot }\end{array}$ & Org Code: PE 137, D9H63 \\
\hline \begin{tabular}{l} 
Surveillance Team: Deborah Coffey \\
\hline
\end{tabular} & \\
\hline
\end{tabular}


PNNL-25241

PROJECTS 68112-SURVEILLANCE REPORT

\section{PURPOSE}

The purpose of sample collection, processing and analysis is to provide characterization data to allow the client to characterize the sand filter media for disposal. The sand filter is located in the $\mathrm{K}$ West Basin.

The K Basin-Project QE was requested to review the completed TI for sample receipt and processing activities leading to submittal of the sample to the Analytical Support Operations (ASO) laboratory for analysis under ASR 9916. The sample was received by M Smoot on 10/20/15 at 10:05 a.m. from the 105KW Basin by CH2MHill CHPRC staff; the sample was collected on 10/19/15 at 1330 (1:30 pm). The sample ID documented on the Chain of Custody form is KW-105 SFBW-001.

\section{APPROACH}

Completed TI-001 was submitted for QE review on 10/28/15. There initially was no DRR form from the technical reviewer included in the submitted TI package showing that all technical reviewer comments were resolved; the technical reviewer did sign off on the cover page of the completed TI on 10/28/15. The technical reviewer of the data reduction and reporting spreadsheet, 68122 TI-001 Data Reduction.xlsx, prepared by Sandy Fiskum, Rick Shimskey, signed the Spreadsheet Review Form, which referenced a DRR form as the location of any spreadsheet comments, but that document was not attached to the completed TI. Both the technical reviewer's DRR form and the revised Spreadsheet Review Form were submitted on 10/29/15 to address concerns.

\section{RESULTS}

The submitted data package included the following:

- Technical Reviewer's DRR form - 1 pp.

- Completed TI-001, Sandfilter Backwash Solids Consolidation-21 pp.

- Attachment A -

BPCL forms for:

Mettler AT400 (SN: N04143) RPL/305 benchtop

Mettler SB16001 (SN: 1125202532) RPL/305 benchtop

Mettler AT400 (SN: 11132992667) RPL/410 fumehood

- Attachment B -

QCS Certificate of calibration for:

Mettler AT400 (SN: N04143) RPL/305 benchtop. Cal Date: 8/24/15 Expires: 8/2016

Mettler SB16001 (SN: 1125202532) RPL/305 benchtop. Cal Date: 2/11/15 Expires:

2/2016

Mettler AT400 (SN: 11132992667$)$ RPL/410 fumehood. Cal Date: 8/18/15 Expires:

$8 / 2016$ 
PNNL-25241

PROJECTS 68112-SURVEILLANCE REPORT

Number: SR-68122-2015-005

Page 3 of 4

- Attachment $C$

Photographs - 2pp.

- Attachment D-

Email confirming that the client did not want/need to observe work in progress $-2 \mathrm{pp}$.

- Attachment E -

Chain of Custody/Analysis Request form for the sample that was received by $\mathrm{M}$ Smoot on 10/20/15 at 10:05 a.m. from the $105 \mathrm{KW}$ Basin by CH2MHill CHPRC staff; the sample was collected on 10/19/15 at $1330(1: 30 \mathrm{pm})$. The sample ID documented on the Chain of Custody form is KW-105 SFBW-001. 1 pp.

Radioactive Shipment Record dated 10/20/15 documenting dose rates and smears of the shipped container. 1 pp.

- Data reduction and reporting spreadsheet, 68122-TI-00 1 Data Reduction.xlsx, prepared by Sandy Fiskum and titled, Calculations from 68122-TI-001, Sandfilter Backwash Solids

Consolidation.

M\&TE Used:

\begin{tabular}{|l|l|}
\hline Balance Identification: & Used: \\
\hline Mettler AT400, serial number: N04143 (360-06-01-048), RPL/305 & $10 / 15 / 15$ \\
\hline Mettler SB 16001 (SN: 1125202532) RPL/305 benchtop & $10 / 21 / 13 ; 10 / 22 / 15$ \\
\hline Mettler AT400 (SN: 11132992667) RPL/410 fumehood & $10 / 23 / 15$ \\
\hline
\end{tabular}

Dates and documentation of performance check measures on the noted dates were consistent with the BPCL forms.

Sources of data entered into the data reduction and reporting spreadsheet, 68122Tl-001 Data Reduction.xlsx were consistent with TI entries and traceable.

\section{Issues of Concern:}

There were no issues of concern, findings or observations identified.

Findings are defined as a statement of fact relating to noncompliance with previously agreed-upon procedures, plans, codes, standards, specifications, or other forms of contractual or legal obligation. It should be understood that any lack of a finding in a specific area is not considered an indication that deficiencies do not exist.

Observations are defined as a weakness that if not corrected, could yield a departure from a requirement although the weakness is not necessarily a departure from requirements. 
There were no findings or observations. There were no issues identified that would result in a Project 68122 Occurrence, Deficiency, or Nonconformance Report and no required corrective actions. It appears that the TI objectives were met.

\section{CORRECTIVE ACTION}

[X] None Required. [ ] Complete [ ] Follow- up Corrective Action:

Surveillance Performed By:

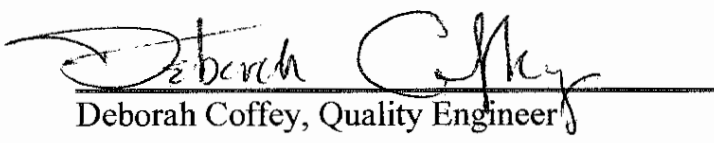

Date: $10 \cdot 29 \cdot 2015$

DISTRIBUTION: Deborah Coffey, Sandy Fiskum, Andy Schmidt, Rick Shimskey and Peg Smoot 

Appendix B

\section{ASR 9916 and Results}





\section{Appendix B}

\section{ASR 9916 and Results}

Appendix B contains the signed Analytical Services Request (ASR) 9916 and Special Instructions generated for the Analytical Support Organization (ASO) analysis of the backwash sand filter solids sample and duplicate. The Special Instructions delineate sample-specific information, required detection limits, quality control (QC) sample requirements, and reporting requirements.

Analytical summary reports generated by the ASO in response this ASR are also provided in Appendix B. The analytical reports provide sample results associated uncertainties, and a discussion of sample processing, QC results, and data limitations.

\section{Appendix B Table of Contents}

ASR 9916 and Special Instructions

ASR 9916 Solids Dry Mass and Undissolved Solids Mass Report

ASR 9916 Gamma Energy Analysis Report

ASR9916 Plutonium-238 and Plutonium-239+240 Report ....

ASR 9916 Neptunium-237 Report

ASR 9916 Americium-241 Report

ASR 9916 Stronium-90 Report. B.34

ASR 9916 Gross Alpha and Beta Report

ASR 9916 Actinides and Strontium-90 Data Tables

ASR 9916 Plutonium Isotopic Analysis by TIMS

B.41

ASR 9916 Radionuclide Data Reduction Excel File

B. 50

ASR 9916 Pu Isotopic Data Reduction Excel File

B. 58 

PNNL-25241

\section{ASO Analytical Service Request Form}

\section{Analytical Service Request (ASR)}

(Information on this COVER PAGE is applicable to all samples submitted under this ASR)

Requestor --- Complete all fields on this COVER PAGE, unless specified as optional or ASR is a revision

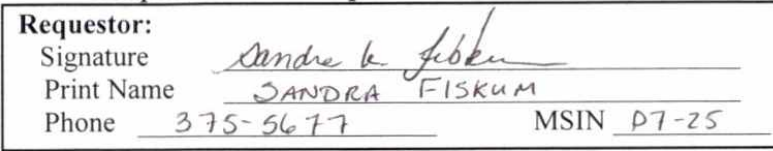

Matrix Type Information

- Liquids: $\square$ Aqueous $\square$ Organic $\square$ Multi-phase

- Solids: $\square$ Soil $\square$ Sludge $\square$ Sediment

$\square$ Glass $\quad \square$ Filter $\square$ Metal

$\square$ Smear $\square$ Organic $\square$ Other

- Other: $\square$ Solid/Liquid Mixture, Slurry
$\square$ Gas
$\square$ Biological Specimen

(If sample matrices vary, specify on Request Page)

\section{Disposal Information}

- Disposition of Virgin Samples:

Virgin samples are returned to requestor unless

archiving provisions are made with receiving group!

If archiving, provide:

Archiving Reference Doc:

- Disposition of Treated Samples:

$\square$ Dispose $\square$ Return

Data Reporting Information

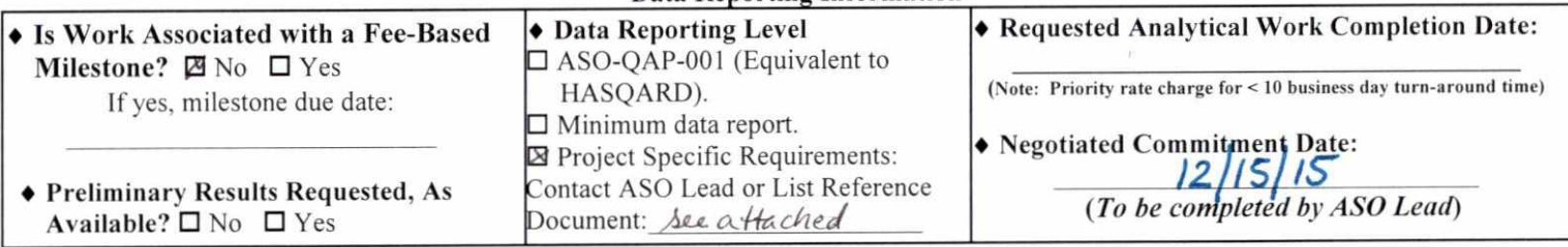

Preliminary Results Requested, As Available? $\square$ No $\square$ Yes

Waste Designation Information

- ASO Sample Information Check List Attached? $\square$ No $\square$ Yes

If no, Reference Doc Attached:

or, Previous ASR Number:

Does the Waste Designation Documentation Indicate Presence of PCBs?

No $\square$ Yes

or, Previous RPL Number:

Send Report To:

sk fiskum

MSIN

MSIN

Additional or Special Instructions

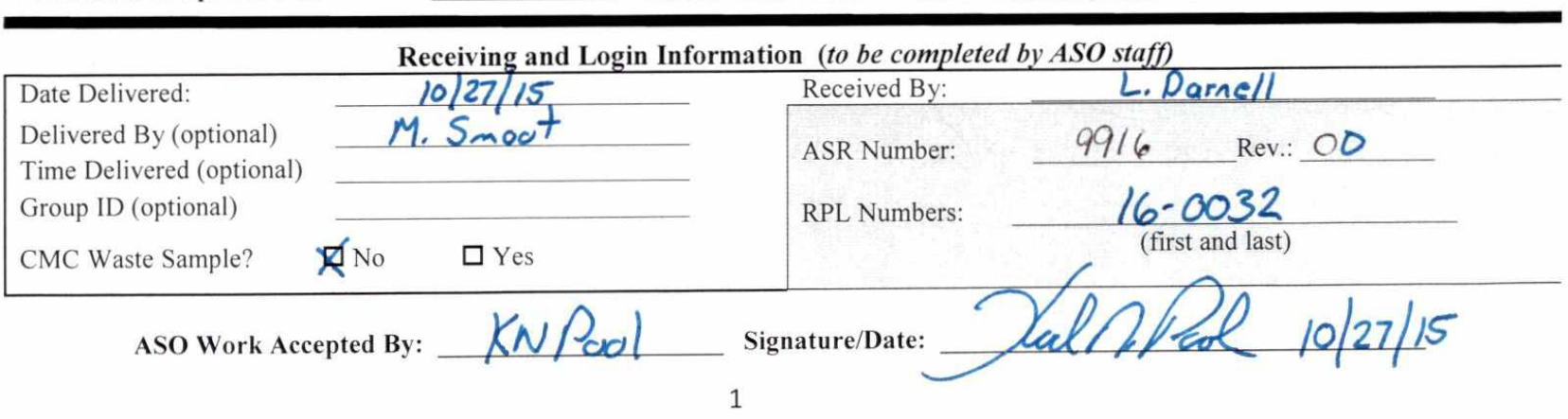


PNNL-25241

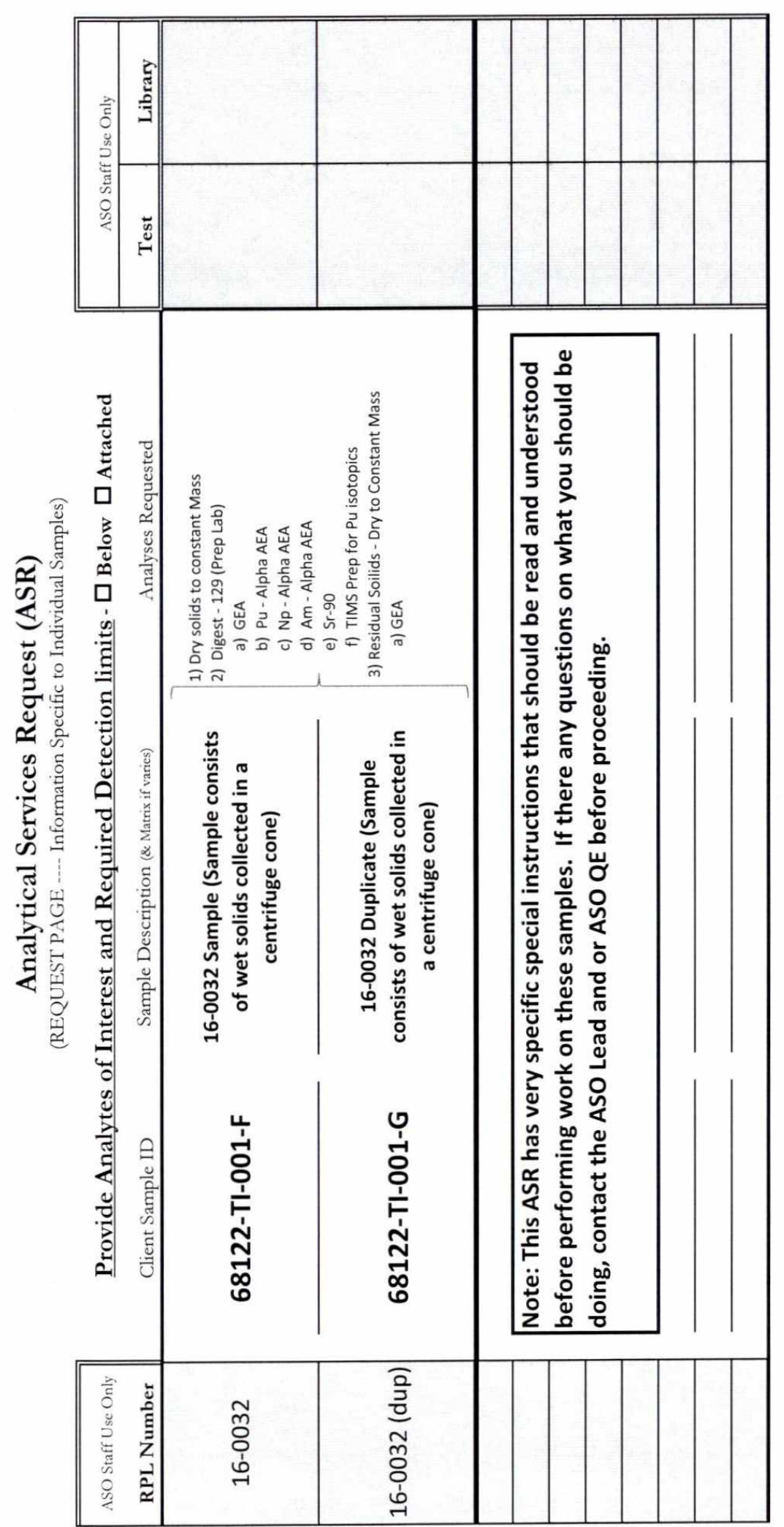




\section{ASO Sample Information Checklist (SICL) Form}

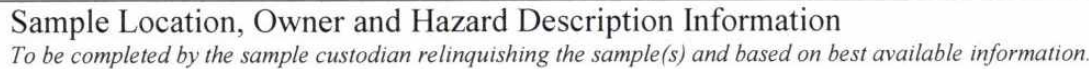

\begin{tabular}{|l|l|l|}
\hline Constituent/Chemical & Concentration & Comment \\
\hline unknown & & \\
\hline & & \\
\hline & & \\
\hline & & \\
\hline & & \\
\hline
\end{tabular}

Are any other comments applicable to sample receipt, storage, handling, or disposition?

Wait for SK Fiskum to authorize disposal of acid digests.

\section{Checklist Prepared By:}

SK Fiskum

sandre

$\frac{k_{1} \text { froken }}{\text { Date }} 10 / 27 / 15$

Printed Name Signature

Date 
PNNL-25241

\section{Special Instructions for K-Basin Sandfilter Backwash Samples}

Cognizant Scientist:

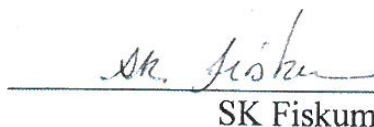

Project Manager:

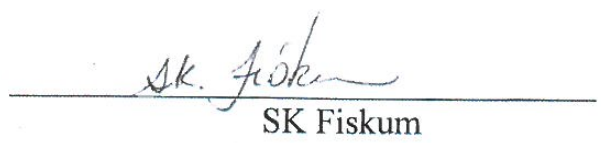

Project Quality Engineer:

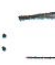

ASO Lead:

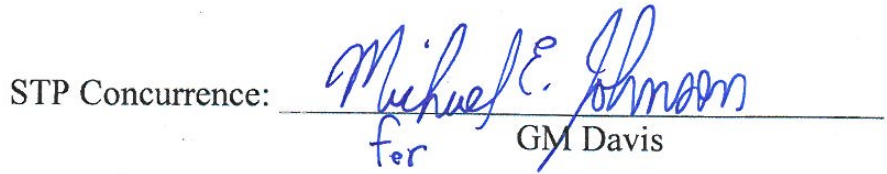
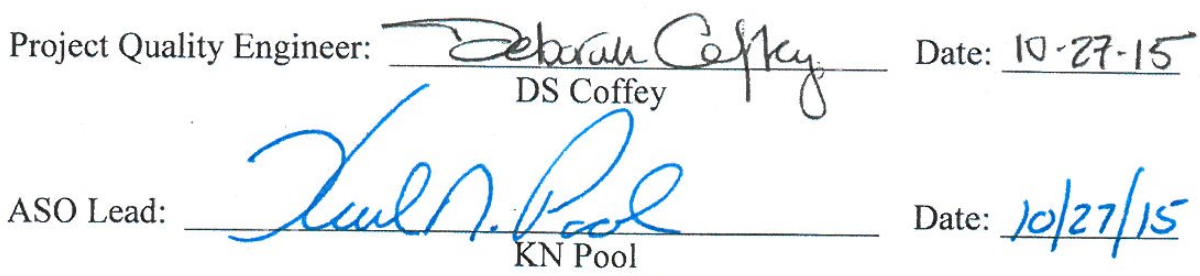

Date: $10 / 27 / 15$

Date: $10 / 27 / 15$

Date: $10 / 27 / 20 / 5$ 


\title{
Special Instructions for K-Basin Sandfilter Backwash Samples
}

\author{
Cognizant Scientist: \\ SK Fiskum, 375-5677
}

A sample was collected by CHPRC staff from the sandfilter backwash processing at the K West (KW) Basin. The sample was received by the project (68122) staff from CHPRC under chain of custody at the RPL on 10/20/15. The material was received in the RPL/525 laboratory and logged into the Radioactive Material Tracking (RMT) system as RMT \#86040.

The 68122 project staff consolidated the solids from this sample into two equal fractions, each at $0.4 \mathrm{~mL}$ with a small overburden of backwash water in 10-mL glass centrifuge tubes. These duplicate samples are presented to the Analytical Support Operations (ASO) laboratory identified as a sample and duplicate for analysis. The sample IDs and container tare masses are shown in Table 1. There is no other sample material available so it is very important to handle the samples carefully.

Table 1. Cross-Reference of Sample ID, RPL ID, Centrifuge Cone Tare

\begin{tabular}{||l|c|c|l||}
\hline Sample ID & RPL ID & $\begin{array}{c}\text { Container } \\
\text { Tare, } \mathbf{g}\end{array}$ & Sample Type \\
\hline $68122-$ TI-001-F & $16-0032$ & 20.6859 & Sample \\
\hline $68122-$ TI-001-G & $16-0032$ & 20.6253 & Sample duplicate \\
\hline \multicolumn{2}{|l|}{ Container tares were collected from balance 113061397, lab 525 hood 13 on $10 / 23 / 15}$. \\
\hline
\end{tabular}

The requested sample processing and analysis schematic is shown in Figure 1. Work is to be performed under the ASO QA Plan. All analysis work is to be charged to N51383.

\section{Radiochemical Analysis}

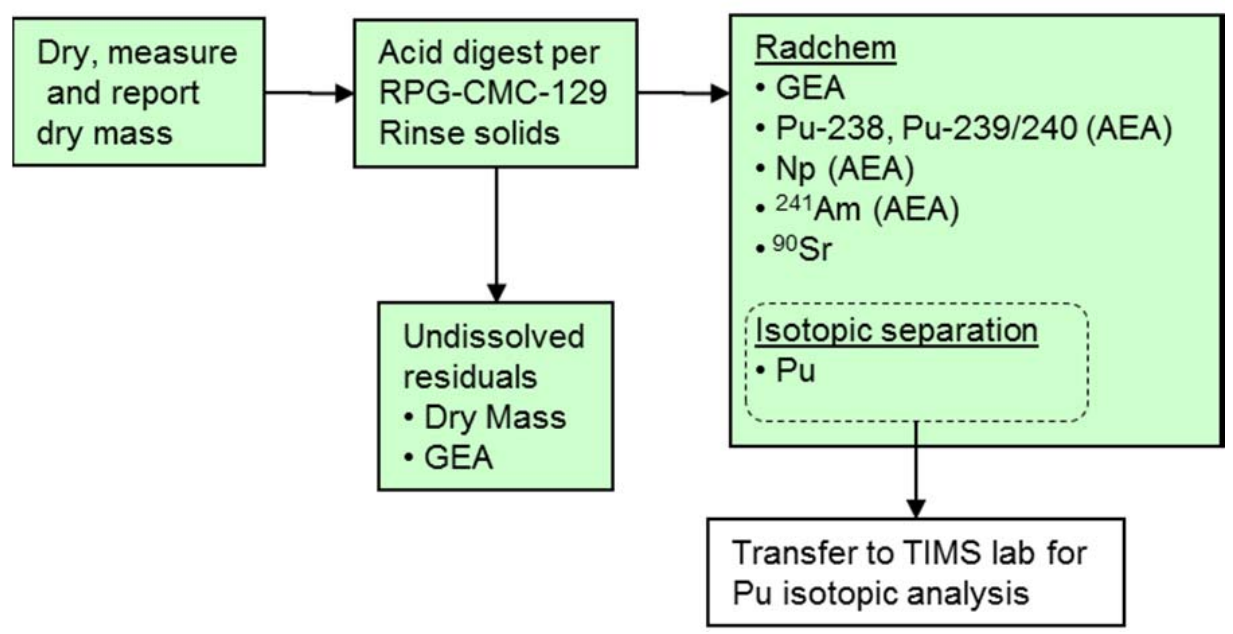

Figure 1. Analysis Schematic for K Basin Backwash Solids 
PNNL-25241

Analytes of interest and required detection limits are provided in Table 3; quality control (QC) sample acceptance criteria are provided in Table 4.

\section{Acid Digestion}

The analytical samples are provided to ASO in tared centrifuge tubes. Analytical samples need to be dried to constant mass at $105^{\circ} \mathrm{C}$ using procedure, RPG-CMC-503, Rev. 0, Determination of Physical Properties of Solutions, Sludges, Slurries and Solids. Determine and report the net dry sample mass.

Acid digest the dried solids according to RPG-CMC-129, Rev. 0, $\mathrm{HNO}_{3}-\mathrm{HCl}$ Acid Extraction of Solids Using a Dry-Block Heater. Report observations associated with the dissolution processing, including the undissolved solids mass.

Residual solids remaining after acid digestions are not expected. If present, they are of interest and shall not be lost (refer to Figure 1). Remove the acid digestate as per procedure; this may entail centrifuging and decanting. Rinse as appropriate, collecting rinse solutions with the acid digestion solution.

After residual solids are rinsed and isolated, dry the solids (in the digestion tube) to constant mass at $105^{\circ} \mathrm{C}$. Calculate the net residual solids mass along with the starting material dry solids mass and report to SK Fiskum. Additional processing of residual solids will depend on the mass relative to the starting (wet/dewatered) material. Additional processing may include GEA.

\section{Acid Digestion Reporting Units}

Report the dry sample mass before digestion as $\mathrm{g}_{\text {dry }}$, and report the dried residuals solids mass after digestion and rinsing as $g_{\text {residual }}$.

\section{Radiochemistry}

\section{Preparations and Analysis}

Acid digestate aliquots shall be directly aliquoted for GEA analysis. Acid digestate aliquots shall be aliquoted for separations, mounting, and/or analysis. Operations will be conducted according to the specific radiochemistry procedures delineated in Table 2 . No procedure or procedure revision substitutions are to be made without prior written authorization from SK Fiskum or CD Carlson to requests submitted by the ASO Lead.

Table 2. Authorized Radiochemistry Procedures for K Basin Sludge Analysis

\begin{tabular}{|l|c|c|c|}
\hline Analyte & Separation & Mounting & Counting/Analysis \\
\hline GEA & NA & NA & $\begin{array}{c}\text { RPG-CMC-450, Rev. 2 Gamma } \\
\text { Energy Analysis (GEA) and Low- } \\
\text { Energy Photon Spectrometry (LEPS) }\end{array}$ \\
\hline $\begin{array}{l}{ }^{238} \mathrm{Pu} \text { and } \\
{ }^{239}+240 \mathrm{Pu} / \mathrm{AEA}\end{array}$ & $\begin{array}{c}\text { RPG-CMC-4017, Rev. 0, } \\
\text { Analysis of Environmental } \\
\text { Water Samples for Actinides } \\
\text { and Strontium-90 }\end{array}$ & $\begin{array}{c}\text { RPG-CMC-496, Rev.1, } \\
\text { Coprecipitation } \\
\text { Mounting of Actinides } \\
\text { for Alpha Spectroscopy }\end{array}$ & $\begin{array}{c}\text { RPG-CMC-422, Rev. 2 Solutions } \\
\text { Analysis: Alpha Spectrometry }\end{array}$ \\
\hline
\end{tabular}


PNNL-25241

ASR 9916 Special Instructions

Page 4 of 9

\begin{tabular}{|c|c|c|c|}
\hline Analyte & Separation & Mounting & Counting/Analysis \\
\hline${ }^{241} \mathrm{Am} / \mathrm{AEA}$ & $\begin{array}{l}\text { RPG-CMC-4017, Rev. 0, } \\
\text { Analysis of Environmental } \\
\text { Water Samples for Actinides } \\
\text { and Strontium-90 }\end{array}$ & $\begin{array}{l}\text { RPG-CMC-496, Rev. 1, } \\
\text { Coprecipitation } \\
\text { Mounting of Actinides } \\
\text { for Alpha Spectroscopy }\end{array}$ & $\begin{array}{l}\text { RPG-CMC-422, Rev. } 2 \text { Solutions } \\
\text { Analysis: Alpha Spectrometry }\end{array}$ \\
\hline${ }^{237} \mathrm{~Np} / \mathrm{AEA}$ & $\begin{array}{l}\text { RPG-CMC-4017, Rev. 0, } \\
\text { Analysis of Environmental } \\
\text { Water Samples for Actinides } \\
\text { and Strontium-90 }\end{array}$ & $\begin{array}{l}\text { RPG-CMC-496, Rev. 1, } \\
\text { Coprecipitation } \\
\text { Mounting of Actinides } \\
\text { for Alpha Spectroscopy }\end{array}$ & $\begin{array}{l}\text { RPG-CMC-422, Rev. } 2 \text { Solutions } \\
\text { Analysis: Alpha Spectrometry }\end{array}$ \\
\hline${ }^{90} \mathrm{Sr}$ & $\begin{array}{l}\text { RPG-CMC-476, Rev. 0, } \\
\text { Strontium Separation using } \\
\text { Eichrom Strontium Resin }\end{array}$ & NA & $\begin{array}{l}\text { RPG-CMC-474, Rev. 1, Measurement } \\
\text { of Alpha and Beta Activity by Liquid } \\
\text { Scintillation Spectrometry }\end{array}$ \\
\hline $\mathrm{Pu}$ isotopic & $\begin{array}{c}\text { RPG-CMC-455, Rev. 0, } \\
\text { Separation of Uranium and } \\
\text { Plutonium for Isotopic Analysis } \\
\text { by Mass Spectroscopy }\end{array}$ & NA & $\begin{array}{l}\text { Deliver to Pu Isotopic Analysis } \\
\text { Workstation } \\
\text { RPL-TIMS-001, Rev. 0, Thermal } \\
\text { Ionization Mass Spectrometry (TIMS) }\end{array}$ \\
\hline
\end{tabular}

The separations conducted to support Pu isotopic analysis need to provide purified fractions with sufficient analyte concentrations to create a measureable signal by TIMS. Therefore, the preparation shall not be considered complete until satisfactory isotopic results are obtained. It is understood that the process/preparation blank (PB) may not have sufficient analyte concentration to meet this objective. There are no laboratory control samples (LCS) or matrix spike (MS) samples required to be processed through separations processes to support isotopic analysis by TIMS.

\section{Radiochemistry Reporting Units}

Report solids sample analyte concentrations as $\mu \mathrm{Ci} / \mathrm{g}_{\text {dry }}$ where $\mathrm{g}_{\text {dry }}$ is the initial dry sample mass determined prior to the start of the PNL-ALO-129 acid digestion.

If needed, report the residual solids GEA analytes as $\mu \mathrm{Ci} / \mathrm{g}_{\text {residual }}$, where $\mathrm{g}_{\text {residual }}$ is the mass of residual solids that did not dissolve during acid digestion. The precision criteria defined in Table 4 do not apply to the undissolved solids.

\section{Quality Control}

All work is required to be conducted to the requirements of the Hanford Analytical Services Quality Assurance Requirements Document (HASQARD, Rev. 3). Performing work to the requirements of the ASO QA Plan (ASO-QAP-001, Rev. 9 or most current revision) will satisfy the HASQARD requirements. Where there is a discrepancy between the data quality objectives (DQOs) in the ASO QA Plan and these Special Instructions, the Special Instructions takes precedence as there are specific $\mathrm{K}$ Basin project requirements.

Preparative quality control (QC) sample analysis is to include a preparation blank (PB) sample, a sample duplicate (provided), an LCS or blank spike (BS) sample and a sample MS (a separate sample is provided for spiking by the ASO) as indicated in Table 4. The BS sample for radioisotopes will be generated after acid digestion on a sample split, i.e., post-digestion spikes. The MS for radioisotopes will be generated after acid digestion on a sample split, i.e., postdigestion spikes. 
PNNL-25241

ASR 9916 Special Instructions

Page 5 of 9

The duplicate, LCS/BS, and MS sample QC acceptance criteria are provided in Table 4. The following section discusses actions to take in the event of QC sample failures.

Note: The ASO staff must inform/report QC sample failures promptly to the ASO Lead who will in turn inform the Cognizant Scientist/Project Manager with copy to the K Basin Project QE (Deborah Coffey), thus enabling Pacific Northwest National Laboratory (PNNL) to fulfill its commitment to the client for prompt notification of such failures. The impact of any QC sample failure on data quality or project schedule (e.g., re-runs) will be assessed in conjunction with the client.

1. The preparation blank (PB) analyte concentration shall be less than the estimated quantitation limit (EQL) or the minimum detectable activity (MDA) of the associated sample. When the $\mathrm{PB}$ concentration is equal to or exceeds the $\mathrm{EQL}$ or MDA, then the $\mathrm{PB}$ concentration shall not exceed $5 \%$ of the measured concentration present in the sample.

2. If and when it has been determined that the data are not useable, then the 68122 Project Manager (PM) must be notified promptly.

3. If and when the MS sample fails to meet the acceptance criteria, the results shall be investigated for potential sources of error by comparing the results of the MS to the BS. When the sources of error cannot be identified, the failure of the MS will be attributed to a sample matrix effect and any resulting limitations on the data shall be included in the report.

\section{Reporting}

The analytical data report shall be prepared in accordance with procedure PNL-ASO-058, Rev. 1, ASO Data Reporting, Section 5.3, Comprehensive Data Report. Please be sure to include action taken with respect to any identified unexpected results and discrepancies.

The Comprehensive Data Report contains three main parts; a data report cover page, a narrative, and the data summary. These elements are identified below; red text indicates project-driven scope. Black text is taken directly from the ASO procedure: PNL-ASO-058, Rev. 1

Data Report Cover Page Contents:

- Header identifying name/address of laboratory

- Customer Name:

- Project \#/WP \#(s):

- ASR \#(s): (ASR forms included date and time of sample receipt)

- Total \# Samples:

- Report Date:

- Report Revision Date: when applicable

- Filename(s): where data files can be accessed

- Dates of Sample Processing and Analysis:

- Procedure(s): Number, revision, and title (both sample processing and analysis)

- M\&TE used: (manufacturer/model) including instrument software (name, version and date), and serial number or property number) as applicable

- Reference Date (when applicable):

- Customer Sample ID and ASO/RPL ID Sample Numbers:

- Report Review and Approval:
Preparer
Date

(Printed name and signature of responsible individual) 
PNNL-25241

ASR 9916 Special Instructions

Page 6 of 9

Technical Reviewer

Date

(Printed name and signature of technical reviewer)

A case narrative describing the analysis, limitations on the analysis results, and QA/QC issues

Narrative Contents:

- Sample Description and Analyses

- Sample dissolution/preparation dates

- Sample Preparation (prior to receipt)

- Method-specific Sample preparation, Separation, Mounting and Counting or Analysis Methods as applicable

- Analysis dates

- Deviations from the written procedure, if any

- Reporting Basis/Units

- QC Criteria/Results

- Limitations of the Data

Interferences/Resolution

Uncertainty

- Comments

Data Summary Contents:

- $\quad$ Customer ID

- ASO/RPL Sample ID

- Analytes of Interest as per ASR form; opportunistic analyses as applicable with reporting units

- IDL, MDL, EQL or MDA as applicable

- $\quad$ Results and uncertainties

- $\quad$ QC results as applicable

- $\quad$ Reference date as applicable

- Additional information as needed - COC forms, Special Instructions, SOW

The following elements may be included in the final report or be traceable to the test results (usually by annotation on bench sheets) and be maintained as ASO records:

- identification of standards used

- identification of M\&TE used

- records of daily check weight tracking

- signature and date of person who performed the test and recorded the data

- analytical bench sheets

- hand calculation review documentation.

Technical reviewers are required to be staff other than the analyst performing the work and knowledgeable of the area being reviewed. The technical review shall be completed and all reviewer issues resolved before reporting final results. Technical reviewers must receive a complete data package including narratives for review. A technical review consists of the following elements:

- evaluation of method and QC performance 
- evaluation of compliance with technical (including procedural) and QC requirements, as defined in the ASR

- verification of transcription accuracy

- check for correctness of calculations

- assuring the correct reporting units (and reference dates) are used

- evaluation of overall consistency and reasonableness of data

- evidence of implementation of appropriate corrective action, when necessary.

Analytical results shall be reported both in hard copy and electronically (including excel data files to support accurate data transcription into project records). Appropriately marked "Preliminary" data reports and electronic files shall be provided by the ASO Lead as soon as practical after completion of analysis. The final ASR data report shall be provided no later than the commitment date on the ASR.

Table 3. Method Detection Limits for Solids

\begin{tabular}{|c|c|c|}
\hline Analyte & Solids & Analysis Method \\
\hline & $\mu \mathrm{Ci} / \mathbf{g}_{(\mathrm{dry})}$ & \\
\hline${ }^{134} \mathrm{Cs}$ & $2.0 \mathrm{E}-01$ & \multirow{7}{*}{$\begin{array}{l}\text { GEA } \\
\text { (Reference date }=\text { date and time of the } \\
\text { first sample analysis measured by GEA.) }\end{array}$} \\
\hline${ }^{137} \mathrm{Cs}$ & $1.5 \mathrm{E}-02$ & \\
\hline${ }^{60} \mathrm{Co}$ & $1.0 \mathrm{E}-02$ & \\
\hline${ }^{152} \mathrm{Eu}$ & $1.5 \mathrm{E}+00$ & \\
\hline${ }^{154} \mathrm{Eu}$ & $1.5 \mathrm{E}+00$ & \\
\hline${ }^{155} \mathrm{Eu}$ & $2.0 \mathrm{E}+00$ & \\
\hline${ }^{241} \mathrm{Am}$ & $1.5 \mathrm{E}+01$ & \\
\hline${ }^{241} \mathrm{Am}$ & $1.0 \mathrm{E}-03$ & \multirow{4}{*}{ Separation and AEA } \\
\hline${ }^{238} \mathrm{Pu}$ & $1.0 \mathrm{E}-03$ & \\
\hline${ }^{239+240} \mathrm{Pu}$ & $1.0 \mathrm{E}-03$ & \\
\hline${ }^{237} \mathrm{~Np}$ & $1.0 \mathrm{E}-03$ & \\
\hline${ }^{90} \mathrm{Sr}$ & $1.0 \mathrm{E}+00$ & Separation and proportional counting \\
\hline \multicolumn{3}{|c|}{$\begin{array}{l}\text { Note: The detection limits (DL) shown in this table are based on dry mass, whereas the DL in } \\
\text { the Quality Assurance Project Plan/Sampling and Analysis Plan (QAPjP/SAP, KBC-33786, } \\
\text { Rev. 2) are based on settled solids (wet) mass basis. These DL values are therefore, tighter } \\
\text { than those in the QAPjP/SAP. }\end{array}$} \\
\hline
\end{tabular}


PNNL-25241

ASR 9916 Special Instructions

Page 8 of 9

Table 4. Analytical Quality Control Acceptance Criteria

\begin{tabular}{|c|c|c|c|c|}
\hline \multirow[t]{2}{*}{ Analyte } & \multirow[t]{2}{*}{ Analytical Technique } & $\begin{array}{l}\text { LCS or BS \% } \\
\text { Recovery }^{(a)}\end{array}$ & $\begin{array}{c}\text { Matrix Spike \% } \\
\text { Recovery }^{(b)}\end{array}$ & \multirow{2}{*}{$\begin{array}{c}\text { Duplicate } \\
\text { RPD }^{(\mathbf{c})}\end{array}$} \\
\hline & & \multicolumn{2}{|c|}{ Post-digestion spike } & \\
\hline $\begin{array}{l}\text { Pu isotopes } \\
\left.\text { (spike material is }{ }^{239} \mathrm{Pu}\right)\end{array}$ & AEA & $80-120 \%$ & $75-125 \%$ & $\leq 20 \%$ \\
\hline${ }^{241} \mathrm{Am}$ & AEA & $80-120 \%$ & $75-125 \%$ & $\leq 20 \%$ \\
\hline${ }^{237} \mathrm{~Np}$ & AEA & $80-120 \%$ & $75-125 \%$ & $\leq 20 \%$ \\
\hline${ }^{90} \mathrm{Sr}$ & Proportional counting & $75-125 \%$ & $75-125 \%$ & $\leq 20 \%$ \\
\hline As identified in Table 3 & GEA & $\begin{array}{l}\text { Counter control } \\
\text { source is used }^{(d)}\end{array}$ & N/A & $\leq 20 \%$ \\
\hline
\end{tabular}

N/A - not applicable

Footnotes:

(a) LCS = Laboratory Control Standard; BS = Blank Spike. A laboratory control sample (LCS) or blank spike (BS) samples are used to monitor the effectiveness of the sample preparation process and are good indicators of method accuracy. Ideally, the LCS is a material similar to the sample being processed, containing the analytes of interest (e.g., standard reference material). An LCS, if available, shall be prepared with each batch of samples processed at the same time. When an appropriate LCS is not available, a BS shall be used in lieu of the LCS. A BS is distilled or deionized water or another suitable matrix spiked with the analytes of interest. It may not be possible to prepare a single BS that contains all analytes of interest (e.g., chemical incompatibility). In such cases, an agreement with the client shall be made to identify the analytes of interest used to prepare the BS, and more than one BS may be used. The BS and AS results are expressed as percent recovery; i.e., the amount measured, divided by the known concentration, multiplied by 100 .

(b) $\mathrm{MS}=$ matrix spike; AS = Analytical Spike. For some methods, the sample accuracy is expressed as the percent recovery of a matrix spike (MS) or analytical spike (AS) sample. Post-digestion spikes and analytical spikes are also included under these acceptance criteria. The spiked sample result is expressed as percent recovery; i.e., the amount measured less the amount in the sample, divided by the spike added, times 100 . One MS (or post spike or analytical spike [AS]) is performed per analytical batch. Samples are batched with similar matrices. For ICP analytes, the accuracy can also be determined based on use of serial dilutions. In cases where the ICP-OES MS concentration is low relative to the sample analyte concentration (resulting in meaningless recovery calculations), matrix effects will be evaluated from a post-digestion spike.

(c) RPD = Relative Percent Difference between the samples. Sample precision is estimated by analyzing replicates taken separately through preparation and analysis.

(d) Per RPG-CMC-450, Rev. 2, a counter control source is checked daily and must be within \pm 3 sigma or $\pm 3 \%$, whichever is greater, of the control value.

\section{References}

68122-TI-001, Rev. 0, Sandfilter Backwash Solids Consolidation

ASO-QAP-001, Rev. 9 or current revision, Analytical Support Operations Quality Assurance Plan

PNL-ASO-052, Rev. 2, Balance Performance Checks

PNL-ASO-058, Rev. 1, ASO Data Reporting

RPG-CMC-129, Rev. 0, $\mathrm{HNO}_{3}$-HCl Acid Extraction of Solids Using a Dry-Block Heater

RPG-CMC-422, Rev. 2, Solutions Analysis: Alpha Spectrometry 
RPG-CMC-450, Rev. 2, Gamma Energy Analysis (GEA) and Low-Energy Photon Spectrometry (LEPS)

RPG-CMC-474, Rev. 1, Measurement of Alpha and Beta Activity by Liquid Scintillation Spectrometry

RPG-CMC-476, Rev. 0, Strontium Separation using Eichrom Strontium Resin

RPG-CMC-496, Rev. 1, Coprecipitation Mounting of Actinides for Alpha Spectroscopy

RPG-CMC-4017, Rev. 0, Analysis of Environmental Water Samples for Actinides and Strontium90

Hanford Analytical Services Quality Assurance Requirements Document (HASQARD), 2007, DOE/RL-96-68, Revision 3, Department of Energy Richland Office, Richland Washington.

Hanford Analytical Services Quality Assurance Requirements Document (HASQARD), September 2014, DOE/RL-96-68, Revision 4, Department of Energy Richland Office, Richland Washington.

QAPjP/SAP, KBC-33786, Rev. 2. 2009. Quality Assurance Project Plan/Sampling and Analysis Plan for Sludge in the KW Engineered Containers. 
Battelle PNNL/RPL/ASO Mass Measurement Analysis Report

P.O. Box 999, 902 Battelle Blvd., Richland, Washington 99352

\section{Mass Measurements}

\begin{tabular}{|l|l|}
\hline Project / WP\#: & $68122 / \mathrm{N} 51383$ \\
\hline ASR\#: & 9916 \\
\hline Client: & S. Fiskum \\
\hline Total \# of Samples: & 2 \\
\hline
\end{tabular}

\begin{tabular}{|c|c|}
\hline Client Sample ID & RPL Number \\
\hline $68122-\mathrm{TI}-001-\mathrm{F}$ & $16-0032$ \\
\hline $68122-\mathrm{TI}-001-\mathrm{G}$ & $16-0032$ (dup) \\
\hline
\end{tabular}

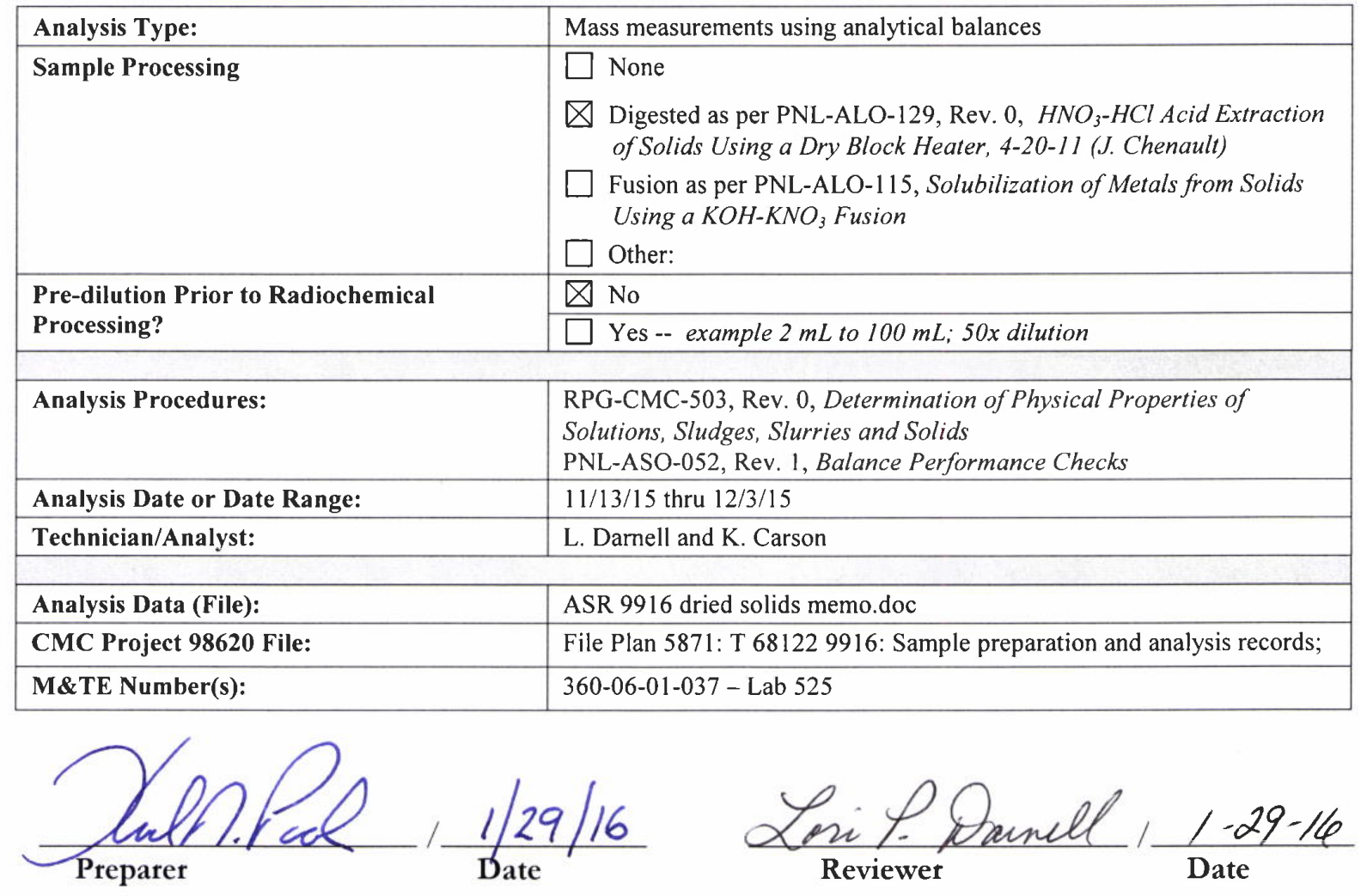




\begin{tabular}{llll}
\hline Date: & December 21, 2015 & Project No: & 68122 \\
To: & Sandy Fiskum & & \\
From: & $\begin{array}{l}\text { Karl Pool } \\
\text { Initial dried solids and residual } \\
\text { dried solids masses for ASR } \\
9916\end{array}$ & Internal Distribution: & File/LB \\
Subject: & & \\
\hline
\end{tabular}

Prior to ASO sample digestion, the slurry samples for ASR 9916 were dried to constant weight in pretared $15 \mathrm{~mL}$ glass centrifuge tubes in lab 525 using a drying oven. The dry masses of the solids prior to digestion are presented in the Table 1. The dried solids were then acid digested using ASO procedure PNL-ALO-129, " $\mathrm{HNO}_{3}-\mathrm{HCl}$ Acid Extraction of Solids Using a Dry-Block Heater". The mixed acid digestion did not completely dissolve the solids. An additional $5 \mathrm{~mL}$ of concentrated nitric acid was added to try and dissolve the residual. At the completion of the acid digestion, significant residual solids remained that were brown and flocculent. The acid digestions were then centrifuged, the liquid removed and solids rinsed several times with $0.5 \mathrm{M} \mathrm{HNO}_{3}$. The rinses were collected and combined with the initial acid digestate. The solids were then transferred to a glass vial for drying. The liquid fraction was left standing for several days before bringing the solution to final volume $(100 \mathrm{~mL})$. Prior to dilution to final volume, the solutions contained a slight wispy fine precipitate that appeared to dissolve upon final dilution. The diluted samples were left to stand overnight to verify no further precipitate developed.

The residual solids were dried in the lab 525 drying oven. The mass of the residual is very small in comparison to the vial mass the solids are dried in. The reported residual solid weights are the average of the two dry weights obtained on different days. The masses are included in Table 1.

Table 1 - Dried solids masses

\begin{tabular}{|l|c|c|c|}
\hline \multicolumn{1}{|c|}{ RPL ID } & Client ID & $\begin{array}{c}\text { Initial dried solids mass } \\
\text { prior to digestion (grams) }\end{array}$ & $\begin{array}{c}\text { Final dried solids mass remaining } \\
\text { after digestion (grams) }\end{array}$ \\
\hline $16-0032$ & $\mathbf{6 8 1 2 2 - T I - 0 0 1 - F}$ & $\mathbf{0 . 0 5 4 5}$ & $\mathbf{0 . 0 0 3 9}$ \\
\hline $16-0032$ (dup) & $\mathbf{6 8 1 2 2 - T I - 0 0 1 - G}$ & $\mathbf{0 . 0 5 6 8}$ & $\mathbf{0 . 0 0 3 9}$ \\
\hline
\end{tabular}


Battelle PNNL/RPL/ASO Radiochemistry Analysis Report

P.O. Box 999, 902 Battelle Blvd., Richland, Washington 99352

\section{Gamma Energy Analysis (GEA)}

$\begin{array}{ll}\text { Project / WP\#: } & 68122 / \mathrm{N} 51383 \\ \text { ASR\#: } & 9916.00 \\ \text { Client: } & \text { SK Fiskum } \\ \text { Total Samples: } & 2\end{array}$

\begin{tabular}{|c|c|}
\hline RPL ID & Client Sample ID \\
\hline $16-0032$ & $68122-$ TI-001-F \\
\hline $16-0032$ DUP & $68122-$ TI-001-G \\
\hline
\end{tabular}

\begin{tabular}{|c|c|}
\hline Analysis Type: & GEA- for all positively measured or non-detected isotopes \\
\hline $\begin{array}{l}\text { Sample Processing Prior to Radiochemical } \\
\text { Processing/Analysis }\end{array}$ & $\begin{array}{l}\square \text { None } \\
\square \text { Digested as per RPG-CMC-129, Rev. } 0 \mathrm{HNO}_{3} \text { - } \mathrm{HCl} \text { Acid Extraction of } \\
\text { Solids Using a Dry Block Heater, Analyst: LP Darnell (11/18/15) \& } \\
\text { KJ Carson (11/24/15) } \\
\square \text { Fusion as per RPG-CMC-115, Solubilization of Metals from Solids } \\
\text { Using a } \mathrm{KOH}-\mathrm{KNO}_{3} \text { Fusion } \\
\square \text { Other: } \\
\text { Preparation may have also involved attaining a GEA geometry that is } \\
\text { compatible with the calibration geometry. }\end{array}$ \\
\hline Analysis Procedure: & $\begin{array}{l}\text { RPG-CMC-450, Rev. } 2 \text { Gamma Energy Analysis (GEA) and Low-Energy } \\
\text { Photon Spectrometry (LEPS) }\end{array}$ \\
\hline Reference Date: & November 24,2015 \\
\hline Analysis Date or Date Range: & November 24, 2015 and December 4, 2015 \\
\hline Technician/Analyst: & KJ Carson, T Trang-Le, L. Darnell \\
\hline Rad Chem Electronic Data File: & RPG-RC1/6-0032 Fiskum.xlsx \\
\hline ASO Project 98620 File: & $\begin{array}{l}\text { File Plan 587I, T4.4 Technical (Radiochemistry), Gamma Calibration, } \\
\text { daily checks, and maintenance records; and T3 standard certificates and } \\
\text { preparation. Also, balance calibration and performance check records. }\end{array}$ \\
\hline M\&TE Number(s): & $\begin{array}{l}\text { Detectors } C, G, M \text { and } N \text { ( } M \& T E \text { unique identifiers in attached } \\
\text { supporting documents) }\end{array}$ \\
\hline
\end{tabular}
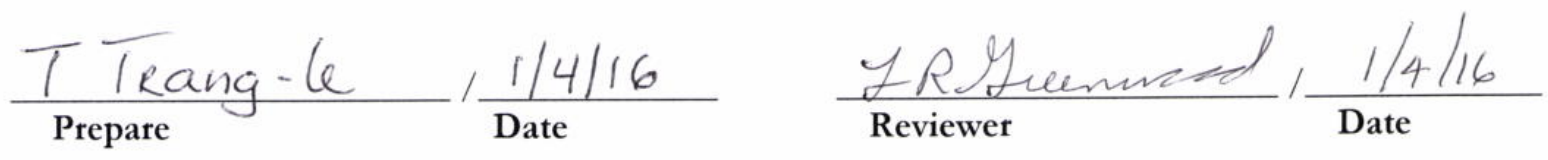
PNNL-25241

Battelle PNNL/RSE/ASO Radiochemistry Analysis Report

\section{SAMPLE RESULTS}

Activities for all gamma emitters detected in these samples are presented in an attached Excel spreadsheet for ASR 9916.00. All sludge data are reported in units of $\mu \mathrm{Ci} / \mathrm{g}_{\text {dry }}$ and all residual solids are reported as $\mu \mathrm{Ci} / \mathrm{g}_{\text {residual }}$ with estimates of the total propagated uncertainty reported at the 1 -sigma level. The $\mathrm{K}$ Basin ASR specifies that the residual solids GEA analytes are to be reported as $\mu \mathrm{Ci} / \mathrm{g}$ residual, where $\mathrm{g}$ residual is the mass of dried residual solids that did not dissolve during acid digestion.

ASO Project File, ASR-9916 has been created for this report including all appropriate supporting records which may include the Pipette Performance Check Sheet, Standard Certificates, Laboratory Bench Sheets and Gamma Energy Analysis printouts. Detector calibration records, control charts and balance calibration records can be found in the ASO Records.

\section{Sample Preparation, Separation, Mounting and Counting Methods}

K-Basin back wash filter samples were prepared in lab 525 under Analytical Service Request (ASR) 9916 for radioanalytical analyses.

ASO received two samples (sample and duplicate) for the project, each sample in a $15 \mathrm{~mL}$ glass centrifuge cone. The solids were dried to constant weight, then quantitatively transferred to a plastic digestion tube where the dried solids were leached with hot dilute nitric and hydrochloric acids per procedure RPG-CMC-129. The leachate solution was used for radioanalytical analyses, only GEA data are included in this report. At the completion of the acid digestion, residual unsolubilized material remained. The residual solids were transferred to a clean $22 \mathrm{~mL}$ glass scintillation vial, dried to constant weight and submitted for GEA analyses. The residual solids do have measurable activity and those results are included in this report.

Quality control (QC) samples prepared include duplicates of all samples as well as a Reagent blank. The quality control (QC) sample results for each of the isotopes measured above background have been evaluated and are discussed below. A summary of the GEA analysis results, including QC sample performance, is given in the attached Data Report.

The following is a list of QC sample results relative to both the $\mathrm{K}$ Basin data quality objectives and the ASO Quality Assurance (QA) Plan (ASO-QAP-001, Rev. 9); in many cases the DQOs are the same. In cases where there are differences in the DQOs, the K Basin DQO takes precedence for data reporting.

\section{QUALITY CONTROL RESULTS}

Tracer:

Tracers are not used for ASO GEA methods.

Process Blank (PB):

The ASO-QAP-001 requires the activities of the gamma emitting isotopes of interest measured in the PB to be within the acceptance criteria of less than $5 \%$ of the sample isotope concentration or less than sample minimum detectable activity (MDA) - (See comments) For isotopes of interest that were not detected in the PB and samples, the PB minimum detectable concentration (MDC) was less than the MDC measured in the samples. The isotopes of interest that were detected in the samples above the MDC are all greater than $5 \%$ of the activity level present in the PB.

Page 2 of 4 
PNNL-25241

Battelle PNNL/RSE/ASO Radiochemistry Analysis Report

\section{$\underline{\text { Required Detection Limits }}$}

The ASR required detection limits were met for all analytes for both the digestate and residual solid samples. The GEA detection limit requirements are shown on the summary data sheets.

Blank Spike (BS)/Laboratory Control Sample (LCS)/ Matrix Spike (MS):

There are no BS, LCS or MS samples analyzed for ASO GEA analyses. Instrument performance is assessed by the analyses of daily control counts and weekly background counts, as discussed below.

Duplicate Relative Percent Difference (RPD):

Duplicate results are required to agree within $<20 \%$ relative percent difference, taking into consideration the statistical uncertainties in the data. The statistical uncertainties in the data are used to calculate the 2 -sigma uncertainty ( $2 \mathrm{~s} \%$ value listed on the report). RPD values below this 2-sigma value are acceptable since the duplicate results agree within the measured 1-sigma uncertainties. Duplicate results for the sample ranged from 5\% to $21 \%$. Eu-152 has a duplicate RPD of $21.4 \%$ which exceeds the acceptance criteria of $<20 \%$ RPD. However, this is acceptable since the RPD is less than the 2-sigma value of $34.0 \%$. Residual solids duplicate RPD range from $5 \%$ to $36 \%$. The RPD for Sb- 125 is $36.3 \%$; however, the 2 -sigma value is $42.9 \%$. Am- 241 has a duplicate RPD of $34.5 \%$ which exceeds the acceptance criteria of $<20 \%$ RPD. In this case the 2 sigma value is $5.1 \%$ indicating that the Am-241 duplicate measurements exceed the measured 2sigma statistical difference.

Replicate Relative Standard Deviation (RSD):

Replicate results are required to agree within $<20 \%$ relative percent difference or within 2 -sigma standard deviation taking into account the uncertainties for each measurement.

\section{Instrument Calibration and Quality Control}

Gamma detectors are calibrated using multi-isotope standards that are NIST-traceable and prepared in the identical counting geometry to samples for all detectors. Counter control sources containing Am-241, Cs- 137 and Co-60 are then analyzed daily before the use of each detector. There is a K Basin DQO that is referenced to ASO procedure RPG-CMC-450, that requires that a counter control source is checked daily and must be within \pm 3 sigma or $\pm 3 \%$ of the control value, whichever is greater. Gamma counting was not performed unless the control counts were within the required limits. Background counts are performed on all gamma detectors at least weekly for either an overnight or weekend count. The most recent background is subtracted from all sample counts.

\section{Assumption and Limitations of the Data}

The digestion was performed exactly as stated in procedure RPG-CMC-129. Following the digestion process, each sample had a visible quantity of residual solids. The residual solids have measureable activity. The GEA results for the residual solids are included in this report.

\section{Interferences/Resolution}

None. 
PNNL-25241

\section{Battelle PNNL/RSE/ASO Radiochemistry Analysis Report}

\section{Uncertainty}

For gamma counting, the uncertainty in the counting data, photon abundance and the nuclear half-life are included in the calculation of the total uncertainty along with a systematic uncertainty for sample preparation. The Canberra Genie software includes both random and systematic uncertainties in the calculation of the total uncertainties which are listed on the report. We conservatively estimate that $2 \%$ is the lowest uncertainty possible for our GEA measurements taking into account systematic uncertainties in gamma calibration standards.

Solid residues were placed in glass LSC vials. Unlike liquid samples, their geometries could not be carefully controlled to match the calibration standards. The solids samples were counted at about $\sim 6 \mathrm{~cm}$ from the detector face to minimize the differences between the sample geometry and the calibration geometry. Calibrations are performed using water samples whereas the samples consisted of unknown undissolved solids (The exact sample mineralogical composition and associated density were not known). The small sample size $(<1 \mathrm{~g})$ minimized the gamma absorption effects; therefore, density corrections were not applied.

\section{Comments}

1. The results account for all dilution factors resulting from sample processing.

2. Minimum Detectable Activity (MDA) and Minimum Detectable Concentration (MDC). Sample results are compared to the process blank results to evaluate if the blank contains $5 \%$ or more of the analyte of interest. When samples undergo digestion and/or dilution (process factors), the MDA must be adjusted for the process factors to accurately compare activity levels in the blank to activity levels in the samples. Process blank results have been adjusted for digestion and/or process factors for evaluation of the $5 \%$ criteria.

3. An occurrence report documents DQO related issue(s) with this report: RPD's outside the $<20 \%$ requirement, OR-98620-12-23-15

Attachment: Data Report Sample Results for ASR 9916. 
PNNL-25241

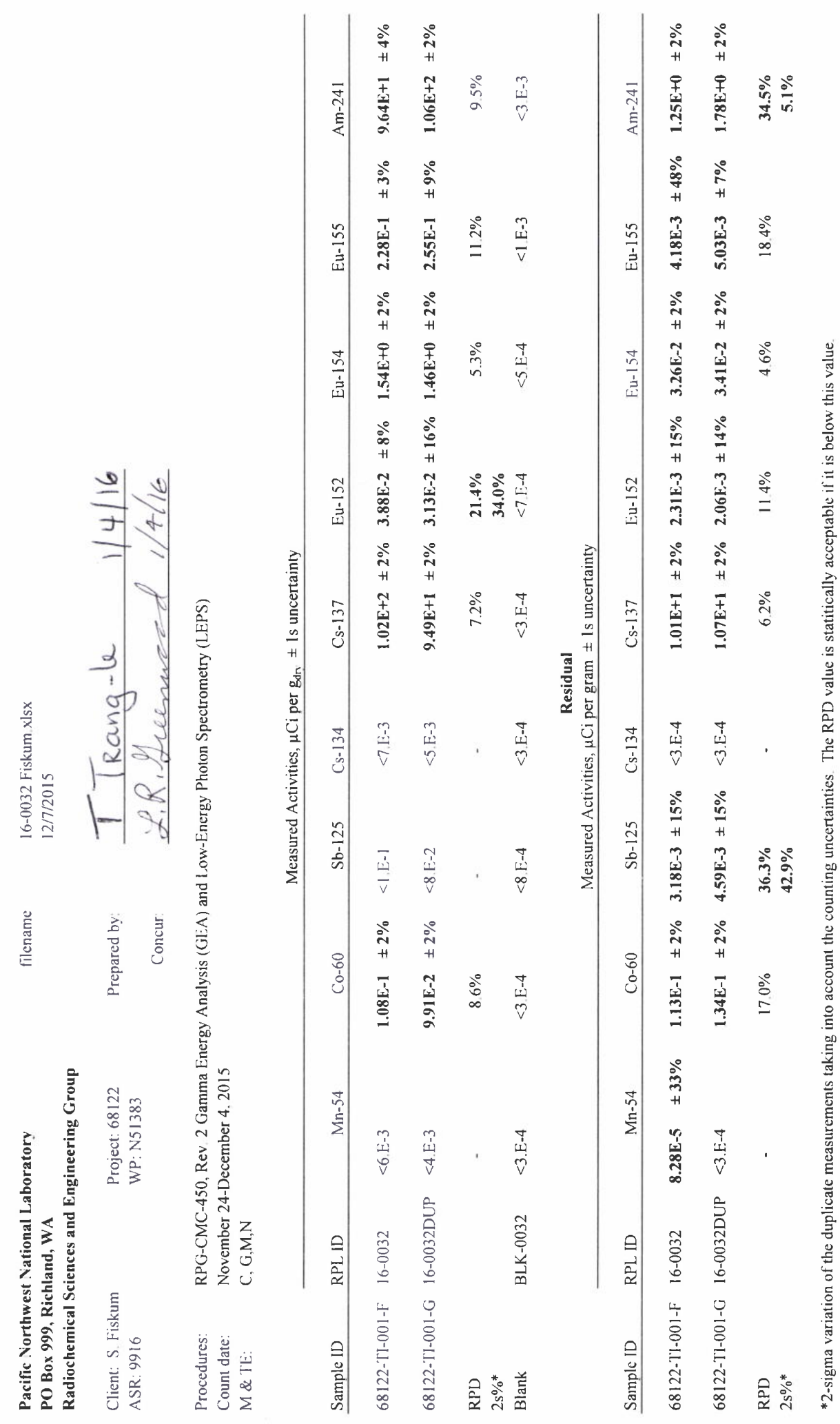




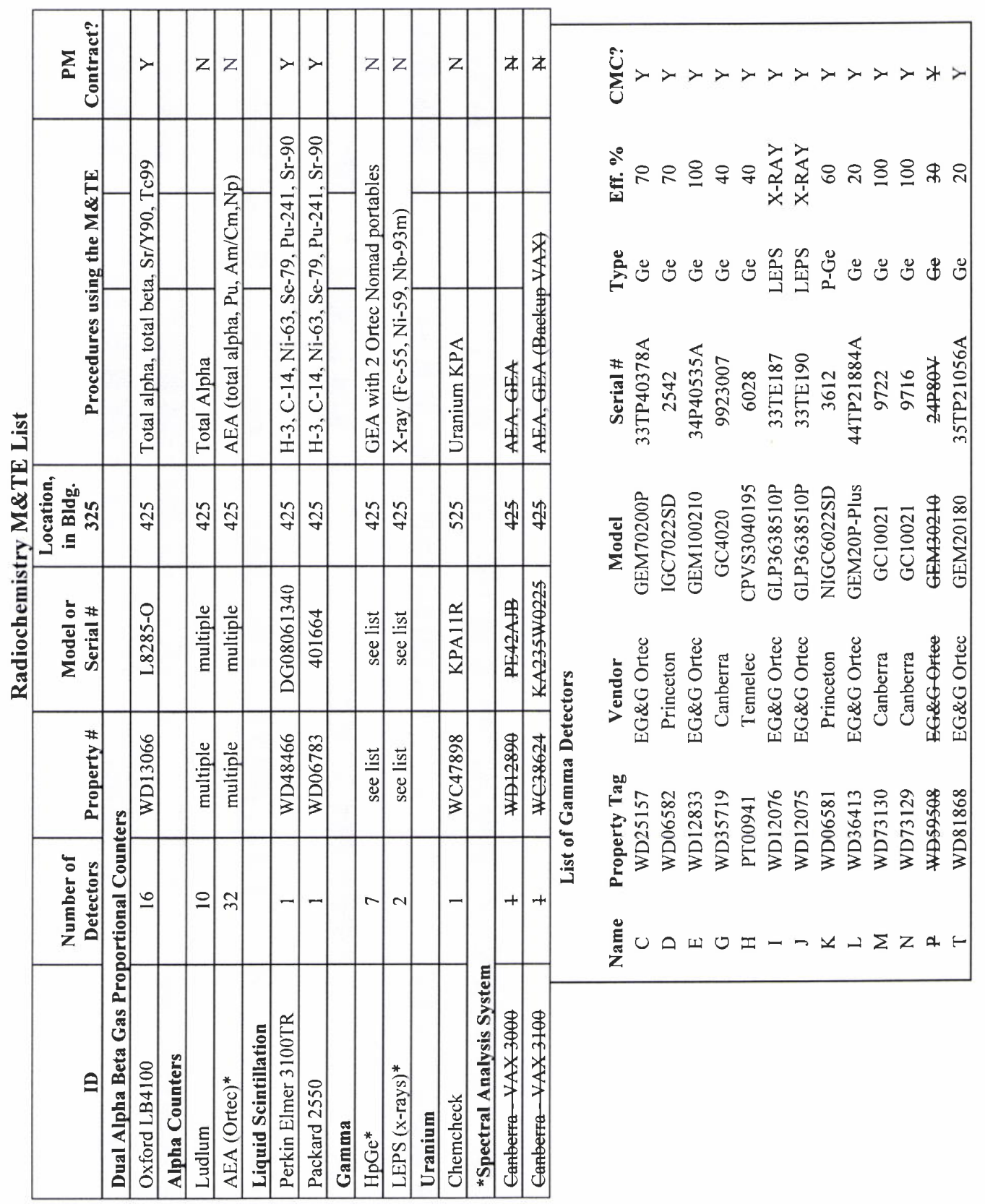




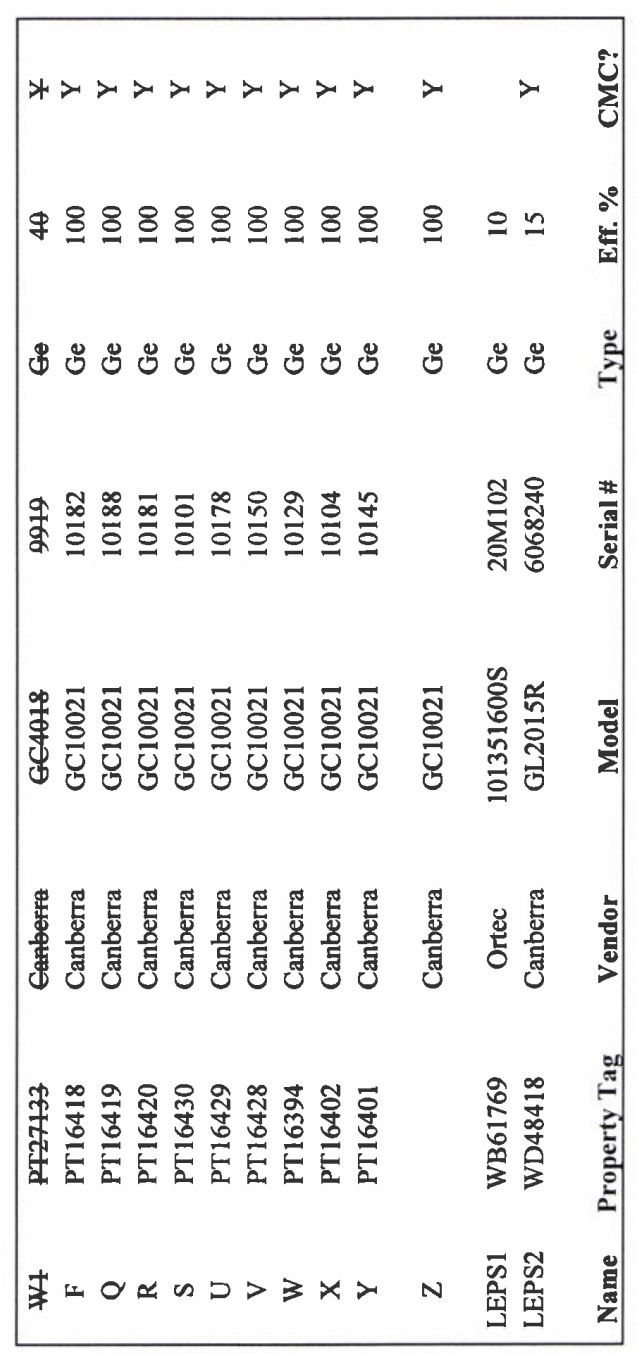

B. 23 
PNNL-25241

Battelle PNNL/RPL/ASO Radiochemistry Analysis Report

P.O. Box 999, 902 Battelle Blvd., Richland, Washington 99352

\section{Plutonium 238, 239+240 Analysis}

Revision 1

\begin{tabular}{|l|l|}
\hline Project /WP\#: & $68122 / \mathrm{N} 51383$ \\
\hline ASR\#: & 9916 \\
\hline Client: & SK Fiskum \\
\hline Total \# of Samples: & 2 \\
\hline
\end{tabular}

\begin{tabular}{|c|c|}
\hline RPL ID & Client Sample ID \\
\hline $16-0032$ & $68122-\mathrm{TI}-001-\mathrm{F}$ \\
\hline 16-0032 DUP & $68122-\mathrm{TI}-001-\mathrm{G}$ \\
\hline
\end{tabular}

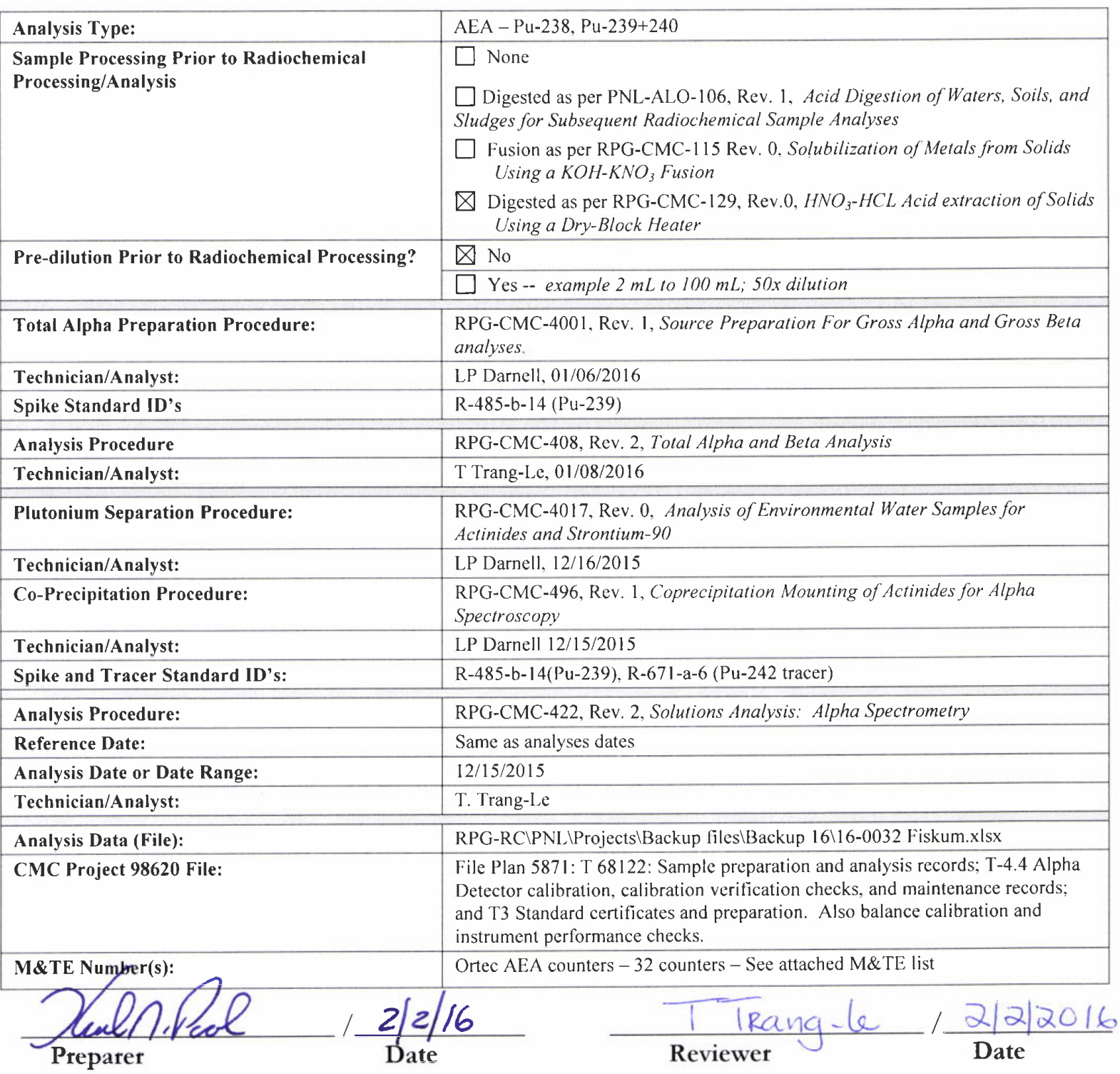


PNNL-25241

Battelle PNNL/RPL/ASO Radiochemistry Analysis Report

Revision 1 - Report revised to report the acid digestion blank data instead of the lab prepared blank data.

\section{Sample Results}

See attached data report, Sample Results for ASR 9916. All data are reported in units of $\mu$ Ci per $g_{d r y}$ with a $1-\sigma$ uncertainty.

\section{Sample Preparation, Separation, Mounting and Counting Methods}

Two wet solids samples submitted under Analytical Service Request (ASR) 9916 were analyzed for analyzed for plutonium by Alpha Spectrometry. Prior to acid digestion, the wet solids were dried to constant weight. The dried solids samples were then acid digested using procedure RPG-CMC-129, " $\mathrm{HNO}_{3}-\mathrm{HCl}$ Acid Extraction of Solids Using a Dry-Block Heater". All the samples were prepared in laboratory 420. The leachate solution was used for radioanalytical analyses; only Pu-AEA data are included in this report.

Following the digestion process, the $\mathrm{Pu}$ was separated from the leachate by anion exchange using procedure RPG-CMC-4017. The separated Pu fraction was then mounted for alpha spectrometry by co-precipitation using procedure RPG-CMC-496, and then counted using alpha spectrometry using procedure RPC-CMC-422. The samples were counted on December 15, 2015; no decay corrections were made.

Although not formally requested by the ASR, gross alpha and beta analyses were performed on each sample and duplicate to obtain information to estimate aliquot sizes for other analyses and for checking the internal consistency of the alpha isotopic data. The gross alpha results are included in the data tables. Gross alpha activity were measured by evaporating small aliquots of leachate onto counting planchets per procedure RPG-CMC-4001 and counting per procedure RPG-CMC-408.

\section{QUALITY CONTROL RESULTS}

Quality control (QC) samples prepared in laboratory 420 include a process blank (PB) and sample duplicates. Additional QC samples were prepared prior to alpha counting including a laboratory blank, a reagent blank spike (RS, $\mathrm{Pu}-239$ ), and addition of $\mathrm{Pu}-239$ standard to an aliquot of the sample digestate selected as the matrix spike (MS).

The QC sample results for Pu-AEA have been evaluated and are discussed below. A summary of the PuAEA analysis results, including QC sample performance, is given in the attached data report.

\section{Tracer:}

The Pu-242 tracer is added to every sample after appropriate dilution and prior to plutonium separations. The use of a $\mathrm{Pu}-242$ tracer corrects for radiochemical yield and mathematically removes the detector counting efficiency from the results calculations. Tracer recovery is required to be high enough to provide acceptable counting statistics. The $\mathrm{Pu}-242$ tracer counting statistics were acceptable for all samples. The tracer recoveries ranged from $95 \%$ to $118 \%$. 


\section{Laboratory Preparation Blank (PB):}

The detection limit achieved in the laboratory preparation blank for Pu-238 is $2.37 \mathrm{E}-4 \mu \mathrm{Ci}$ per $\mathrm{g}_{\mathrm{dry}}$ and for $\mathrm{Pu}-239+240$ is $9.59 \mathrm{E}-4 \mu \mathrm{Ci}$ per $\mathrm{g}_{\mathrm{dry}}$. The activity level of the plutonium alpha emitters present in the blank is well below $5 \%$ of the activity present in the sample, meeting the acceptance criteria of less than $5 \%$ of the sample activity or less than the sample MDA.

\section{Blank Spike (BS)/Reagent Spike (RS):}

The BS recovery of $104 \%$ (Pu-239) meets the acceptance criteria of $80 \%$ to $120 \%$ recovery.

\section{Matrix Spike (MS):}

The MS recovery of $101 \%$ (Pu-239) meets the acceptance criterion of $75 \%$ to $125 \%$ recovery. Note: The MS sample was prepared after digestion, by adding a known quantity of Pu-239 standard to a diluted aliquot of the digestate. Sample number 16-0032 (68122-TI-001-F) was selected as the matrix spike sample.

\section{Laboratory Duplicate - Relative Percent Difference (RPD):}

For sample $68122-\mathrm{TI}-001-\mathrm{F} / \mathrm{G}$, the Pu-238 sample and duplicate RPD of $1 \%$ within the acceptance limit of $\leq 20 \%$ RPD for. The RPD for Pu- $239+240$ is $0.4 \%$, within the acceptance limit of $\leq 20 \%$ RPD.

\section{Instrument Quality Control}

Alpha counters receive initial calibration with NIST traceable sources to determine the counter efficiency. When internal tracers are not used, the counter efficiency is used in calculation of final results.

Detector backgrounds are determined every 4 weeks or after the last analytical run, whichever is longer. Detector background counts are subtracted from all subsequent sample counts. A process blank is analyzed with each analytical batch to evaluate for contamination in the sample preparation process.

\section{Assumption and Limitations of the Data}

None

Attachment: Data Report -- Sample Results for ASR 9916. 
PNNL-25241

Battelle PNNL/RPL/ASO Radiochemistry Analysis Report

P.O. Box 999, 902 Battelle Blvd., Richland, Washington 99352

\section{Neptunium 237 Analysis Revision 1}

\begin{tabular}{|l|l|}
\hline Project / WP\#: & $68122 / \mathrm{N} 51383$ \\
\hline ASR\#: & 9916 \\
\hline Client: & SK Fiskum \\
\hline Total \# of Samples: & 2 \\
\hline
\end{tabular}

\begin{tabular}{|c|c|}
\hline Sample IDs & RPL Number \\
\hline $68122-$ TI-001-F & $16-0032$ \\
\hline $68122-$ TI-001-G & $16-0032$ DUP \\
\hline
\end{tabular}

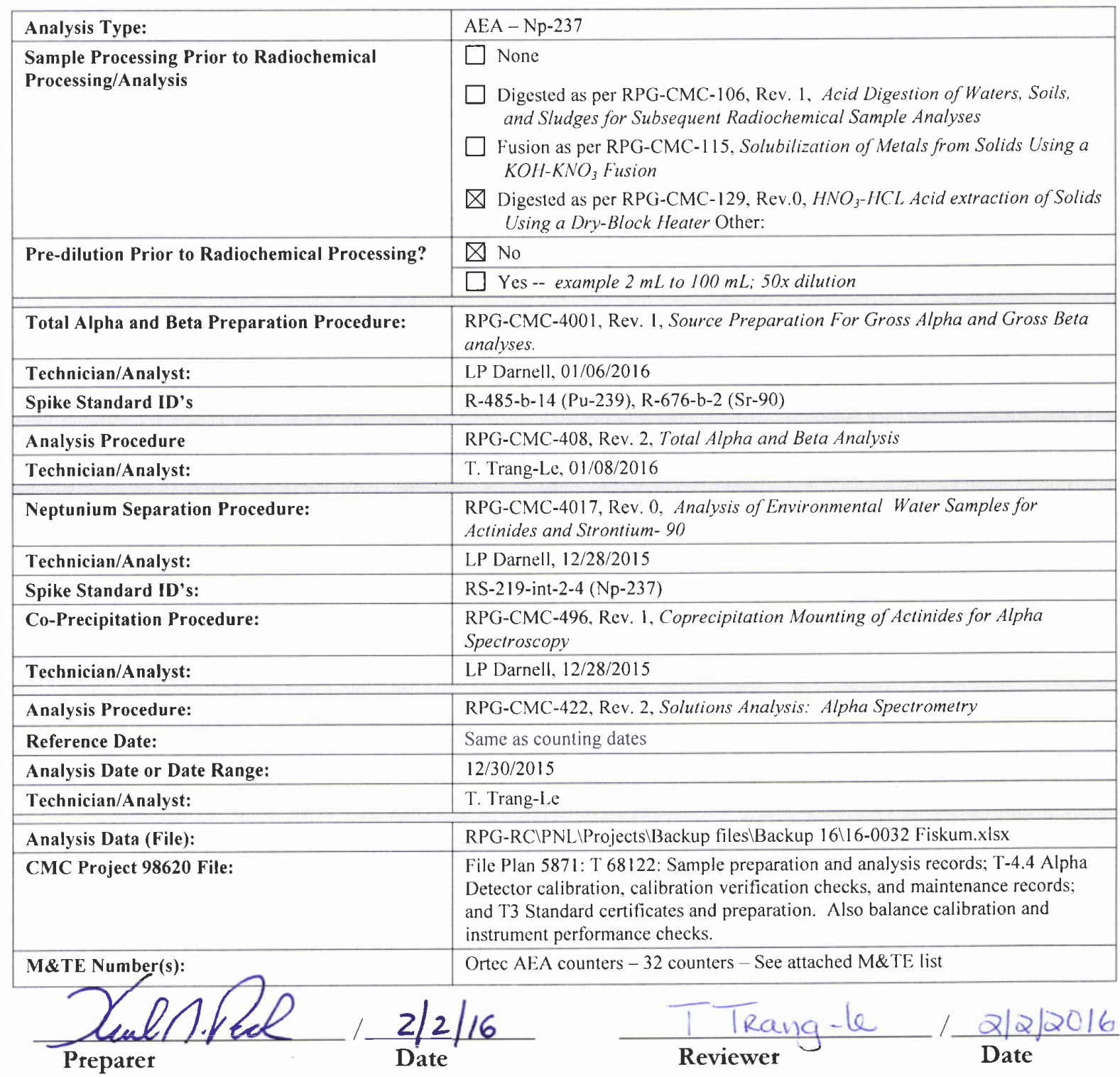


PNNL-25241

\section{Battelle PNNL/RPL/ASO Radiochemistry Analysis Report}

Revision 1 - Report revised to clarify the matrix spike QC discussion.

\section{Sample Results}

See attached data report, Sample Results for ASR 9916. All data are reported in units of uCi per $\mathrm{g}_{-}$dry with a $1-\sigma$ uncertainty unless noted otherwise (see comments).

\section{Sample Preparation, Separation, Mounting and Counting Methods}

Two wet solids samples submitted under Analytical Service Request (ASR) 9916 were analyzed for analyzed for neptunium by Alpha Spectrometry. Prior to acid digestion, the wet solids were dried to constant weight. The dried solids samples were then acid digested using procedure RPG-CMC-129, " $\mathrm{HNO}_{3}-\mathrm{HCl}$ Acid Extraction of Solids Using a Dry-Block Heater". All the samples were prepared in laboratory 420. The leachate solution was used for radioanalytical analyses; only Np-AEA is reported in this report.

Following the digestion process, the $\mathrm{Np}$ was separated from the sludge leachate using anion exchange chromatography using procedure RPG-CMC-4017. The separated Np fraction was mounted for alpha spectrometry by co-precipitation using procedure RPG-CMC-496, and then counted by alpha spectrometry using procedure RPC-CMC-422.

Although not formally requested by the ASR, gross alpha and gross beta analyses were performed on each sample to obtain information to estimate aliquot sizes for other analyses and for checking the internal consistency of the $\mathrm{Np}$ alpha isotopic data. The gross alpha and gross beta results are included in the data tables as supplemental information only. Gross alpha and gross beta activity were measured by evaporating small aliquots of leachate onto counting planchets per procedure RPG-CMC-4001 and counting per procedure RPG-CMC-408.

\section{QUALITY CONTROL RESULTS}

Quality control (QC) samples include an acid digestion blank, sample duplicate. Additional QC samples were prepared prior to separations; these include a laboratory separation blank, a reagent blank spike (BS), and a matrix spike (MS) made by adding Np-237 standard to a diluted sample.

\section{Tracer:}

Tracer is not used for analyses of $\mathrm{Np}$.

Laboratory Preparation Blank (PB) and Laboratory separations blank (LB):

The Np-237 activity measured in the PB is required to be within the acceptance criteria of less than sample minimum detectable activity (MDA) or less than $5 \%$ of the sample isotope concentration. The Np-237 PB is <MDA; thus meeting the acceptance criteria. There are no acceptance criteria for LB.

\section{Blank Spike (BS) - reagent spike (RS):}

The RS recovery of $93 \%$ meets the acceptance criteria of $80 \%$ to $120 \%$ recovery. 
PNNL-25241

\title{
Battelle PNNL/RPL/ASO Radiochemistry Analysis Report
}

\author{
Matrix Spike (MS):
}

The MS recovery of $96 \%$ meets the acceptance criterion of $75 \%$ to $125 \%$ recovery. Note: the MS sample was prepared "after" digestion, by adding a known Np-237 standard quantity to an aliquot of the leachate. Sample number 16-0032 (68122-TI-00l-F) was selected as the matrix spike sample.

\section{Duplicate -- Relative Percent Difference (RPD):}

Duplicate results are required to agree within $\leq 20 \%$ RPD. Duplicate results were $15 \%$ RPD. The $\mathrm{Np}-237$ activity detected in the samples all have $1-\sigma$ counting error of $10 \%$ or greater. $1-\sigma$ counting error at these levels indicates the activity measured in the samples is nearing the minimum detectable activity for the samples.

\section{Instrument Quality Control}

Alpha counters undergo calibration annually to determine the counter's efficiency over the normal calibration range of 3 to $6 \mathrm{MeV}$. The vendor software determines a constant detector efficiency for this energy range. Np samples are counted and results calculated using the established detector efficiency.

Detector backgrounds are determined every 4 weeks or after the last analytical run, whichever is longer. Detector background counts are subtracted from all subsequent sample counts. A process blank is analyzed with each analytical batch to evaluate for contamination in the sample preparation process.

\section{Assumption and Limitations of the Data}

Undissolved residue remained after the completion of the acid digestion/leach of all sludge samples.

\section{Comments}

1. The results have been corrected for all dilution factors resulting from sample processing.

2. Post-Digestion Spike (PS) - A spike made after the initial sample preparation (e.g., fusion, digestion, or leach) is considered a PS. When extremely radioactive samples are analyzed, most of the radioanalytical spikes are made after the sample preparation (to avoid excessive consumption of spike and avoid creating unnecessary waste) and are post-digestion spikes. The MS prepared with this batch of sample is considered a PS, since the Np-237 spike was not added prior to the digestion process.

3. The 1-sigma uncertainty represents the total propagated error associated with processing and counting operations and include; weighing errors, volume uncertainties, and counting error.

4. The sample results are compared to the process blank to evaluate if the blank contains $5 \%$ or more of the measured isotope; the process blank result has been adjusted for all processing factors for evaluation of the $5 \%$ criterion.

5. The Laboratory Blank (LB) is prepared using laboratory reagents and provides data on the cleanliness of the radiochemistry preparation/separation processes. LB results are not normalized to processing or dilution factors associated with the samples. 
PNNL-25241

\section{Battelle PNNL/RPL/ASO Radiochemistry Analysis Report}

6. The sample results are compared to the process blank to evaluate if the blank contains $5 \%$ or more of the measured isotope; the process blank result has been adjusted for all processing factors for evaluation of the $5 \%$ criterion.

Attachment: Data Report -- Sample Results for ASR 9916. 
PNNL-25241

Battelle PNNL/RPL/ASO Radiochemistry Analysis Report

P.O. Box 999, 902 Battelle Blvd., Richland, Washington 99352

\section{Am-241 Analysis}

Revision 2

\begin{tabular}{|l|l|}
\hline Project /WP\#: & $68122 /$ N51383 \\
\hline ASR\#: & 9916 \\
\hline Client: & SK Fiskum \\
\hline Total \# of Samples: & 2 \\
\hline
\end{tabular}

\begin{tabular}{|c|c|}
\hline RPL ID & Client Sample ID \\
\hline $16-0032$ & $68122-T I-001-F$ \\
\hline $16-0032$ DUP & $68122-T I-001-G$ \\
\hline
\end{tabular}

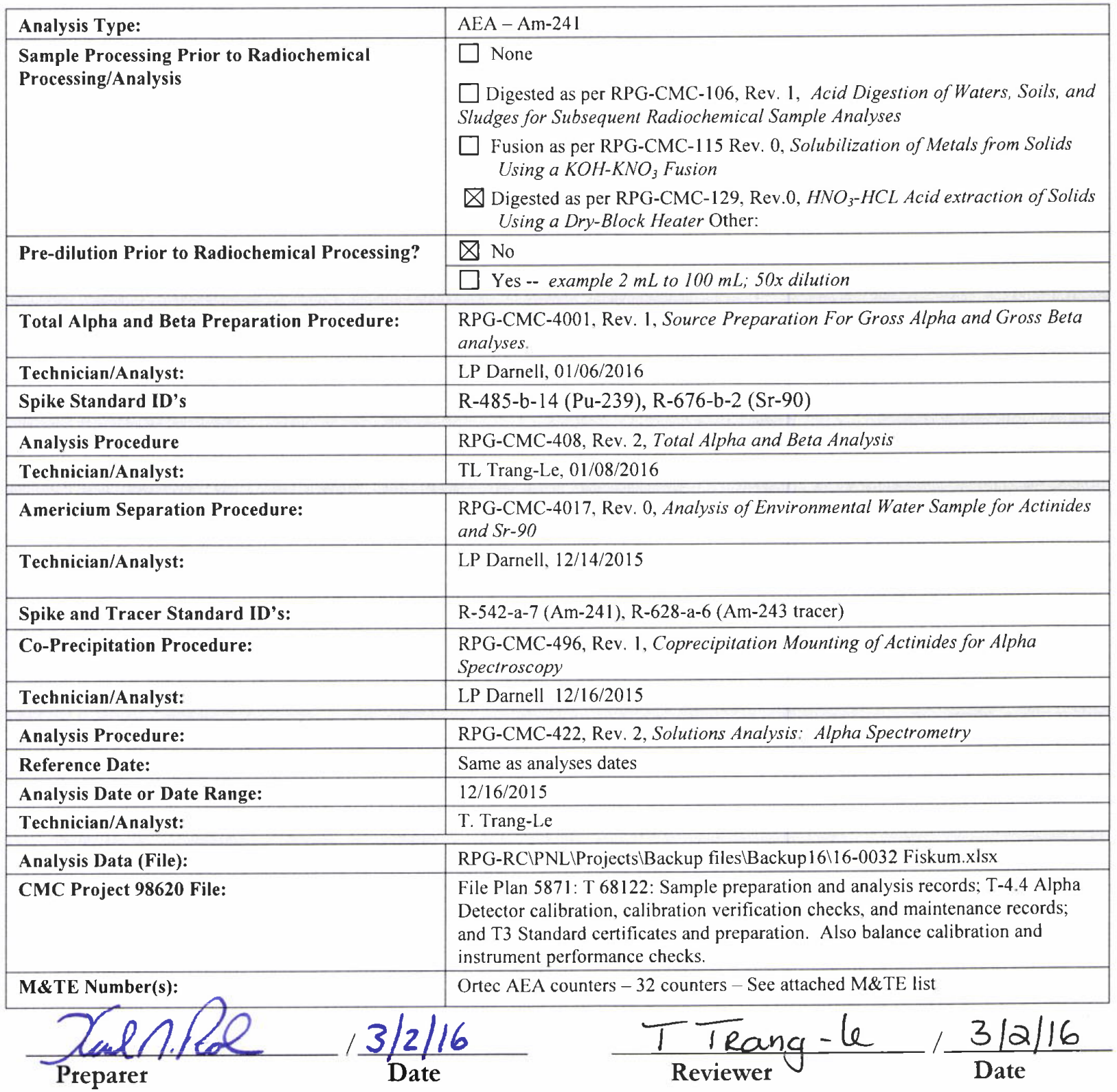


PNNL-25241

Battelle PNNL/RPL/ASO Radiochemistry Analysis Report

Revision 1 - Report revised to clarify application of MDA value to the acid digestion blank.

Revision 2 - Report revised to correct the Americium separation procedure reference on the cover page

Sample Results

See attached data report, Sample Results for ASR 9916. All data are reported in units of $\mu$ Ci per $g_{d r y}$ with a $1-\sigma$ uncertainty (see comments).

Sample Preparation, Separation, Mounting and Counting Methods

Two wet solids samples submitted under Analytical Service Request (ASR) 9916 were analyzed for analyzed for americium by Alpha Spectrometry. Prior to acid digestion, the wet solids were dried to constant weight. The dried solids samples were then acid digested using procedure RPG-CMC-129, " $\mathrm{HNO}_{3}-\mathrm{HCl}$ Acid Extraction of Solids Using a Dry-Block Heater". All the samples were prepared in laboratory 420. The leachate solution was used for radioanalytical analyses; only Am-AEA data are included in this report.

Following the digestion process, the Am was separated from the leachate by anion exchange using procedure RPG-CMC-4017. The separated Am fraction was then mounted for alpha spectrometry by co-precipitation using procedure RPG-CMC-496, and then counted using alpha spectrometry using procedure RPC-CMC-422. The samples were counted on December 16, 2015; no decay corrections were made.

Although not formally requested by the ASR, gross alpha and gross beta analyses were performed on each sample to obtain information to estimate aliquot sizes for other analyses and for checking the internal consistency of the Am alpha isotopic data. The gross alpha and gross beta results are included in the data tables as supplemental information only. Gross alpha and gross beta activity were measured by evaporating small aliquots of leachate onto counting planchets per procedure RPG-CMC-4001 and counting per procedure RPG-CMC-408.

\section{QUALITY CONTROL RESULTS}

Quality control (QC) samples prepared in laboratory 420 include a process blank (PB) and sample duplicates. Additional QC samples were prepared prior to alpha counting including a laboratory blank, a reagent blank spike (BS, Am-241), and addition of Am-241 standard to an aliquot of the sample digestate selected as the matrix spike (MS).

The QC sample results for Am-AEA have been evaluated and are discussed below. A summary of the Alpha-AEA analysis results, including QC sample performance, is given in the attached data report.

Tracer:

The Am-243 tracer is added to every sample after appropriate dilution and prior to americium separations. The Am-243 tracer corrects for radiochemical yield and mathematically removes the detector counting efficiency from the results calculations. Tracer recovery is required to be high enough to provide acceptable counting statistics. The Am-243 tracer counting statistics were acceptable for all samples. The tracer recoveries ranged from $98 \%$ to $117 \%$. 


\section{Battelle PNNL/RPL/ASO Radiochemistry Analysis Report}

\section{Laboratory Preparation Blank (PB):}

The detection limit achieved in the acid digestion preparation blank for Am-241 is $1.81 \mathrm{E}-4 \pm 15 \%$ $\mu \mathrm{Ci}$ per $\mathrm{g}_{\mathrm{dry}}$ (Note: The minimum detectable activity for the acid digestion preparation blank is $2.9 \mathrm{E}-5 \mu \mathrm{Ci}$ per $\left.\mathrm{g}_{\mathrm{dry}}\right)$. The Am-241 activity measured in the PB are required to be within the acceptance criteria of less than $5 \%$ of the sample isotope concentration or less than sample minimum detectable activity (MDA) - see comments. The PB Am-24l activity is significantly less than $5 \%$ of any sample activity. There are no acceptance criteria for LB

\section{Blank Spike (BS)/Reagent Spike (RS):}

The RS recovery of $100 \%$ (Am-241) meets the acceptance criteria of $80 \%$ to $120 \%$ recovery.

\section{Matrix Spike (MS):}

The MS recovery of $101 \%$ (Am-241) meets the acceptance criterion of $75 \%$ to $125 \%$ recovery. Note: the MS sample was prepared after digestion, by adding a known quantity of Am-241 standard to a diluted aliquot of the digestate. Sample number 16-0032 (68122-TI-001-F) was selected as the matrix spike sample.

\section{Laboratory Duplicate - Relative Percent Difference (RPD):}

The Am-241 sample and duplicate RPD of $8 \%$ less than $\leq 20 \%$ RPD for sample $68122-T I-001-$ F/G.

\section{Instrument Quality Control}

Alpha counters receive initial calibration with NIST traceable sources to determine the counter efficiency. When internal tracers are not used, the counter efficiency is used in calculation of final results.

Detector backgrounds are determined every 4 weeks or after the last analytical run, whichever is longer. Detector background counts are subtracted from all subsequent sample counts. A process blank is analyzed with each analytical batch to evaluate for contamination in the sample preparation process.

\section{Assumption and Limitations of the Data}

None

Attachment: Data Report -- Sample Results for ASR 9916. 
Battelle PNNL/RPL/ASO Radiochemistry Analysis Report

P.O. Box 999, 902 Battelle Blvd., Richland, Washington 99352

\section{Sr-90 by Liquid Scintillation Spectrometry Revision 1}

\begin{tabular}{|l|l|}
\hline Project /WP\#: & $68122 / \mathrm{N} 51383$ \\
\hline ASR\#: & 9916 \\
\hline Client: & SK Fiskum \\
\hline Total \# of Samples: & 2 \\
\hline
\end{tabular}

\begin{tabular}{|c|c|}
\hline RPL ID & Client Sample ID \\
\hline $16-0032$ & $68122-T I-001-F$ \\
\hline $16-0032$ DUP & $68122-T I-001-G$ \\
\hline
\end{tabular}

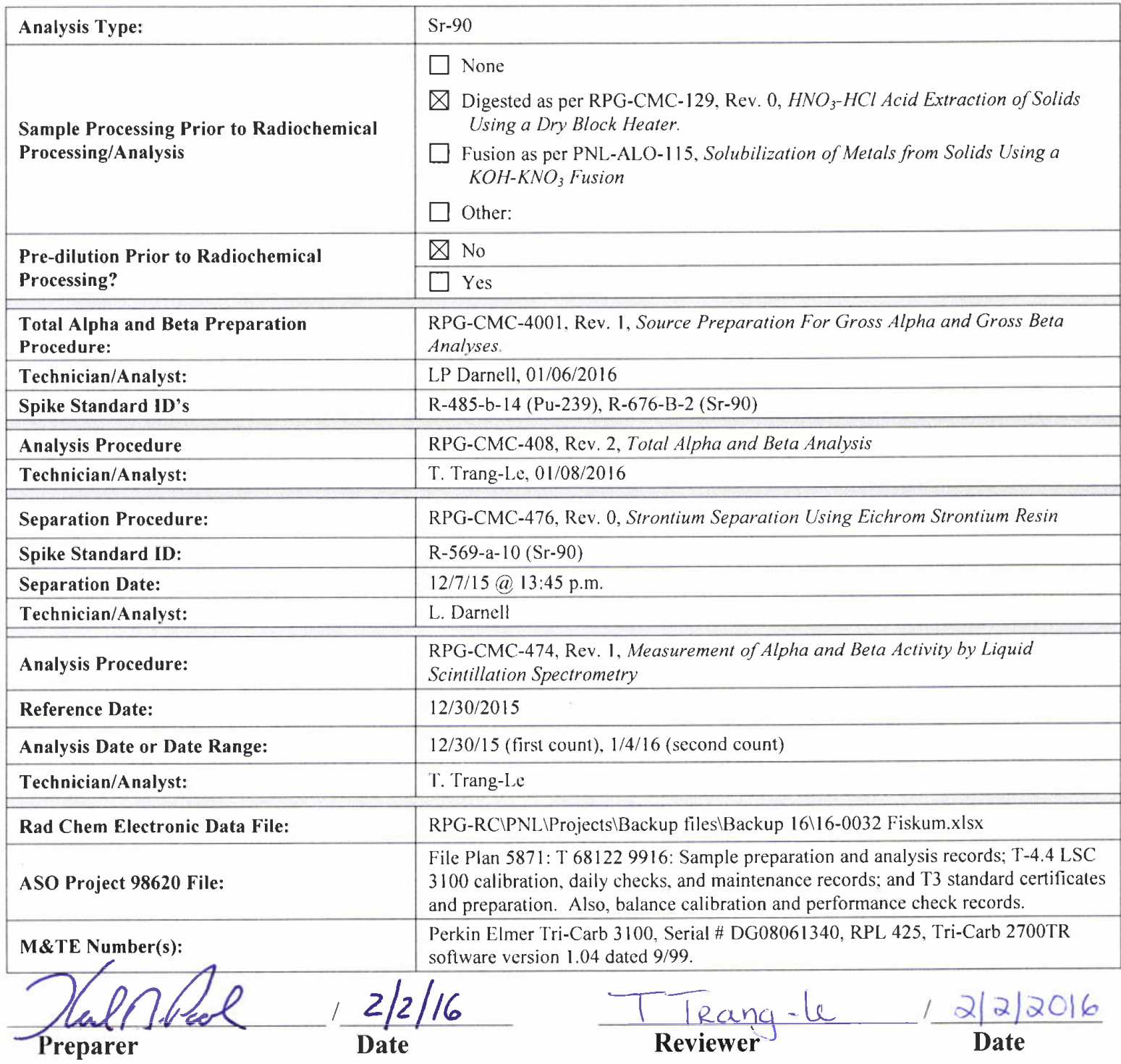




\section{Battelle PNNL/RPL/ASO Radiochemistry Analysis Report}

Revision 1 - Report revised to correct the sample result uncertainty and provide the correct reference for the sample preparation location.

\section{SAMPLE RESULTS}

See attached data report, Sample Results for ASR 9916. All sample data are reported in $\mu \mathrm{Ci} / \mathrm{g}_{\mathrm{dry}}$ with a $1-\sigma$ uncertainty (see Comments).

\section{Sample preparation, separation, mounting, and counting}

Two wet solids samples submitted under Analytical Service Request (ASR) 9916 were analyzed for Sr90 by chemical separation and liquid scintillation counting. Prior to acid digestion, the wet solids were dried to constant weight. The dried solids samples were then acid digested using procedure RPG-CMC-129, " $\mathrm{HNO}_{3}-\mathrm{HCl}$ Acid Extraction of Solids Using a Dry-Block Heater". All the samples were prepared in laboratory 420 . The leachate solution was used for radioanalytical analyses; only $\mathrm{Sr}-90$ data are included in this report.

Although not formally requested by the ASR, gross alpha and gross beta analyses were performed on each sample to obtain information to estimate aliquot sizes for other analyses and for checking the internal consistency of the Sr-90 data. The gross alpha and gross beta results are included in the data tables as supplemental information only. Gross alpha and gross beta activity were measured by evaporating small aliquots of leachate onto counting planchets per procedure RPG-CMC-4001 and counting per procedure RPG-CMC-408.

\section{QUALITY CONTROL RESULTS}

Radioanalytical quality control (QC) samples prepared in samples prepared in laboratory 420 and include a process blank (PB), and sample duplicate. No Sr-90 MS was prepared at time of digestion. Additional laboratory QC samples were prepared prior to separations; these include a laboratory separation blank, a reagent blank spike (BS), and a matrix spike (i.e., addition of $\mathrm{Sr}-90$ standard to an aliquot of one of the samples).

\section{Instrument Calibration Control}

Laboratory Preparation Blank and Laboratory separations blank (LB):

The Sr-90 activity measured in the PB is required to be within the acceptance criteria of less than sample minimum detectable activity (MDA) or less than $5 \%$ of the sample isotope concentration. The Sr-90 PB is $<$ MDA; thus meeting the acceptance criteria. There are no acceptance criteria for LB (see Comments).

\section{Blank Spike (BS) - reagent spike:}

The BS recovery of $96 \%$ meets the procedure acceptance criteria of $80 \%$ to $120 \%$ recovery.

\section{Matrix Spike (MS):}

The MS recovery of $98 \%$ meets the acceptance criterion of $75 \%$ to $125 \%$ recovery. Note: the MS sample was prepared "after" digestion (see comments), by adding a known Sr-90 standard quantity to an aliquot of 16-0032 (68122-TI-001-F). 
PNNL-25241

\title{
Battelle PNNL/RPL/ASO Radiochemistry Analysis Report
}

\author{
Duplicate -- Relative Percent Difference (RPD):
}

Duplicate results are required to agree within $\leq 20 \%$ RPD. The ASO QAP further specifies that the two results need to be $>5$ times the MDA or have individual uncertainties $<20 \%$. Duplicate result was $0.5 \%$ RPD; thus meeting the $\leq 20 \%$ requirement.

\section{Instrument Quality Control}

The liquid scintillation counter is calibrated for tritium and C-14 using quenched standard sets that are purchased from the vendor. Daily control counts are then performed using a tritium, C-14, and a background count sample. The instrument software assesses the performance of the control counts and provides control charts to ensure the continuing calibration of the instrument. If the daily performance check fails, then the instrument is not used. Preventative maintenance and repairs are performed by the vendor under our service contract. The counting efficiency for $\mathrm{Sr}-90$ is assumed to be $100 \%$; therefore no specific Sr-90 calibration is performed. The LSC system calibration and performance is verified by assessing the recovery of a reagent spike and a matrix spike that are included in every batch of samples. A preparation blank (i.e., digestion blank) and a laboratory separations blank are also included with every batch of samples; the instrument background is subtracted from all results and the preparation and separation blanks are used to assess sample contamination during sample processing steps.

\section{Assumption and Limitations of the Data}

The 1- $\sigma$ uncertainty reported for each $\mathrm{Sr}-90$ result has been set at $2 \%$. Although the calculated uncertainty values are less than $2 \%$ for all samples, the radiochemistry convention is to not report calculated uncertainties less than $2 \%$, but to provide a more realistic estimate of the uncertainty in view of systematic uncertainties that are not fully accounted for in the uncertainty calculations.

\section{Comments}

1. The results have been corrected for all dilution factors resulting from sample processing.

2. Post-Digestion Spike (PS) - A spike made after the initial sample preparation (e.g., fusion, digestion, or leach) is considered a PS. When extremely radioactive samples are analyzed, most of the radio-analytical spikes are made after the sample preparation (to avoid excessive consumption of spike and avoid creating unnecessary waste) and are post-digestion spikes. The MS prepared with this batch of sample is considered a PS, since the Sr-90 spike was not added prior to the digestion process.

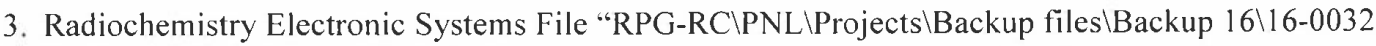
Fiskum.xlsx" has been created for this report. Supporting records such as Pipette Performance Verification forms, Laboratory Bench Record, Laboratory Sample Preparation Bench Sheet, Standards Certifications and preparation records, and balance calibration and performance check records are maintained per RS\&E Group ASO File Plan 5871.

4. Sample results are compared to the process blank results to evaluate if the blank contains $5 \%$ or more of the measured isotope; the process blank results have been adjusted for all processing factors for the evaluation of the $5 \%$ criterion.

5. The stated 1- $\sigma$ uncertainty represents the total propagated error associated with processing and counting operations and includes weighing errors, volume uncertainties, and counting error.

Attachment: Data Report -- Sample Results for ASR 9916 
PNNL-25241

Battelle PNNL/RPL/ASO Radiochemistry Analysis Report

P.O. Box 999, 902 Battelle Blvd., Richland, Washington 99352

\section{Gross Alpha and Beta Revision 1}

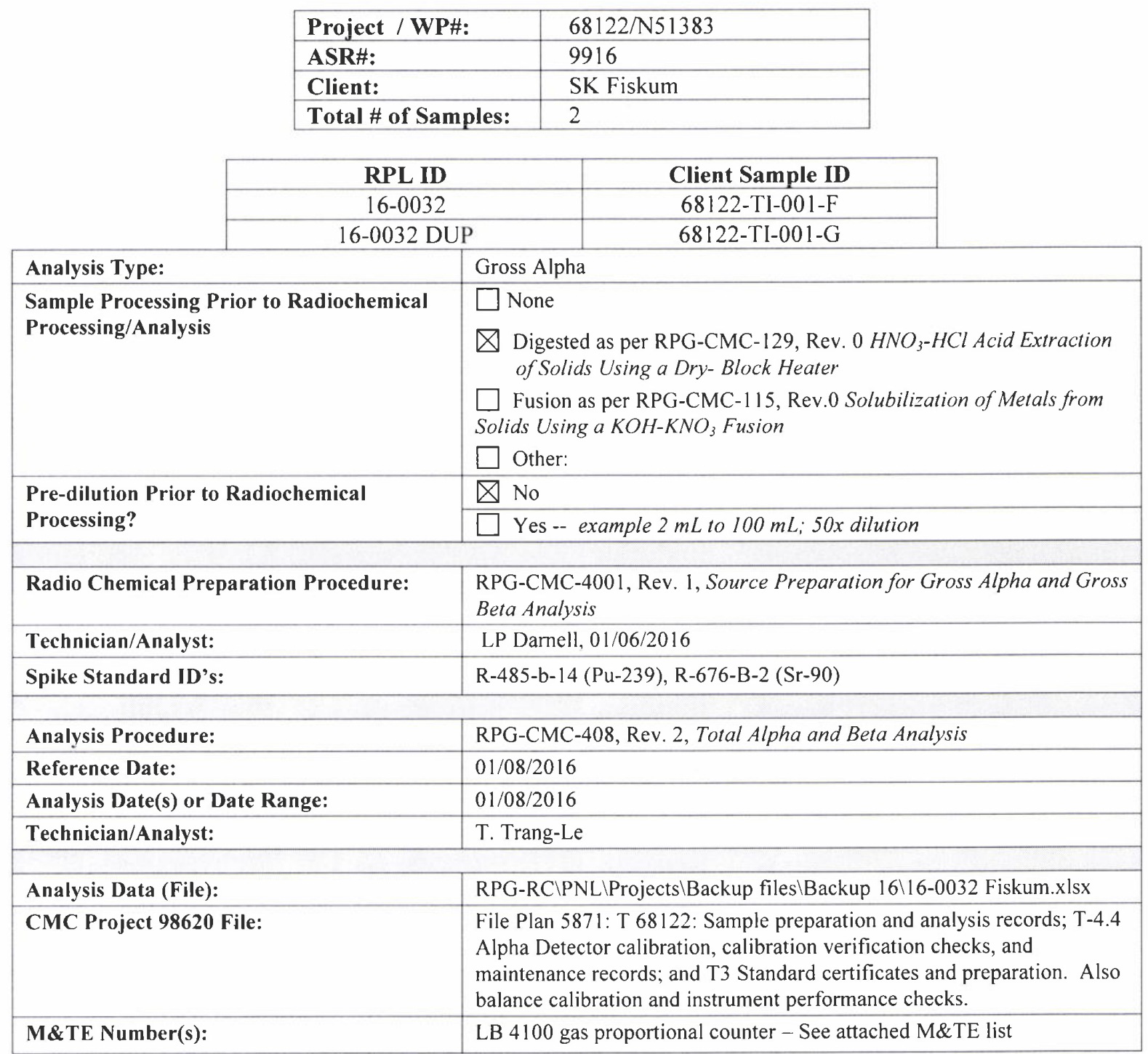
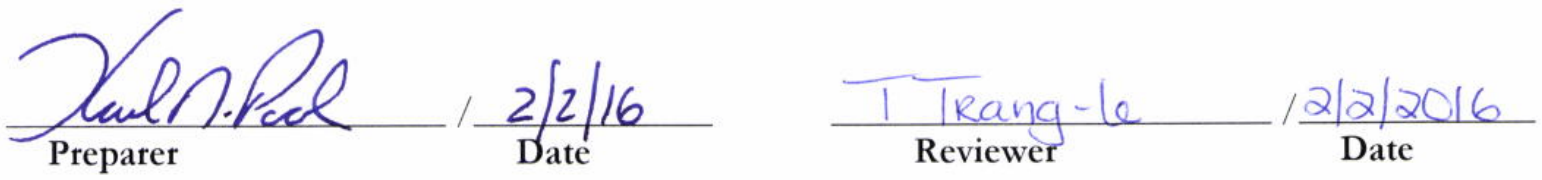
Revision 1 - Report revised to add reference date for sample counting and correct the QC sample discussion to include the preparation of laboratory blank.

\section{Sample Results}

See attached data report, sample results for ASR 9916. All data are reported in units of $\mu$ Ci per $g_{d r y}$ solids with a $1-\sigma$ uncertainty (see comments).

\section{Sample Preparation, Separation, Mounting and Counting Methods}

Two wet solids samples submitted under Analytical Service Request (ASR) 9916 were analyzed for gross alpha/gross beta. Prior to acid digestion, the wet solids were dried to constant weight. The dried solids samples were then acid digested using procedure RPG-CMC-129, " $\mathrm{HNO} \mathrm{N}_{3}-\mathrm{HCl}$ Acid Extraction of Solids Using a Dry-Block Heater". All the samples were prepared in laboratory 420. Aliquots of the acid digestions were diluted $\sim 100 \mathrm{x}$ and mounted for gross alpha/gross beta counting using procedure RPGCMC-4001, then counted using alpha/beta gas proportional counters per procedure RPG-CMC-408.

\section{QUALITY CONTROL RESULTS}

Quality control (QC) samples prepared in laboratory 420 include a laboratory duplicate sample and a preparation blank. Additional QC samples were prepared prior to alpha and beta counting including a laboratory blank, a reagent blank spike (RS, Pu-239 and Sr-90), and addition of Pu-239 and Sr-90 standard to a diluted aliquot of the sample selected as the matrix spike (MS).

A summary of the Gross Alpha and Gross Beta analysis results, including QC sample performance, is given in the attached data report.

Tracer:

Tracer is not used for this analysis.

Laboratory Preparation Blank (PB) and Laboratory blank (LB):

The gross alpha activity measured in the PB is required to be within the acceptance criteria of less than $5 \%$ of the sample isotope concentration or less than sample minimum detectable activity (MDA). Each sample counting disc was counted for 100 minutes. The PB and LB alpha and beta activity are less than the MDA

Blank Spike (BS) - Reagent Spike (RS):

The RS (Pu-239) recovery of $87 \%$ and $(\mathrm{Sr}-90)$ recovery of $97 \%$ meets the acceptance criteria of $80 \%$ to $120 \%$ recovery.

\section{Matrix Spike (MS):}

The MS (Pu-239) recovery of $128 \%$ exceeds the acceptance criterion of $75 \%$ to $125 \%$ recovery. The MS (Sr-90) recovery of $113 \%$ meets the acceptance criterion of $75 \%$ to $125 \%$. Note: the MS sample was prepared by adding a known Pu-239 and Sr-90 standard quantity to an aliquot of the digestate. Sample number 16-0032 (68122-TI-001-F) was selected as the matrix spike sample. 
Battelle PNNL/RPL/ASO Radiochemistry Analysis Report

Duplicate -- Relative Percent Difference (RPD):

Sample and duplicate sample result RPD is $6 \%$ for the gross alpha and $5 \%$ for the gross beta. Both RPD results are within the acceptance criterion of $\leq 20 \%$.

\section{Instrument Quality Control}

LB4 100 alpha and Beta counters undergo initial calibration to determine the detector efficiency. The established efficiency for each detector is used in the final calculation of the sample gross alpha and beta activity. Continuing calibration verification checks are performed on the detectors once per day as the system is used. Detector backgrounds are obtained once per day or as the system is used or per batch.

\section{Assumption and Limitations of the Data}

The gross alpha/beta analyses was run twice to confirm the gross beta results. The sum of the individual beta emitters is only $2 / 3$ of the gross beta result. The alpha activity in the samples is about twice that of the beta. The gross beta results are biased high due to the high alpha activity.

Attachment: Data Report -- Sample Results for ASR 9916. 


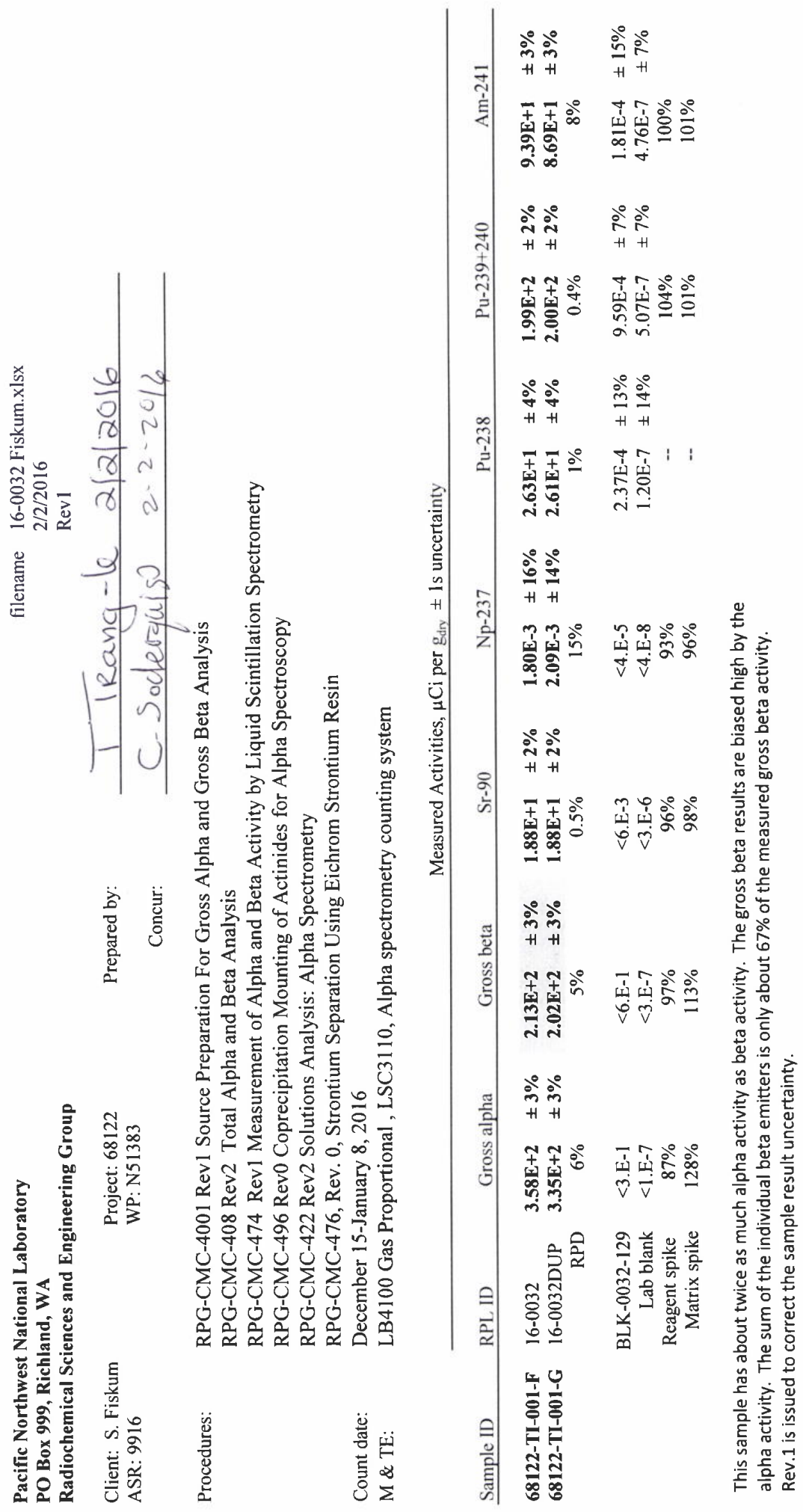


PNNL/Radiochemistry Processing Laboratory

P.O. Box 999, 902 Battelle Blvd., Richland, Washington 99352

\section{PLUTONIUM ISOTOPIC ANALYSIS BY TIMS}

Project / WP\#: $\quad$ 68122// N51383

ASR\#: $\quad 9916$

Client: $\quad$ SK Fiskum

Total Samples: $\quad 2$

\begin{tabular}{|c|c|c|}
\hline Client ID & RPL Number & TIMS ID \\
\hline 68122-TI-001-F & $16-0032$ & $16-0032 \mathrm{~F}$ \\
\hline $68122-\mathrm{TI}-001-\mathrm{F}$ & $16-0032$ & $16-0032 \mathrm{~F} \mathrm{\# 2}$ \\
\hline $68122-\mathrm{TI}-001-\mathrm{G}$ & $16-0032$ (dup) & $16-0032 \mathrm{G}$ \\
\hline $68122-\mathrm{TI}-001-\mathrm{G}$ & $16-0032$ (dup) & $16-0032 \mathrm{G} \# 2$ \\
\hline
\end{tabular}

\begin{tabular}{|c|c|}
\hline Analysis Type: & Plutonium Isotopic Analysis by TIMS \\
\hline $\begin{array}{l}\text { Sample Processing Prior to } \\
\text { Radiochemical Processing/Analysis }\end{array}$ & $\begin{array}{l}\text { Digested as per RPG-CMC-129, Rev.0, HNO3-HCL Acid Extraction of } \\
\text { Solids Using a Dry-Block Heater } \\
\text { Chemical separation via RPG-CMC-455, Rev. 0, Separation of } \\
\text { Uranium and Plutonium for Isotopic Analysis by Mass Spectrometry }\end{array}$ \\
\hline Analysis Procedure: & RPL-TIMS-001, Rev. 0, Thermal Ionization Mass Spectrometry (TIMS) \\
\hline Analysis Date /Reference Date: & January 27 to February 2, 2016 \\
\hline Technician/Analyst: & J.M. Peterson \\
\hline Report Date: & February 4, 2016 \\
\hline Instrument Electronic Data File: & RPG-IA\Triton\ASR 9916 Sandy Pu \\
\hline $\begin{array}{l}\text { Data Reduction and Reporting } \\
\text { Spreadsheet: }\end{array}$ & RPG-IA|Triton\ASR-9916 Data PSR 9916 Sandy.xlsx \\
\hline Project 9916 File: & RPL 301/ASO Records/ASR 9916 \\
\hline M\&TE Number(s): & TIMS System: Serial Number: 00831 \\
\hline
\end{tabular}

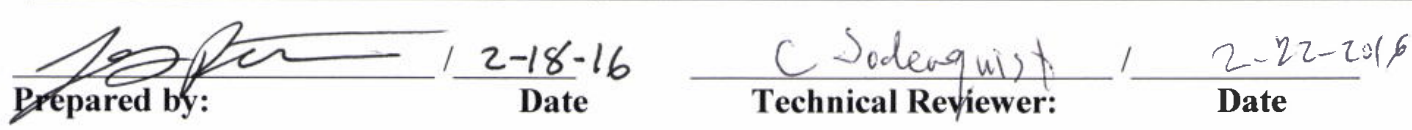


PNNL-25241

\section{PNNL/Radiochemistry Processing Laboratory}

\section{Sample Preparation Methods}

Plutonium isotopic analysis samples were received in Teflon holders with the material at dryness. The samples were dissolved in a minimum amount of $0.5 \mathrm{M} \mathrm{HNO}_{3}$ (approximately 10-50 uL) at the time of filament loading.

Standards and samples were prepared by dropping 1-5 uL of the prepared solution onto a rhenium filament and lightly heating until dryness ( $\sim 1$ amp of current), the filament was then heated to 2 amps for 10 seconds to fix the sample.

Filaments used for all samples had been degassed for up to 3 hours at 5 amps and then stored in a desiccator until use. All filaments were handled with clean tools to minimize any cross contamination.

All samples submitted for Thermal Ionization Mass Spectrometry (TIMS) analysis were delivered in duplicate with a process blank from sample preparation activities using the procedures, RPG-CMC-129, Rev.0, HNO3-HCL Acid Extraction of Solids Using a Dry-Block Heater and RPG-CMC-455, Rev, 0, Separation of Uranium and Plutonium for Isotopic Analysis by Mass Spectrometry.

\begin{tabular}{|c|c|c|}
\hline Client ID & RPL Number & TIMS ID \\
\hline $68122-$ TI-001-F & $16-0032$ & $16-0032 \mathrm{~F}$ \\
\hline $68122-$ TI-001-F & $16-0032$ & dup-0032 F \#2 \\
\hline $68122-$ TI-001-G & $16-0032$ (dup) & $16-0032 \mathrm{G}$ \\
\hline $68122-$ TI-001-G & $16-0032$ (dup) & dup-0032 G \#2 \\
\hline--- & --- & Blk-0032 \\
\hline
\end{tabular}

The TIMS laboratory prepared all submitted samples and one sample in replicate (same solution, different filament);), this was identified as 16-0032 F Rep. Three filaments of SRM-946 and SRM-947 were prepared for the analysis, as well as a blank filament and reagent blank $(0.5 \mathrm{M}$ $\mathrm{HNO}_{3}$ ). Filaments can be analyzed multiple times if need be, this occurs with standards primarily.

All samples were loaded into the TIMS source on January 26, 2016 and pumped down overnight The instrument source pumped down to a pressure of $<<5 \times 10^{-7}$ torr. The ion getter pressure for all analyses was $5 \times 10^{-8}$ torr (or less).

\section{Sample Analysis Method}

Plutonium samples and standards were analyzed on a single secondary electron multiplier (SEM) detector targeting a ${ }^{239} \mathrm{Pu}$ signal between 100,000 counts per second (cps) and $500,000 \mathrm{cps}$. This was achieved by heating an ionizing filament between $4500 \mathrm{~mA}$ and $5500 \mathrm{~mA}$ and an evaporation filament between $1200 \mathrm{~mA}$ to $2000 \mathrm{~mA}$ and finding the combination of the two that achieve the greatest signal without evaporating the sample too quickly. The ${ }^{239} \mathrm{Pu}$ peak was 
PNNL-25241

\section{PNNL/Radiochemistry Processing Laboratory}

centered in the magnet and the mass calibration updated daily prior to analysis. The signal was then focused and tuned via a series of lenses to optimize the signal strength. Each isotope signal beam was integrated for three seconds with a three second dead time between each scan. Each run of the samples are the sum of forty scans (less scans that are used for detector yield factor). In addition to the target plutonium isotopes, the ${ }^{235} \mathrm{U}$ peak was scanned; this isotope can be used to indicate or correct for contamination in the ${ }^{238} \mathrm{Pu}$ analysis by ${ }^{238} \mathrm{U}$.

\section{RESULTS AND UNCERTIANTY}

The results of the samples analysis is in the table below. The uncertainty of the analysis is provided as the standard deviation (in $\mathrm{At} \%$ and $\mathrm{Wt} \%$ ) of the pooled measurements made by the instrument ( $\sim 36$ averaged measurement).

\begin{tabular}{|c|c|c|c|c|c|c|c|c|c|c|}
\hline & \multicolumn{2}{|c|}{${ }^{239} \mathrm{Pu}$} & \multicolumn{2}{|c|}{${ }^{238} \mathrm{Pu}$} & \multicolumn{2}{|c|}{${ }^{240} \mathrm{Pu}$} & \multicolumn{2}{|c|}{${ }^{241} \mathrm{Pu}$} & \multicolumn{2}{|c|}{${ }^{242} \mathrm{Pu}$} \\
\hline & At $\%$ & StDev & At\% & StDev & At $\%$ & StDev & At $\%$ & StDev & At\% & StDer \\
\hline $16-0032 \mathrm{~F}$ & 86.32 & 0.04 & 0.1456 & 0.0157 & 12.92 & 0.05 & 0.3890 & 0.0059 & 0.2341 & 0.0059 \\
\hline $16-0032 \mathrm{~F} \# 2$ & 85.73 & 0.33 & 0.8223 & 0.3877 & 12.83 & 0.07 & 0.3886 & 0.0065 & 0.2310 & 0.0051 \\
\hline dup-0032 G & 85.72 & 0.22 & 0.8323 & 0.2710 & 12.83 & 0.06 & 0.3853 & 0.0044 & 0.2304 & 0.0049 \\
\hline dup-0032 G \#2 & 86.05 & 0.13 & 0.4359 & 0.1321 & 12.89 & 0.03 & 0.3872 & 0.0051 & 0.2322 & 0.0049 \\
\hline \multirow[t]{3}{*}{ blk-0032 } & 0.2547 & 0.1026 & 99.54 & 0.2217 & 0.0489 & 0.0842 & 0.0676 & 0.0750 & 0.0863 & 0.1310 \\
\hline & \multicolumn{2}{|c|}{${ }^{239} \mathrm{Pu}$} & \multicolumn{2}{|c|}{${ }^{238} \mathrm{Pu}_{\mathrm{u}}$} & \multicolumn{2}{|c|}{${ }^{240} \mathrm{Pu}$} & \multicolumn{2}{|c|}{${ }^{241} \mathrm{Pu}$} & \multicolumn{2}{|c|}{${ }^{242} \mathrm{Pu}$} \\
\hline & $w t \%$ & StDev & $W t \%$ & StDev & $W t \%$ & StDev & $w+\%$ & StDev & $w t \%$ & StDev \\
\hline $16-0032 \mathrm{~F}$ & 86.26 & 0.04 & 0.1449 & 0.0157 & 12.96 & 0.05 & 0.3920 & 0.0060 & 0.2369 & 0.0060 \\
\hline $16-0032 \mathrm{FH}$ & 85.68 & 0.33 & 0.8184 & 0.3859 & 12.88 & 0.07 & 0.3917 & 0.0066 & 0.2338 & 0.0052 \\
\hline dup-0032 G & 85.68 & 0.22 & 0.8284 & 0.2698 & 12.87 & 0.06 & 0.3884 & 0.0044 & 0.2332 & 0.0050 \\
\hline dup- $0032 \mathrm{G}$ \#2 & 86.00 & 0.13 & 0.4338 & 0.1314 & 12.94 & 0.03 & 0.3902 & 0.0052 & 0.2350 & 0.0049 \\
\hline blk-0032 & 0.2557 & 0.1030 & 99.54 & 0.2242 & 0.0493 & 0.0849 & 0.0685 & 0.0759 & 0.0877 & 0.1332 \\
\hline
\end{tabular}

\section{QUALITY CONTROL RESULTS}

\section{Laboratory Control Sample (LCS)/Mass Bias Standard (MBS)}

Two isotopic standards were run at the opening, closing, and after every 5 unique samples; a mass bias standard (MBS), SRM-946 and a laboratory control sample (LCS), SRM-947. Based on the results of the SRM-946 standard and an acceptance criterion of $\pm 5 \%$ of the decay calculated certified value, it was determined that no mass bias correction factor is needed for these samples or standards. All standards were found to be within the control chart limits established for the method and covered in a memorandum, Control chart limits for SRM-946 and $S R M-947$, delivered and approved January 22, 2016.

\begin{tabular}{|r|c|c|c|c|c|}
\hline SRM-946 Standards & $\begin{array}{c}{ }^{239} \mathrm{Pu} \\
\text { (\% Recovery) }\end{array}$ & $\begin{array}{c}{ }^{238} \mathrm{Pu} \\
\text { (\% Recovery) }\end{array}$ & $\begin{array}{c}{ }^{240} \mathrm{Pu} \\
\text { (\% Recovery) }\end{array}$ & $\begin{array}{c}{ }^{241} \mathrm{Pu} \\
\text { (\% Recovery) }\end{array}$ & $\begin{array}{c}{ }^{242} \mathrm{Pu} \\
\text { (\% Recovery) }\end{array}$ \\
\hline 946-STD-02 & $100.0 \%$ & $101.0 \%$ & $99.89 \%$ & $98.16 \%$ & $100.4 \%$ \\
\hline 946-STD-03 & $100.0 \%$ & $101.2 \%$ & $100.1 \%$ & $99.71 \%$ & $101.2 \%$ \\
\hline 946-STD-03 & $100.0 \%$ & $104.3 \%$ & $99.67 \%$ & $99.20 \%$ & $101.8 \%$ \\
\hline
\end{tabular}


PNNL-25241

\section{PNNL/Radiochemistry Processing Laboratory}

\begin{tabular}{|r|c|c|c|c|c|}
\hline $\begin{array}{c}\text { SRM-946 } \\
\text { Control Limits }\end{array}$ & ${ }^{239} \mathrm{Pu}($ At\%) & ${ }^{238} \mathrm{Pu}$ (At\%) & ${ }^{240} \mathrm{Pu}$ (At\%) & ${ }^{241} \mathrm{Pu}$ (At\%) & ${ }^{242} \mathrm{Pu}$ (At\%) \\
\hline Upper & 86.31 & 0.1990 & 12.54 & 0.6370 & 0.5981 \\
\hline Lower & 86.06 & 0.1698 & 12.47 & 0.4344 & 0.5838 \\
\hline $\begin{array}{c}\text { SRM-947 } \\
\text { Control Limits }\end{array}$ & ${ }^{239} \mathrm{Pu}$ (At\%) & ${ }^{238} \mathrm{Pu}($ At\%) & ${ }^{240} \mathrm{Pu}($ At\%) & ${ }^{241} \mathrm{Pu}$ (At\%) & ${ }^{242} \mathrm{Pu}$ (At\%) \\
\hline Upper & 79.06 & 0.2958 & 19.04 & 0.7699 & 1.239 \\
\hline Lower & 78.76 & 0.1587 & 18.93 & 0.4515 & 1.215 \\
\hline
\end{tabular}

\begin{tabular}{|r|c|c|c|c|c|}
\hline SRM-946 Standards & ${ }^{239} \mathrm{Pu}($ At\%) & ${ }^{238} \mathrm{Pu}($ At\%) & ${ }^{240} \mathrm{Pu}($ At\%) & ${ }^{241} \mathrm{Pu}$ (At\%) & ${ }^{242} \mathrm{Pu}($ At\%) \\
\hline 946-STD-02 & 86.24 & 0.1832 & 12.49 & 0.4891 & 0.5883 \\
\hline 946-STD-03 & 86.20 & 0.1835 & 12.52 & 0.4968 & 0.5929 \\
\hline 946-STD-03 & 86.25 & 0.1892 & 12.47 & 0.4943 & 0.5967 \\
\hline & & & & & \\
\hline SRM-947 Standards & ${ }^{239} \mathrm{Pu}(\mathrm{Wt} \%)$ & ${ }^{238} \mathrm{Pu}(\mathrm{Wt} \%)$ & ${ }^{240} \mathrm{Pu}(\mathrm{Wt} \%)$ & ${ }^{241} \mathrm{Pu}(\mathrm{Wt} \%)$ & ${ }^{242} \mathrm{Pu}(\mathrm{Wt} \%)$ \\
\hline 947 STD-01 & 78.94 & 0.2280 & 19.03 & 0.5779 & 1.231 \\
\hline 947 STD-03 & 78.92 & 0.2427 & 19.02 & 0.5785 & 1.235 \\
\hline 947 STD-03 & 78.89 & 0.2360 & 18.99 & 0.6595 & 1.223 \\
\hline
\end{tabular}

The control charting is provided in terms of atom percent (At\%) and the client requested that the results be reported in wt $\%$. The control chart, limits established in At $\%$ are comparable to wt $\%$, standards that pass the control charting acceptance criteria for wt $\%$ will also pass when those limits were established in At\%.

\section{Filament Blank(FB):}

The background counts per second of the degassed filaments used were assessed by analyzing a blank rhenium filament with no reagent or sample added. The results were acceptable for ${ }^{239} \mathrm{Pu}$, ${ }^{240} \mathrm{Pu},{ }^{241} \mathrm{Pu}$, and ${ }^{242} \mathrm{Pu}$ with counts $<0.1 \%$ of the sample's intensity (a standard with the lowest cps analyzed was used for this comparison). The ${ }^{238} \mathrm{Pu}$ and ${ }^{235} \mathrm{U}$ fail this analysis due to environmental contamination of uranium in the fume hoods. Their isotopic contributions are still quite small; $0.2 \%$ for ${ }^{238} \mathrm{Pu}$ and $1.5 \%$ for ${ }^{235} \mathrm{U}$ and are probably negligible when compared to the diluent and the process chemistry.

\begin{tabular}{|r|c|c|c|c|c|c|}
\hline Sample ID & ${ }^{239} \mathrm{Pu}(\mathrm{cps})$ & ${ }^{238} \mathrm{Pu}(\mathrm{cps})$ & ${ }^{240} \mathrm{Pu}(\mathrm{cps})$ & ${ }^{241} \mathrm{Pu}(\mathrm{cps})$ & ${ }^{242} \mathrm{Pu}(\mathrm{cps})$ & ${ }^{235} \mathrm{U}(\mathrm{cps})$ \\
\hline Filament Blank & 0.4 & 2 & 0.2 & 0.4 & 0.2 & 0.3 \\
\hline 946-STD-01 & 350978 & 743 & 50997 & 2002 & 2414 & 23 \\
\hline Percent of intensity & $0.0001 \%$ & $0.2 \%$ & $0.0004 \%$ & $0.02 \%$ & $0.01 \%$ & $1.5 \%$ \\
\hline
\end{tabular}

\section{Diluent Blank (DB):}

The samples are prepared in a $0.5 \mathrm{M} \mathrm{HNO}_{3}$ solution. The diluent blank is an evaluation of the background (counts per second) background contamination contribution from the preparation fume hood and reagents. The results were acceptable for ${ }^{239} \mathrm{Pu},{ }^{240} \mathrm{Pu},{ }^{241} \mathrm{Pu}$, and ${ }^{242} \mathrm{Pu}$ with 
PNNL-25241

\section{PNNL/Radiochemistry Processing Laboratory}

counts $<0.1 \%$ of the samples' intensity. The ${ }^{238} \mathrm{Pu}$ and ${ }^{235} \mathrm{U}$ fail this analysis due to uranium contamination in the diluent acid. The ${ }^{238} \mathrm{Pu}$ and ${ }^{235} \mathrm{U}$ contributions are $14 \%$ for ${ }^{238} \mathrm{Pu}$ and $4 \%$ for ${ }^{235} \mathrm{U}$, but these are not the most significant source of background contamination.

\begin{tabular}{|r|c|c|c|c|c|c|}
\hline Sample ID & ${ }^{239} \mathrm{Pu}(\mathrm{cps})$ & ${ }^{238} \mathrm{Pu}(\mathrm{cps})$ & ${ }^{240} \mathrm{Pu}(\mathrm{cps})$ & ${ }^{241} \mathrm{Pu}(\mathrm{cps})$ & ${ }^{242} \mathrm{Pu}(\mathrm{cps})$ & ${ }^{235} \mathrm{U}$ (cps) \\
\hline Diluent Blank & 1.3 & 106 & 0.3 & 0.3 & 0.2 & 0.9 \\
\hline 946-STD-01 & 350978 & 743 & 50997 & 2002 & 2414 & 23 \\
\hline Percent of intensity & $0.0004 \%$ & $14 \%$ & $0.001 \%$ & $0.01 \%$ & $0.01 \%$ & $4 \%$ \\
\hline
\end{tabular}

Process Blank (PB):

The separation process for the plutonium is described in procedure RPG-CMC- 455 and creates a process blank. This sample provides an indication of the contamination contributed by the separation process.

If the process blank results are compared to the diluent and the filament blank results and the acceptance criteria defined in RPL-TIMS-001, then the results are acceptable for ${ }^{239} \mathrm{Pu},{ }^{240} \mathrm{Pu}$, ${ }^{241} \mathrm{Pu}$, and ${ }^{242} \mathrm{Pu}$ with counts $<0.1 \%$ of the samples intensity. The ${ }^{238} \mathrm{Pu}$ and ${ }^{235} \mathrm{U}$ both fail the acceptance criteria due to contamination of uranium from the process chemistry. The separation process is the most significant source of unwanted uranium in the analytical samples.

\begin{tabular}{|r|c|c|c|c|c|c|}
\hline Sample ID & ${ }^{239} \mathrm{Pu}(\mathrm{cps})$ & ${ }^{238} \mathrm{Pu}(\mathrm{cps})$ & ${ }^{240} \mathrm{Pu}$ (cps) & ${ }^{241} \mathrm{Pu}(\mathrm{cps})$ & ${ }^{242} \mathrm{Pu}$ (cps) & ${ }^{235} \mathrm{U}$ (cps) \\
\hline blk-0032 & 0.6 & 269 & 0.1 & 0.2 & 0.2 & 2.8 \\
\hline 946-STD-01 & 350978 & 743 & 50997 & 2002 & 2414 & 23 \\
\hline Percent of intensity & $0.0002 \%$ & $36 \%$ & $0.0003 \%$ & $0.01 \%$ & $0.01 \%$ & $13 \%$ \\
\hline
\end{tabular}

\section{Duplicate Sample Relative Percent Difference (RPD):}

Both of the samples were provided in duplicate; and these were created during the analytical separation process using procedure RPG-CMC-455. All of the isotopes for the sample and duplicate were within < $1 \%$ RPD, based on wt\%, except for ${ }^{238} \mathrm{Pu}$. The ${ }^{238} \mathrm{Pu}$ varied dramatically in the samples resulting in RPD's of $140 \%$ for $16-0032 \mathrm{~F}$ and $63 \%$ for dup-0032-G. This is clearly due to contamination by ${ }^{238} \mathrm{U}$, this is very difficult to avoid when working with such small amounts of sample, in this case nanogram (or less) amounts of material

\begin{tabular}{|r|c|c|c|c|c|}
\hline Sample ID & ${ }^{239} \mathrm{Pu}($ At\%) & ${ }^{238} \mathrm{Pu}($ At\%) & ${ }^{240} \mathrm{Pu}($ At\%) & ${ }^{241} \mathrm{Pu}($ At\%) & ${ }^{242} \mathrm{Pu}(\mathrm{At} \%)$ \\
\hline $16-0032 \mathrm{~F}$ & 86.32 & 0.1456 & 12.92 & 0.3890 & 0.2341 \\
\hline 16-0032 F \#2 & 85.73 & 0.8223 & 12.83 & 0.3886 & 0.2310 \\
\hline RPD & $0.68 \%$ & $140 \%$ & $0.66 \%$ & $0.09 \%$ & $1.34 \%$ \\
\hline dup-0032 G & 85.72 & 0.8323 & 12.83 & 0.3853 & 0.2304 \\
\hline dup-0032 G \#2 & 86.05 & 0.4359 & 12.89 & 0.3872 & 0.2322 \\
\hline RPD & $0.38 \%$ & $63 \%$ & $0.49 \%$ & $0.47 \%$ & $0.76 \%$ \\
\hline
\end{tabular}

Per client request, these results are presented as $w t \%$ Plutonium. 
PNNL-25241

\section{PNNL/Radiochemistry Processing Laboratory}

\section{Replicate Sample Relative Standard Deviation (RSD):}

A replicate sample of 16-0032 F was prepared in the TIMS laboratory (same sample, different filament). All of the isotopes for the sample and duplicate were within $<1 \%$ RSD, based on wt $\%$, except for ${ }^{238} \mathrm{Pu}$. The ${ }^{238} \mathrm{Pu}$ was measured with a RSD of 107.9 percent. It is noteworthy that this replicate result is less variable than the aggregate error of ${ }^{238} \mathrm{Pu}$ for all the samples received but is still quite high. This is likely due to contamination by ${ }^{238} \mathrm{U}$ in the environment

\begin{tabular}{|r|c|c|c|c|c|}
\hline Sample ID & ${ }^{239} \mathrm{Pu}(\mathrm{Wt} \%)$ & ${ }^{238} \mathrm{Pu}(\mathrm{Wt} \%)$ & ${ }^{240} \mathrm{Pu}(\mathrm{Wt} \%)$ & ${ }^{241} \mathrm{Pu}(\mathrm{Wt} \%)$ & ${ }^{242} \mathrm{Pu}(\mathrm{Wt} \%)$ \\
\hline $16-0032 \mathrm{~F}$ & 86.26 & 0.1449 & 12.96 & 0.3920 & 0.2369 \\
\hline $16-0032 \mathrm{~F} \mathrm{\# 2}$ & 85.68 & 0.8184 & 12.88 & 0.3917 & 0.2338 \\
\hline \hline 16-0032 F Rep & 86.29 & 0.1300 & 12.96 & 0.3911 & 0.2368 \\
\hline Average & 86.08 & 0.3644 & 12.93 & 0.3916 & 0.2358 \\
\hline \%RSD & 0.3993 & 107.9 & 0.3712 & 0.1122 & 0.7532 \\
\hline
\end{tabular}

\section{Instrument Calibration}

The mass spectrometer is mass calibrated from ${ }^{23} \mathrm{Na}$ to ${ }^{242} \mathrm{Pu}$. The instrument is peak centered on ${ }^{239} \mathrm{Pu}$ prior to each analysis. This peak centering updates the mass calibration table each time it is scanned. In addition to peak centering the signal output of the sample is tuned and maximized via a series of lenses. The SEM detector background and yield are assessed on a regular basis, and they typically do not need updating unless significant changes are observed in standard ratios.

\section{Interferences/Resolution}

It is known that the ${ }^{24 I} \mathrm{Pu}$ standard contains the decay product, ${ }^{24 !} \mathrm{Am}$, which will skew the analysis of ${ }^{241} \mathrm{Pu}$. Based on the records provided for the standards the decay can be calculated but these standards have also been separated previously, the dates of which are not fully recorded, this causes errors in the ${ }^{241} \mathrm{Pu}$ calculation. It is believed that the error in the standard ${ }^{241} \mathrm{Pu}$ is not due to any instrument bias and strictly due to the accounting for ${ }^{241} \mathrm{Am}$ in the standards, thus the control limits for ${ }^{241} \mathrm{Pu}$ are larger in range than the other isotopes. The separation performed on the samples prior to TIMS analysis not only separated Pu from U but also removed any ${ }^{241} \mathrm{Am}$ from the $\mathrm{Pu}$ fraction. This removes any significant contamination of ${ }^{241} \mathrm{Am}$ in the ${ }^{241} \mathrm{Pu}$ of the samples.

The MBS is used to determine if mass corrections are needed for the standards, the LCS is intended to be the quality check. The LCS required no mass bias, thus no bias factor was applied to the samples. The results of the LCS samples were within the control chart limits specified.

The plutonium results for ${ }^{238} \mathrm{Pu}$ have very high error associated with them. This is likely due to ${ }^{238} \mathrm{U}$ contamination. The ${ }^{235} \mathrm{U}$ is analyzed during this analysis as a means to identify the error in the ${ }^{238} \mathrm{Pu}$ as possibly being associated with uranium. We lack the isotopic ratio of the uranium and thus cannot correct for the uranium contamination but can identify its presence. Additionally the blank analyses conducted provide additional basis for the uranium contamination. 


\section{PNNL/Radiochemistry Processing Laboratory}

It was noted that the ${ }^{238} \mathrm{Pu}$ samples showed higher standard deviation in the analysis for samples with ${ }^{238} \mathrm{Pu}<0.19 \mathrm{wt} \%$. This can be interpreted in two ways, one the ${ }^{238} \mathrm{U}$ is a minor component and is evaporating off of the filament to a point of depletion, leaving only ${ }^{238} \mathrm{Pu}$ or two, the opposite effect that the Pu is being evaporated leaving the Uranium. The most likely is that the uranium is evaporating off the filament leaving the ${ }^{238} \mathrm{Pu}$, as all plutonium isotopes will burn off in a similar way and no such variability is observed in the other plutonium isotopes.

All analyses make use of the attached Retarding Potential Quadrupole Lens (RPQ). The RPQ helps in filtering out large peak tailing from impacting smaller peaks. The RPQ is an energy filter that discriminates the dispersed ions that are not in the primary beam, when a large isotopic signal is neighboring a much smaller signal (i.e., ${ }^{239} \mathrm{Pu}$ in ${ }^{238} \mathrm{Pu}$ ), the peak tailing of ${ }^{239} \mathrm{Pu}$ can impact the results of the ${ }^{238} \mathrm{Pu}$. The use of the RPQ makes this potential impact 20 parts per billion and thus peak tailing is not an issue in this analysis.

Attachment: Data Report, Data Summary, Decay Calculations, Certificate of analysis SRM-946 and SRM-947 
PNNL-25241

PNNL/Radiochemistry Processing Laboratory

Resutts and QCsummery. ASR9916

\begin{tabular}{|c|c|c|c|c|c|c|c|c|c|c|}
\hline & \multicolumn{2}{|c|}{ सPu } & \multicolumn{2}{|c|}{${ }_{\mathrm{Pu}}^{\mathrm{Pa}}$} & \multicolumn{2}{|c|}{${ }^{200 \mathrm{Pu}}$} & \multicolumn{2}{|c|}{${ }^{241} \mathrm{Pu}$} & \multicolumn{2}{|c|}{${ }^{20} \mathrm{Pu}$} \\
\hline & $A \pm \%$ & SHEV & $A \%$ & StDeV & $A \%$ & SLDEN & $A \%$ & SDEN & $A \oplus \%$ & SoDer \\
\hline $160022 \mathrm{~F}$ & 8632 & 0.4 & 01456 & 00057 & 1292 & $00 B$ & 0.390 & $a 0 ; \theta$ & az31 & 0,000 \\
\hline $1600 \mathrm{E} 2 \mathrm{~F}+2$ & $\overline{2} \overline{3}$ & 039 & 0823 & $0.38 \pi$ & 128 & 0,7 & $0 \%$ & $a 006$ & 02310 & 0,05 \\
\hline dpdapg & 872 & $0 z$ & 0803 & azmo & 128 & 006 & 0.353 & 00004 & $a 204$ & 0,008 \\
\hline do-cosegte & 8605 & a13 & 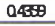 & a.139 & $12 \theta$ & $0.0 B$ & 03372 & 00,51 & 0209 & 0,000 \\
\hline \multirow[t]{3}{*}{$\forall k-0$ arg } & aEs & Q1106 & 9854 & 02007 & 0040 & $a \cos$ & 00086 & $00 \pi 0$ & 0008 & a1310 \\
\hline & \multicolumn{2}{|c|}{${ }^{m_{P U}}$} & \multicolumn{2}{|c|}{${ }_{\mathrm{Pu}}^{2 \mathrm{P}_{\mathrm{H}}}$} & \multicolumn{2}{|c|}{${ }^{20} \mathrm{Pu}$} & \multicolumn{2}{|c|}{${ }^{x x_{1}} \mathrm{PU}$} & \multicolumn{2}{|c|}{${ }^{20} \mathrm{Pu}_{4}$} \\
\hline & We\% & SLDer & $W \%$ & STer & we\% & StDer & We\% & StDer & We\% & stoev \\
\hline $16002 \mathrm{~F}$ & 8626 & 004 & Q.149 & acos & 1296 & $0 \omega 5$ & $0 \mp \pm 0$ & 0,000 & $a x \oplus$ & $a \cos 0$ \\
\hline 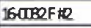 & 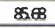 & 038 & 08184 & $0 \%$ & 1288 & 0.7 & $a \approx 17$ & 0008 & 02398 & 00000 \\
\hline deposeg G & 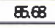 & $a z$ & 08084 & 0208 & 1287 & 005 & 03884 & $a c 044$ & Q.320 & 0.0050 \\
\hline dep-(ISPG G & 800 & a13 & Q4338 & Q1314 & 1294 & 0.8 & a五监 & $0 \cos 2$ & $0 \geq \pm 0$ & 0,008 \\
\hline$\forall k-\infty \Omega_{2}$ & 028 & Q1980 & 9954 & 02220 & QOEB & 0089 & 00005 & $0,0 A$ & $0.08 \pi$ & a.1330 \\
\hline
\end{tabular}

Blarks

\begin{tabular}{|c|c|c|c|c|c|c|}
\hline Sample ID & ${ }_{P u(\Phi)}$ & ${ }_{\text {Pu }}(\Phi)$ & ${ }^{20} \mathrm{Pu}_{\mathrm{u}}(\Phi \Phi)$ & ${ }^{241} \mathrm{Pu}\left(\mathrm{CW}^{2}\right)$ & ${ }^{20} \mathrm{Pu}(\mathrm{CQ})$ & 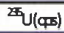 \\
\hline Filamert Bari & Q4 & 2 & a2 & Q4 & 02 & Q3 \\
\hline 946.5100 & 35078 & 78 & 5007 & 202 & 2444 & $\mathcal{B}$ \\
\hline Perert of interity & $0000 \%$ & $a z \%$ & $0.000 \%$ & $00 \%$ & $000 \%$ & 196 \\
\hline Sample ID & 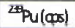 & Pul(x) & ${ }^{4} \mathrm{Pu}(\Phi)$ & pul(qs) & "Pu(pos) & $\bar{E}(\phi s)$ \\
\hline DiluertBark & 13 & 106 & 03 & 03 & 02 & a9 \\
\hline 946.51001 & $350 / 8$ & $7 \mathrm{BB}$ & 50007 & 2002 & 2414 & 23 \\
\hline Peroert of irternity & $0.10 \% \%$ & 1086 & 0 anom & $a \lll \%$ & $00 \%$ & 46 \\
\hline Sample ID & ${ }^{2 \theta_{\mathrm{P}}(\mathrm{q}(\mathrm{px})}$ & एक्रि(qx) & 29pu(ps) & ${ }^{241} \mathrm{Pu}(\mathrm{Qps})$ & 2epu(ps) & "द)(4\$) \\
\hline$\forall k-000$ & a6 & $2 \oplus$ & $a_{1}$ & 02 & 02 & 28 \\
\hline 946 StD 0 & 7978 & 78 & 5 勿7 & 200 & 2414 & $B$ \\
\hline Percert of irtensty & $0000 \%$ & $30 x$ & $a \cos x \%$ & $00 \%$ & $00 \%$ & 1706 \\
\hline
\end{tabular}

RPDAnalysis

\begin{tabular}{|c|c|c|c|c|c|}
\hline Sampla ID & ${ }^{720} \mathrm{Pu}(\mathrm{ANO})$ & 28u(AeA) & ${ }^{20}$ PulAea & ${ }^{2 x \mid P u}\left(A^{*} A\right)$ & ${ }^{20}$ Pu(AEA) \\
\hline 16002 & 8632 & 01456 & 1292 & 03900 & 0234 \\
\hline $160002 \mathrm{~F}=$ & $8 \pi$ & 0823 & 1283 & 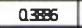 & az310 \\
\hline $\mathrm{APC}$ & $Q \notin \#$ & $100 \%$ & $a_{67 \%}$ & $0,0 \%$ & $13 \% \%$ \\
\hline deposec & 8ूर & 08323 & 1288 & 0.358 & 02304 \\
\hline dp-CDERG & s605 & $0450 \theta$ & $12 \Phi$ & $038 \pi 2$ & $a<2$ \\
\hline PPC & Q3⿻肀 & 6 & $049 \%$ & $047 \%$ & 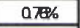 \\
\hline Sample 10 & ${ }^{35} \mathrm{Pu}(\mathrm{w}$ (e) & ${ }_{\text {Rutwed }}$ & 2hur(ned) & 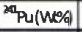 & ${ }^{20} \mathrm{Pu}$ (wed \\
\hline 160002 & 8626 & 01449 & 1296 & $0 \times 900$ & 0209 \\
\hline $1600 \mathrm{RO} \mathrm{FH}$ & $\boldsymbol{E} \in \mathbf{B}$ & 08184 & 128 & $0 \approx 70$ & az338 \\
\hline $\mathrm{PPC}$ & $07 \%$ & 1006 & $07 \%$ & $0.1 \%$ & $19 \%$ \\
\hline denosec & Eळक & 08884 & 128 & 03 & 02352 \\
\hline 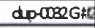 & 8600 & 0438 & 1294 & Q & $a 2 \pm 0$ \\
\hline & $04 \%$ & 6 & $0.9 \%$ & $09 \%$ & $0 \$$ \\
\hline
\end{tabular}

Duplicate andysis

\begin{tabular}{|c|c|c|c|c|c|}
\hline Sample ID & ${ }^{24} \mathrm{Pu}(\mathrm{W}$ CO) & $2 \pi \mathrm{Pu}(\mathrm{M}$ Cof & "Pu(Me/a) & ${ }^{21}$ Pu (Wes) & ${ }^{\infty}$ Pu (Wto) \\
\hline 160002 & $\$ 26$ & a149 & 1296 & 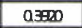 & 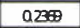 \\
\hline $1600125 \mathrm{~F}$ 相 & கூகB & a8184 & 1288 & $a \geq 17$ & $02 x$ \\
\hline $1600 \mathrm{R} 2 \mathrm{Fel}$ & 80 & 01300 & 1296 & $0 \geq 911$ & $a 2 \oplus$ \\
\hline Averaf & 8608 & ax44 & 129 & $0 \geq 916$ & 0208 \\
\hline$\%$ & am & II. .9 & 03712 & a112n & axs \\
\hline
\end{tabular}

Standards and LCS analysis

\begin{tabular}{|c|c|c|c|c|c|}
\hline Name & ${ }^{27} \mathrm{Pu}(\mathrm{ACA}$ & ${ }^{27} \mathrm{Pu}(\mathrm{AEC})$ & ${ }^{20} \mathrm{Pu}(\mathrm{ACO})$ & ${ }^{2 \pi} \mathrm{Pu}(\mathrm{AOQ})$ & 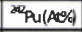 \\
\hline SPMgene & 863 & 0.9 & 1250 & 049 & 059 \\
\hline $\mathrm{RSD}$ & 0.000 & $a \mathbb{R}^{-}$ & acor & aol & Q.01 \\
\hline Certifiedvalue & $8 B 3$ & Q.1814 & 1251 & 0.402 & 0,580 \\
\hline Pecowery & $100 \%$ & $1021 \%$ & $99 \%$ & 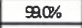 & $101 \%$ \\
\hline Controd Lints & ${ }^{27 P u}(\mathrm{ACA}$ & ${ }^{2 \pi} \mathrm{Pu}(\mathrm{AeC})$ & ${ }^{209}$ Pu(ACA) & ${ }^{20} \mathrm{Pu}(\mathrm{AeO})$ & ${ }^{B D} \mathrm{Pu}(\mathrm{AE} \%)$ \\
\hline uper & $\mathbf{8 3 1 1}$ & 0.1900 & 1254 & 06000 & 05891 \\
\hline Lover & 8606 & Q1ens & 1247 & 0.4344 & 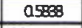 \\
\hline Nerme & ${ }^{25} \mathrm{Pu}(\mathrm{At} / \mathrm{A}$ & Thu(A) & ${ }^{20} \mathrm{Pu}(\mathrm{AeC})$ & ${ }^{2 \pi} \mathrm{Pu}(\mathrm{A} \% \mathrm{~A}$ & ${ }^{20} \mathrm{Pu}(\mathrm{At} / \mathrm{\alpha})$ \\
\hline SRMPAT & 7892 & 024 & 1901 & an & 183 \\
\hline $\mathrm{RSI}$ & $a 000 B$ & 0,00 & oan & $00 B$ & and \\
\hline Certifiedvalue & 789 & 02010 & 1906 & aston & 1221 \\
\hline Poovery & $10 \%$ & $1081 \%$ & $9 \%$ & $1064 \%$ & $99 \%$ \\
\hline Controd limits & ${ }^{I B P} \mathrm{Pu}(\mathrm{A} \in \mathrm{A}$ & ${ }^{20 p}$ Pu(ACA) & ${ }^{20} \mathrm{Pu}(\mathrm{ALC})$ & ${ }^{2+1} \mathrm{Pu}(\mathrm{ALOA}$ & ${ }^{2 \pi} \mathrm{Pu}(\mathrm{AN} \%)$ \\
\hline Utper & 706 & 030 & 1904 & $a \pi$ & 124 \\
\hline Lover & $78 \pi$ & 016 & 1B9 & 0.5 & 124 \\
\hline Poded PEC & 0,0004 & 0038 & 00008 & 0098 & 0007 \\
\hline
\end{tabular}


PNNL/Radiochemistry Processing Laboratory

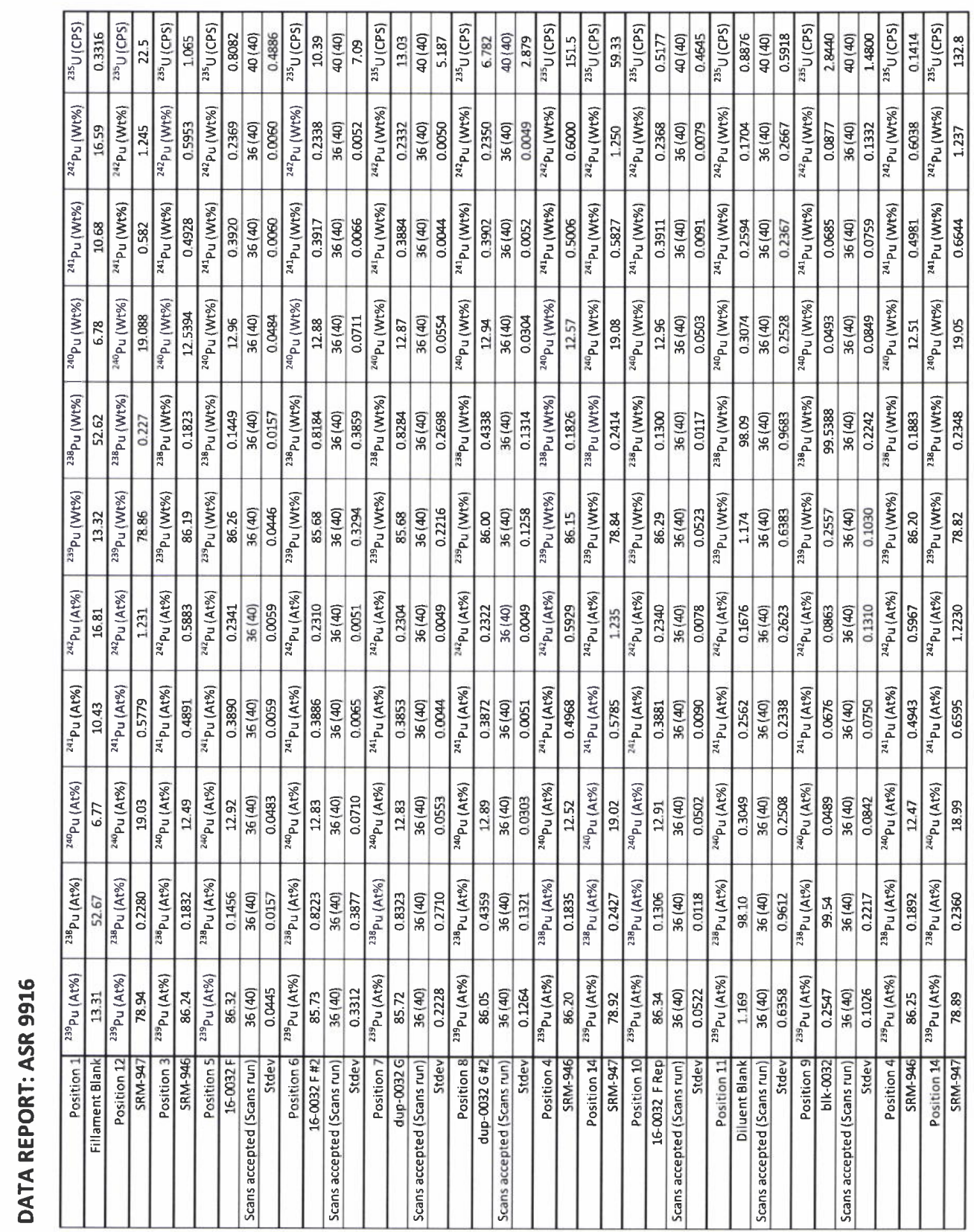

Page 9 of 9 
PNNL-25241

$\begin{array}{ll}\begin{array}{ll}\text { Title: } & \text { Radiochemical data reduction } \\ \text { Filename: } & \text { ASR } 9916 \text { Data Reduction.xIsx }\end{array} \\ \text { Revision: } & 0\end{array}$

Date Prepared: $\quad 1 / 21 / 2016$

Prepared By: $\quad$ SK Fiskum

Purpose: $\quad$ The purpose of this spreadsheet is to calculate the activity concentration as a wet settled solids, total slurry concentration from the reported dry solids concentrations.

Approach: $\quad$ Centrifuged solids mass and volume data are copied from 68122-TI-001 Data Reduction Final. The dry wt \% solids was added from the ASO report for ASR 9916.

The GEA, alpha-emitter, and Sr-90 data reported by ASO was converted to total $\mathrm{UCi}$ in the acid digest and the UDS. The total uCi content in the dissolved fraction was calculated (dissolved $\mathrm{uCi} /$ total uCi) for each analyte. More than $99 \%$ of the activity dissolved except for Co-60 where 91 to $93 \%$ of the Co-60 dissolved.

The dissolved isotope activity was converted to the centrifuged solids mass basis by dividing the total $\mathrm{uCi}$ by the wet centrifuged solids mass. A similar calculation was conducted to evaluate the activity concentration as a function of wet centrifuged solids volume.

Finally, the isotopic ratios of Pu was compared to Sr-90 and Cs-137 to see if there was a different fractionation in the sand filter solids relative to the $K$ Basin sludge. In this case, the sand filter solids relative Pu content was significantly higher than that of the sludge and suspended solids from the settling tests. 
PNNL-25241

Grav shaded values imported from 68122-TI-001.

\begin{tabular}{|c|c|c|c|c|c|c|c|c|c|c|}
\hline Parent Container ID & $\begin{array}{l}\text { Container } \\
\text { Type }\end{array}$ & 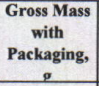 & $\begin{array}{c}\text { Packaging } \\
\text { Mass, } \mathbf{g}\end{array}$ & $\begin{array}{l}\text { Gross Sample } \\
\text { Container } \\
\text { Mass, g }\end{array}$ & $\begin{array}{c}\text { Empty Mass } \\
\text { with } \\
\text { Packaging, g }\end{array}$ & $\begin{array}{c}\text { Packaging } \\
\text { Mass, g }\end{array}$ & $\begin{array}{c}\text { Empty Sample } \\
\text { Container } \\
\text { Mass, g }\end{array}$ & $\begin{array}{l}\text { Net Slurry } \\
\text { Mass, g }\end{array}$ & $\begin{array}{l}\text { Centrifuged } \\
\text { Solids, wt\% }\end{array}$ & $\begin{array}{c}\text { Dry Solids, } \\
\text { wt } \%\end{array}$ \\
\hline KW-105SFBW-001 & $\begin{array}{l}\text { 1-L poly } \\
\text { bottle }\end{array}$ & 887.0 & 31.2 & 855.8 & 123.1 & 31.5 & 91.6 & 764.2 & $0.11 \%$ & $0.0146 \%$ \\
\hline
\end{tabular}

\begin{tabular}{|c|c|c|c|c|c|c|c|c|}
\hline Subsample Container ID & $\begin{array}{l}\text { Container } \\
\text { Type }\end{array}$ & Tare, $\mathrm{g}$ & $\begin{array}{c}\text { Gross Mass, } \\
\mathrm{g}\end{array}$ & $\begin{array}{c}\text { Sludge Volume, } \\
\mathrm{mL}^{*}\end{array}$ & $\begin{array}{l}\text { Total Slurry } \\
\text { Volume, mL }\end{array}$ & $\begin{array}{l}\text { Net Slurry } \\
\text { Mass, g }\end{array}$ & $\left|\begin{array}{l}\text { Net Centrifuged } \\
\text { Sludge Mass, } \mathrm{g}^{\star}\end{array}\right|$ & $\begin{array}{c}\text { Centrifuged } \\
\text { Sludge } \\
\text { Density, } \\
\mathrm{g} / \mathrm{mL}^{\star}\end{array}$ \\
\hline 68122-TI-001-F & $\begin{array}{l}10 \text {-mL glass } \\
\text { cent tube }\end{array}$ & 20.6859 & 21.2217 & 0.40 & 0.50 & 0.5358 & 0.44 & $1.09 * *$ \\
\hline 68122-TI-001-G & $\begin{array}{l}10 \text {-mL glass } \\
\text { cent tube }\end{array}$ & 20.6253 & 21.1095 & 0.40 & 0.50 & 0.4842 & 0.38 & 0.96 \\
\hline
\end{tabular}

Assumption: the water density is $1 \mathrm{~g} / \mathrm{mL}$.

as slightly confounded by the slanted surface of sludge in the centrifuge tube

**The third significant figure is shown for information only.

ASR 9916 dry solids mass data

68122-TI-001-F

16-0032

$\frac{\text { Dry solids mass, } \mathrm{g} \quad \text { UDS (post acid digestion), g }}{0.0545}$

0.0568

0.0039
0.0039

0.0039

\begin{tabular}{rc} 
wt $\%$ UDS & Mass loss on drying \\
\hline $6.7 \%$ & $87 \%$ \\
$6.4 \%$ & $85 \%$ \\
$6.5 \%$ &
\end{tabular}

Sum

0.1113

Uncertainty estimation

Sample ID

Backwash Sand Filter Sample

Sample information
Container information

68122-TI-001-F
Wet centrifuged solids
Sample

Wet centrifuged solids

Sample

Container tare mass
Vial + cent solids + aq

Cent sludge volume
Slurry (total) solids volume

$\begin{array}{ll}\text { Liquid density } & \mathrm{mL} \\ \text { Liquid volume } & \mathrm{mL}\end{array}$

Liquid mass

Cent sludge mas

Cent sludge density

\begin{tabular}{lrrr} 
Units & 10-mL glass cent tube \\
\hline Value Uncertainty \\
\hline $\mathrm{g}$ & $\mathbf{2 0 . 6 8 5 9}$ & 0.0021 & $0.010 \%$ \\
$\mathrm{~g}$ & $\mathbf{2 1 . 2 2 1 7}$ & 0.0021 & $0.010 \%$ \\
$\mathrm{~mL}$ & $\mathbf{0 . 4 0}$ & 0.05 & $12.5 \%$ \\
$\mathrm{~mL}$ & $\mathbf{0 . 5 0}$ & 0.05 & $10.0 \%$ \\
$\mathrm{~g} / \mathrm{mL}$ & 1.0 & 0.005 & $0.5 \%$ \\
$\mathrm{~mL}$ & 0.10 & 0.07 & $70.7 \%$ \\
$\mathrm{~g}$ & 0.10 & 0.07 & $70.7 \%$ \\
$\mathrm{~g}$ & 0.44 & 0.07 & $\mathbf{1 6 . 2} \%$ \\
$\mathrm{~g} / \mathrm{mL}$ & 1.09 & 0.22 & $20.5 \%$ \\
& & &
\end{tabular}

Balances
Balance ID

Balance range

$\begin{array}{rr}\text { ASO } & \text { Proiect } \\ 1113292667 & \text { N04143 }\end{array}$

$299.9980 \quad 299.9978$ lower control bound

$300.0022 \quad 300.0020$ upper control bound

$0.0042 \quad 0.0042$ Range interva

$0.0021 \quad 0.0021$ Half range inerval (balance uncertainty)

Sample ID

Backwash Sand Filter Sample

Sample information

16-0032
Dry solids

Dry solids
Sample

Container information Unis

10 -mL $g$

Container tare mas

Cent sludge mass

Units
$\mathrm{g}$
$\mathrm{g}$

$\begin{array}{lll}\mathbf{2 0 . 6 8 5 9} & 0.0021 & 0.01 \%\end{array}$

$\begin{array}{lll}20.7404 & 0.0021 & 0.01 \%\end{array}$

68122-TI-001-G

Wet centrifuged solids

Duplicate

10-mL glass cent tube

Value Uncertainty

$\begin{array}{lll}20.6253 & 0.0021 & 0.010 \%\end{array}$

21.109

0.4

0.50

0.1
0.1
0.38
0.96

g

16-0032 dup

Dry Solids

Duplicat

10-mL glass cent tube

Value Uncertainty

\begin{tabular}{ccc}
\multicolumn{2}{c}{ Value Uncertainty } \\
$\mathbf{2 0 . 6 2 5 3}$ & 0.0021 & $0.01 \%$ \\
$\mathbf{2 0 . 6 8 2 1}$ & 0.0021 & $0.01 \%$ \\
0.0568 & 0.0030 & $\mathbf{5 . 2 \%}$
\end{tabular}

File: ASR 9916 Data Reduction.xlsx 


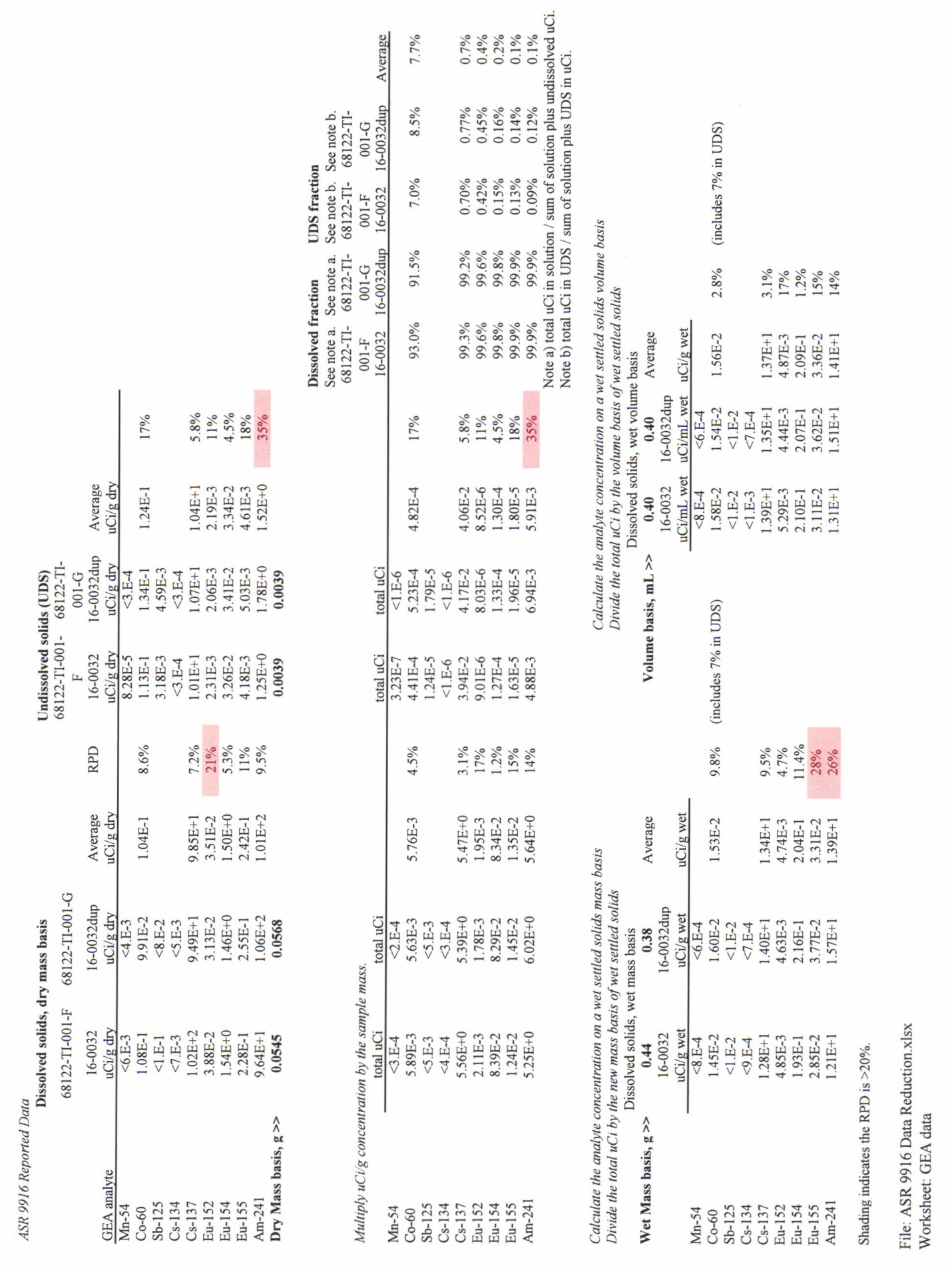


PNNL-25241
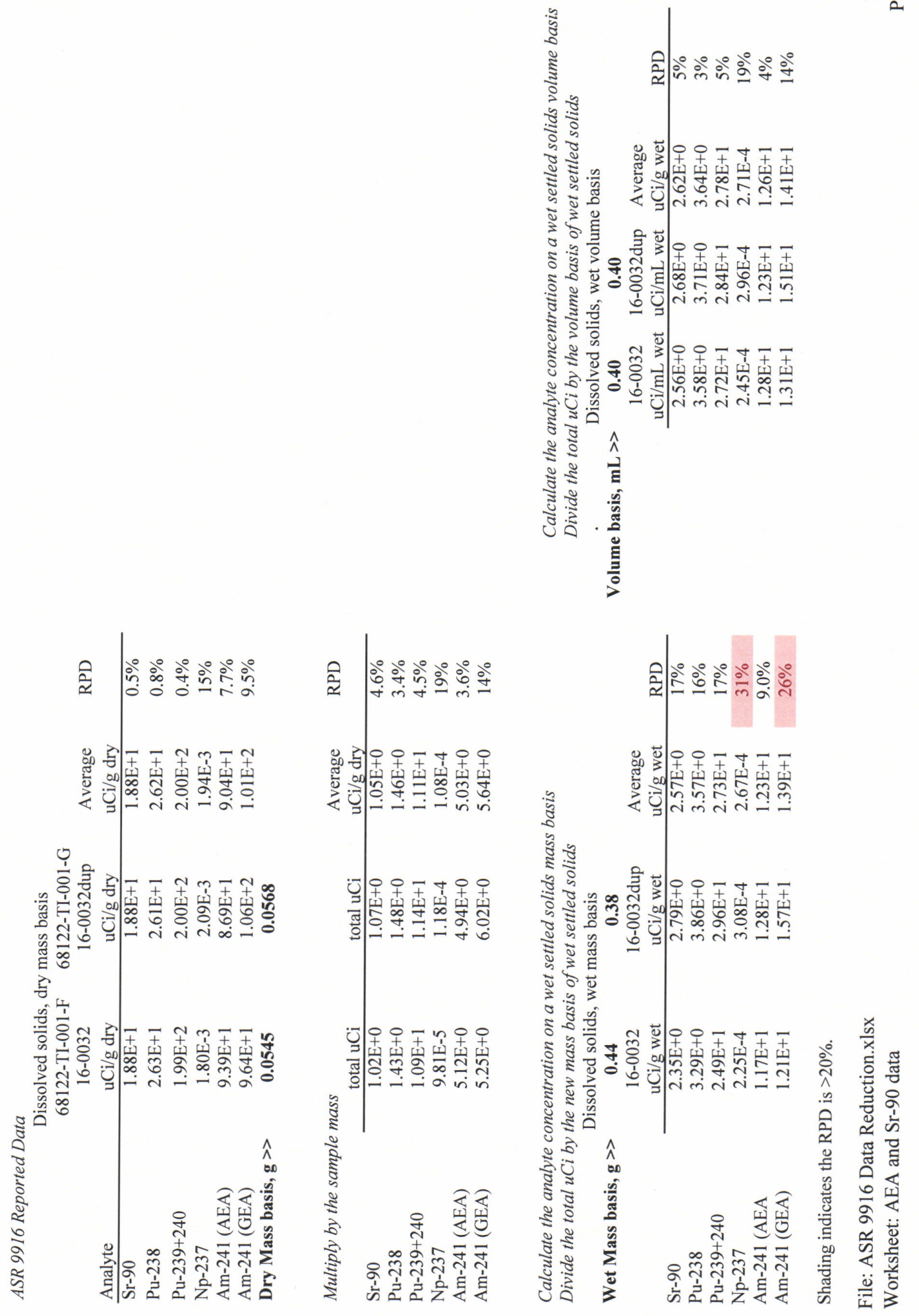
PNNL-25241

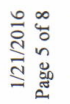

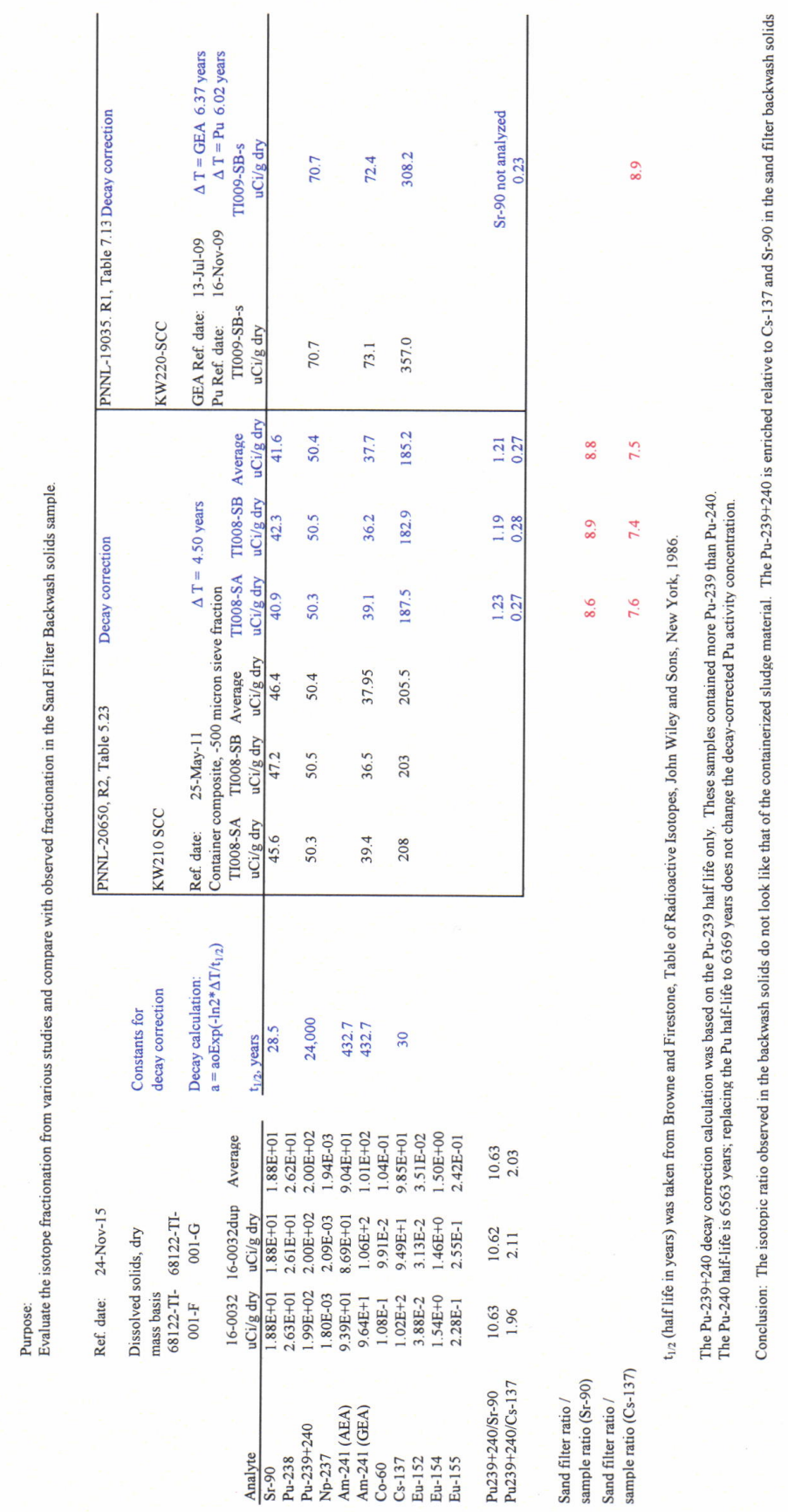


PNNL-25241

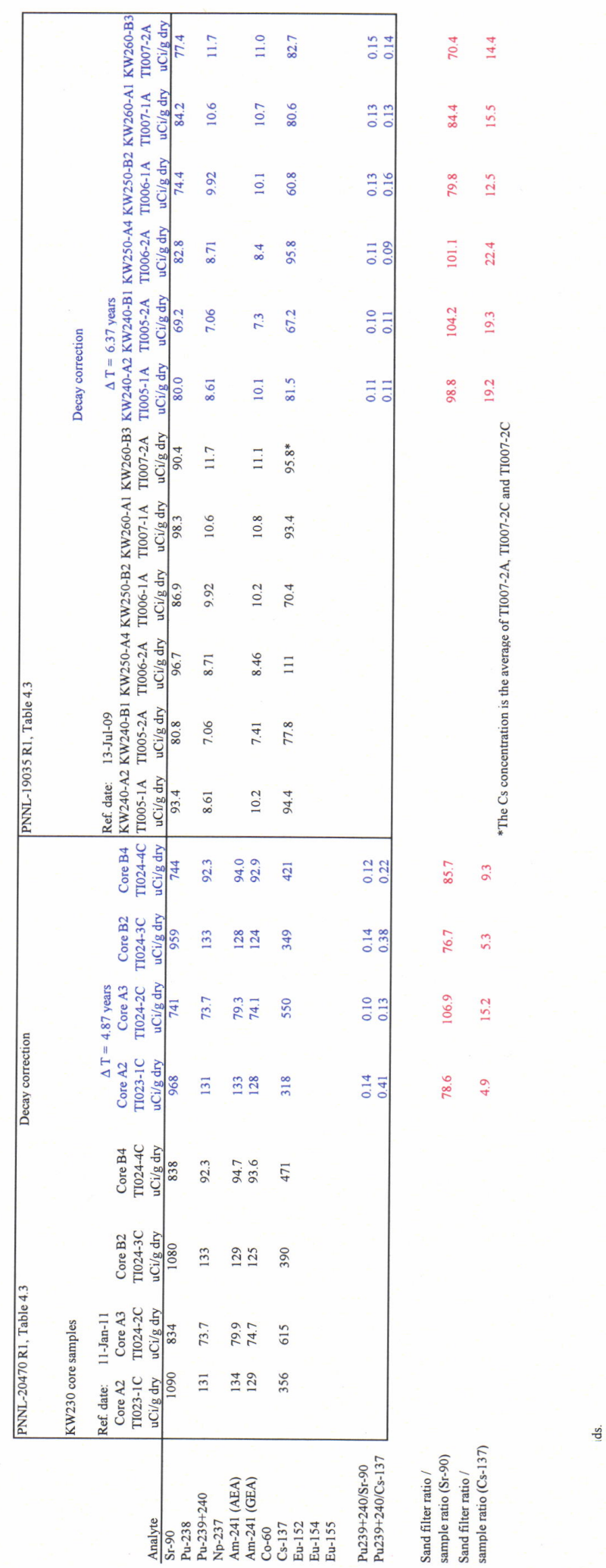


PNNL-25241

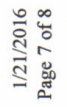

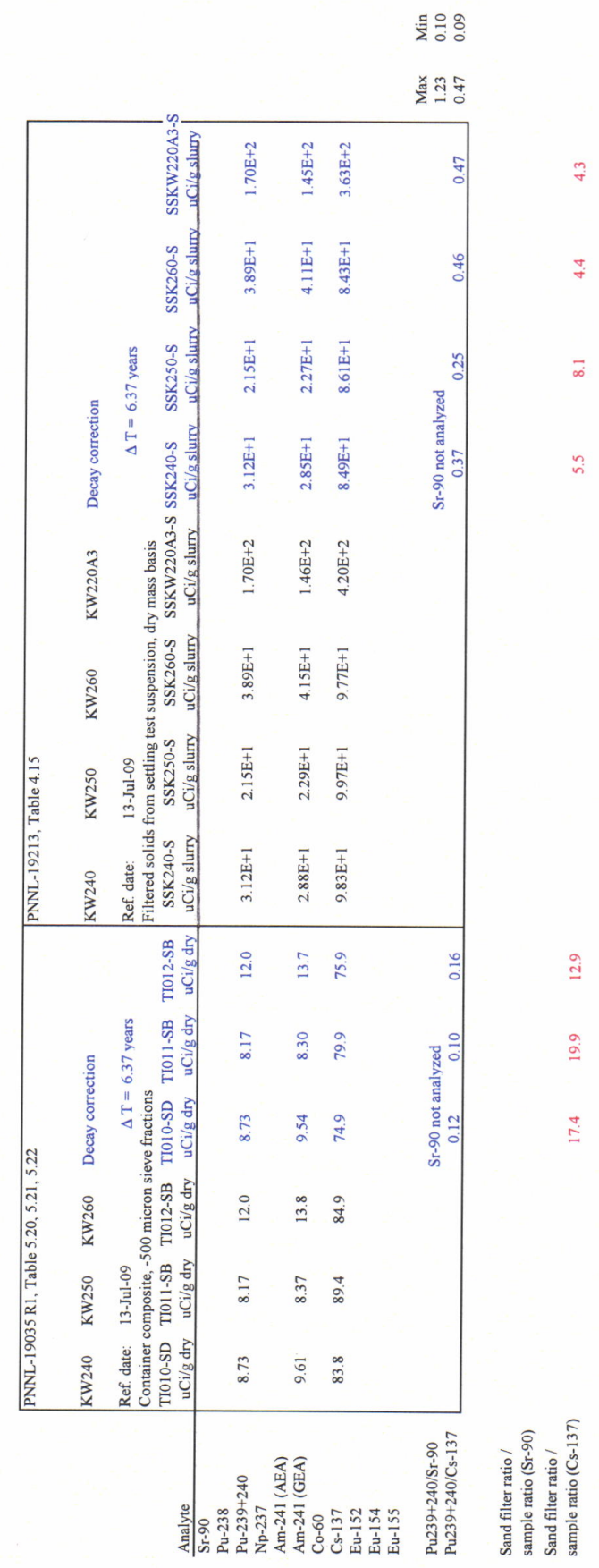


Spreadsheet Review Form

\begin{tabular}{|l|c|l|c|}
\hline Spreadsheet Author Name: & SK Fiskum & Review Date: & $2 / 9 / 2016$ \\
\hline Date Prepared: & $1 / 21 / 2016$ & Spreadsheet Subject: & $\begin{array}{c}\text { Sand filter back wash solids } \\
\text { radiochemical characterization }\end{array}$ \\
\hline Reviewer Name: & Rick Shimskey & File Name: & ASR 9916 Data Reduction.xlsx \\
\hline Reviewer Title: & Research Engineer & Revision No. & 0 \\
\hline
\end{tabular}

Scope of Spreadsheet Review: (Check one or more of the following)

\begin{tabular}{|l|l|l|l|}
\hline$\square$ & $\begin{array}{l}\text { General Validation Review: (General review and } \\
\text { spot checks) }\end{array}$ & $\square$ & $\begin{array}{l}\text { Independent calculation check (With hand calculations or } \\
\text { independent spreadsheet software) }\end{array}$ \\
\hline$\square$ & $\begin{array}{l}\text { Review of updated spreadsheet/calc (Revised } \\
\text { portion only) }\end{array}$ & $\square$ & Other: \\
\hline$\square$ & $\begin{array}{l}\text { l00\% Verification Review (Verification of all } \\
\text { cells/calculations) }\end{array}$ & & \\
\hline
\end{tabular}

\section{REVIEW CHECK LIST}

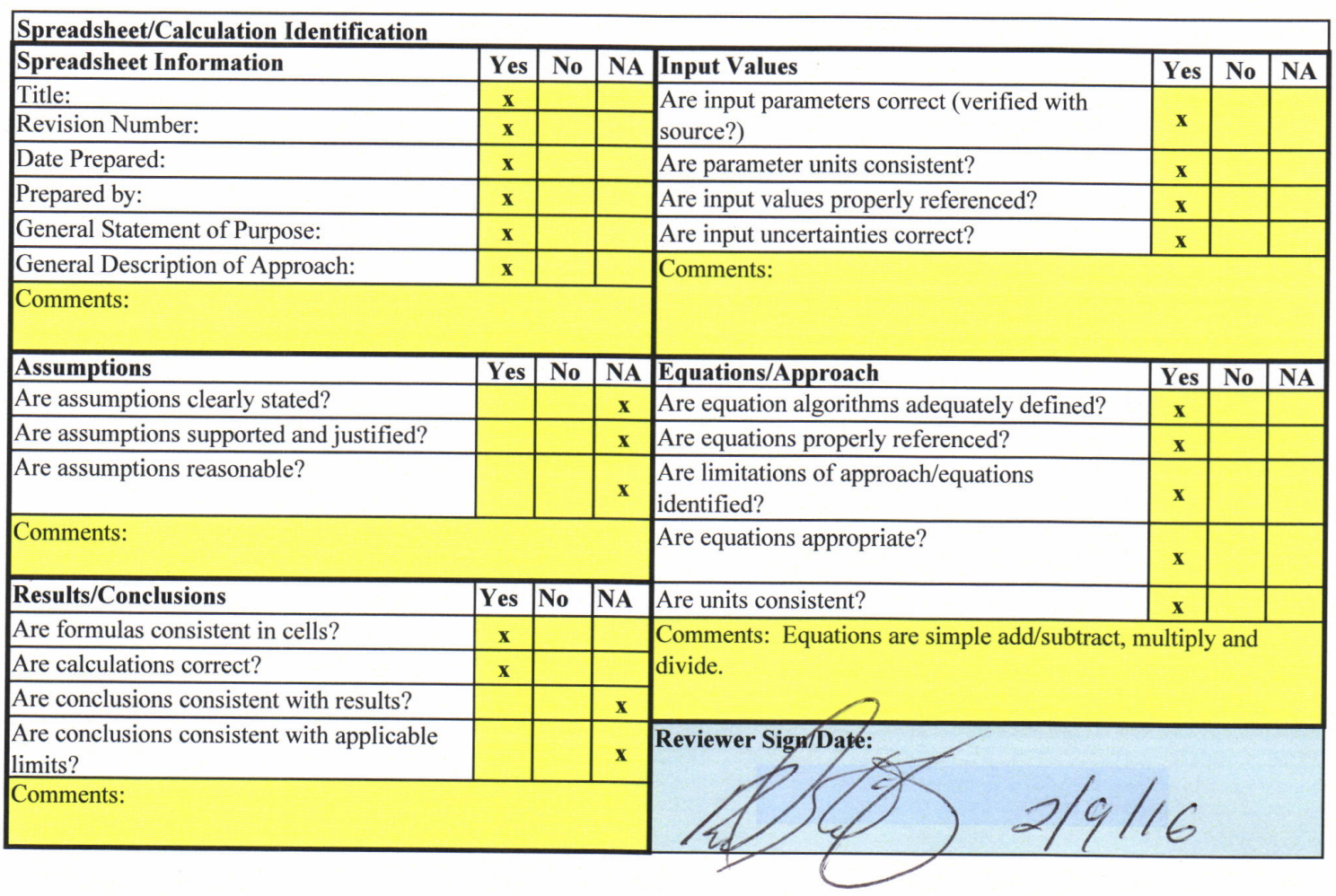


PNNL-25241

Filename: ASR 9916 Pu isotopic correction Rev. 1.xlsx

Tab: ASR $9916 \mathrm{Pu}$ isotopic correction Rev. 1.xlsx

The samples were each prepared in duplicate for TIMS analysis.

This spreadsheet tab averages each sample pair.

It also calculates the fraction of Pu-239 relative to the sum of $\mathrm{Pu}-239$ and $\mathrm{Pu}-240$

The average values are rolled up into the next tab, Radionuc. Calc.

\begin{tabular}{|c|c|c|c|c|c|}
\hline & $\begin{array}{l}\text { Pu-239 } \\
\text { Atom \% }\end{array}$ & Pu-238 & Pu-240 & Pu-241 & Pu-242 \\
\hline $16-0032 \mathrm{~F}$ & 86.32 & 0.1456 & 12.92 & 0.3890 & 0.2341 \\
\hline $16-0032 \mathrm{F \# 2}$ & 85.73 & 0.8223 & 12.83 & 0.3886 & 0.2310 \\
\hline dup-0032 G & 85.72 & 0.8323 & 12.83 & 0.3853 & 0.2304 \\
\hline dup-0032 G \#2 & 86.05 & 0.4359 & 12.89 & 0.3872 & 0.2322 \\
\hline \multicolumn{6}{|c|}{ Average of the replicate preparations } \\
\hline $16-0032 \mathrm{~F}$ & 86.03 & 0.4840 & 12.88 & 0.3888 & 0.2326 \\
\hline \multirow[t]{2}{*}{$16-0032 \mathrm{G}$} & 85.89 & 0.6341 & 12.86 & 0.3863 & 0.2313 \\
\hline & Weight \% & & & & \\
\hline $16-0032 \mathrm{~F}$ & 86.26 & 0.1449 & 12.96 & 0.3920 & 0.2369 \\
\hline $16-0032 \mathrm{~F} \# 2$ & 85.68 & 0.8184 & 12.88 & 0.3917 & 0.2338 \\
\hline dup-0032 G & 85.68 & 0.8284 & 12.87 & 0.3884 & 0.2332 \\
\hline dup-0032 G \#2 & 86.00 & 0.4338 & 12.94 & 0.3902 & 0.2350 \\
\hline \multicolumn{6}{|c|}{ Average of the replicate preparations } \\
\hline $16-0032 \mathrm{~F}$ & 85.97 & 0.4817 & 12.92 & 0.3919 & 0.2354 \\
\hline $16-0032 \mathrm{G}$ & 85.84 & 0.6311 & 12.91 & 0.3893 & 0.2341 \\
\hline
\end{tabular}

$\frac{\text { Atom fraction }{ }^{239} \mathrm{Pu} \text { in }{ }^{239,240} \mathrm{Pu}}{0.869818}$

Weight fraction ${ }^{239} \mathrm{Pu}$ in ${ }^{239,240} \mathrm{Pu}$ 0.86935

0.86931 

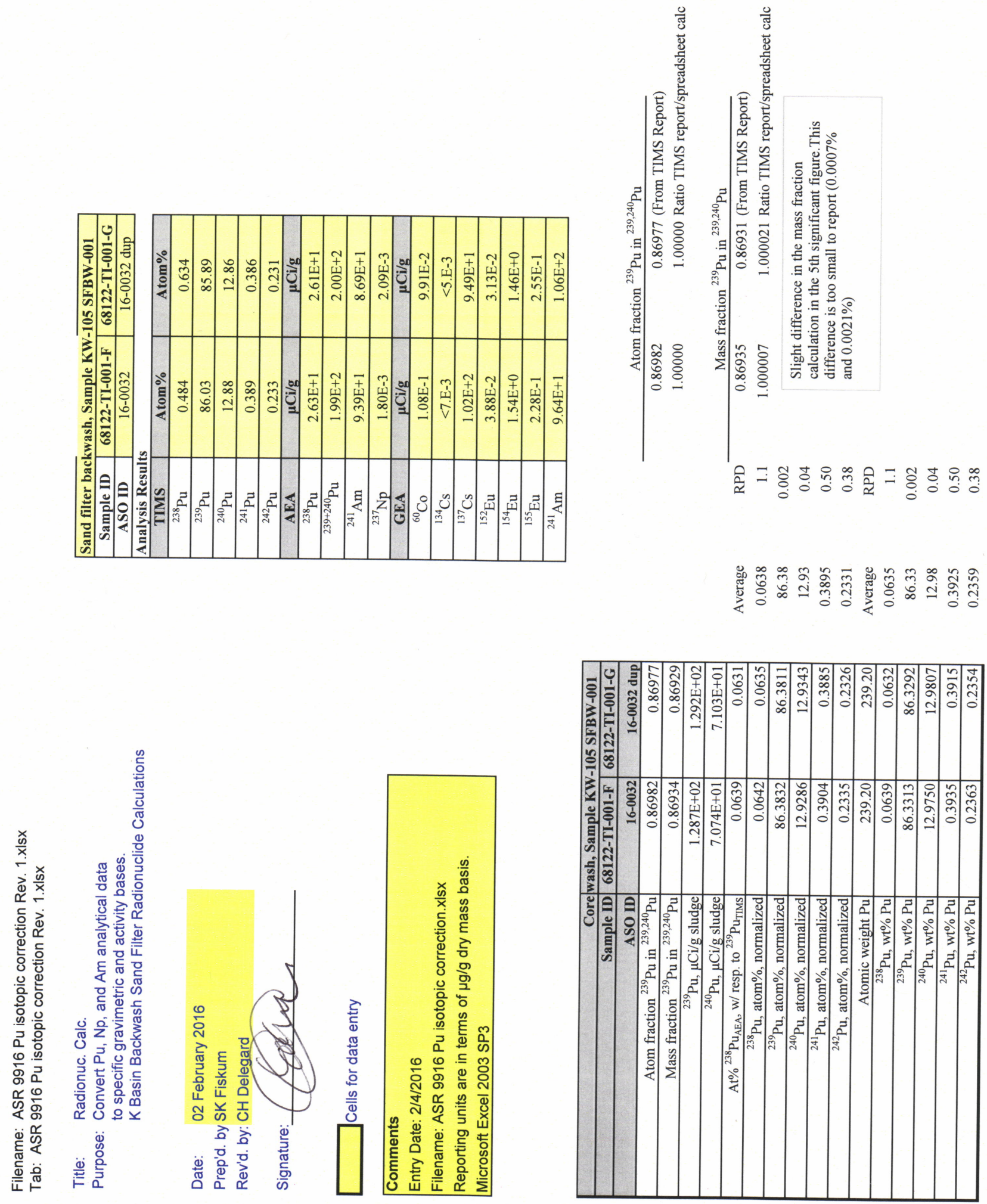

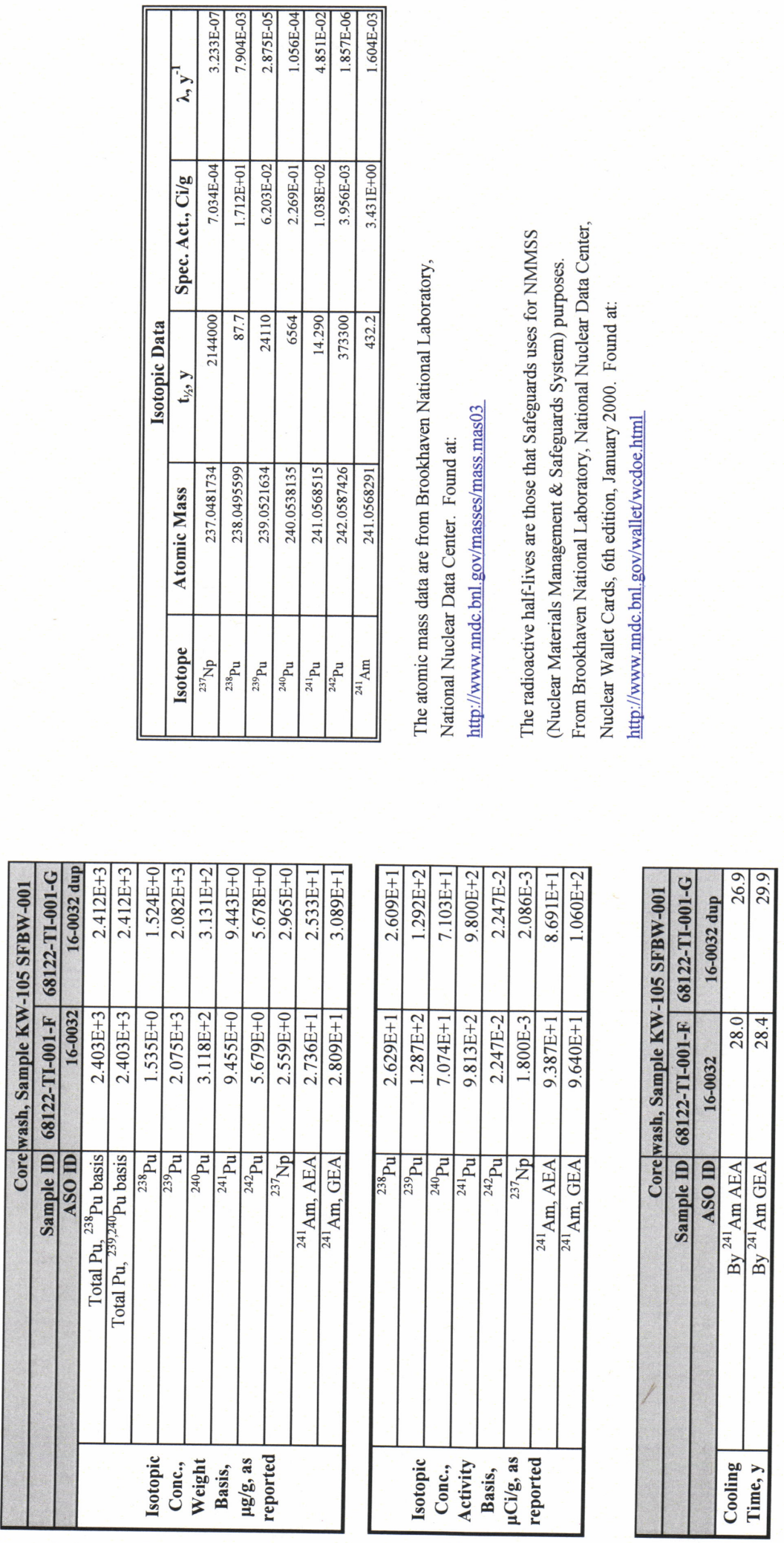
PNNL-25241

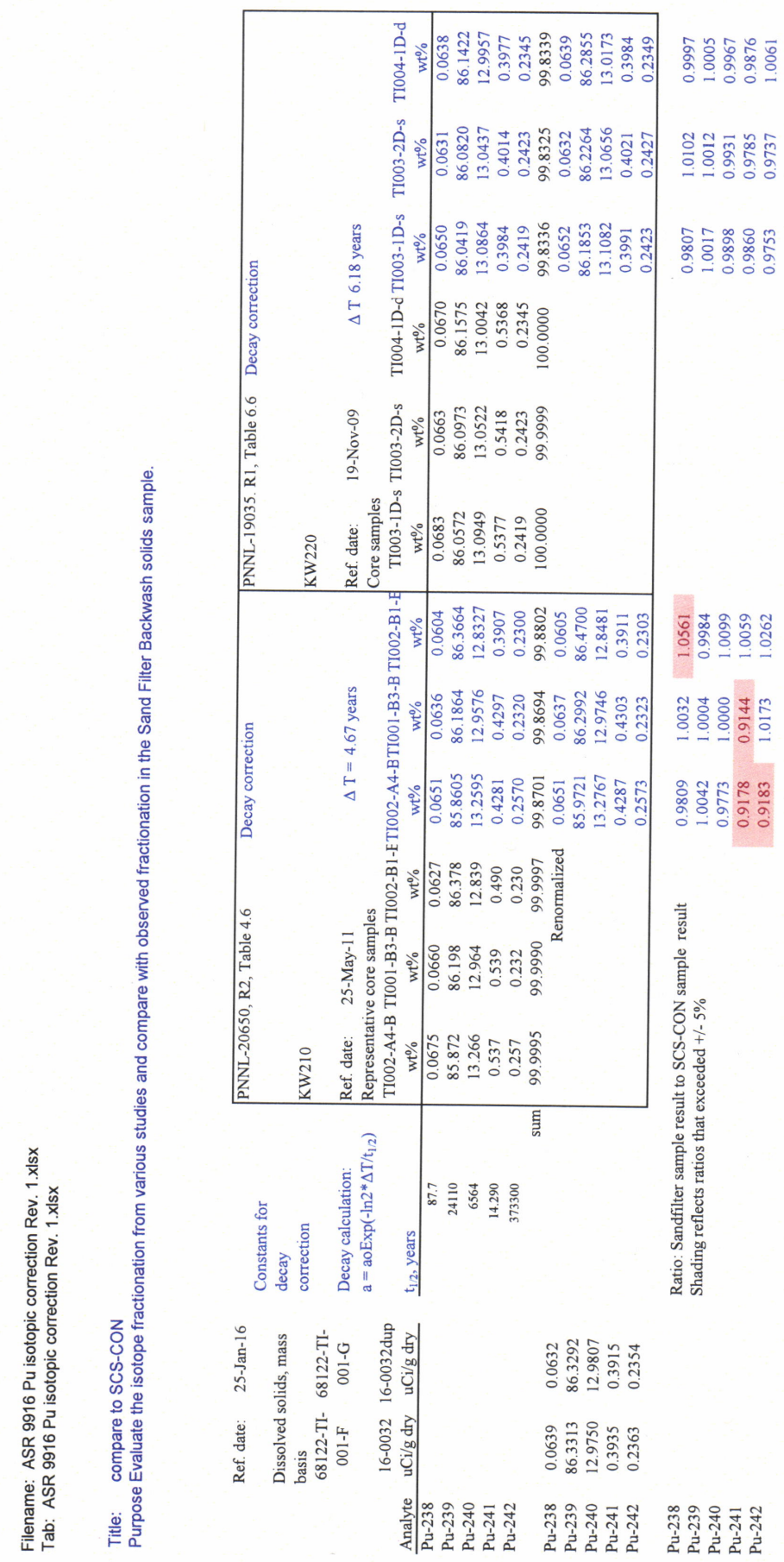


PNNL-25241

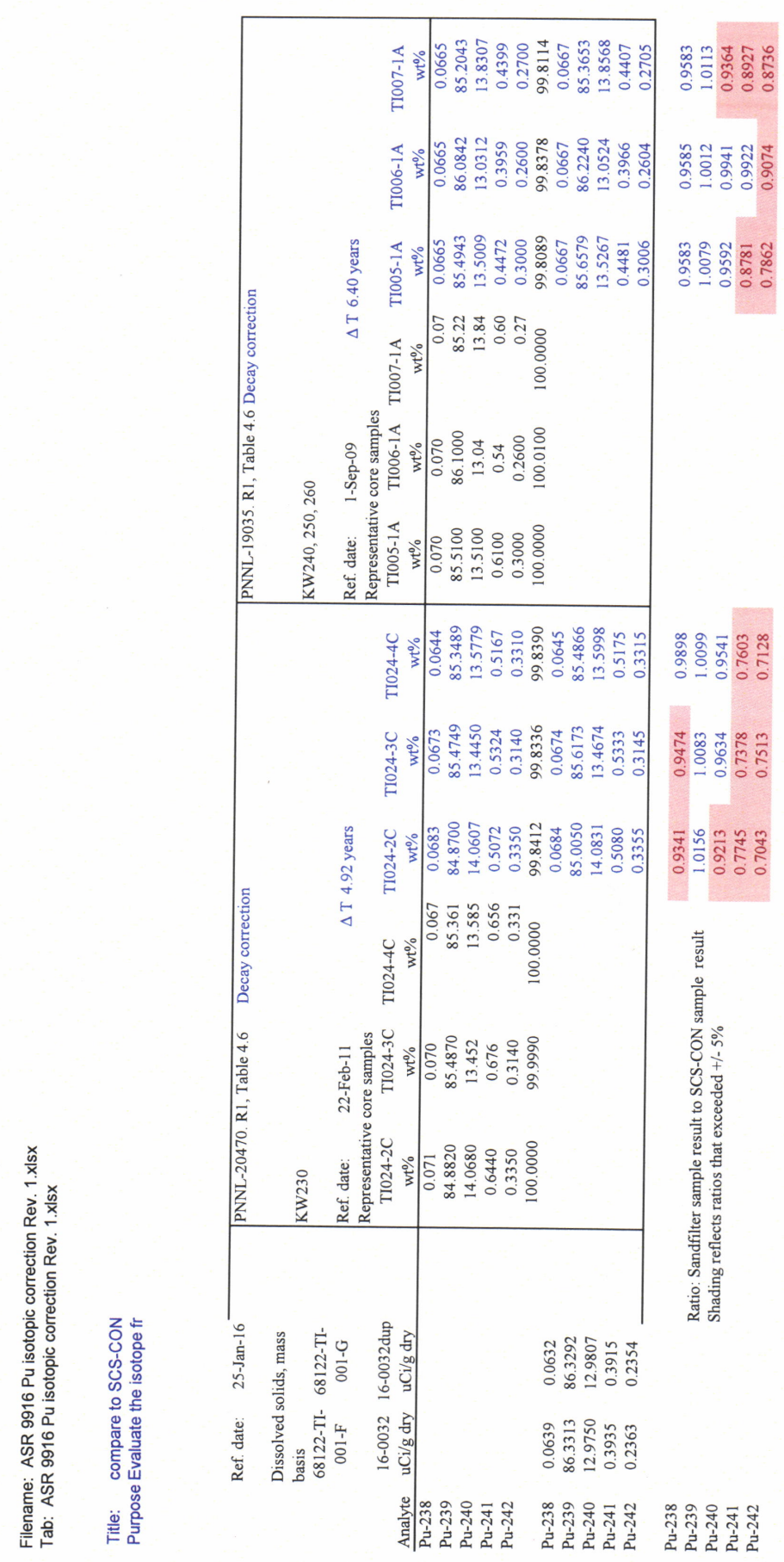


Filename: ASR $9916 \mathrm{Pu}$ isotopic correction Rev. 1.xIsx

Tab: ASR $9916 \mathrm{Pu}$ isotopic correction Rev. 1.xlsx

\section{Spreadsheet Review Form}

\begin{tabular}{|l|c|l|c|}
\hline Spreadsheet Author Name: & SK Fiskum & Review Date: & $2 / 10 / 2016$ \\
\hline Date Prepared: & $2 / 2 / 2016$ & Spreadsheet Subject: & "Radionuc. Calc." tab \\
\hline Reviewer Name: & Cal Delegard & File Name: & ASR 9916 Pu isotopic correction.xlsx \\
\hline Reviewer Title: & chemist & Revision No. & 1 \\
\hline
\end{tabular}

\section{Scope of Spreadsheet Review: (Check one or more of the following)}

\begin{tabular}{|l|l|l|l|}
\hline$\square$ & $\begin{array}{l}\text { General Validation Review: (General review and } \\
\text { spot checks) }\end{array}$ & $\square$ & $\begin{array}{l}\text { Independent calculation check (With hand calculations or } \\
\text { independent spreadsheet software) }\end{array}$ \\
\hline$\square$ & $\begin{array}{l}\text { Review of updated spreadsheet/calc (Revised } \\
\text { portion only) }\end{array}$ & $\square$ & $\begin{array}{l}\text { Other: Point-by-point 100\% review of TIMS data input (TIMS } \\
\text { calculation spreadsheet) to "Radionuc. Calc." tab. }\end{array}$ \\
\hline $\mathbf{X}$ & $\begin{array}{l}100 \% \text { Verification Review (Verification of all } \\
\text { cells/calculations) }\end{array}$ & & \\
\hline
\end{tabular}

\section{REVIEW CHECK LIST}

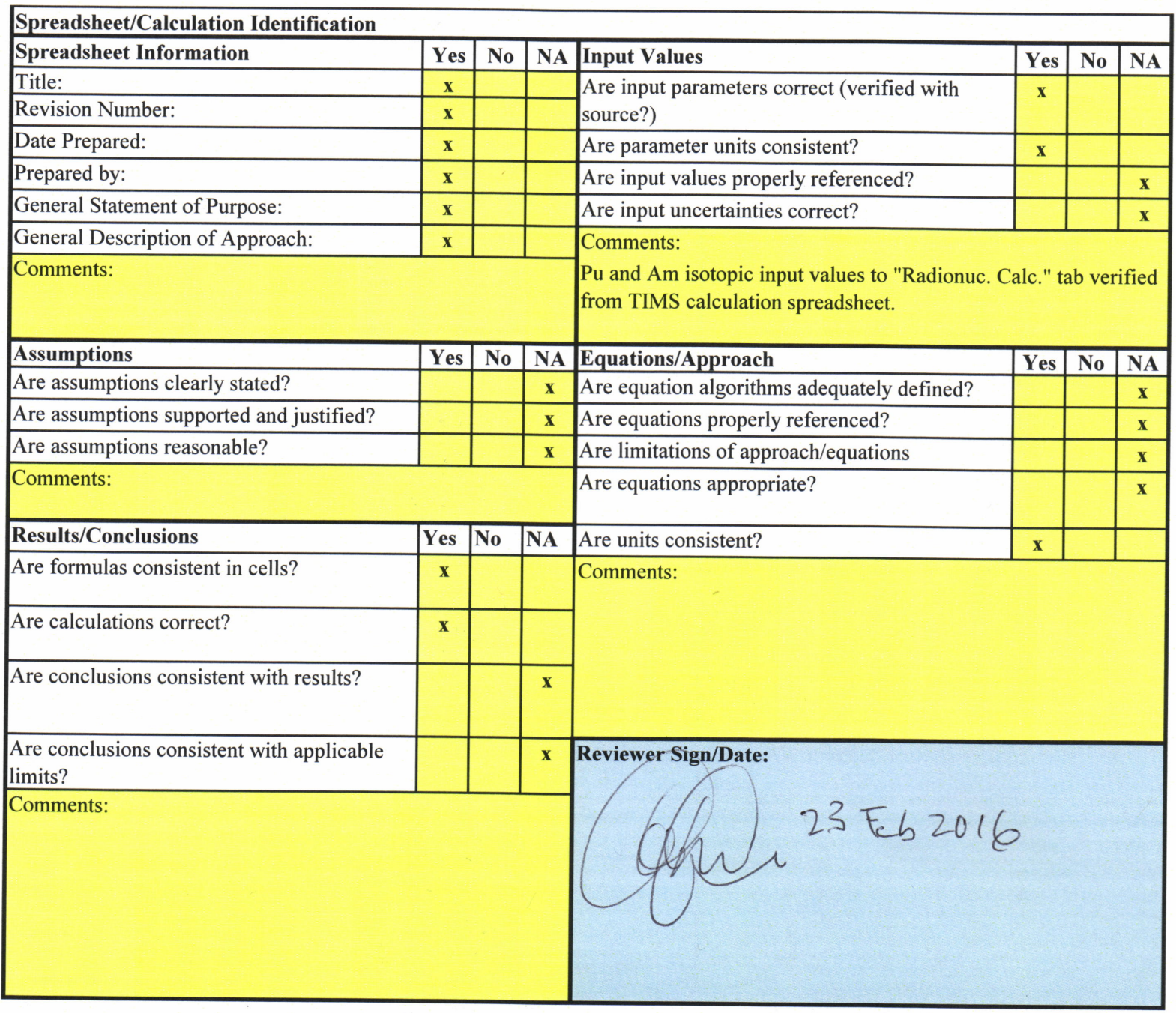





\section{Distribution}

No. of

Copies

10 Local Distribution

CH2M Hill Plateau Remediation Corporation

GM Davis

$\mathrm{X} 4-01$

EG Erpenbeck

$\mathrm{N} 2-70$

ME Johnson

$\mathrm{X} 4-01$

CS Thurlow

G3-39

Pacific Northwest National Laboratory

SK Fiskum

P7-25

MR Smoot

$\mathrm{P} 7-25$

DS Coffey

P7-25

KN Pool

P7-25

AJ Schmidt

P8-60

RW Shimskey

P7-25

Distr.1 




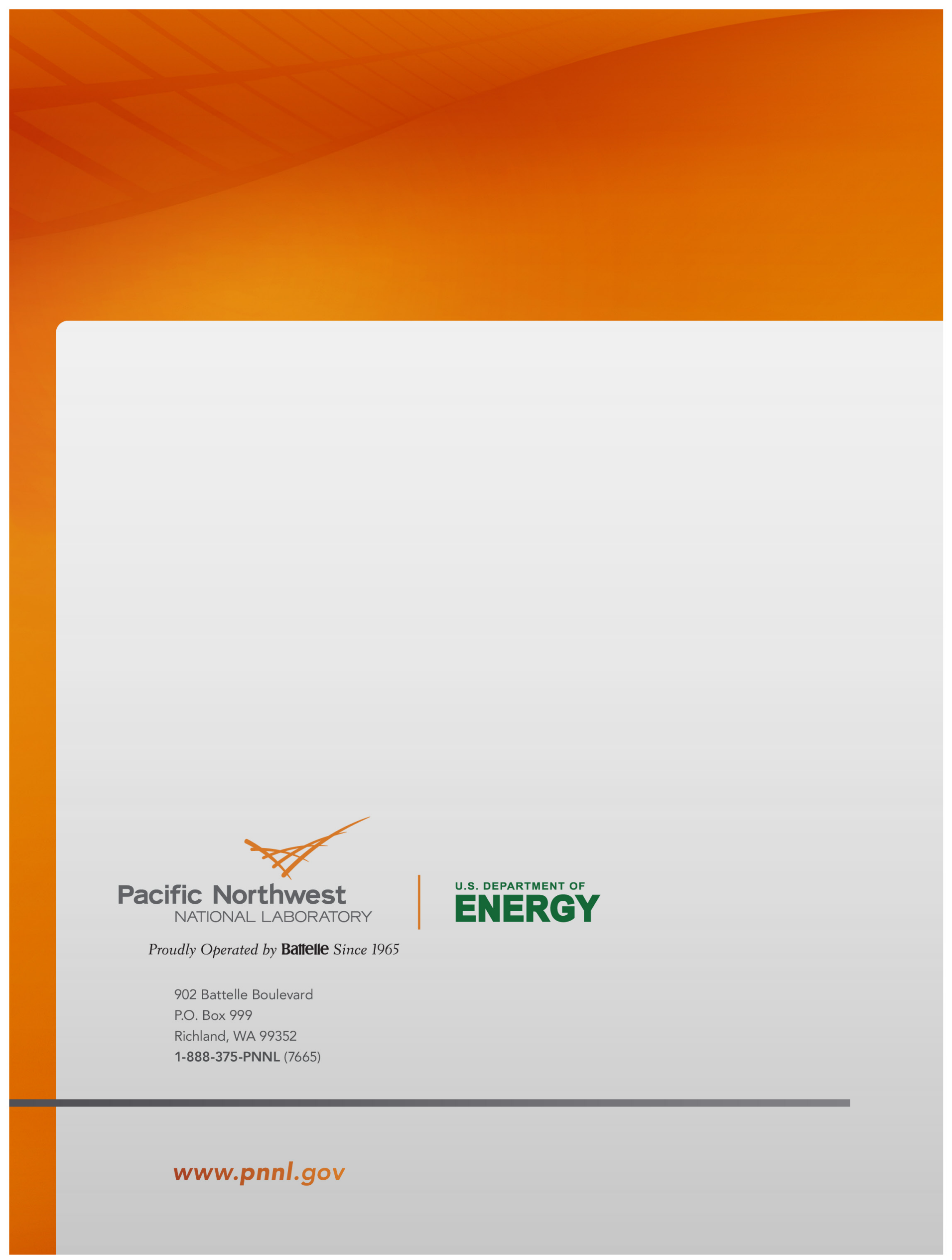

